\title{
WestVirginiaUniversity
}

THE RESEARCH REPOSITORY @ WVU

Graduate Theses, Dissertations, and Problem Reports

2003

\section{Epileptiform bursting in the disinhibited neonatal cerebral cortex}

Jason Eric Wells

West Virginia University

Follow this and additional works at: https://researchrepository.wvu.edu/etd

\section{Recommended Citation}

Wells, Jason Eric, "Epileptiform bursting in the disinhibited neonatal cerebral cortex" (2003). Graduate Theses, Dissertations, and Problem Reports. 1905.

https://researchrepository.wvu.edu/etd/1905

This Dissertation is protected by copyright and/or related rights. It has been brought to you by the The Research Repository @ WVU with permission from the rights-holder(s). You are free to use this Dissertation in any way that is permitted by the copyright and related rights legislation that applies to your use. For other uses you must obtain permission from the rights-holder(s) directly, unless additional rights are indicated by a Creative Commons license in the record and/ or on the work itself. This Dissertation has been accepted for inclusion in WVU Graduate Theses, Dissertations, and Problem Reports collection by an authorized administrator of The Research Repository @ WVU.

For more information, please contact researchrepository@mail.wvu.edu. 


\title{
Epileptiform Bursting in the Disinhibited Neonatal Cerebral Cortex
}

\author{
Jason Eric Wells \\ Dissertation submitted to the \\ School of Medicine \\ at West Virginia University \\ in partial fulfillment of the requirements \\ for the degree of
}

Doctor of Philosophy

in

Anatomy

Ariel Agmon, Ph.D., Chair

Albert Berrebi, Ph.D.

Janine Mendola, Ph.D.

Bernard Schreurs, Ph.D.

William Wonderlin, Ph.D.

Department of Neurobiology and Anatomy

Morgantown, West Virginia

2003

Keywords: cerebral cortex, epilepsy, $\mathrm{HCN}, \mathbf{I}_{\mathrm{h}}$, immunocytochemistry, oscillation 


\section{Abstract \\ Epileptiform Bursting in the Disinhibited Neonatal Cerebral Cortex}

\section{Jason Eric Wells}

The cerebral cortex, which include the neocortex and hippocampus, is an elaborate neuronal network communicating mainly through glutamate and $\gamma$ aminobutyric acid (GABA). Glutamate, operating via AMPA, kainate, and NMDA receptors excites neurons, and operating via metabotropic glutamate receptors can either increase or decrease the excitation in the neuronal network. GABA, operating through $\mathrm{GABA}_{\mathrm{A}}$ and $\mathrm{GABA}_{\mathrm{B}}$ receptors, inhibits the mature neuronal network, and $\mathrm{GABA}_{\mathrm{A}}$ receptor blockade in the adult cerebral cortex leads to epileptiform bursts. In contrast, in the neonatal cerebral cortex, $\mathrm{GABA}_{\mathrm{A}}$ has been proposed to function as an excitatory neurotransmitter, and glutamatergic synapses are claimed to be underdeveloped. It is important to understand the mechanisms underlying epileptiform activity in the neonate, because epileptiform activity in the neonate can potentially damage the developing cerebral cortex. In this dissertation I explore the role of GABA in controlling epileptiform activity in the neonatal cerebral cortex. Bath application of $\mathrm{GABA}_{\mathrm{A}}$ receptor antagonists induced spontaneous generation of large-amplitude population discharges resembling interictal bursts, a form of epileptiform activity; activation of $\mathrm{GABA}_{\mathrm{A}}$ receptors reduced the amplitude of interictal bursts. Interictal bursts were mediated by glutamatergic neurotransmission, demonstrating that glutamate synapses are functional in the neonate. We conclude that GABA is inhibitory in the neonatal cerebral cortex because it serves to suppress excitatory synchronous activity. Interictal bursts in the neonatal hippocampus were generated in a temporally precise rhythm. The rhythmicity of interictal bursts was not modulated by $\mathrm{GABA}_{\mathrm{B}}$ receptors, calcium activated potassium conductances, or internally released calcium, but manipulations that facilitate or suppress the hyperpolarization-activated cation current, $\mathrm{I}_{\mathrm{h}}$, increased or decreased, respectively, the frequency of the bursts. We conclude $I_{h}$ plays a major role in pacing neonatal interictal bursts. Immunocytochemistry illustrated that $\mathrm{I}_{\mathrm{h}}$ channel subunits in neonatal pyramidal neurons were distributed predominately in somata, while in the juvenile and mature hippocampus and neocortex the subunits were mostly found in GABAergic terminals and in the membrane of apical dendrites of pyramidal neurons, with diminished or no expression inside the somata. We conclude that the unique expression of $\mathrm{I}_{\mathrm{h}}$ channel subunits in the neonatal hippocampus could contribute to the increased temporal precision of interictal bursts at this developmental stage. 


\section{Dedication}

This work is dedicated to my wife,

Donna Wells.

She taught me this lesson:

When it comes to the battle between the rock and the stream, the stream always wins; not by strength, but by perseverance. 


\section{Acknowledgements}

I want to extend my sincere gratitude to Aric Agmon, Ph.D. His thoughtful guidance has helped develop my professional and personal growth. He provided me with persistent encouragement and support. He taught me a myriad of techniques and scientific principles, but there is one thing he taught me for which I am most thankful. He taught me how to think properly. This alone has made the last five years worthwhile.

I would also like to thank my entire dissertation committee for their time and thoughtful guidance. They were always willing to help me and to provide their insight. Their input was an invaluable piece of this work. I would like to thank Albert Berrebi, Ph.D. for his aid with immunocytochemistry experiments.

I would like to thank Xiaoming Jin, Ph.D., Cary Johnson, Jen Leasa and Hang Hu for their help and for their friendships.

I would like to also thank my parents and my sister for their encouragement and support. Most importantly, I would like to thank my wife, Donna, for her support, encouragement and inspiration. This work is as much hers as it is mine. 


\section{Table of Contents}

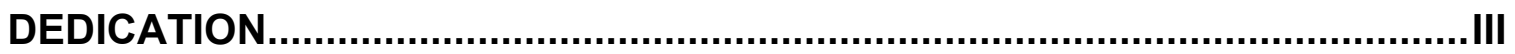

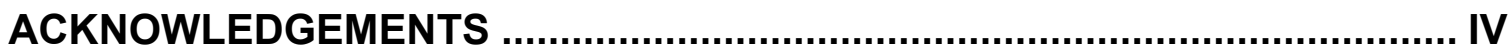

TABLE OF CONTENTS …....................................................................... V

LIST OF ABBREVIATIONS ................................................................. XII

CHAPTER 1: INTRODUCTION AND LITERATURE REVIEW...........................1

1.1 Hippocampal Neurons, Anatomy, and Physiology .................................................... 2

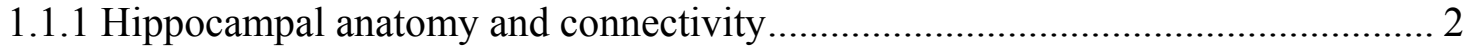

1.1.2 Pyramidal neurons .................................................................................. 4

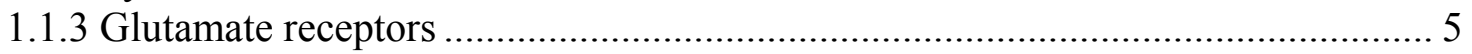

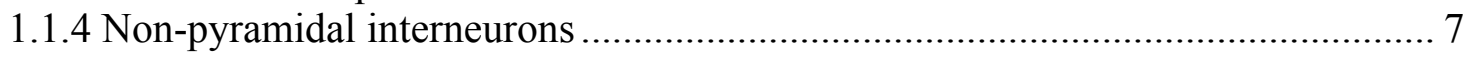

1.2 Generation of Excitatory and Inhibitory GABA Responses in Hippocampal

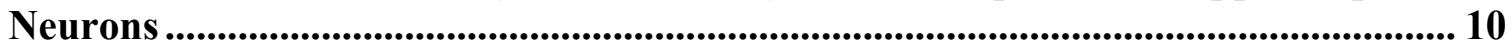

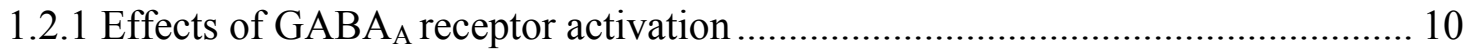

1.2.2 Inhibition mediated by $\mathrm{GABA}_{\mathrm{B}}$ receptors................................................. 12

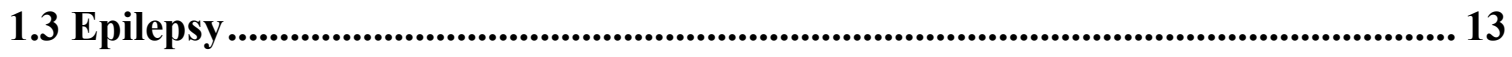

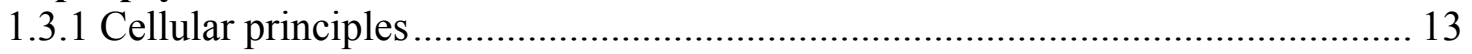

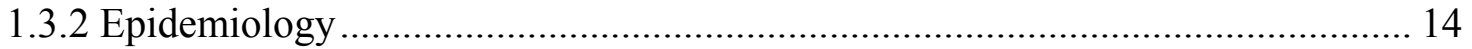

1.3.3 Electrophysiological properties of epileptic manifestations ........................... 15

1.4 The Hippocampal Slice as a Model for Studying Epilepsy .................................... 16

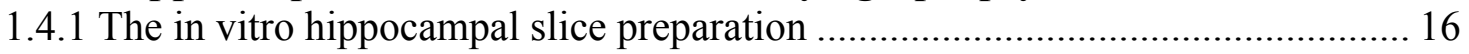

1.4.2 In vitro models of epilepsy ........................................................................ 17

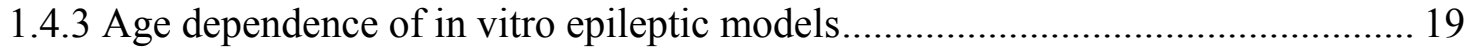

1.4.4 Rhythmicity of IIBs in the hippocampus ................................................. 20

1.6 The Hyperpolarization Activated, Cyclic-Nucleotide Sensitive, Nonselective Cation Current, $I_{h}$........................................................................................................... 21

1.7 Figures........................................................................................................................................ 26

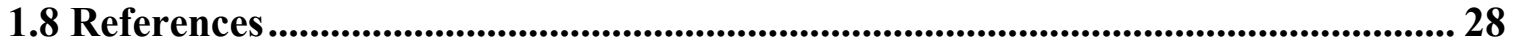

CHAPTER 2: OBJECTIVES AND RATIONALES ...........................................47 
2.1 Objective 1- To determine if GABA is an inhibitory or excitatory neurotransmitter in the cerebral cortex.

2.2 Objective 2- To determine the mechanisms involved in timing and modulating the frequency of rhythmic IIBs in the neonatal hippocampus.

2.3 Objective 3- To determine the expression pattern of $I_{h}$ channel subunits in the developing cerebral cortex.

\section{CHAPTER 3: GABAERGIC INHIBITION SUPPRESSES PAROXYSMAL NETWORK ACTIVITY IN THE NEONATAL RODENT HIPPOCAMPUS AND NEOCORTEX}

3.1 Abstract........................................................................................................................... 52

3.2 Introduction............................................................................................................. 53

3.3 Materials and Methods..................................................................................................... 54

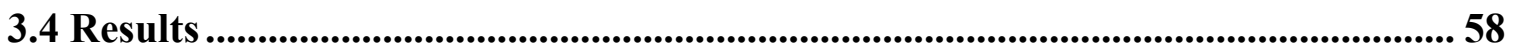

3.4.1 $\mathrm{GABA}_{\mathrm{A}} \mathrm{R}$ antagonists elicited spontaneous paroxysmal events in neonatal CA3

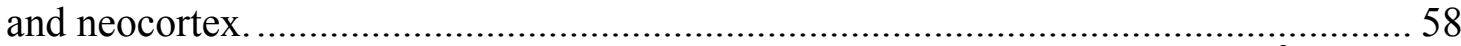

3.4.2 SPFPs elicited by $\mathrm{GABA}_{\mathrm{A}} \mathrm{R}$ antagonists occurred at earlier ages in $\mathrm{Mg}^{2+}$-free

ACSF

3.4.3 $\mathrm{GABA}_{\mathrm{A}} \mathrm{R}$ blockers elicited paroxysmal activity in an age-dependent manner ... 62

3.4.4 Age-dependent changes in mean sPFP frequency, amplitude and effective duration

3.4.5 Spontaneous activity was often observed in $\mathrm{Mg}^{2+}$-free ACSF alone.

3.4.6 In $\mathrm{Mg}^{2+}$-free ACSF, GABA $\mathrm{A}$ antagonists increased amplitude (but not frequency) of spontaneous events in CA3 and frequency (but not amplitude) in neocortex.

3.4.7 $\mathrm{GABA}_{\mathrm{A}} \mathrm{R}$ agonists depressed the amplitude (but not frequency) of sPFPs in CA3

3.4.8 Glutamatergic antagonists strongly suppressed frequency (but not amplitude) of sPFPs 68

3.5 Discussion............................................................................................................................. 70 3.5.1 Differential development of excitatory synaptic networks in hippocampus and

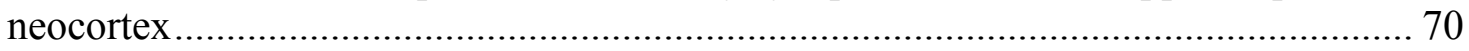

3.5.2 GABA prevents runaway excitation in the neonatal cortex.......................... 71

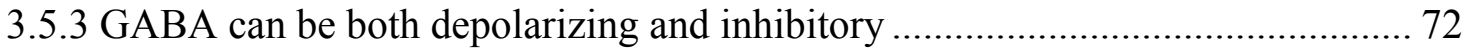

3.5.4 Spontaneous network activity in the neonatal hippocampus ............................ 73

3.5.5 Differential actions of GABAergic and glutamatergic antagonists in hippocampus

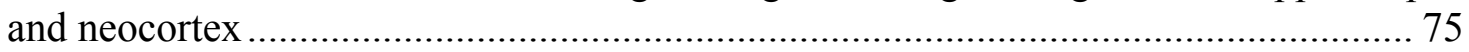

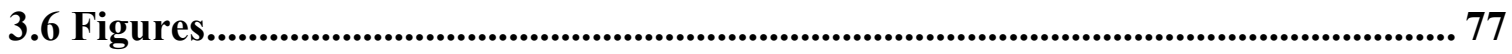




\section{CHAPTER 4: THE ROLE OF THE HYPERPOLARIZATION-ACTIVATED CATIONIC CURRENT IH IN THE TIMING OF INTERICTAL BURSTS IN THE} NEONATAL HIPPOCAMPUS

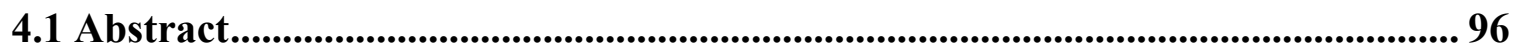

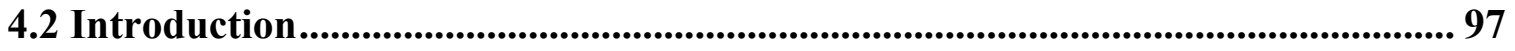

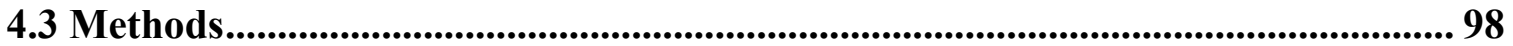

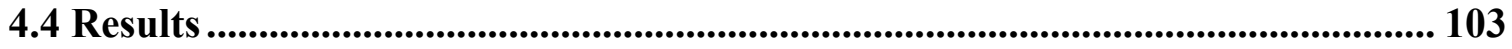

4.4.1 Neonatal IBs exhibit pacemaker-like regularity ......................................... 104

4.4.3 Blocking $\mathrm{I}_{\mathrm{h}}$ strongly reduced $\mathrm{nIB}$ frequency and regularity ............................ 105

4.4.4 Increasing intracellular cAMP strongly increased nIB frequency.................... 108

4.4.5 Cyclic AMP effects on nIB frequency were PKA-independent ....................... 109

4.4.6 Burst amplitudes were strongly correlated with the preceding but not the

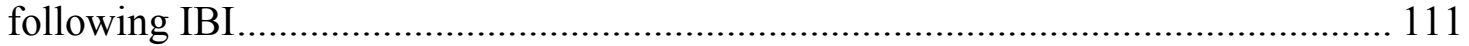

4.4.7 A simple computational model simulated the effect of ZD-7288 on nIB frequency

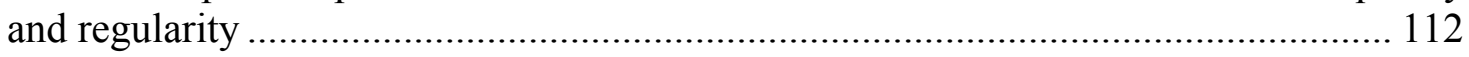
4.4.8 The effect of blocking $I_{h}$ was well modeled by a reduction in the steady-state rate of sEPSPs but not by an increase in its time constant of recovery .......................... 114

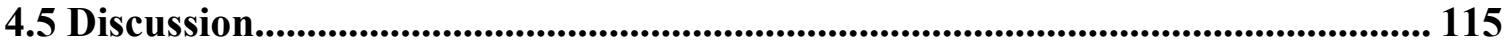
4.5.1 Blocking $\mathrm{I}_{\mathrm{h}}$ can be modeled either by an increase in the burst threshold or by a decrease in the rate of spontaneous synaptic release ......................................... 116 4.5.2 $\mathrm{I}_{\mathrm{h}}$ channels with the appropriate properties are expressed in the neonatal CA3 118 4.5.3 Burst amplitudes reflect recovery from synaptic depression.......................... 119 4.5.4 The mechanisms of pacing by $\mathrm{I}_{\mathrm{h}}$ are system-specific ................................ 120

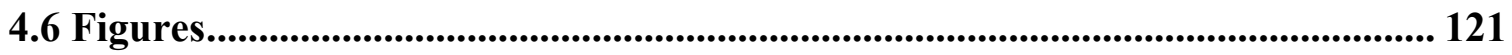

4.7 References........................................................................................................... 131

CHAPTER 5: PROPERTIES OF RHYTHMIC INTERICTAL BURSTS IN AREA CA3 OF THE NEONATAL HIPPOCAMPUS ............................................. 142

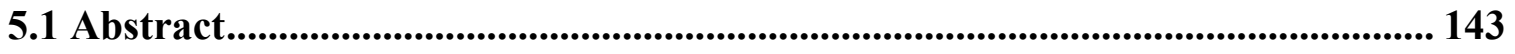

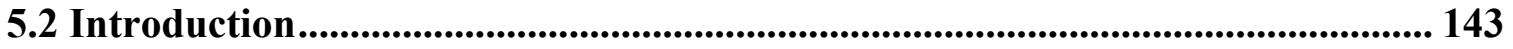

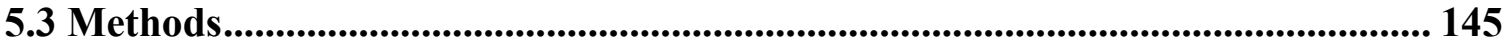

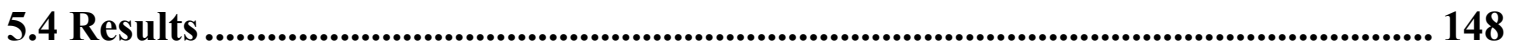

5.4.1 Periodic IIBs in hippocampal slices were limited to the early postnatal period 148

5.4.2 The IIBs originated in the CA3 region .................................................... 149 
5.4.3 IIBs are synchronous network events requiring chemical and electrical

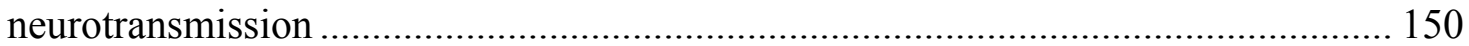

5.4.4 IIB frequency was sensitive to extracellular $\mathrm{K}^{+}$concentration........................ 151

5.4.5 Effects of metabotropic receptors on IIBs ................................................... 152

5.4.6 Post-paroxysmal suppression mediated by calcium-activated potassium currents

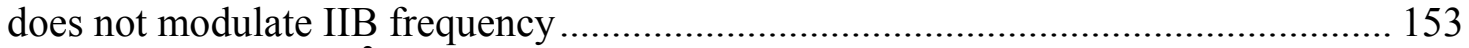

5.4.7 Intracellular $\mathrm{Ca}^{2+}$ release does not modulate IIB frequency ........................... 154

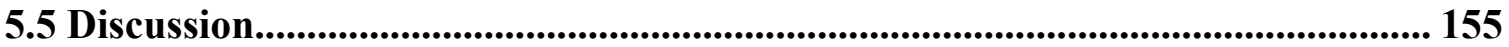

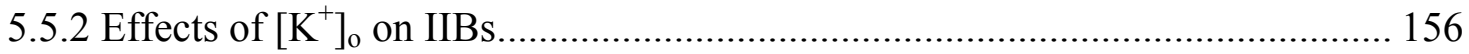

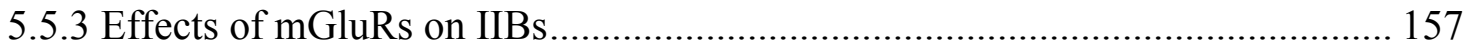

5.5.4 Role of GABA $_{B}$ and calcium-activated potassium conductances in IIBs......... 158

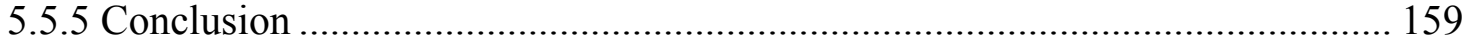

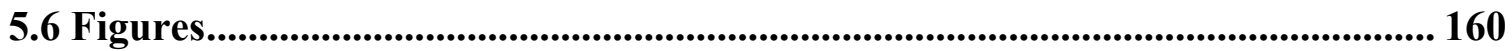

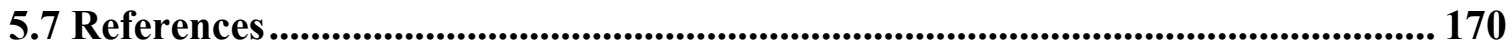

CHAPTER 6: DEVELOPMENTAL ALTERATIONS OF HCN1 AND HCN2 EXPRESSION IN THE MOUSE NEOCORTEX AND HIPPOCAMPUS ............178

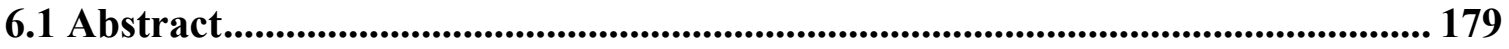

6.2 Introduction........................................................................................................................ 180

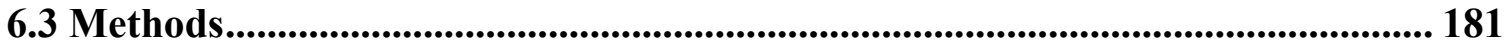

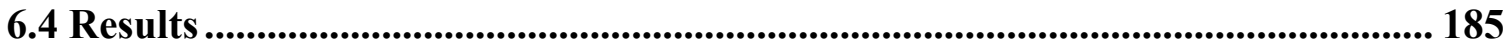

6.4.1 HCN1 expression in the developing and mature neocortex.............................. 185

6.4.2 HCN2 expression in the developing and mature neocortex............................ 187

6.4.3 HCN1 expression in the developing and mature hippocampus ...................... 188

6.4.4 HCN2 expression in the developing and mature hippocampus ...................... 189

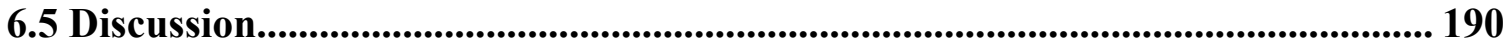

6.5.1 Summary of $\mathrm{HCN}$ and $\mathrm{I}_{\mathrm{h}}$ expression in the neocortex ................................ 191

6.5.3 Co-expression of multiple HCN subunits ...................................................... 194

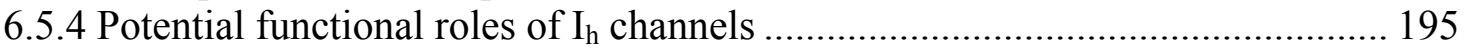

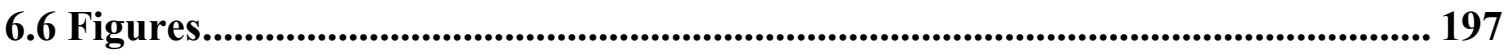

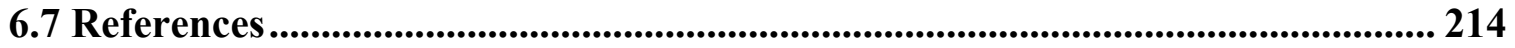

CHAPTER 7:GENERAL DISCUSSION................................................ 218

7.1 Summary and significance of the current study ................................................... 219

7.2 Comparisons with previous studies .............................................................................. 220 


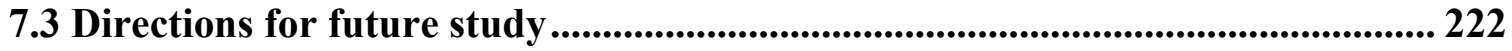

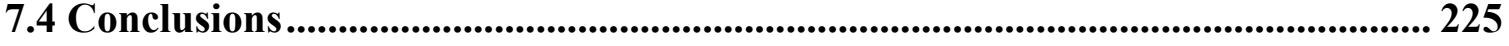

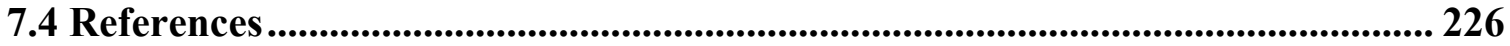

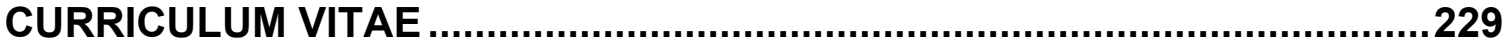


List of Figures

\section{CHAPTER 1}

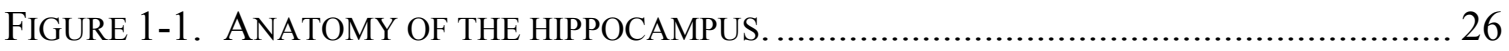

FIGURE 1-2. THE ORIENTATION OF HIPPOCAMPAL NEURONS............................................ 27

\section{CHAPTER3}

FIGURE 3-1. SPONTANEOUS PAROXYSMAL FIELD POTENTIALS (SPFPS) ELICITED IN NEONATAL HIPPOCAMPUS AND NEOCORTEX BY GABAA RECEPTOR (GABAAR)

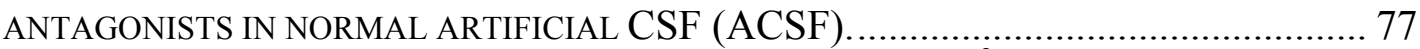

FigurE 3-2. SPFPS ELICITED BY GABA ${ }_{\mathrm{A}} \mathrm{R}$ ANTAGONISTS IN $\mathrm{MG}^{2+}$-FREE ACSF. ............. 79

FIGURE 3-3. AGE-DEPENDENT CHANGES IN INCIDENCE, FREQUENCY, AMPLITUDE AND EFFECTIVE DURATION OF SPFPS ELICITED BY GABA ${ }_{\mathrm{A}}$ R ANTAGONISTS AS A FUNCTION OF AGE.

FIGURE 3-4. GABA ${ }_{\mathrm{A}} \mathrm{R}$ ANTAGONISTS ADDED TO $\mathrm{MG}^{2+}$-FREE ACSF INCREASE AMPLITUDES (BUT NOT FREQUENCY) OF SPONTANEOUS EVENTS IN HIPPOCAMPUS, AND FREQUENCY (BUT NOT AMPLITUDES) IN NEOCORTEX.

FIGURE 3-5. THE GABA ${ }_{\mathrm{A}}$ R AGONIST MUSCIMOL DEPRESSED AMPLITUDES (BUT NOT FREQUENCY) OF SPFPS OCCURRING IN $50 \mu \mathrm{M}$ 4-AMINOPYRIDINE (4-AP). ................ 84

FiguRE 3-6. THE N-METHYL-D-ASPARTATE (NMDA)-RECEPTOR ANTAGONIST D(-)-2AMINO-5-PHOSPHONOPENTANOIC ACID (APV) DEPRESSED FREQUENCY, BUT NOT AMPLITUDES, OF SPFPS ELICITED BY GABA $A$ R ANTAGONISTS IN $\mathrm{MG}^{2+}$-FREE ACSF. 85

FIGURE 3-7. THE NON-NMDA RECEPTOR ANTAGONIST CNQX ALSO DEPRESSED FREQUENCY OF SPFPS ELICITED BY GABA $\mathrm{A}$ ANTAGONISTS IN $\mathrm{MG}^{2+}$-FREE ACSF. . 87

\section{CHAPTER 4}

FIGURE 4-1. A HORIZONTAL HIPPOCAMPAL SLICE FROM A P4 MOUSE AS VISUALIZED DURING THE EXPERIMENT.

Figure 4-2. NeONATAL InTERICTAL BURSts (NIBS) In AREA CA3 ARE HIGHLY REGUlAR.

FIGURE 4-3. BLOCKING I I STRONGLY REDUCED IIB FREQUENCY AND REGULARITY........ 123

FIGURE 4-4. INCREASING INTRACELLULAR CAMP STRONGLY ACCELERATED NIB FREQUENCY IN A PKA-INDEPENDENT MANNER.

FIGURE 4-5. AMPLITUDES OF NIBS WERE STRONGLY CORRELATED WITH THE PRECEDING BUT NOT THE FOLLOWING INTERBURST INTERVALS...

FIGURE 4-6. A 3-PARAMETER COMPUTATIONAL MODEL SIMULATED THE EFFECT OF ZD7288 ON NIB FREQUENCY AND REGULARITY.

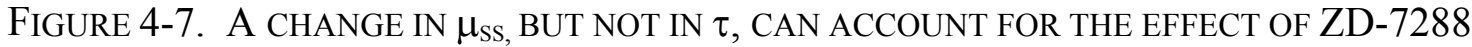
ON NIB FREQUENCY AND REGULARITY.

\section{CHAPTER 5}

FIGURE 5-1. IIBS ELICITED IN HORIZONTAL SLICES OF NEONATAL HIPPOCAMPUS BY GABAZINE IN $\mathrm{MG}^{2+}$-FREE ACSF FOLLOW A RHYTHMIC PATTERN............................. 160

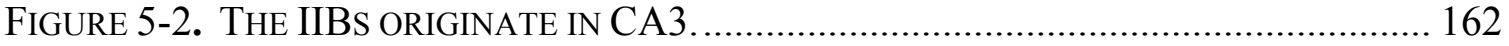

FIGURE 5-3. THE IIBS ARE SYNCHRONOUS, NETWORK EVENTS REQUIRING ACTION POTENTIALS AND CHEMICAL AND ELECTRICAL NEUROTRANSMISSION. 164 
FIGURE 5-4. INCREASING $\left[\mathrm{K}^{+}\right]_{\mathrm{O}}$ INCREASES THE FREQUENCY OF IIBS........................... 165

FIGURE 5-5. THE EFFECTS OF GABA B AND MGLURS ON IIB FREQUENCY...................... 166

FIGURE 5-6. CALCIUM ACTIVATED POTASSIUM CONDUCTANCES AND CALCIUM RELEASE FROM INTERNAL STORES HAVE NO EFFECT ON IIB FREQUENCY .............................. 168

\section{CHAPTER 6}

FIGURE 6-1. HCN1 IMMUNOREACTIVITY EXHIBITS A DEVELOPMENTAL PROGRESSION TOWARDS DISTAL APICAL DENDRITES IN THE NEOCORTEX.

FiguRE 6-2. DEVELOPMENTAL VARIATIONS OF HCN1 IMMUNOREACTIVITY IN THE NEOCORTEX OCCURS WITHIN SOMATA AND PUNCTA.

FIGURE 6-3. HCN2 IMMUNOREACTIVITY IN THE NEOCORTEX DECREASES WITH DEVELOPMENT.

FiguRE 6-4. DEVELOPMENTAL VARIATIONS OF HCN2 IMMUNOREACTIVITY IN THE NEOCORTEX OCCURS WITHIN PYRAMIDAL AND GABAERGIC SOMATA.

FiguRE 6-5. DEVELOPMENTAL VARIATIONS OF HCN1 IMMUNOREACTIVITY IN THE HIPPOCAMPUS OCCUR WITHIN PYRAMIDAL CELL SOMATA AND DENDRITES AND WITHIN GABAERGIC PUNCTA.

Figure 6-6. GABAERGIC CELLS, PV CELLS, AND GABAERGIC PUNCTA EXPRESS HCN1 IN THE HIPPOCAMPUS. 207

FiguRE 6-7. DEVELOPMENTAL VARIATIONS OF HCN2 IMMUNOREACTIVITY IN THE HIPPOCAMPUS OCCUR WITHIN SOMATA AND DENDRITES.

FIGURE 6-8. HCN2 IMMUNOREACTIVITY IS FOUND WITHIN GABAERGIC AND PARVALBUMIN NEURONS.

FIGURE 6-9. SUMMARY DIAGRAMS ILLUSTRATING THE DEVELOPMENTAL ALTERATION OF HCN1 AND HCN2 IN THE NEOCORTEX AND HIPPOCAMPUS. 


\section{List of Abbreviations}

$\begin{array}{ll}\text { 4-AP } & \text { 4-aminopyridine } \\ \text { ACPD } & \text { 1-amino-1,3-cyclopentanedicarboxylic acid } \\ \text { aCSF } & \text { artificial cerebrospinal fluid } \\ \text { AMPA } & \text { 2-amino-3-(3-hydroxy-5-methylisoxazol-4-yl)propionic acid } \\ \text { AP-5 } & \text { D-2-amino-5-phosphopentanoate } \\ \text { BMC } & \text { bicuculline methchloride } \\ \text { CA } & \text { cornu ammonis } \\ \text { CamK } & \text { type II Ca }{ }^{2+} \text { /calmodulin-dependent protein kinase } \\ \text { CNQX } & \text { 6-cyano-7-nitroquinoxaline-2,3-dione } \\ \text { CV } & \text { coefficient of variation } \\ \text { ENOs } & \text { early network oscillations } \\ \text { GABA } & \text { GABA } \text { receptors } \\ \text { GABA } & \text { GABA } \\ \text { GABA } & \text {-amino butyric acid } \\ \text { GBZ } & \text { gabazine, } \\ \text { GDPs } & \text { giant depolarizing potentials } \\ \text { HCN } & \text { hyperpolarization-activated cyclic nucleotide-sensitive cation gene family } \\ \text { I }_{\text {AHP }} & \text { afterhyperpolarization potential } \\ \text { IBI } & \text { interburst interval } \\ \text { IBMX } & \text { 3-Isobutyl-1-methylxanthine } \\ \text { I }_{\text {h }} & \text { hyperpolarization activated, cyclic-nucleotide sensitive, nonselective } \\ \text { cation current } & \\ \text { IIBs } & \text { interictal bursts } \\ \left.\text { [K }{ }^{+}\right]_{0} & \text { extracellular potassium concentration } \\ \text { PFPs } & \text { paroxysmal field potentials } \\ \text { mEPSP } & \text { miniature excitatory post-synaptic potential } \\ \text { mGluRs } & \text { metabotropic glutamate receptors } \\ \text { NMDA } & \text { n-methy-d-aspartate } \\ \text { PDSs } & \text { paroxysmal depolarization shifts } \\ \text { PV } & \text { parvalbumin } \\ \text { SL-M } & \text { stratum lacunosum-moleculare } \\ \text { SO } & \text { stratum oriens. } \\ \text { SP } & \text { stratum pyramidale } \\ \text { SR } & \text { stratum radiatum } \\ \text { TTX } & \text { tetrodotoxin } \\ & \end{array}$


CHAPTER 1: Introduction and Literature Review 


\subsection{Hippocampal Neurons, Anatomy, and Physiology}

The cerebral cortex is a laminar brain structures. It includes the neocortex, composed of six layers of neurons, and the hippocampus, composed of 3 layers of neurons. The neocortex, a phylogentically younger portion of the cerebral cortex (Barton, 1996; Keverne et al, 1996), plays a major role in sensory perception, motor skills, and cognition. A primitive area of cerebral cortex, the hippocampus, is located in the medial temporal lobe and bestows the abilities of storing and comprehending spatial information and the production of new long-term contextual memories (Jarrard, 1995). The hippocampus, which will be discussed further below, contains a diverse array of neurons varying widely in their morphology and connectivity (Amaral and Witter, 1995).

\subsubsection{Hippocampal anatomy and connectivity}

The hippocampal formation consists of the hippocampus proper, the dentate gyrus, and the subiculum. The hippocampus proper, often referred to as Cornu Ammonis (CA) (meaning Ammon's horn), is divided into four major subdivisions, CA1 though CA4 (Amaral and Witter, 1989). The principal neurons of the hippocampus proper and the dentate gyrus are arranged into two interlocking semi-circles (Fig. 1-1). There are between 200,000 and 500,000 principal cells, also called pyramidal neurons, in Ammon's horn of the mouse (Abusaad et al, 1999; Wimer et al, 1980). They lie in an easily identifiable band called the stratum pyramidale. Three other layers are also readily recognized: the strata radiatum, oriens, and lacunosum-moleculare. The stratum radiatum is found adjacent to the stratum pyramidale on the side nearest the pia mater, and the stratum oriens is found adjacent to the stratum pyramidale on the ependymal side 
(Amaral and Witter, 1989). The stratum lacunosum-moleculare resides just below pia, adjacent to the stratum radiatum (Fig. 1-1). The axons of the pyramidal neurons of CA3 arise from the neurons' basal surfaces, enter into the stratum oriens, and turn to pass through the stratum pyramidale and then into the stratum radiatum of CA1 (Amaral and Witter, 1995). These axons form excitatory synaptic terminals and excitatory en passant synapses in the stratum pyramidale and stratum radiatum and release the neurotransmitter glutamate (Ottersen et al, 1995; Scharfman, 1995). The principal cells of the dentate gyrus are the excitatory granule cells (Scharfman, 1995). In the mouse there are between 300,000 and 450,000 granule cells. Their dendrites reside in the molecular layer and their axons, called mossy fibers, extend to make synapses in area CA3 (Martin et al, 2002).

The basic circuitry of the hippocampus forms an excitatory trisynaptic pathway from the entorhinal cortex to CA1 (Traub and Miles, 1991). The entorhinal cortex projects to the granule cells of the dentate gyrus via the perforant pathway, the granule cells project to the $\mathrm{CA} 3$ pyramidal neurons via the mossy fibers, and the CA3 pyramidal neurons project to the CA1 pyramidal neurons via the Schaffer collaterals. In addition to this trisynaptic circuit there are other synaptic connections in the hippocampus. For example, neighboring CA3 (Miles and Wong, 1986) and CA1 (Hablitz, 1984) pyramidal neurons are extensively connected to one another with excitatory synapses. This extensive interconnectivity indeed makes the CA3 highly prone to hypersynchronization leading to epileptiform bursts. Inhibitory connections made by a large variety of nonpyramidal interneurons are also present. Detailed characteristics of the main neuronal types are described below. 


\subsubsection{Pyramidal neurons}

After Golgi introduced it to the scientific community, his reazione nera (black reaction) was one of the methods of choice for studying neuronal morphology. Using the Golgi technique and a multitude of others, pyramidal neurons have been widely studied in the cerebral cortex. Here we will focus on their properties in the hippocampus.

Pyramidal neurons have a conical cell body and are arranged so that the apex is directed towards the pia mater of the hippocampus (Fig. 1-1). A large apical dendrite extends from the apex of the cell body and enters into the stratum radiatum and the stratum lacunosum-moleculare (Ishizuka, 1995; Turner et al, 1995). Other sets of dendrites arise from the basal portion of the broad cell body and extend laterally (Blackstad and Kjaerheim, 1961). All of the dendrites are densely covered with spines, each spine typically receiving at least one synapse. Additionally, the proximal apical dendrites of CA3 pyramidal neurons bear large complex spines called thorny excrescences. These spines form a synaptic complex with mossy fiber terminals of the dentate gyrus granule cells in a thin layer, the stratum lucidum, visible between the stratum radiatum and the stratum pyramidale (Blackstad and Kjaerheim, 1961).

The axons of pyramidal neurons, especially those in the CA3, form numerous collateral branches that serve to provide a large number of synaptic connections between adjacent neurons. A single CA3 pyramidal neuron's axon may give rise to nearly 60,000 synapses and span two-thirds of the longitudinal extent of the hippocampus (Sik et al, 1993; Li et al, 1994). CA3 pyramidal neurons are capable of firing action potentials in high frequency bursts due to unique voltage- and $\mathrm{Ca}^{2+}$-dependent currents (Mutani, 1986). Burst firing pyramidal neurons in the somatosensory regions of neocortex have 
also been described (Agmon and Connors, 1989; Agmon and Connors, 1992). However, burst firing is not a feature of all pyramidal neurons; in other parts of the cerebral cortex they typically display an adapting firing pattern, meaning that in response to a sustained excitatory input they initially generate two or three action potentials followed by additional action potentials at a decreasing rate (Dantzker and Callaway, 2000). Pyramidal neurons use the excitatory amino acid neurotransmitter glutamate (Ottersen et al, 1995; Scharfman, 1995). The synaptic response to this neurotransmitter is mediated by ionotropic and metabotropic glutamatergic receptors.

\subsubsection{Glutamate receptors}

There are three ionotropic glutamate receptors: kainic acid receptors, 2-amino-3(3-hydroxy-5-methylisoxazol-4-yl)propionic acid (AMPA) receptors, and n-methyl-daspartate (NMDA) receptors. The kainic acid receptor is selectively activated by domoic and kainic acids (Betz, 1990). While both the kainate and AMPA receptors are antagonized with 6-cyano-7-nitroquinoxaline-2,3-dione (CNQX), kainate and AMPA receptors are a separate group of proteins (Werner et al, 1991; Egebjerg et al, 1991). Selective agonist, such as 4-AHCP (Brehm et al, 2003), and antagonist, such as LY294486 (Clarke et al, 1997), for the kainate receptor, and selective antagonists for the AMPA receptor, such as GYKI 53655 (Kidd and Isaac, 1999), CP-465,022 (Menniti et al, 2003) and LY300168 (Rasmussen and Vandergriff, 2003), permit AMPA receptor and kainate receptor mediated currents to be distinguished. The AMPA receptor and kainate receptor mediated currents have decay time constants of approximately $4 \mathrm{~ms}$ and $150 \mathrm{~ms}$, respectively, in the neocortex (Kidd and Isaac, 1999). The AMPA receptor is a cation 
channel permeable to $\mathrm{Na}^{+}, \mathrm{K}^{+}$and in some cases $\mathrm{Ca}^{2+}$. AMPA receptors quickly desensitize, terminating the flow of postsynaptic currents (Sarantis et al, 1993).

The third ionotropic glutamate receptor, the NMDA receptor, is nearly ten-fold more permeable for $\mathrm{Ca}^{2+}$ than it is for $\mathrm{Na}^{+}$and $\mathrm{K}^{+}$. This receptor/channel mediates excitatory postsynaptic currents of relatively long duration (to hundreds of milliseconds) and can be selectively antagonized by D-2-amino-5-phosphopentanoate (AP-5). Additionally, the NMDA receptor is unique in that at resting membrane potentials the open channel is blocked by $\mathrm{Mg}^{2+}$ ions (Nowak et al, 1984; Ascher and Nowak, 1988; Lodge, 1988; Li-Smerin and Johnson, 1996). Following membrane depolarization, for example by activation of adjacent AMPA receptors, the $\mathrm{Mg}^{2+}$ blockade may be released, causing influx of current through the NMDA receptor and further depolarization. Therefore, the NMDA receptor functions as an amplification system that generates a long-lasting membrane depolarization. While it is common for a single synapse to express both NMDA and AMPA receptors, the ratio of NMDA receptors to AMPA receptors is much higher in the early postnatal hippocampus compared to the adult (Durand et al, 1996).

Glutamate also activates metabotropic glutamate receptors (mGluRs), and these receptors can be divided into three groups. Group I mGluRs activate phospholipase C leading to phosphoinositide hydrolysis (Johnson and Chamberlain, 1999; Sladeczek et al, 1985), while activation of group II and group III mGluRs inhibits adenylyl cyclase leading to decreased production of cAMP. Group I and II mGluRs are agonized by 1amino-1,3-cyclopentanedicarboxylic acid (ACPD) (Manzoni et al, 1990). LY341495 antagonizes Group II mGluRs at nanomolar concentrations and all groups at higher 
concentrations (Kingston et al, 1998; Johnson et al, 1999). The effects of mGluRs on epileptiform bursting will be discussed in Chapter 5 .

\subsubsection{Non-pyramidal interneurons}

The principal cells of the hippocampal formation, the granule and pyramidal neurons, are glutamatergic projection neurons. All other neurons are non-projecting interneurons (Buckmaster and Soltesz, 1996), and represent 11\% of the hippocampal neuronal population (Woodson et al, 1989). There are many varieties of hippocampal interneurons, most have the following characteristics in common: 1) they are inhibitory in function (Knowles and Schwartzkroin, 1981a,b) utilizing GABA as their neurotransmitter (Buckmaster and Soltesz, 1996; Sloviter and Nilaver, 1987), 2) they have a nonpyramidal morphology, 3) their dendrites are aspiny or only sparsely spiny, 4) their axon terminals contain flattened vesicles and form symmetric synapses with their targets (LeVay, 1973), and 5) they often have the ability to fire at very fast frequencies of up to several hundred Hz (Freund and Buzsaki, 1996). Inhibitory interneurons are grouped and classified in many ways including by their physiological firing patterns (Kawaguchi and Hama, 1987), their morphology, (Somogyi and Freund, 1989), and by the calciumbinding proteins and neuropeptides they express (Hokfelt et al, 1980), such as parvalbumin and somatostatin. Interneurons form an extensive GABAergic network making synapses on both pyramidal neurons and other interneurons (Gulyas et al, 1996). Parra et al (1998) classified interneurons according to various features, and suggest that in the CA1 region alone there are 52 types of interneurons. Here we will limit our discussion to the main hippocampal interneurons, including the better-known chandelier and basket cells (see Figure 1-2). 
Chandelier cells are so named because their axonal plexuses give rise to up to 300 radially oriented "candles" or strings of en passant terminals in the strata pyramidale and oriens (Somogyi et al, 1983). The rows of terminals are arranged parallel to the initial segments of the pyramidal neurons' axons, permitting the Chandelier cells to make extensive axo-axonic synapses. In fact, this feature has earned this cell another name, the axo-axonic cell (Somogyi et al, 1985). These cells express parvalbumin, their somata are in the stratum pyramidale, and they give rise to smooth dendrites that reside in all layers of the hippocampus.

The term "basket cell" originated with Ramon y Cajal's description of the cerebellar cortex, where the Purkinje cells' somata and proximal dendrites are surrounded by a "basket" of axon terminals, hence the neuron giving rise to the plexus of terminals was named the "basket" cell. The basket cells in the hippocampus form an extensive network of axon terminals on the perisomatic region of pyramidal neurons, and they express parvalbumin. (McBain et al, 1994; Sik et al, 1995). Their somata typically lie in the stratum radiatum or stratum pyramidale (Nunzi et al, 1985). Basket cells usually receive excitatory input from all the various excitatory pathways in the hippocampus on their dendrites, which span the entire depth of the stratum oriens (Gulyas et al, 1993; Buhl et al, 1994a; Sik et al, 1995).

Buhl et al. (1994b) and Sik et al. (1995) were the first to describe bistratified trilaminar and horizontal trilaminar interneurons. Both of these groups of neurons have cell bodies in or very near the stratum pyramidale. The dendrites of the bistratified trilaminar cells extend radially into the stratum oriens and the stratum radiatum, but do not enter the stratum lacunosum-moleculare. The axons of the bistratified trilaminar cells 
extend widely throughout the stratum oriens and also into the proximal stratum radiatum. The soma and dendrites of the horizontal trilaminar neurons are limited to the stratum oriens, but its axons extend throughout the strata oriens, pyramidale, and into the proximal radiatum. Radial cells are similar to the bistratified cells in that they have widespread axonal arbors, except the radial cells also extend dendrites further into the stratum lacunosum-moleculare. An additional type of interneuron, the O-LM cell, expresses somatostatin and has its axonal arbors restricted to stratum lacunosummoleculare and has its cell body and dendrites located in the stratum oriens among the axonal branches of the pyramidal cells (Han et al, 1993, McBain et al, 1994).

Several important functions have been assigned to hippocampal inhibitory interneurons. The roles of the hippocampal interneurons include: 1) restricting and controlling the level of excitability in a neuronal network, thus preventing the generation of epileptic activity (Sloviter, 1987, 1991), 2) induction and maintenance of neuronal network oscillations in the theta, gamma (40-100 Hz), and ultrafast "ripple" $(200 \mathrm{~Hz})$ frequency ranges (Ylinen et al, 1995a,b; Bragin et al, 1995; Soltesz and Deschenes, 1993; Fraser and MacVicar, 1991; Buzsaki et al, 1983, 1992), and 3) the release of GABA as a neurotrophic factor promoting neuronal proliferation and synaptogenesis during development (Ben-Ari, 2001; Barker et al, 1998; Lauder et al, 1998). Given the importance of the functional role of these neurons, a more thorough examination of their synaptic influence is warranted. 


\subsection{Generation of Excitatory and Inhibitory GABA Responses in Hippocampal}

\section{Neurons}

In 1955, it was reported that "Factor I" (I for Inhibition) was responsible for neuronal inhibition (Florey and McLennan, 1955). Later found to be $\gamma$-aminobutyric acid (GABA), its role as an inhibitory neurotransmitter was initially realized because its application strongly suppressed the activation of the mammalian nervous system (Florey and McLennan, 1955) and in the crayfish it was found to be present only in inhibitory neurons (Kravitz et al, 1963). Nearly five decades later, a much more detailed account of GABA's physiological role is available. In the forebrain, GABA operates by acting upon two different receptor types: $\mathrm{GABA}_{\mathrm{A}}$ and $\mathrm{GABA}_{\mathrm{B}} . \mathrm{GABA}_{\mathrm{A}}$ and $\mathrm{GABA}_{\mathrm{B}}$ receptors are ionotropic and metabotropic, respectively, and have a seemingly ubiquitous expression in the nervous system (Chu et al, 1990).

\subsubsection{Effects of $G A B A_{A}$ receptor activation}

Hippocampal interneurons are activated by granule cells, pyramidal axons, and afferent neurons from outside the hippocampus. They release GABA from their presynaptic terminals, producing postsynaptic $\mathrm{GABA}_{\mathrm{A}}$ receptor activation. This receptor is an ionotropic ligand-gated ion channel permeable mainly to $\mathrm{Cl}^{-}$and to a much lesser extent, $\mathrm{HCO}_{3}^{-}$(Kaila, 1994; Bormann et al, 1987). The open-time of the channel is approximately $20-30 \mathrm{~ms}$, thus the $\mathrm{GABA}_{\mathrm{A}}$ receptor regulates a relatively fast form of inhibition (Newberry and Nicoll, 1985). The receptor is a heteropentamer assembled from up to 5 of 18 known subunits. Each subunit has four transmembrane domains (Sieghart et al, 1999). Upon activation, the $\mathrm{GABA}_{\mathrm{A}}$ receptor decreases input resistance (i.e. increases conductance) by allowing $\mathrm{Cl}^{-}$to permeate the membrane. $\mathrm{GABA}_{\mathrm{A}}$ receptor 
activation is inhibitory in the adult (Krnjevic, 1976; Ben-Ari et al, 1981) because it opens a conductance with a reversal potential (i.e. the membrane potential towards which the synaptic current will pull the membrane) more negative than the firing threshold (the membrane potential where an action potential will be generated). $\mathrm{GABA}_{\mathrm{A}}$ activation typically allows $\mathrm{Cl}^{-}$influx into the cell, causing a membrane hyperpolarization. $\mathrm{Cl}^{-}$ moves into the cell because it is maintained at a low intracellular concentration by $\mathrm{KCC} 2$, a $\mathrm{Cl}^{-}-\mathrm{K}^{+}$co-transporter that extrudes $\mathrm{Cl}^{-}$from the neuron (Rivera et al, 1999). In contrast to mature systems, in the neonatal hippocampus GABA has been shown to depolarize neurons sufficiently to fire action potentials (Dzhala and Staley, 2003; Kohling et al, 2000; Leinekugel et al, 1999; Leinekugel, 1997; Owens et al, 1996; Staley et al, 1995; Ben-Ari et al, 1994; Cherubini et al, 1991; Ben-Ari et al, 1989). The depolarizing effect of GABA in the neonate is believed to be due to a high intracellular concentration of $\mathrm{Cl}^{-}$ which flows out of the cell upon $\mathrm{GABA}_{\mathrm{A}}$ receptor activation (Staley et al, 1995). The high intracellular $\mathrm{Cl}^{-}$concentration in immature neurons is a result of (1) a $\mathrm{Na}^{+}-\mathrm{K}^{+}-2 \mathrm{Cl}^{-}$ transporter being expressed much more in neonatal neurons compared to adult neurons (Sun and Murali, 1999), and (2) KCC2 is not yet expressed at high levels (Rivera et al, 1999).

Even though the action of $\mathrm{GABA}_{\mathrm{A}}$ receptors in the neonate is depolarizing, their activation should not necessarily be construed as an excitatory event. The reversal potential for the $\mathrm{GABA}_{\mathrm{A}}$ receptor/channel is much more negative, even when depolarizing, than is the reversal potential for an excitatory (glutamate) channel (approximately -55 mV and $0 \mathrm{mV}$, respectively) (Leinekugel, 1999; Silvotti and Nistri, 1991). Therefore, when both of these channels are activated together in an intact 
hippocampal neuronal network, the GABA channel greatly reduces the depolarizing effect the activated glutamate channel has on the membrane potential by shunting out current flowing through the excitatory channel. Therefore, GABA is still functioning in an inhibitory fashion, even though it is depolarizing. In support of this, activating $\mathrm{GABA}_{\mathrm{A}}$ receptors in the neonatal hippocampus with muscimol prevents AMPA-receptor mediated bursting in the newborn hippocampus (postnatal days 0-2) (Lamsa, 2000). The exact role of $\mathrm{GABA}_{\mathrm{A}}$ receptors in the neonatal hippocampus is still controversial (BenAri, 2001), and will be further discussed in Chapter 3.

\subsubsection{Inhibition mediated by $G A B A_{B}$ receptors}

In contrast to the $\mathrm{GABA}_{\mathrm{A}}$ receptor, the $\mathrm{GABA}_{\mathrm{B}}$ receptor induces a slow and sustained form of inhibition (Alger, 1984). The $\mathrm{GABA}_{\mathrm{B}}$ receptor works via a metabotropic mechanism and is located at both post- and presynaptic membranes (Davies et al, 1995). Postsynaptic activation of $\mathrm{GABA}_{B}$ receptors leads to an increase in $\mathrm{K}^{+}$ conductance, mediated through a pertussis toxin-sensitive GTP-binding protein (Gprotein) (Thalmann, 1988; Newberry and Nicoll, 1984). This G-protein mediated $\mathrm{K}^{+}$ channel activation leads to a slow and long-lasting hyperpolarizing synaptic potential with a duration reaching hundreds of milliseconds (Dutar and Nicoll, 1988; Alger, 1984) to seconds (Avoli, 1996). The main effect of presynaptic $\mathrm{GABA}_{B}$ receptor activation is believed to be the reduction of neurotransmitter released at the synapse (Bowery et al, 1980). This effect is mediated by a pertussis toxin-sensitive G-protein that binds directly

to $\mathrm{Ca}^{2+}$ channels, thus impairing $\mathrm{Ca}^{2+}$ flux into the axon terminal, reducing the probability of neurotransmitter release (Dolphin et al, 1989; Dolphin and Scott, 1987; Holz et al, 1986). 
A typical inhibitory post-synaptic potential in hippocampal neurons contains two parts, an initial fast, short-lasting inhibitory potential (via $\mathrm{GABA}_{\mathrm{A}}$ receptors) followed by a slower, long-lasting inhibitory potential (via $\mathrm{GABA}_{\mathrm{B}}$ receptors) (Knowles et al, 1984; Alger, 1984; Newberry and Nicoll, 1984). As described below, disrupting the GABAergic influence regulated by these receptors has profound effects on hippocampal neurons.

\subsection{Epilepsy}

\subsubsection{Cellular principles}

Epileptiform bursts are characterized by intense, excessive and synchronous action potential firing in groups of cortical neurons (Traub and Miles, 1991; Glauser and Clancy, 1992; Avoli, 2001). GABAergic inhibition exerted by interneurons suppresses epileptiform bursting and controls the generation of action potentials by hippocampal neurons by diminishing the input elicited by glutamatergic synaptic inputs (Miles et al, 1996; Lamsa et al, 2000). The inhibitory control of pyramidal neurons is so delicately balanced that even a small decrease in the inhibitory actions of GABA results in epileptiform bursting (Sloviter, 1987; Chagnac-Amatai and Connors, 1989; Langenstroth et al, 1996). Among the multitude of mechanisms that could decrease GABAergic inhibition in the hippocampus are a decrease in GABAergic synaptic efficiency, for example by $\mathrm{GABA}_{\mathrm{A}}$ blockade or a disruption in the $\mathrm{Cl}^{-}$gradient (Traub and Miles, 1991), a decrease in interneuron number (Bernard et al, 2000) or a decrease in the mossy fiber activation of interneurons (Sloviter, 1987). 


\subsubsection{Epidemiology}

The prevalence of epilepsy is relatively very high, with at least one person suffering from the disease out of every 200 people in the world's population, thus making it the most common neurological disorder (Kubova and Moshe, 1994; Bradford, 1995), causing human suffering and high economic costs. Most often epilepsy will first afflict its victims within the first decade of life (Holmes, 1997). This is especially troubling since the immature brain has unique factors rendering it more susceptible to the damaging effects of an epileptic seizure than the adult brain. The immature brain relies heavily on ketone metabolism, and the large supply of oxygen needed for such metabolism is reduced in a seizure, thereby diminishing the availability of energy resources (Wasterlain, 1997). In addition, immature glia are inefficient at removing high levels of extracellular potassium ions that are released during epileptic seizures, and this leaves the tissue in a hyperexcitable state, lowering the threshold for another seizure to occur (Prince, 1983; Prince, 1985; Prince and Connors, 1986; Wasterlain, 1997; Chen et al, 1999). There is a controversy as to whether children with epilepsy will suffer any long-term ill effects from the disease. While many epileptic children outgrow the disease without any long-term disabilities (Wasterlain and Shiraski, 1994), there are some epileptic children that develop both behavioral and cognitive problems. The distribution of IQ scores from epileptic children is skewed toward lower values (Farwell et al, 1985). To add insult to injury, the IQ scores and psychiatric state of the epileptic patients usually do not improve, but progressively worsen as they age (Bourgeois et al, 1983; Farwell et al, 1985; Wakamoto et al, 2000; Oguni et al, 2002). 


\subsubsection{Electrophysiological properties of epileptic manifestations}

Epileptiform bursts can occur as long bouts of action potentials lasting tens of seconds (ictal bursts) or as short-lasting ( 1-2 s) bouts called interictal bursts (IIBs), sonamed because they typically occur between epochs of ictal activity (Jensen and Yaari, 1988). IIBs can be recorded extracellularly as paroxysmal field potentials (PFPs; in Chapter 3, IIBs are referred to as PFPs) and intracellularly as so-called paroxysmal depolarization shifts (PDSs) that consist of a $\sim 1-2$ second long depolarization superimposed by rapid bursts of action potentials. An epileptiform burst is terminated by a $\mathrm{K}^{+}$-induced hyperpolarization that is activated by both the membrane depolarization and the intracellular rise in $\mathrm{Ca}^{2+}$ concentration (Wong and Prince, 1981). During an IIB, neurons synchronously undergo a single PDS, while during an ictal burst neurons undergo a repetitive train of synchronous PDSs (Jensen and Yaari, 1988; Traub et al, 1996).

The causal relationship between ictal and interictal bursts is of some debate in the epilepsy research community. Some investigations have suggested that IIBs are involved with the suppression of ictal bursts (Swartzwelder et al, 1987; Avoli and Barbarosie, 1999; Avoli, 2001; de Curtis and Avanzini, 2001), and others provide evidence that suggest IIBs lead to ictal bursts, since the rate of IIB occurrence often increases just prior to an ictal event (Wada et al, 1974; Lewis et al, 1989; Nagao et al, 1996; Dzhala and Staley, 2003). 


\subsection{The Hippocampal Slice as a Model for Studying Epilepsy}

\subsubsection{The in vitro hippocampal slice preparation}

Given that epilepsy has such negative effects on human society, much attention is focused on studying the disorder in the laboratory. One prevalent method to study epilepsy utilizes the in vitro hippocampal slice preparation (Yamamoto, 1972; Traub and Miles, 1991). When the living hippocampus is sliced in $300-500 \mu \mathrm{m}$ sections perpendicular to its long axis, the tri-synaptic loop originating in the entorhinal cortex and ending in the CA1 field of Ammon's horn remains relatively intact and functional. The tissue slices can then be kept alive and maintained for many hours by bathing them in an oxygenated solution of artificial cerebrospinal fluid (aCSF). These living hippocampal slices can used to study various hippocampal properties, including those relating to epilepsy (Yamamoto, 1972; Oliver et al, 1977). It should be noted that limitations to the in vitro slice exist. Since the brain has been cut to to make the slice, neurons near the surface may be damaged, fiber pathways are often incomplete or severed, oxygen tension near the center of the slice could be inadequate, and (most importantly) all sensory and modulatory afferents are lost. These limitations hinder the generalization of in vitro results to the intact animal. However, despite these limitations, the in vitro slice is often the method of choice to study brain physiology at the cellular level due to easy experimental access to the tissue with microelectrodes or with applied neurochemicals. A variety of techniques have been used to induce and study epileptiform bursts in the in vitro hippocampal slice. 


\subsubsection{In vitro models of epilepsy}

A variety of experimental methods can be used to induce epileptiform bursts in the in vitro hippocampal slice (Dichter and Ayala, 1987). The models, while varied in their mechanism of action, share the common feature of increasing the excitability of hippocampal neurons.

The "kindling model" of in vitro epilepsy is unique because it does not require any pharmacological manipulation of the brain slice. It is a derivative of an in vivo preparation involving the repeated application of sub-convulsive trains of electrical stimuli to hippocampal or amygdala sites that eventually result in electrographic and motor seizures (Goddard et al, 1969; McNamara et al, 1980). For the in vitro preparation, one-second-long trains of high-frequency stimuli are administered to the $\mathrm{CA} 3$ region, inducing spontaneous epileptiform bursts in the slice. This bursting is the result of the stimulus trains inducing a long-term enhancement in excitatory synaptic efficiency (Stasheff et al, 1985).

The other methods to induce epileptiform bursts involve various pharmacological manipulations. One of these models entails removing or reducing the $\mathrm{Mg}^{2+}$ content in the bath solution from standard levels of $1.3-2 \mathrm{mM}$ to below $0.4 \mathrm{mM}$. Typically $10-40$ minutes after the perfusion of $\mathrm{Mg}^{2+}$-free (or reduced $\mathrm{Mg}^{2+}$ ) medium, both ictal bursts and IIBs can be recorded in the hippocampus (Anderson et al, 1986, 1990; Mody et al, 1987; Schneiderman and MacDonald, 1987; Tancredi et al, 1990; Gloveli et al, 1995). It is believed that the following effects could underlie the increases in neuronal excitability and the facilitation of epileptiform bursting in $\mathrm{Mg}^{2+}$-deficient medium: 1) $\mathrm{Mg}^{2+}$, s role in antagonizing both pre- and postsynaptic $\mathrm{Ca}^{2+}$ entry is lost (Llinas and Walton, 1980), 2) 
surface charge screening is altered lowering the threshold for action potential generation (McLaughlin et al, 1971; Mody et al, 1987), and 3) the $\mathrm{Mg}^{2+}$ block of NMDA channels is eliminated, permitting the channel to conduct current without the typical pre-requisite of membrane depolarization (Neuman, Cherubini, and Ben-Ari, 1989; Tancredi et al, 1990). Finally, it should also be noted that there is a single report (Whittington et al, 1995) that a $\mathrm{Mg}^{2+}$-deficient environment reduces GABAergic inhibition. Whittington and colleagues (1995) suggested that the reduced $\mathrm{Mg}^{2+}$ concentration permits ATP to leach from the neurons leading to a dephosphorylation of the $\mathrm{GABA}_{\mathrm{A}}$ channel that reduced the amplitude of hyperpolarizing inhibitory synaptic potentials by $52 \%$ in their study.

Three additional models are also commonly used. They are 1) elevation of extracellular $\mathrm{K}^{+}\left(\left[\mathrm{K}^{+}\right]_{\mathrm{o}}\right)$, 2) bath application of 4-aminopyridine (4-AP), an antagonist of an early transient $\mathrm{K}^{+}$current (also called the A-current; reviewed by Rudy (1988)) and 3) bath application of $\mathrm{GABA}_{\mathrm{A}}$ receptor antagonists. The "High-K $\mathrm{K}^{+}$" model of epileptiform bursting is produced by increasing $\left[\mathrm{K}^{+}\right]_{\mathrm{o}}$ from the standard level of $\sim 3 \mathrm{mM}$ to $\sim 8 \mathrm{mM}$ (Korn et al, 1987; McBain et al, 1994). Such an increase induces both spontaneous ictal bursts and IIBs. It has been previously suggested that this epileptiform bursting is elicited because the increase in $\left[\mathrm{K}^{+}\right]_{0}$ results in (1) more depolarized membrane potentials, (2) a reduction in the efficiency of $\mathrm{K}^{+}-\mathrm{Cl}^{-}$cotransport (Staley and Proctor, 1999) which causes the $\mathrm{Cl}^{-}$reversal potential to move in the positive direction, thus reducing the hyperpolarizing effect of $\mathrm{GABA}_{\mathrm{A}}$ receptor activation, and (3) a decrease in the afterhyperpolarizing potential following an action potential permitting action potentials to be generated at a faster rate (Korn et al, 1987; Traynelis and Dingledine, 1988). In Chapter 5 we propose a novel mechanism for the effect of increasing $\left[\mathrm{K}^{+}\right]_{\mathrm{o}}$. 
Application of 4-AP results in similar activity . Its actions parallel the epileptiform bursting that occur when $\left[\mathrm{K}^{+}\right]_{\mathrm{o}}$ is increased, however 4-AP also increases the size of excitatory post-synaptic potentials and it increases their spontaneous rate of occurrence (Thesleff, 1980; Perreault and Avoli, 1991; Traub et al, 1995).

Many convulsant drugs are known to diminish inhibition produced by GABAergic receptors (Avoli, 1988), and removal of inhibition exerted by $\mathrm{GABA}_{\mathrm{A}}$ receptors is a widely used model of epileptiform bursting in the hippocampal brain slice (Schwartzkroin and Prince, 1977; Hablitz, 1987). Drugs such as penicillin (Dichter and Spencer, 1968,1969a,b; Dichter et al, 1973), bicuculline (Avoli et al, 1997), picrotoxin (Newland and Cull-Candy, 1992), and gabazine (Heaulme et al, 1986) are used to block the $\mathrm{GABA}_{\mathrm{A}}$ receptor. In hippocampal neurons, these drugs block increases in conductance associated with inhibitory synaptic potentials and permit the occurrence of prolonged bouts of excitatory post-synaptic potentials (Dingledine and Gjerstad, 1979 and 1980); this erosion of inhibition and facilitation of excitation elicits epileptiform bursting.

\subsubsection{Age dependence of in vitro epileptic models}

The hippocampus has the neuronal network sufficient to generate and sustain epileptic activity (Traub and Miles, 1991). While there is abundant knowledge of both ictal and interictal bursts occurring in the adult hippocampal slice (Gutnick et al., 1982; Wong et al., 1986; Hablitz, 1987; Traub and Miles, 1991), very few studies of epilepsy have been performed in the neonatal (postnatal age 0-7 days; P0-P7) hippocampal slice. Indeed, most of the studies that have examined the neonatal hippocampus found that epileptic activity cannot be induced in the neonate. Anderson et al. (1990) found that 
penicillin and picrotoxin were ineffective prior to $\mathrm{P} 9$ and P8, respectively; Psarropoulou and Descombes (1999) demonstrated that blocking $\mathrm{GABA}_{\mathrm{A}}$ receptors with bicuculline is not sufficient to elicit spontaneous epileptiform bursts in the first postnatal week; Gloveli et al. (1995) found that reducing $\mathrm{Mg}^{2+}$ had no effect before P7; Wong and Yamada (2001) observed that 4-AP, reducing extracellular $\mathrm{Mg}^{+}$, and blocking either $\mathrm{GABA}_{\mathrm{A}}$ or $\mathrm{GABA}_{\mathrm{B}}$ receptors were all unproductive at eliciting epileptiform bursts in the first postnatal week. In Chapter 3 we describe a novel model in which IIBs can be reliably initiated in the neonatal cerebral cortex.

\subsubsection{Rhythmicity of IIBs in the hippocampus}

IIBs that occur in the hippocampus often occur in a highly regular rhythm. For example, IIBs rhythmically occur with the application of picrotoxin (Merlin et al, 1995; Curtis and Avanzini, 2001) or 4-AP (Avoli et al, 1996) to the slice's bathing medium. Korn et al. (1987) demonstrate rhythmic IIBs by elevating extracellular $\mathrm{K}^{+}$concentration.

While much attention has been given to ionic currents and synaptic circuitry involved with the generation of IIBs (Ayala et al, 1973; Traub and Miles, 1991; Curtis and Avanzini, 2001), less attention has been given to deciphering the mechanism(s) responsible for generating the precise periodicity of IIBs. It has been suggested that IIBs are terminated by $\mathrm{Ca}^{2+}$-activated $\mathrm{K}^{+}$conductances that hyperpolarize neurons and inhibit neuronal activity (Robinson et al, 1993), and the following IIB can only occur when this post-burst inhibition decays (Lebovitz, 1979). Additionally, it has been suggested that bursts are terminated by an activity-dependant depression of excitatory synapses (i.e. each burst depletes excitatory synapses of releasable neurotransmitter vesicles) (Staley et al, 1998, 2001). The following IIB can only occur once the synapse has recovered a 
critical number of these vesicles (Chamberlin et al, 1990), which occurs on the same time scale as the interval between the bursts (Stevens and Wesseling, 1998). Each of these models proposes that the IIBs are paced by a recovery from a form of suppression; however, an alternative mechanism would be that a slow build-up of excitation is pacing the IIBs. A unique ionic current, called $\mathrm{I}_{\mathrm{h}}$, paces the heartbeat and influences a variety of other non-neural and neural phenomena (Ito et al, 1965; Brown and DiFrancesco, 1980; Soltesz et al, 1991; DiFrancesco, 1993; Janigro et al, 1994; Maccaferri and McBain, 1996; Santoro and Tibbs, 1999; Santoro et al, 2000), and it could mediate a slow increase in excitation during epilepsy (Timofeev et al, 2002). $\mathrm{I}_{\mathrm{h}}$ is described in detail below, and in Chapter 5 it will be explored as the mechanism that paces IIBs.

\subsection{The Hyperpolarization Activated, Cyclic-Nucleotide Sensitive, Nonselective Cation Current, $I_{h}$}

Neurons possess a vast repertoire of ion channels, including classical types such as the depolarization-activated $\mathrm{Na}^{+}$and $\mathrm{K}^{+}$channels underlying the action potential, as well as less-known channels. Ito and colleagues first illustrated the current conducted by one of these less-known channels (Ito and Oshima, 1965). They described a depolarizing current that was activated by membrane hyperpolarization in the feline motoneuron. This current was later also discovered in the Purkinje cells of the sino-atrial node in the heart (Brown and DiFrancesco, 1980). Because it was an inward current that was activated by membrane hyperpolarization, it seemed to be a "funny" or "queer" current, and it was initially named $I_{f}$ or $I_{q}$, but it is now customarily called $I_{h}$ because it is activated by membrane hyperpolarization. $I_{h}$ has been found in many types of neurons and in many neuronal compartments. $I_{h}$ is expressed in both cortical pyramidal cells (Constanti and 
Galvan, 1983; Maccaferri et al, 1993; Gasparini and DiFrancesco, 1997; Santoro et al, 2000) and interneurons (Maccaferri and McBain, 1996), and in neurons found in the cerebellum (Southan et al, 2000), substantia nigra (Harris and Libri, 1995), thalamus (McCormick and Pape, 1990; Williams et al, 1997), ventral tegmentum (Jian et al, 1994), and amygdala (Womble and Moises, 1993). Additionally, $\mathrm{I}_{\mathrm{h}}$ can be localized in segments of the neuron other than the soma: patch-clamp recordings from single axon terminals and dendrites reveal $\mathrm{I}_{\mathrm{h}}$ to be present in the synaptic axonal terminals of cerebellar basket cells (Southan et al, 2000), in the calyx of Held in the auditory brainstem (Cuttle et al, 2001), and in hippocampal pyramidal cell dendrites (Magee, 1998).

In addition to having a seemingly ubiquitous expression in the brain, $\mathrm{I}_{\mathrm{h}}$ functions in many roles. It contributes to the resting membrane potential and input resistance of neurons - when $\mathrm{I}_{\mathrm{h}}$ is blocked neurons hyperpolarize and have a marked $(\sim 30 \%)$ increase in input resistance (McCormick and Pape, 1990; Maccaferri et al, 1993). $I_{h}$ serves to limit the hyperpolarizing influence of $\mathrm{K}^{+}$conductances following intense action potential activity (Eng et al, 1990) and can shape firing patterns by limiting afterhyperpolarizing potentials. It has also been proposed that presynaptic $\mathrm{I}_{\mathrm{h}}$ channels in mossy fiber terminals are necessary for the induction of long-term potentiation in the CA3 (Mellor et al, 2002; but see Chevaleyre and Castillo (2002) for a different interpretation). The unconventional mechanism of being activated upon hyperpolarization makes $I_{h}$ particularly useful as a pacemaker by providing depolarization during rhythmic or oscillatory activity (Ito et al, 1965; Santoro and Tibbs, 1999; Santoro et al, 2000). Pacemaking action of $\mathrm{I}_{\mathrm{h}}$ has been described in many locations, including the heart (DiFrancesco, 1985, 1993), hippocampus (Strata et al, 1997), and thalamus (McCormick 
and Pape, 1990). It is possible that $I_{h}$ is involved with the generation of epileptiform bursting (Timofeev et al, 2002), and blocking $I_{h}$ could potentially be a viable treatment for epilepsy (Kitayama et al., 2003). In Chapter 5 we demonstrate that IIBs are paced by $I_{h}$.

$I_{h}$ channels have other characteristics that underscore their importance in rhythm generation (Pape, 1996; Santoro and Tibbs, 1999; Robinson and Siegelbaum, 2003), in addition to being activated by membrane hyperpolarization. The channel is permeable to $\mathrm{K}^{+}$and $\mathrm{Na}^{+}$ions, $\mathrm{I}_{\mathrm{h}}$ has a reversal potential of around $-35 \mathrm{mV}$, and $\mathrm{I}_{\mathrm{h}}$ does not inactivate with time (Halliwell and Adams, 1982; Mayer and Westbrook, 1983; Crepel and PenitSoria, 1986; Spain et al, 1987; McCormick and Pape, 1990; Maccaferri et al, 1993; Pape, 1996; Santoro and Tibbs, 1999), thus permitting the flow of a sustained depolarizing current that is capable of driving cells over firing threshold. Also, the $I_{h}$ channel's cytoplasmic domain binds cyclic nucleotides (Wainger et al, 2001), and upon nucleotide binding the conduction of the channel is enhanced and the activation curve of the channel is shifted towards more depolarized potentials (Luthi and McCormick, 1999; Santoro and Tibbs, 1999; Santoro et al, 2000; Chen et al, 2001). This permits various hormones to regulate the activity of $I_{h}$. For example, $\beta$-adrenergic stimulation of the heartbeat occurs by increasing the intracellular production of cAMP in the sino-atrial node purkinje cells, thereby increasing current conduction through $\mathrm{I}_{\mathrm{h}}$ channels (Pape, 1996).

There are four known $I_{h}$ channel subunits, HCN1 through HCN4, (Clapham, 1998; Ludwig et al, 1999a; Santoro et al, 1998) that are the products of the HCN (hyperpolarization-activated cyclic nucleotide-sensitive cation) gene family. The $\mathrm{I}_{\mathrm{h}}$ channel is tetrameric, and while all four homomeric channels have been studied in 
heterologous expression systems (Pape, 1996; Clapham, 1998; Robinson and Siegelbaum, 2003), the coassembly of HCN1 with HCN2 (Chen et al, 2001; Ulens and Tytgat, 2001) and HCN1 with HCN4 (Altomare et al, 2003) are the only heteromeric channels studied. The four subunits display different activation kinetics (Clapham, 1998). Generally speaking, HCN1 activates faster than HCN2, which activates faster than $\mathrm{HCN} 3$, which activates faster than $\mathrm{HCN} 4$, with the rates of activation spreading from milliseconds to seconds (Franz et al, 2000; Moosmang et al, 2001). Therefore, differential gene expression can account for the variability seen in the period of rhythms regulated by $I_{h}$ channels in different cell types (Santoro and Tibbs, 1999): for example, the photoreceptors in the retina express solely HCN1 which allow them to quickly reverse a light induced hyperpolarization, whereas the heart highly expresses HCN4 permitting $\mathrm{I}_{\mathrm{h}}$ to play a role in generating the relatively slow rhythm of heart contractions. Each of the subunits also display differences in their sensitivity to cyclic nucleotides in the order of HCN4 > HCN3 > HCN2 > HCN1 (Ishii et al, 1999; Ludwig et al, 1999b; Chen et al, 2001; Wainger et al, 2001).

Expression of $\mathrm{HCN}$ subunit mRNA is regulated by hippocampal activity and development. For example, in the CA3 region of the hippocampus, mRNA for HCN1 is expressed in the neonate but is downregulated after two weeks of life, whereas HCN4 mRNA expression increases with development (Bender et al, 2001). Additionally, seizure activity in the hippocampus caused a downregulation of HCN1 subunit mRNA in CA1 and an upregulation of HCN2 subunit mRNA in CA1 and CA3 (Brewster et al, 2002). Immunocytochemistry studies found that there is a developmental change in the amount of subunits present in the hippocampal neuropil (Vasilyev and Barish, 2002); 
however, the exact neuron types and neuronal compartments (i.e. dendrites, somata, axons, etc.) expressing the different HCN subunits throughout hippocampal development remain unknown. Chapter 6 describes the development of $\mathrm{HCN}$ immunoreactivity in the cerebral cortex in detail. 


\subsection{Figures}

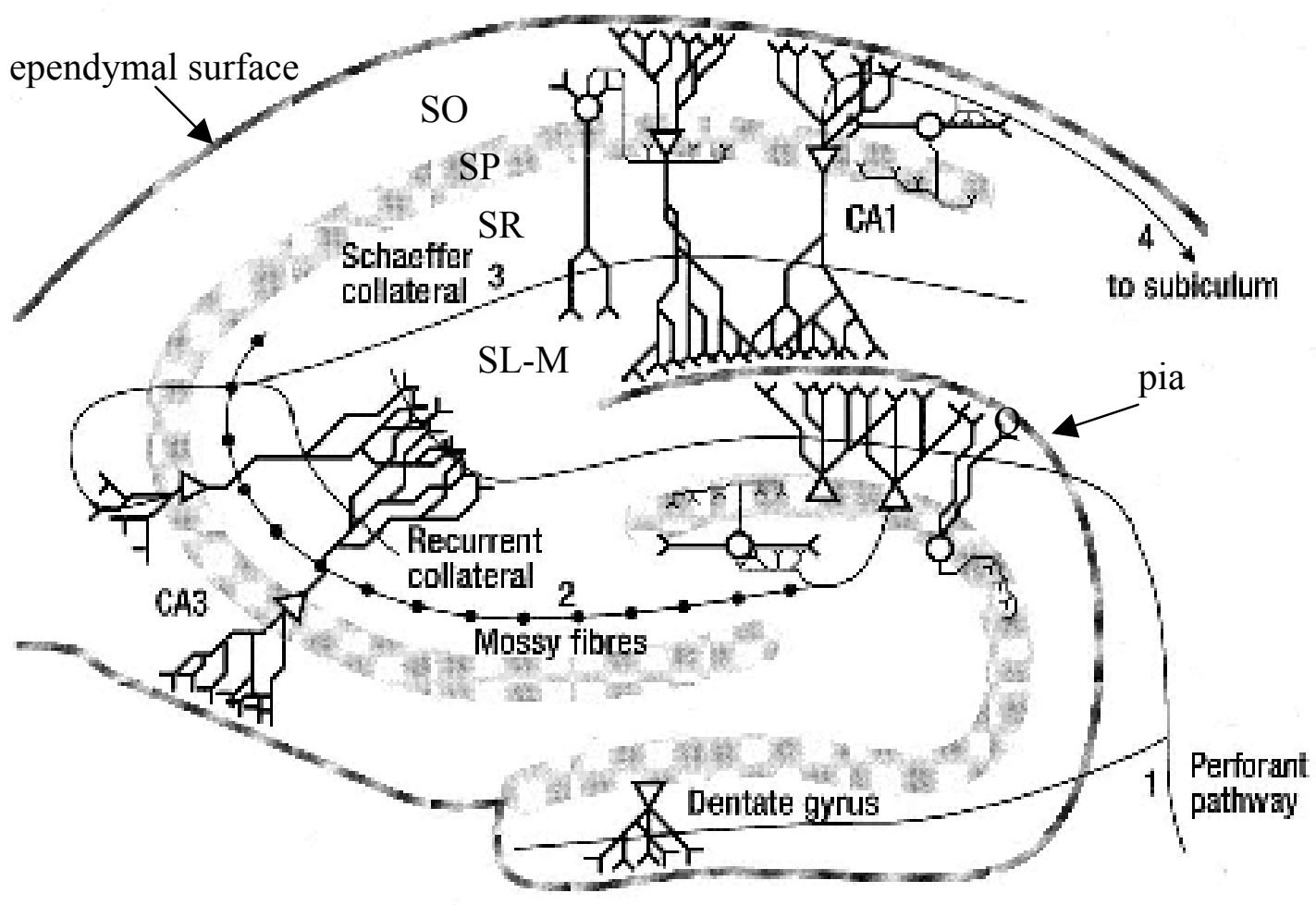

FiguRE 1-1. ANATOMY OF THE HIPPOCAMPUS.

Principle neurons (glutamatergic neurons) and interneurons (GABAergic neurons) are indicated with triangles and circles, respectively. $S O$, stratum oriens; $S P$, stratum pyramidale; $S R$, stratum radiatum; $S L-M$, stratum lacunosum-moleculare. Perforant pathway projection originates in entorhinal cortex. 


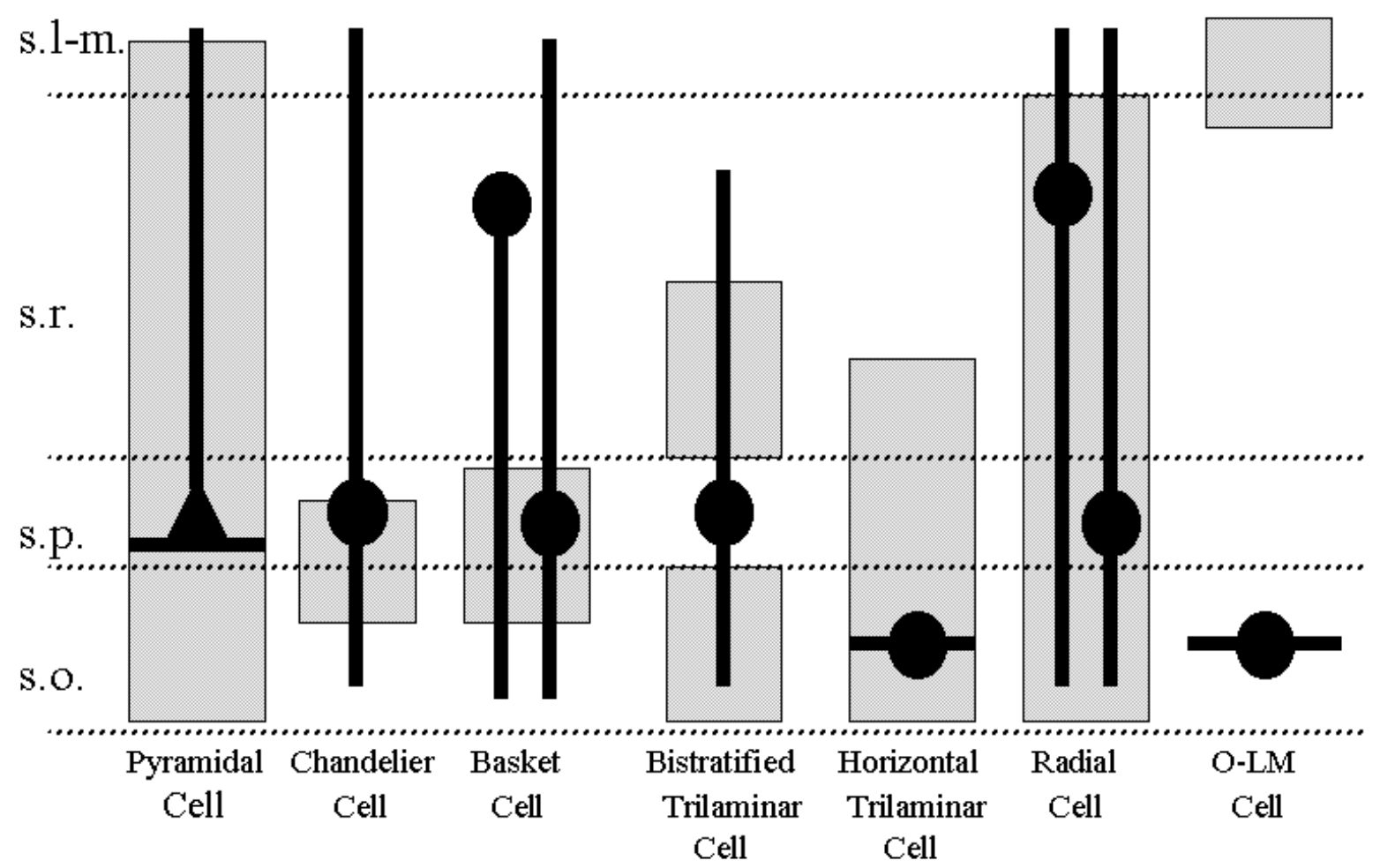

FIGURE 1-2. THE ORIENTATION OF HIPPOCAMPAL NEURONS.

Neuron somas are indicated with filled black circles, dendrites are indicated with thick black lines, and location of axon terminals are indicated with gray squares. Adapted from Fruend and Buzsaki (1996). SL- $M$, stratum lacunosum-moleculare; $S R$, stratum radiatum; $S P$, stratum pyramidale; $S O$, stratum oriens. 


\subsection{References}

Agmon A, Connors BW. (1989) Repetitive burst-firing neurons in the deep layers of mouse somatosensory cortex. Neurosci Lett 99:137-141.

Agmon A, Connors BW. (1992) Correlation between intrinsic firing patterns and thalamocortical synaptic responses of neurons in the mouse barrel cortex. J Neurosci 12(1): 319-329.

Alger BE (1984) Characteristics of a slow hyperpolarizing synaptic potential in rat hippocampal pyramidal cells in vitro. J Neurophysiol 52:892-910.

Amaral DG, Witter MP (1989) The three-dimensional organization of the hippocampal formation: a review of anatomical data. Neuroscience 31:571-591.

Amaral DG, Witter MP (1995) Hippocampal formation. In: The Rat Nervous System. Ed: Paxinos G. Academic Press, Inc.:San Diego.

Anderson WW, Stasheff SF, Swartzwelder HS, Wilson WA (1990) Regenerative, all-ornone electrographic seizures in the rat hippocampal slice in $\mathrm{Mg}$-free and physiological medium. Brain Res 532:288-298.

Ascher P, Nowak L (1988) The role of divalent cations in the N-methyl-D-aspartate responses of mouse central neurones in culture. J Physiol 399:247-266.

Avoli M (2001) Do interictal discharges promote or control seizures? Experimental evidence from an in vitro model of epileptiform discharge. Epilepsia 42:2-4.

Avoli M, Barbarosie M (1999) Interictal-ictal interactions and limbic seizure generation. Rev Neurol (Paris) 155:468-471.

Avoli M, Hwa G, Louvel J, Kurcewicz I, Pumain R, Lacaille JC (1997) Functional and pharmacological properties of GABA-mediated inhibition in the human neocortex. Can J Physiol Pharmacol 75:526-534.

Barker JL, Behar T, Li YX, Liu QY, Ma W, Maric D, Maric I, Schaffner AE, Serafini R, Smith SV, Somogyi R, Vautrin JY, Wen XL, Xian H (1998) GABAergic cells and signals in CNS development. Perspect Dev Neurobiol 5:305-322.

Barton RA (1996) Neocortex size and behavioural ecology in primates. Proc R Soc Lond B Biol Sci 263:173-177

Ben-Ari Y (2001) Developing networks play a similar melody. Trends Neurosci 24:353360 . 
Ben-Ari Y, Krnjevic K, Reiffenstein RJ, Reinhardt W (1981) Inhibitory conductance changes and action of gamma-aminobutyrate in rat hippocampus. Neuroscience 6:2445-2463.

Ben-Ari Y, Cherubini E, Corradetti R, Gaiarsa JL (1989) Giant synaptic potentials in immature rat CA3 hippocampal neurones. J Physiol 416:303-325.

Ben-Ari Y, Rovira C, Gaiarsa JL, Corradetti R, Robain O, Cherubini E (1990) GABAergic mechanisms in the CA3 hippocampal region during early postnatal life. Prog Brain Res 83:313-321.

Bender RA, Brewster A, Santoro B, Ludwig A, Hofmann F, Biel M, Baram TZ (2001) Differential and age-dependent expression of hyperpolarization- activated, cyclic nucleotide-gated cation channel isoforms 1-4 suggests evolving roles in the developing rat hippocampus. Neuroscience 106:689-698.

Betz $H$ (1990) Ligand-gated ion channels in the brain: the amino acid receptor superfamily. Neuron 5:383-392.

Bormann J, Hamill OP, Sakmann B (1987) Mechanism of anion permeation through channels gated by glycine and gamma-aminobutyric acid in mouse cultured spinal neurones. J Physiol 385:243-286.

Bourgeois BF, Prensky AL, Palkes HS, Talent BK, Busch SG (1983) Intelligence in epilepsy: a prospective study in children. Ann Neurol 14:438-444.

Bowery NG, Hudson AL, Price GW (1987) GABAA and GABAB receptor site distribution in the rat central nervous system. Neuroscience 20:365-383.

Bowery NG, Hill DR, Hudson AL, Doble A, Middlemiss DN, Shaw J, Turnbull M (1980) (-)Baclofen decreases neurotransmitter release in the mammalian CNS by an action at a novel GABA receptor. Nature 283:92-94.

Bradford HF (1995) Glutamate, GABA and epilepsy. Prog Neurobiol 47:477-511.

Brehm L, Greenwood JR, Hansen KB, Nielsen B, Egebjerg J, Stensbol TB, BraunerOsborne H, Slok FA, Kronborg TT, Krogsgaard-Larsen P (2003) (S)-2-Amino-3(3-hydroxy-7,8-dihydro-6H-cyclohepta[d]isoxazol-4- yl)propionic acid, a potent and selective agonist at the GluR5 subtype of ionotropic glutamate receptors. Synthesis, modeling, and molecular pharmacology. J Med Chem 46:1350-1358.

Brewster A, Bender RA, Chen Y, Dube C, Eghbal-Ahmadi M, Baram TZ (2002) Developmental febrile seizures modulate hippocampal gene expression of hyperpolarization-activated channels in an isoform- and cell-specific manner. $\mathrm{J}$ Neurosci 22:4591-4599. 
Buckmaster PS, Soltesz I (1996) Neurobiology of hippocampal interneurons: a workshop review. Hippocampus 6:330-339.

Buhl EH, Halasy K, Somogyi P (1994a) Diverse sources of hippocampal unitary inhibitory postsynaptic potentials and the number of synaptic release sites. Nature 368:823-828.

Buhl EH, Han ZS, Lorinczi Z, Stezhka VV, Karnup SV, Somogyi P (1994b) Physiological properties of anatomically identified axo-axonic cells in the rat hippocampus. J Neurophysiol 71:1289-1307.

Buzsaki G, Eidelberg E (1983) Phase relations of hippocampal projection cells and interneurons to theta activity in the anesthetized rat. Brain Res 266:334-339.

Buzsaki G, Horvath Z, Urioste R, Hetke J, Wise K (1992) High-frequency network oscillation in the hippocampus. Science 256:1025-1027.

Chagnac-Amitai Y, Connors BW (1989) Horizontal spread of synchronized activity in neocortex and its control by GABA-mediated inhibition. J Neurophysiol 61:747758.

Chamberlin NL, Traub RD, Dingledine R (1990) Role of EPSPs in initiation of spontaneous synchronized burst firing in rat hippocampal neurons bathed in high potassium. J Neurophysiol 64:1000-1008.

Chen K, Baram TZ, Soltesz I (1999) Febrile seizures in the developing brain result in persistent modification of neuronal excitability in limbic circuits. Nat Med 5:888894.

Chen S, Wang J, Siegelbaum SA (2001) Properties of hyperpolarization-activated pacemaker current defined by coassembly of HCN1 and HCN2 subunits and basal modulation by cyclic nucleotide. J Gen Physiol 117:491-504.

Cherubini E, Rovira C, Gaiarsa JL, Corradetti R, Ben Ari Y (1990) GABA mediated excitation in immature rat CA3 hippocampal neurons. Int J Dev Neurosci 8:481490.

Chu DC, Albin RL, Young AB, Penney JB (1990) Distribution and kinetics of GABAB binding sites in rat central nervous system: a quantitative autoradiographic study. Neuroscience 34:341-357.

Clapham DE (1998) Not so funny anymore: pacing channels are cloned. Neuron 21:5-7.

Clarke VR, Ballyk BA, Hoo KH, Mandelzys A, Pellizzari A, Bath CP, Thomas J, Sharpe EF, Davies CH, Ornstein PL, Schoepp DD, Kamboj RK, Collingridge GL, Lodge D, Bleakman D (1997) A hippocampal GluR5 kainate receptor regulating 
inhibitory synaptic transmission. Nature 389:599-603.

Constanti A, Galvan M (1983) Fast inward-rectifying current accounts for anomalous rectification in olfactory cortex neurones. J Physiol 335:153-178.

Crepel F, Penit-Soria J (1986) Inward rectification and low threshold calcium conductance in rat cerebellar Purkinje cells. An in vitro study. J Physiol 372:1-23.

Cuttle MF, Rusznak Z, Wong AY, Owens S, Forsythe ID (2001) Modulation of a presynaptic hyperpolarization-activated cationic current (I(h)) at an excitatory synaptic terminal in the rat auditory brainstem. J Physiol 534:733-744.

Dantzker JL, Callaway EM (2000) Laminar sources of synaptic input to cortical inhibitory interneurons and pyramidal neurons. Nat Neurosci 3:701-707.

Davies CH, Clarke VR, Jane DE, Collingridge GL (1995) Pharmacology of postsynaptic metabotropic glutamate receptors in rat hippocampal CA1 pyramidal neurones. $\mathrm{Br}$ J Pharmacol 116:1859-1869.

de Bode S, Curtiss S (2000) Language after hemispherectomy. Brain Cogn 43:135-138.

de Curtis M, Avanzini G (2001) Interictal spikes in focal epileptogenesis. Prog Neurobiol 63:541-567.

Debray C, Diabira D, Gaiarsa JL, Ben-Ari Y, Gozlan H (1997) Contributions of AMPA and GABA(A) receptors to the induction of NMDAR- dependent LTP in CA1. Neurosci Lett 238:119-122.

Dichter M, Spencer WA (1968) Hippocampal penicillin "spike" discharge: epileptic neuron or epileptic aggregate? Neurology 18:282-283.

Dichter M, Spencer WA (1969a) Penicillin-induced interictal discharges from the cat hippocampus. I. Characteristics and topographical features. J Neurophysiol 32:649-662.

Dichter M, Spencer WA (1969b) Penicillin-induced interictal discharges from the cat hippocampus. II. Mechanisms underlying origin and restriction. J Neurophysiol 32:663-687.

Dichter M, Herman C, Selzer M (1973) Penicillin epilepsy in isolated islands of hippocampus. Electroencephalogr Clin Neurophysiol 34:631-638.

Dichter MA, Ayala GF (1987) Cellular mechanisms of epilepsy: a status report. Science 237:157-164. 
DiFrancesco D (1985) The cardiac hyperpolarizing-activated current, if. Origins and developments. Prog Biophys Mol Biol 46:163-183.

DiFrancesco D (1993) Pacemaker mechanisms in cardiac tissue. Annu Rev Physiol $55: 455-472$.

Dingledine R, Gjerstad L (1979) Penicillin blocks hippocampal IPSPs, unmasking prolonged EPSPs. Brain Res 168:205-209.

Dingledine R, Gjerstad L (1980) Reduced inhibition during epileptiform activity in the in vitro hippocampal slice. J Physiol 305:297-313.

Dolphin AC, Scott RH (1987) Calcium channel currents and their inhibition by (-)baclofen in rat sensory neurones: modulation by guanine nucleotides. J Physiol 386:1-17.

Dolphin AC, McGuirk SM, Scott RH (1989) An investigation into the mechanisms of inhibition of calcium channel currents in cultured sensory neurones of the rat by guanine nucleotide analogues and (-)-baclofen. Br J Pharmacol 97:263-273.

Durand GM, Kovalchuk Y, Konnerth A (1996) Long-term potentiation and functional synapse induction in developing hippocampus. Nature 381:71-75.

Dutar P, Nicoll RA (1988) Pre- and postsynaptic GABAB receptors in the hippocampus have different pharmacological properties. Neuron 1:585-591.

Dzhala, VI, Staley KJ (2003) Excitatory actions of endogenously released GABA contribute to initiation of ictal epileptiform activity in the developing hippocampus. J Neurosci 23:1840-1846.

Egebjerg J, Bettler B, Hermans-Borgmeyer I, Heinemann S (1991) Cloning of a cDNA for a glutamate receptor subunit activated by kainate but not AMPA. Nature 351:745-748.

Eng DL, Gordon TR, Kocsis JD, Waxman SG (1990) Current-clamp analysis of a timedependent rectification in rat optic nerve. J Physiol 421:185-202.

Farwell JR, Dodrill CB, Batzel LW (1985) Neuropsychological abilities of children with epilepsy. Epilepsia 26:395-400.

Fishman MA (1979) Febrile seizures: the treatment controversy. J Pediatr 94:177-184.

Fletcher EJ, Lodge, D. (1996) New developments in the molecular pharmacology of $\alpha$ amino-3-hydroxy-5-methyl-4-isoxazole proprionate and kainate receptors. Pharmacol Ther 70:65-89. 
Florey E, McLennan H. (1955) The release of an inhibitory substance from mammalian brain and its action on peripheral synaptic transmission. J Physiol 130:446-455.

Fox S, Krnjevic K, Morris ME, Puil E, Werman R (1978) Action of baclofen on mammalian synaptic transmission. Neuroscience 3:495-515.

Franz O, Liss B, Neu A, Roeper J (2000) Single-cell mRNA expression of HCN1 correlates with a fast gating phenotype of hyperpolarization-activated cyclic nucleotide-gated ion channels (Ih) in central neurons. Eur J Neurosci 12:26852693.

Fraser DD, MacVicar BA (1991) Low-threshold transient calcium current in rat hippocampal lacunosum- moleculare interneurons: kinetics and modulation by neurotransmitters. J Neurosci 11:2812-2820.

Freund TF, Buzsaki G (1996) Interneurons of the hippocampus. Hippocampus 6:347-470.

Gaiarsa JL, Zagrean L, Ben-Ari Y (1994) Neonatal irradiation prevents the formation of hippocampal mossy fibers and the epileptic action of kainate on rat CA3 pyramidal neurons. J Neurophysiol 71:204-215.

Gaiarsa JL, Tseeb V, Ben-Ari Y (1995) Postnatal development of pre- and postsynaptic GABAB-mediated inhibitions in the CA3 hippocampal region of the rat. $\mathrm{J}$ Neurophysiol 73:246-255.

Gaiarsa JL, Corradetti R, Cherubini E, Ben-Ari Y (1990) The allosteric glycine site of the $\mathrm{N}$-methyl-D-aspartate receptor modulates GABAergic-mediated synaptic events in neonatal rat CA3 hippocampal neurons. Proc Natl Acad Sci U S A 87:343-346.

Gaiarsa JL, Corradetti R, Cherubini E, Ben-Ari Y (1991) Modulation of GABA-mediated Synaptic Potentials by Glutamatergic Agonists in Neonatal CA3 Rat Hippocampal Neurons. Eur J Neurosci 3:301-309.

Garaschuk O, Hanse E, Konnerth A (1998) Developmental profile and synaptic origin of early network oscillations in the CA1 region of rat neonatal hippocampus. J Physiol 507:219-236.

Gasparini S, DiFrancesco D (1997) Action of the hyperpolarization-activated current (Ih) blocker ZD 7288 in hippocampal CA1 neurons. Pflugers Arch 435:99-106.

Gilbert DL, Glauser TA (1999) Complications and costs of treatment of refractory generalized convulsive status epilepticus in children. J Child Neurol 14:597-601.

Glauser TA, Clancy RR (1992) Adequacy of routine EEG examinations in neonates with clinically suspected seizures. J Child Neurol 7:215-220. 
Gloveli T, Albrecht D, Heinemann U (1995) Properties of low Mg2+ induced epileptiform activity in rat hippocampal and entorhinal cortex slices during adolescence. Brain Res Dev Brain Res 87:145-152.

Goddard GV, McIntyre DC, Leech CK (1969) A permanent change in brain function resulting from daily electrical stimulation. Exp Neurol 25:295-330.

Gubellini P, Ben-Ari Y, Gaiarsa JL (2001) Activity- and age-dependent GABAergic synaptic plasticity in the developing rat hippocampus. Eur J Neurosci 14:19371946.

Gulyas AI, Freund TF (1996) Pyramidal cell dendrites are the primary targets of calbindin D28k- immunoreactive interneurons in the hippocampus. Hippocampus 6:525-534.

Gutnick MJ, Bergman S (1982) Model for simulating cyclic variations in focal epileptogenic excitability. Isr J Med Sci 18:119-125.

Gutnick MJ, Connors BW, Prince DA (1982) Mechanisms of neocortical epileptogenesis in vitro. J Neurophysiol 48:1321-1335.

Hablitz JJ (1984) Picrotoxin-induced epileptiform activity in hippocampus: role of endogenous versus synaptic factors. J Neurophysiol 51:1011-1027.

Hablitz JJ (1987) Spontaneous ictal-like discharges and sustained potential shifts in the developing rat neocortex. J Neurophysiol 58:1052-1065.

Halliwell JV, Adams PR (1982) Voltage-clamp analysis of muscarinic excitation in hippocampal neurons. Brain Res 250:71-92.

Han ZS, Buhl EH, Lorinczi Z, Somogyi P (1993) A high degree of spatial selectivity in the axonal and dendritic domains of physiologically identified local-circuit neurons in the dentate gyrus of the rat hippocampus. Eur J Neurosci 5:395-410.

Harris NC, Constanti A (1995) Mechanism of block by ZD 7288 of the hyperpolarization-activated inward rectifying current in guinea pig substantia nigra neurons in vitro. J Neurophysiol 74:2366-2378.

Harris NC, Libri V, Constanti A (1994) Selective blockade of the hyperpolarizationactivated cationic current (Ih) in guinea pig substantia nigra pars compacta neurones by a novel bradycardic agent, Zeneca ZM 227189. Neurosci Lett 176:221-225.

Heaulme M, Chambon JP, Leyris R, Wermuth CG, Biziere K (1986) Specific binding of a phenyl-pyridazinium derivative endowed with GABAA receptor antagonist 
activity to rat brain. Neuropharmacology 25:1279-1283.

Hokfelt T, Johansson O, Ljungdahl A, Lundberg JM, Schultzberg M (1980) Peptidergic neurones. Nature 284:515-521.

Holmes GL (1997) Epilepsy in the developing brain: lessons from the laboratory and clinic. Epilepsia 38:12-30.

Holmes GL, Khazipov R, Ben-Ari Y (2002) New concepts in neonatal seizures. Neuroreport 13:A3-8.

Holz GGt, Rane SG, Dunlap K (1986) GTP-binding proteins mediate transmitter inhibition of voltage- dependent calcium channels. Nature 319:670-672.

Ishii TM, Takano M, Xie LH, Noma A, Ohmori H (1999) Molecular characterization of the hyperpolarization-activated cation channel in rabbit heart sinoatrial node. $\mathrm{J}$ Biol Chem 274:12835-12839.

Ishizuka N, Cowan WM, Amaral DG (1995) A quantitative analysis of the dendritic organization of pyramidal cells in the rat hippocampus. J Comp Neurol 362:1745.

Ito M, Oshima T (1965) Electrical behaviour of the motoneurone membrane during intracellularly applied current steps. J Physiol 180:607-635.

Janigro D, West GA, Nguyen TS, Winn HR (1994) Regulation of blood-brain barrier endothelial cells by nitric oxide. Circ Res 75:528-538.

Jarrard LE (1995) What does the hippocampus really do? Behav Brain Res 71:1-10.

Jensen MS, Yaari Y (1988) The relationship between interictal and ictal paroxysms in an in vitro model of focal hippocampal epilepsy. Ann Neurol 24:591-598.

Jiang ZG, Pessia M, North RA (1994) Neurotensin excitation of rat ventral tegmental neurones. J Physiol 474:119-129.

Johnson BG, Wright RA, Arnold MB, Wheeler WJ, Ornstein PL, Schoepp DD (1999a) [3H]-LY341495 as a novel antagonist radioligand for group II metabotropic glutamate (mGlu) receptors: characterization of binding to membranes of $\mathrm{mGlu}$ receptor subtype expressing cells. Neuropharmacology 38:1519-1529.

Johnson MP, Chamberlain M, Kelly GM (1999b) Phosphoinositide hydrolysis in vivo with group I metabotropic glutamate receptor agonists. Brain Res 821:539-545.

Johnston GA (1996) GABAc receptors: relatively simple transmitter -gated ion channels? 
Trends Pharmacol Sci 17:319-323.

Kaila K (1994) Ionic basis of GABAA receptor channel function in the nervous system. Prog Neurobiol 42:489-537.

Kawaguchi Y, Hama K (1987) Two subtypes of non-pyramidal cells in rat hippocampal formation identified by intracellular recording and HRP injection. Brain Res 411:190-195.

Keverne EB, Martel FL, Nevison CM (1996) Primate brain evolution: genetic and functional considerations. Proc R Soc Lond B Biol Sci 263:689-696.

Khalilov I, Dzhala V, Ben-Ari Y, Khazipov R (1999) Dual role of GABA in the neonatal rat hippocampus. Dev Neurosci 21:310-319.

Khazipov R, Ragozzino D, Bregestovski P (1995) Kinetics and Mg2+ block of N-methylD-aspartate receptor channels during postnatal development of hippocampal CA3 pyramidal neurons. Neuroscience 69:1057-1065.

Khazipov R, Leinekugel X, Khalilov I, Gaiarsa JL, Ben-Ari Y (1997) Synchronization of GABAergic interneuronal network in CA3 subfield of neonatal rat hippocampal slices. J Physiol 498:763-772.

Khazipov R, Esclapez M, Caillard O, Bernard C, Khalilov I, Tyzio R, Hirsch J, Dzhala V, Berger B, Ben-Ari Y (2001) Early development of neuronal activity in the primate hippocampus in utero. J Neurosci 21:9770-9781.

Khazipov RN, Zefirov AL, Ben-Ari E (1998) [GABA--the basic mediator of excitation in the early stages of hippocampal development]. Usp Fiziol Nauk 29:55-67.

Kidd FL, Isaac JT (1999) Developmental and activity-dependent regulation of kainate receptors at thalamocortical synapses. Nature 400:569-573.

Kingston AE, Ornstein PL, Wright RA, Johnson BG, Mayne NG, Burnett JP, Belagaje R, Wu S, Schoepp DD (1998) LY341495 is a nanomolar potent and selective antagonist of group II metabotropic glutamate receptors. Neuropharmacology $37: 1-12$.

Knowles WD, Schwartzkroin PA (1981a) Local circuit synaptic interactions in hippocampal brain slices. J Neurosci 1:318-322.

Knowles WD, Schwartzkroin PA (1981b) Axonal ramifications of hippocampal Ca1 pyramidal cells. J Neurosci 1:1236-1241. 
Knowles WD, Schneiderman JH, Wheal HV, Stafstrom CE, Schwartzkroin PA (1984) Hyperpolarizing potentials in guinea pig hippocampal CA3 neurons. Cell Mol Neurobiol 4:207-230.

Kohling R, Vreugdenhil M, Bracci E, Jefferys JG (2000) Ictal epileptiform activity is facilitated by hippocampal GABAA receptor-mediated oscillations. J Neurosci 20:6820-6829.

Korn SJ, Giacchino JL, Chamberlin NL, Dingledine R (1987) Epileptiform burst activity induced by potassium in the hippocampus and its regulation by GABA-mediated inhibition. J Neurophysiol 57:325-340.

Kravitz EA, Kuffler SW, Potter DD. (1963) Gamma-aminobutryic acid and other blocking compounds in crutacea. III. Their relative concentrations in seperated motor and inhibitory axons. J Neurophysiol 26:739-751.

Krishnamoorthy KS, Zalneraitis EL, Young RS, Bernad PG (1983) Phenytoin-induced choreoathetosis in infancy: case reports and a review. Pediatrics 72:831-834.

Krnjevic K (1981) Action of GABA on hippocampal neurons. Adv Biochem Psychopharmacol 29:231-237.

Kubova H, Moshe SL (1994) Experimental models of epilepsy in young animals. J Child Neurol 9 Suppl 1:S3-11.

Lamsa K, Palva JM, Ruusuvuori E, Kaila K, Taira T (2000) Synaptic GABA(A) activation inhibits AMPA-kainate receptor-mediated bursting in the newborn (P0P2) rat hippocampus. J Neurophysiol 83:359-366.

Langenstroth M, Albowitz B, Kuhnt U (1996) Partial suppression of GABAA-mediated inhibition induces spatially restricted epileptiform activity in guinea pig neocortical slices. Neurosci Lett 210:103-106.

Lauder JM, Liu J, Devaud L, Morrow AL (1998) GABA as a trophic factor for developing monoamine neurons. Perspect Dev Neurobiol 5:247-259.

Lebovitz RM (1979) Autorhythmicity of spontaneous interictal spike discharge at hippocampal penicillin foci. Brain Res 172:35-55.

Leinekugel X, Medina I, Khalilov I, Ben-Ari Y, Khazipov R (1997) Ca2+ oscillations mediated by the synergistic excitatory actions of GABA(A) and NMDA receptors in the neonatal hippocampus. Neuron 18:243-255.

Leinekugel X, Khazipov R, Cannon R, Hirase H, Ben-Ari Y, Buzsaki G (2002) Correlated bursts of activity in the neonatal hippocampus in vivo. Science 296:2049-2052. 
Leinekugel X, Khalilov I, McLean H, Caillard O, Gaiarsa JL, Ben-Ari Y, Khazipov R (1999) GABA is the principal fast-acting excitatory transmitter in the neonatal brain. Adv Neurol 79:189-201.

LeVay S (1973) Synaptic patterns in the visual cortex of the cat and monkey. Electron microscopy of Golgi preparations. J Comp Neurol 150:53-85.

Lewis DV, Jones LS, Swartzwelder HS (1989) The effects of baclofen and pertussis toxin on epileptiform activity induced in the hippocampal slice by magnesium depletion. Epilepsy Res 4:109-118.

Li XG, Somogyi P, Ylinen A, Buzsaki G (1994) The hippocampal CA3 network: an in vivo intracellular labeling study. J Comp Neurol 339:181-208.

Li-Smerin Y, Johnson JW (1996) Kinetics of the block by intracellular Mg2+ of the NMDA-activated channel in cultured rat neurons. J Physiol 491:121-135.

Lodge D, Davies SN, Jones MG, Millar J, Manallack DT, Ornstein PL, Verberne AJ, Young N, Beart PM (1988) A comparison between the in vivo and in vitro activity of five potent and competitive NMDA antagonists. $\mathrm{Br} \mathrm{J}$ Pharmacol 95:957-965.

Ludwig A, Zong X, Hofmann F, Biel M (1999a) Structure and function of cardiac pacemaker channels. Cell Physiol Biochem 9:179-186.

Ludwig A, Zong X, Stieber J, Hullin R, Hofmann F, Biel M (1999b) Two pacemaker channels from human heart with profoundly different activation kinetics. Embo J 18:2323-2329.

Lukasiewicz PD (1996) GABAC receptors in the vertebrate retina. Mol Neurobiol 12:181-194.

Luthi A, McCormick DA (1999) Modulation of a pacemaker current through $\mathrm{Ca}(2+)$ induced stimulation of cAMP production. Nat Neurosci 2:634-641.

Luthi A, Bal T, McCormick DA (1998) Periodicity of thalamic spindle waves is abolished by ZD7288,a blocker of Ih. J Neurophysiol 79:3284-3289.

Maccaferri G, McBain CJ (1996) The hyperpolarization-activated current (Ih) and its contribution to pacemaker activity in rat CA1 hippocampal stratum oriens-alveus interneurones. J Physiol 497:119-130.

Maccaferri G, Mangoni M, Lazzari A, DiFrancesco D (1993) Properties of the hyperpolarization-activated current in rat hippocampal CA1 pyramidal cells. $\mathrm{J}$ Neurophysiol 69:2129-2136. 
Magee JC (1998) Dendritic hyperpolarization-activated currents modify the integrative properties of hippocampal CA1 pyramidal neurons. J Neurosci 18:7613-7624

Manzoni O, Fagni L, Pin JP, Rassendren F, Poulat F, Sladeczek F, Bockaert J (1990) (trans)-1-amino-cyclopentyl-1,3-dicarboxylate stimulates quisqualate phosphoinositide-coupled receptors but not ionotropic glutamate receptors in striatal neurons and Xenopus oocytes. Mol Pharmacol 38:1-6.

Martin LA, Tan SS, Goldowitz D (2002) Clonal architecture of the mouse hippocampus. J Neurosci 22:3520-3530.

Mayer ML, Westbrook GL (1983) A voltage-clamp analysis of inward (anomalous) rectification in mouse spinal sensory ganglion neurones. J Physiol 340:19-45.

McBain CJ (1994) Hippocampal inhibitory neuron activity in the elevated potassium model of epilepsy. J Neurophysiol 72:2853-2863.

McCormick DA, Pape HC (1990) Properties of a hyperpolarization-activated cation current and its role in rhythmic oscillation in thalamic relay neurones. J Physiol 431:291-318.

McLaughlin SG, Szabo G, Eisenman G (1971) Divalent ions and the surface potential of charged phospholipid membranes. J Gen Physiol 58:667-687.

McLean HA, Caillard O, Ben-Ari Y, Gaiarsa JL (1996) Bidirectional plasticity expressed by GABAergic synapses in the neonatal rat hippocampus. J Physiol 496:471-477.

McNamara JO, Byrne MC, Dasheiff RM, Fitz JG (1980) The kindling model of epilepsy: a review. Prog Neurobiol 15:139-159.

Meador KJ (2002) Neurodevelopmental effects of antiepileptic drugs. Curr Neurol Neurosci Rep 2:373-378.

Mellor J, Nicoll RA, Schmitz D (2002) Mediation of hippocampal mossy fiber long-term potentiation by presynaptic Ih channels. Science 295:143-147.

Menniti FS, Buchan AM, Chenard BL, Critchett DJ, Ganong AH, Guanowsky V, Seymour PA, Welch WM (2003) CP-465,022, a selective noncompetitive AMPA receptor antagonist, blocks AMPA receptors but is not neuroprotective in vivo. Stroke 34:171-176.

Merlin LR, Taylor GW, Wong RK (1995) Role of metabotropic glutamate receptor subtypes in the patterning of epileptiform activities in vitro. J Neurophysiol 74:896-900. 
Miles R, Wong RK (1986) Excitatory synaptic interactions between CA3 neurones in the guinea-pig hippocampus. J Physiol 373:397-418.

Miles R, Toth K, Gulyas AI, Hajos N, Freund TF (1996) Differences between somatic and dendritic inhibition in the hippocampus. Neuron 16:815-823.

Mody I, Lambert JD, Heinemann U (1987) Low extracellular magnesium induces epileptiform activity and spreading depression in rat hippocampal slices. J Neurophysiol 57:869-888.

Moosmang S, Stieber J, Zong X, Biel M, Hofmann F, Ludwig A (2001) Cellular expression and functional characterization of four hyperpolarization-activated pacemaker channels in cardiac and neuronal tissues. Eur J Biochem 268:16461652.

Mutani R (1986) Neurophysiological mechanisms underlying epileptogenesis. Funct Neurol 1:385-389.

Nagao T, Alonso A, Avoli M (1996) Epileptiform activity induced by pilocarpine in the rat hippocampal- entorhinal slice preparation. Neuroscience 72:399-408.

Neuman RS, Cherubini E, Ben-Ari Y (1989) Endogenous and network bursts induced by N-methyl-D-aspartate and magnesium free medium in the CA3 region of the hippocampal slice. Neuroscience 28:393-399.

Newberry NR, Nicoll RA (1984) Direct hyperpolarizing action of baclofen on hippocampal pyramidal cells. Nature 308:450-452.

Newberry NR, Nicoll RA (1985) Comparison of the action of baclofen with gammaaminobutyric acid on rat hippocampal pyramidal cells in vitro. J Physiol 360:161185.

Newland CF, Cull-Candy SG (1992) On the mechanism of action of picrotoxin on GABA receptor channels in dissociated sympathetic neurones of the rat. J Physiol 447:191-213.

Nowak L, Bregestovski P, Ascher P, Herbet A, Prochiantz A (1984) Magnesium gates glutamate-activated channels in mouse central neurones. Nature 307:462-465.

Nunzi MG, Gorio A, Milan F, Freund TF, Somogyi P, Smith AD (1985) Cholecystokinin-immunoreactive cells form symmetrical synaptic contacts with pyramidal and nonpyramidal neurons in the hippocampus. J Comp Neurol 237:485-505. 
Oguni H, Tanaka T, Hayashi K, Funatsuka M, Sakauchi M, Shirakawa S, Osawa M (2002) Treatment and long-term prognosis of myoclonic-astatic epilepsy of early childhood. Neuropediatrics 33:122-132.

Oliver AP, Hoffer BJ, Wyatt RJ (1977) The hippocampal slice: a system for studying the pharmacology of seizures and for screening anticonvulsant drugs. Epilepsia 18:543-548.

Ottersen OP, Hjelle OP, Osen K, Lake JH (1995) Amino Acid Neurotransmitters. In: The Rat Nervous System. Ed: Paxinos G. Academic Press, Inc.:San Diego.

Owens DF, Boyce LH, Davis MB, Kriegstein AR (1996) Excitatory GABA responses in embryonic and neonatal cortical slices demonstrated by gramicidin perforatedpatch recordings and calcium imaging. J Neurosci 16:6414-6423.

Pape HC (1996) Queer current and pacemaker: the hyperpolarization-activated cation current in neurons. Annu Rev Physiol 58:299-327.

Parra P, Gulyas AI, Miles R (1998) How many subtypes of inhibitory cells in the hippocampus? Neuron 20:983-993.

Pellock JM (1998) Use of midazolam for refractory status epilepticus in pediatric patients. J Child Neurol 13:581-587.

Perreault P, Avoli M (1991) Physiology and pharmacology of epileptiform activity induced by 4- aminopyridine in rat hippocampal slices. J Neurophysiol 65:771785.

Poolos NP, Migliore M, Johnston D (2002) Pharmacological upregulation of h-channels reduces the excitability of pyramidal neuron dendrites. Nat Neurosci 5:767-774.

Prichard JS (1974) Convulsive disorders in children: some notes on the diagnosis and treatment. Pediatr Clin North Am 21:981-989.

Prince DA (1983) Mechanisms of epileptogenesis in brain-slice model systems. Res Publ Assoc Res Nerv Ment Dis 61:29-52.

Prince DA (1985) Physiological mechanisms of focal epileptogenesis. Epilepsia 26:S314.

Prince DA, Connors BW (1986) Mechanisms of interictal epileptogenesis. Adv Neurol 44:275-299.

Psarropoulou C, Descombes S (1999) Differential bicuculline-induced epileptogenesis in rat neonatal, juvenile and adult CA3 pyramidal neurons in vitro. Brain Res Dev Brain Res 117:117-120. 
Rasmussen K, Vandergriff J (2003) The selective iGluR1-4 (AMPA) antagonist LY300168 attenuates morphine- withdrawal-induced activation of locus coeruleus neurons and behavioural signs of morphine withdrawal. Neuropharmacology 44:88-92.

Rivera C, Voipio J, Payne JA, Ruusuvuori E, Lahtinen H, Lamsa K, Pirvola U, Saarma M, Kaila K (1999) The $\mathrm{K}+/ \mathrm{Cl}$ - co-transporter $\mathrm{KCC} 2$ renders GABA hyperpolarizing during neuronal maturation. Nature 397:251-255.

Robinson HP, Kawahara M, Jimbo Y, Torimitsu K, Kuroda Y, Kawana A (1993) Periodic synchronized bursting and intracellular calcium transients elicited by low magnesium in cultured cortical neurons. J Neurophysiol 70:1606-1616.

Robinson RB, Siegelbaum SA (2003) HYPERPOLARIZATION-ACTIVATED CATION CURRENTS: From Molecules to Physiological Function. Annu Rev Physiol 65:453-480.

Rovira C, Gho M, Ben-Ari Y (1990) Block of GABAb-activated K+ conductance by kainate and quisqualate in rat CA3 hippocampal pyramidal neurones. Pflugers Arch 415:471-478.

Rudy B (1988) Diversity and ubiquity of K channels. Neuroscience 25:729-749.

Santoro B, Tibbs GR (1999) The HCN gene family: molecular basis of the hyperpolarization-activated pacemaker channels. Ann N Y Acad Sci 868:741-764.

Santoro B, Liu DT, Yao H, Bartsch D, Kandel ER, Siegelbaum SA, Tibbs GR (1998) Identification of a gene encoding a hyperpolarization-activated pacemaker channel of brain. Cell 93:717-729.

Santoro B, Chen S, Luthi A, Pavlidis P, Shumyatsky GP, Tibbs GR, Siegelbaum SA (2000) Molecular and functional heterogeneity of hyperpolarization-activated pacemaker channels in the mouse CNS. J Neurosci 20:5264-5275.

Sarantis M, Ballerini L, Miller B, Silver RA, Edwards M, Attwell D (1993) Glutamate uptake from the synaptic cleft does not shape the decay of the non-NMDA component of the synaptic current. Neuron 11:541-549.

Scharfman HE (1995) Electrophysiological diversity of pyramidal-shaped neurons at the granule cell layer/hilus border of the rat dentate gyrus recorded in vitro. Hippocampus 5:287-305.

Schmitz D, Schuchmann S, Fisahn A, Draguhn A, Buhl EH, Petrasch-Parwez E, Dermietzel R, Heinemann U, Traub RD (2001) Axo-axonal coupling. a novel mechanism for ultrafast neuronal communication. Neuron 31:831-840. 
Schneiderman JH, MacDonald JF (1987) Effects of reduced magnesium on hippocampal synchrony. Brain Res 410:174-178.

Schwartzkroin PA, Prince DA (1977) Penicillin-induced epileptiform activity in the hippocampal in vitro prepatation. Ann Neurol 1:463-469.

Sieghart W, Fuchs K, Tretter V, Ebert V, Jechlinger M, Hoger H, Adamiker D (1999) Structure and subunit composition of $\operatorname{GABA}(\mathrm{A})$ receptors. Neurochem Int 34:379-385.

Sik A, Tamamaki N, Freund TF (1993) Complete axon arborization of a single CA3 pyramidal cell in the rat hippocampus, and its relationship with postsynaptic parvalbumin- containing interneurons. Eur J Neurosci 5:1719-1728.

Sik A, Penttonen M, Ylinen A, Buzsaki G (1995) Hippocampal CA1 interneurons: an in vivo intracellular labeling study. J Neurosci 15:6651-6665.

Sladeczek F, Pin JP, Recasens M, Bockaert J, Weiss S (1985) Glutamate stimulates inositol phosphate formation in striatal neurones. Nature 317:717-719.

Sloviter RS (1987) Decreased hippocampal inhibition and a selective loss of interneurons in experimental epilepsy. Science 235:73-76.

Sloviter RS (1991) Feedforward and feedback inhibition of hippocampal principal cell activity evoked by perforant path stimulation: GABA-mediated mechanisms that regulate excitability in vivo. Hippocampus 1:31-40.

Sloviter RS, Nilaver G (1987) Immunocytochemical localization of GABA-, cholecystokinin-, vasoactive intestinal polypeptide-, and somatostatin-like immunoreactivity in the area dentata and hippocampus of the rat. J Comp Neurol 256:42-60.

Smith SJ, Thompson SH (1987) Slow membrane currents in bursting pace-maker neurones of Tritonia. J Physiol 382:425-448.

Soltesz I, Deschenes M (1993) Low- and high-frequency membrane potential oscillations during theta activity in CA1 and CA3 pyramidal neurons of the rat hippocampus under ketamine-xylazine anesthesia. J Neurophysiol 70:97-116.

Soltesz I, Lightowler S, Leresche N, Jassik-Gerschenfeld D, Pollard CE, Crunelli V (1991) Two inward currents and the transformation of low-frequency oscillations of rat and cat thalamocortical cells. J Physiol 441:175-197. 
Somogyi P, Nunzi MG, Gorio A, Smith AD (1983) A new type of specific interneuron in the monkey hippocampus forming synapses exclusively with the axon initial segments of pyramidal cells. Brain Res 259:137-142.

Somogyi P, Freund TF, Hodgson AJ, Somogyi J, Beroukas D, Chubb IW (1985) Identified axo-axonic cells are immunoreactive for GABA in the hippocampus and visual cortex of the cat. Brain Res 332:143-149.

Southan AP, Morris NP, Stephens GJ, Robertson B (2000) Hyperpolarization-activated currents in presynaptic terminals of mouse cerebellar basket cells. J Physiol 526 Pt 1:91-97.

Spain WJ, Schwindt PC, Crill WE (1987) Anomalous rectification in neurons from cat sensorimotor cortex in vitro. J Neurophysiol 57:1555-1576.

Staley KJ, Soldo BL, Proctor WR (1995) Ionic mechanisms of neuronal excitation by inhibitory GABAA receptors. Science 269:977-981.

Staley KJ, Longacher M, Bains JS, Yee A (1998) Presynaptic modulation of CA3 network activity. Nat Neurosci 1:201-209.

Staley KJ, Bains JS, Yee A, Hellier J, Longacher JM (2001) Statistical model relating CA3 burst probability to recovery from burst- induced depression at recurrent collateral synapses. J Neurophysiol 86:2736-2747.

Stasheff SF, Bragdon AC, Wilson WA (1985) Induction of epileptiform activity in hippocampal slices by trains of electrical stimuli. Brain Res 344:296-302.

Stevens CF, Wesseling JF (1998) Activity-dependent modulation of the rate at which synaptic vesicles become available to undergo exocytosis. Neuron 21:415-424.

Strata F, Atzori M, Molnar M, Ugolini G, Tempia F, Cherubini E (1997) A pacemaker current in dye-coupled hilar interneurons contributes to the generation of giant GABAergic potentials in developing hippocampus. J Neurosci 17:1435-1446.

Sun D, Murali SG (1999) $\mathrm{Na}^{+-} \mathrm{K}+-2 \mathrm{Cl}-$ cotransporter in immature cortical neurons: A role in intracellular Cl- regulation. J Neurophysiol 81:1939-1948.

Swartzwelder HS, Lewis DV, Anderson WW, Wilson WA (1987) Seizure-like events in brain slices: suppression by interictal activity. Brain Res 410:362-366.

Tancredi V, Hwa GG, Zona C, Brancati A, Avoli M (1990) Low magnesium epileptogenesis in the rat hippocampal slice: electrophysiological and pharmacological features. Brain Res 511:280-290. 
Thalmann RH (1988) Blockade of a late inhibitory postsynaptic potential in hippocampal CA3 neurons in vitro reveals a late depolarizing potential that is augmented by pentobarbital. Neurosci Lett 95:155-160.

Thesleff S (1980) Aminopyridines and synaptic transmission. Neuroscience 5:1413-1419.

Traub RD, Miles R, Jefferys JG (1993) Synaptic and intrinsic conductances shape picrotoxin-induced synchronized after-discharges in the guinea-pig hippocampal slice. J Physiol 461:525-547.

Traub RD, Jefferys JG, Whittington MA (1994) Enhanced NMDA conductance can account for epileptiform activity induced by low $\mathrm{Mg} 2+$ in the rat hippocampal slice. J Physiol 478 Pt 3:379-393.

Traub RD, Colling SB, Jefferys JG (1995) Cellular mechanisms of 4-aminopyridineinduced synchronized after- discharges in the rat hippocampal slice. J Physiol 489:127-140.

Traub RD, Borck C, Colling SB, Jefferys JG (1996) On the structure of ictal events in vitro. Epilepsia 37:879-891.

Traynelis SF, Dingledine R (1988) Potassium-induced spontaneous electrographic seizures in the rat hippocampal slice. J Neurophysiol 59:259-276.

Turner DA, Li XG, Pyapali GK, Ylinen A, Buzsaki G (1995) Morphometric and electrical properties of reconstructed hippocampal CA3 neurons recorded in vivo. J Comp Neurol 356:580-594.

Ulens C, Tytgat J (2001) Functional heteromerization of HCN1 and HCN2 pacemaker channels. J Biol Chem 276:6069-6072.

Wada JA, Sato M, Corcoran ME (1974) Persistent seizure susceptibility and recurrent spontaneous seizures in kindled cats. Epilepsia 15:465-478.

Wainger BJ, DeGennaro M, Santoro B, Siegelbaum SA, Tibbs GR (2001) Molecular mechanism of cAMP modulation of HCN pacemaker channels. Nature 411:805810.

Wakamoto H, Nagao H, Hayashi M, Morimoto T (2000) Long-term medical, educational, and social prognoses of childhood-onset epilepsy: a population-based study in a rural district of Japan. Brain Dev 22:246-255.

Wasterlain CG (1997) Recurrent seizures in the developing brain are harmful. Epilepsia 38:728-734. 
Werner P, Voigt M, Keinanen K, Wisden W, Seeburg PH (1991) Cloning of a putative high-affinity kainate receptor expressed predominantly in hippocampal CA3 cells. Nature 351:742-744.

Whittington MA, Traub RD, Jefferys JG (1995) Erosion of inhibition contributes to the progression of low magnesium bursts in rat hippocampal slices. J Physiol 486:723-734.

Williams SR, Turner JP, Hughes SW, Crunelli V (1997) On the nature of anomalous rectification in thalamocortical neurones of the cat ventrobasal thalamus in vitro. $\mathrm{J}$ Physiol 505:727-747.

Wimer RE, Wimer CC, Chernow CR, Balvanz BA (1980) The genetic organization of neuron number in the pyramidal cell layer of hippocampal regio superior in house mice. Brain Res 196:59-77.

Womble MD, Moises HC (1993) Hyperpolarization-activated currents in neurons of the rat basolateral amygdala. J Neurophysiol 70:2056-2065.

Wong M, Yamada KA (2001) Developmental characteristics of epileptiform activity in immature rat neocortex: a comparison of four in vitro seizure models. Brain Res Dev Brain Res 128:113-120.

Wong RK, Prince DA (1978) Participation of calcium spikes during intrinsic burst firing in hippocampal neurons. Brain Res 159:385-390.

Wong RK, Prince DA (1981) Afterpotential generation in hippocampal pyramidal cells. J Neurophysiol 45:86-97.

Wong RK, Traub RD, Miles R (1986) Cellular basis of neuronal synchrony in epilepsy. Adv Neurol 44:583-592.

Woodson W, Nitecka L, Ben-Ari Y (1989) Organization of the GABAergic system in the rat hippocampal formation: a quantitative immunocytochemical study. J Comp Neurol 280:254-271.

Yamamoto C (1972) Intracellular study of seizure-like afterdischarges elicited in thin hippocampal sections in vitro. Exp Neurol 35:154-164.

Ylinen A, Soltesz I, Bragin A, Penttonen M, Sik A, Buzsaki G (1995a) Intracellular correlates of hippocampal theta rhythm in identified pyramidal cells, granule cells, and basket cells. Hippocampus 5:78-90.

Ylinen A, Bragin A, Nadasdy Z, Jando G, Szabo I, Sik A, Buzsaki G (1995b) Sharp wave-associated high-frequency oscillation $(200 \mathrm{~Hz})$ in the intact hippocampus: network and intracellular mechanisms. J Neurosci 15:30-46. 
CHAPTER 2: Objectives and Rationales 
This investigation was focused on the mouse hippocampus; however, when it was applicable the neocortex was also studied, permitting comparisons to be made between these two structures. The experiments in this study were performed to fulfill three separate objectives, and the results of these experiments will be discussed in Chapters 3 through Chapter 6. The purpose of this chapter is to introduce the objectives of the current study and outline the manner in which they will be presented in the remainder of the dissertation.

\subsection{Objective 1- To determine if $G A B A$ is an inhibitory or excitatory neurotransmitter in the cerebral cortex.}

The literature suggests the neurotransmitter GABA plays opposing roles at different developmental stages of the cerebral cortex. In the adult, synaptic GABA release serves an inhibitory function by opening chloride channels increasing the resting conductance, which reduces neuronal activity by decreasing the probability of action potential firing. However, in the first postnatal week, GABA has been implicated as an excitatory neurotransmitter, because the chloride current conducted through the GABA channel, which typically hyperpolarizes adult neurons, depolarizes immature neurons. This depolarization brings the neuronal membrane potential closer to firing threshold, which has lead some investigators to claim that GABA increases the probability of action potential firing in the neonatal cerebral cortex. These claims have led to the assertion that GABA (not glutamate) is the main excitatory neurotransmitter in the neonatal cerebral cortex. However, even in view of GABA's depolarizing action, it seems improbable that GABA would not serve to inhibit neonatal neurons, because the neonatal cerebral cortex would otherwise be in a near perpetual state of hyper-excitation, unless there is little or 
no glutamatergic neurotransmission in the neonate. Therefore, the first objective of this study was (1) to determine if GABA was an inhibitory neurotransmitter in the neonatal cerebral cortex and (2) to determine if glutamatergic neurotransmission is already functional and excitatory in the neonatal cerebral cortex. The experiments addressing this objective and their outcomes are described in Chapter 3.

\subsection{Objective 2- To determine the mechanisms involved in timing and}

modulating the frequency of rhythmic IIBs in the neonatal hippocampus.

Upon completion of the first objective, GABA was found to be an inhibitory neurotransmitter in the neonatal hippocampus and neocortex. It was found that spontaneous release of GABA prevented the occurrence of paroxysmal bursts in the hippocampus and neocortex. These bursts resembled IIBs, repetitive short bursts which are often recorded between seizures (ictal bursts) in epileptic patients or in in-vitro models of epilepsy. Unlike the neocortex, IIBs in the neonatal hippocampus reliably occurred in a strikingly regular temporal rhythm, suggesting an underlying pacing mechanism. Therefore, the second objective of this study, discussed in chapters 4 and 5 , was to discover the ionic mechanisms involved with timing IIB or modulating their frequency and to determine if this precision of the IIB rhythm was unique to the neonate. Chapter 4 discusses the mechanism determined to time this rhythm, while Chapter 5 discusses the potential mechanisms that were determined not to be involved with or only slightly modulate IIB frequency, as well as age dependent characteristics of IIBs. 


\subsection{Objective 3- To determine the expression pattern of $I_{h}$ channel subunits in}

\section{the developing cerebral cortex.}

Based on the results of the second objective of this study, we determined that the hyperpolarization-activated cationic pacemaker current, $\mathrm{I}_{\mathrm{h}}$, plays a major role in timing rhythmic IIBs in the hippocampal network. Additionally, we found that IIBs have a much more precise rhythm in the neonate. The literature shows that mRNA levels for the subunits composing these channels change with development in the hippocampus. Antibodies against the $I_{h}$ channel subunit proteins permit specific staining of cells containing these subunits, and initial published immunocytochemistry studies have shown that the overall level of $I_{h}$ channel subunits in the neuropil is also changing during postnatal development. However, it was not known which neuronal subtypes in the hippocampus are altering their expression of $\mathrm{I}_{\mathrm{h}}$ channel subunits with development, and if these subunits are expressed in different cellular compartments at different times in postnatal development. Therefore, the third objective of this study was to determine: 1) what neuronal types are expressing which $I_{h}$ channel subunits, 2) are the $I_{h}$ channel subunits selectively expressed in certain neuronal compartments (for example, expression in the dendrites or axon terminals), and 3) does this expression pattern change with development? Experiments addressing these goals with antibodies directed against the two most common $I_{h}$ channel subunits found in the cerebral cortex will be discussed in Chapter 6. 


\section{Chapter 3: GABAergic Inhibition Suppresses Paroxysmal}

Network Activity in the Neonatal Rodent Hippocampus

and Neocortex

This chapter was published in The Journal of Neuroscience, December 1, 2000, 20(23):8822-8830. 


\subsection{Abstract}

In the adult cerebral cortex, the neurotransmitter $\gamma$-amino butyric acid (GABA) is strongly inhibitory, as it profoundly decreases neuronal excitability and suppresses network propensity for synchronous activity. When fast, $\mathrm{GABA}_{\mathrm{A}}$ receptor $\left(\mathrm{GABA}_{\mathrm{A}} \mathrm{R}\right)$ mediated neurotransmission is blocked in the mature cortex, neuronal firing is synchronized through recurrent excitatory (glutamatergic) synaptic connections, generating population discharges manifested extracellularly as spontaneous paroxysmal field potentials (sPFPs). This epileptogenic effect of $\mathrm{GABA}_{\mathrm{A}} \mathrm{R}$ antagonists has rarely been observed in the neonatal cortex and, indeed, GABA in the neonate has been proposed to have an excitatory, rather than inhibitory, action. In contrast, we show here that when fast GABAergic neurotransmission was blocked in slices of neonatal mouse and rat hippocampus and neocortex, sPFPs occurred in nearly half the slices from postnatal days 4-7 (P4-P7) neocortex and in most slices from P2-P7 hippocampus. In $\mathrm{Mg}^{2+}$-free solution, $\mathrm{GABA}_{\mathrm{A}} \mathrm{R}$ antagonists elicited sPFPs in nearly all slices of $\mathrm{P} 2$ and older neocortex and $\mathrm{P} 0$ and older hippocampus. $\mathrm{Mg}^{2+}$-free solution alone induced spontaneous events in the majority of P2 and older slices from both regions; addition of $\mathrm{GABA}_{\mathrm{A}} \mathrm{R}$ antagonists caused a dramatic increase in the mean amplitude, but not frequency, of these events in hippocampus, and in their mean frequency, but not amplitude, in neocortex. In hippocampus, $\mathrm{GABA}_{\mathrm{A}} \mathrm{R}$ agonists suppressed amplitudes, but not frequency, of sPFPs, while glutamate antagonists suppressed frequency but not amplitudes. We conclude that neonatal rodent cerebral cortex possesses glutamatergic circuits capable of generating synchronous network activity but, as in the adult, tonic $\mathrm{GABA}_{\mathrm{A}} \mathrm{R}$-mediated inhibition prevents this activity from becoming paroxysmal. 


\subsection{Introduction}

The cerebral cortical mantle, which includes the hippocampus and the neocortex, is an intricate network of neurons communicating through chemical and electrical synapses, and utilizing glutamate and GABA as the major neurotransmitters. In the adult cortex, excitation is mediated mostly by glutamate receptors of the NMDA or AMPA subtypes, while $\mathrm{GABA}$, acting through fast $\left(\mathrm{GABA}_{\mathrm{A}}\right)$ and slow $\left(\mathrm{GABA}_{B}\right)$ receptors, is strongly inhibitory, as it profoundly decreases the excitability of individual neurons and suppresses the propensity of the network to generate synchronous discharges (Connors et al., 1988). Indeed, when $\mathrm{GABA}_{\mathrm{A}}$ receptors $\left(\mathrm{GABA}_{\mathrm{A}} \mathrm{Rs}\right)$ in the mature hippocampus or neocortex are blocked, positive feedback mediated by recurrent excitatory (glutamatergic) circuits triggers a chain-reaction of neuronal firing, culminating in epileptiform events (Wong et al., 1986; Traub and Miles, 1991). These events have an all-or-none character, and consist of synaptically-induced discharges of action potentials, which occur nearly simultaneously in all neurons within a given location, and propagate over relatively long distances with little decrement (Gutnick et al., 1982; Wong and Traub, 1983; Traub and Miles, 1991). In extracellular recordings, they are manifested as large-amplitude paroxysmal field potentials (PFPs) (Connors, 1984).

Earlier studies of the immature rodent hippocampus in-vivo (Harris and Teyler, 1983; Michelson and Lothman, 1989) and in vitro (Schwartzkroin, 1981; Mueller et al., 1984; Muller et al., 1989) and of the immature rodent neocortex in vitro (Kriegstein et al., 1987; Luhmann and Prince, 1991; Agmon and O'Dowd, 1992; Burgard and Hablitz, 1993) generally failed to find spontaneous or evoked inhibitory synaptic activity during the first, and even second postnatal weeks (but see Swann et al., 1989 for inhibitory 
responses in area CA3 as early as P5). This view was modified by later studies, which showed that GABAergic synapses in both regions were already functional during the first postnatal week, albeit with immature properties. Thus, at least until P5, responses to exogenous or synaptically released GABA, both in the hippocampus (Ben-Ari et al., 1989; Zhang et al., 1990) and in the neocortex (Agmon et al., 1996; Owens et al., 1996), exhibit a positive reversal potential relative to the resting membrane potential, and are therefore depolarizing. This effect, together with the occurrence of spontaneous, $\mathrm{GABA}_{\mathrm{A}} \mathrm{R}$-dependent network activity in the neonatal hippocampus (Ben-Ari et al., 1989; Garaschuk et al., 1998), has been interpreted by several groups of investigators (Ben Ari et al., 1994; Owens et al., 1996; Leinekugel et al., 1999) as an indication of an excitatory action of GABA during the first postnatal week. However, if GABA is excitatory, it remains unclear what prevents paroxysmal discharges in the neonate.

A straightforward test of the functional role of spontaneously released GABA in the neonatal cerebral cortex is to block $\mathrm{GABA}_{\mathrm{A}} \mathrm{Rs}$. If GABA is inhibitory, blocking $\mathrm{GABA}_{\mathrm{A}}$ Rs would result in synchronous population discharges, as it does in the adult. We show here that blocking $\mathrm{GABA}_{\mathrm{A}}$ Rs does indeed elicit spontaneous PFPs (sPFPs) in the neonatal hippocampus and neocortex, strongly indicating an inhibitory role for GABAergic neurotransmission from the earliest postnatal ages.

\subsection{Materials and Methods}

Slice preparation and solutions: Timed-pregnant ICR white mouse and Sprague-Dawley rat dams (Hilltop Lab Animals, Scottdale, PA) were monitored at 12 hour intervals to determine time of delivery. The first 24 hours after birth were designated P0. Pups were anesthetized by inhalation of methoxyflurane ("Metofane", Mallinckrodt Veterinary, 
Mandelein, IL) in a glass jar, decapitated, and the brain removed into ice-cold artificial CSF (ACSF, composition in mM: $\mathrm{NaCl} 126, \mathrm{KCl} 3, \mathrm{NaH}_{2} \mathrm{PO}_{4} 1.2, \mathrm{MgSO}_{4} 1.3, \mathrm{CaCl}_{2} 2$, $\mathrm{NaHCO}_{3} 26$ and dextrose 20) saturated with a 95:5 mixture of $\mathrm{O}_{2}: \mathrm{CO}_{2}$. Coronal slices, $500-\mu \mathrm{m}$ thick, were cut using a Vibraslicer (WPI, Sarasota, FL) and maintained for at least $1 \mathrm{hr}$ submerged in a holding chamber filled with recirculated, oxygenated ACSF at room temperature, prior to transfer to the recording chamber. For nominally $\mathrm{Mg}^{2+}$-free ACSF, $\mathrm{MgCl}_{2}$ was substituted by an equimolar concentration of $\mathrm{CaCl}_{2}$ (for a total of 3.3 $\mathrm{mM} \mathrm{CaCl} 2$ ), to maintain the total divalent cation concentration.

Drugs: Bicuculline methchloride (BMC), SR-95531 (gabazine, GBZ), muscimol hydrobromide, 6-cyano-7-nitroquinoxaline-2,3-dione (CNQX) disodium, D(-)-2-amino5-phosphonopentanoic acid (APV) and 4-aminopyridine (4-AP) were purchased from $\mathrm{RBI} /$ Sigma (Natick, MA), prepared as stock solutions in distilled water at (typically) 1000-fold final concentration, divided into aliquots and stored at $-20^{\circ} \mathrm{C}$. During the experiment, thawed aliquots were kept on ice and protected from light until use.

Electrophysiological recordings: For electrophysiological recording, individual slices were transferred to a submersion chamber, transilluminated and continuously superfused with room-temperature oxygenated ACSF at 2-3 $\mathrm{ml} / \mathrm{min}$. Extracellular field potentials were recorded using glass micropipettes (1 mm O.D., $0.58 \mathrm{~mm}$ I.D., A-M Systems Inc., Carlsborg, WA) pulled on a Flaming-Brown pipette puller (Sutter Instruments, Novato, $\mathrm{CA}$ ), their tips broken under microscopic control to a final outer diameter of about $5 \mu \mathrm{m}$, and filled with $0.9 \% \mathrm{NaCl}$. DC signals were recorded using a unity gain headstage connected to a 1000X gain amplifier (Intronix Technologies, Bolton, Ontario, Canada), low-pass filtered at $1 \mathrm{kHz}$, digitized with an analog-to-digital board (National 
Instruments, Austin, TX) at 1000 samples/sec, and streamed to disk, using software written by AA in the LabView environment (National Instruments, Austin, TX). Slices were routinely maintained in the recording chamber for 8 or more hours following the dissection without any apparent deterioration of the responses.

Data acquisition followed one of two paradigms. In an earlier set of experiments (illustrated in Figs. 4-7), activity was sampled under steady-state conditions, by taking records of 5 min duration in control solution, after at least $20 \mathrm{~min}$ in the experimental condition, and after at least 20 min of washout. In these experiments, superfusion was usually stopped during the 5 min of data acquisition, to eliminate spurious signals resulting from fluctuations in bath level. In a later set of experiments (illustrated in Figs. 1-2), activity was sampled continuously for up to $64 \mathrm{~min}$, throughout the wash-in and wash-out of the experimental solution. In these experiments, a reference micropipette was placed in the bath and its signal subtracted from the record, thereby removing the fluctuation noise. To verify that transiently stopping the superfusion (in the earlier set of experiments) did not have any short- or long-term effects on the sPFPs, control experiments were done $(n=6)$ in which sPFPs (elicited in $C A 3$ by $\mathrm{GABA}_{\mathrm{A}} \mathrm{R}$ antagonists in $\mathrm{Mg}^{2+}$-free $\mathrm{ACSF}$ ) were recorded before, during and after a 15-min pause in superfusion (3-fold longer than the pause during data acquisition). No significant differences were observed in average sPFP frequency, amplitude and effective duration (see below for definitions) during the first $5 \mathrm{~min}$ of perfusion pause, compared to the period before the pause (ratios over control values were $99.4 \% \pm 1.6 \%, \mathrm{p}=0.44 ; 101.9 \% \pm 7.4 \%, \mathrm{p}=0.39$; and $103.7 \% \pm 3.0 \%, \mathrm{p}=0.14$, respectively). Minor and marginally significant reductions in mean amplitude and frequency were observed during the last 5-min period of the 15 
min pause $(87.4 \% \pm 6.4 \%, \mathrm{p}=0.08 ; 79.7 \% \pm 12.5 \%, \mathrm{p}=0.11$, respectively $)$, and both parameters recovered fully $10 \mathrm{~min}$ after resuming superfusion $(99.7 \% \pm 6.2 \%, p=0.44$ and $104.8 \% \pm 6.2 \%, \mathrm{p}=0.34$, respectively).

In most experiments, recordings from $\mathrm{CA} 3$ and the neocortex were done from the same slice simultaneously. Paroxysmal events in the two regions were not temporally correlated, and were therefore analyzed independently and are reported separately for each region. In some slices, propagation of paroxysmal events between the two regions was noted (for example, Fig. 6A, left panel); in all such cases, events could be assigned unambiguously to their structure of origin, by comparing waveforms, amplitudes and times of occurrence of sPFPs between the two areas.

Data analysis: Data analysis was done using routines written in the LabView environment. Records were smoothed off-line by pooling and averaging data points in groups of 32 points, resulting in $10-20 \mu \mathrm{V}$ peak-to-peak noise level in the final record and an effective sampling rate of $32-80 \mathrm{~Hz}$, more than adequate for sampling extracellular paroxysmal events which ranged from $1-2 \mathrm{~s}$ in total duration and 50-1200 $\mu \mathrm{V}$ in amplitude. Spontaneous events were identified by software, and verified by visual examination. Frequency of spontaneous events was defined as their mean rate of occurrence (i.e. number of events/duration of record). In most cases frequency was calculated from a representative 5 min record, but in slices with high frequency of events shorter records were used. Amplitude was defined as the difference between the most negative and most positive data points during an event. For each slice, average sPFP amplitude was calculated from all the events in the same record used for determining frequency. Effective duration was defined as the area under the sPFP trace divided by the 
peak-to-peak amplitude; in other words, effective duration is the width of a square wave with the same amplitude and area as the PFP. To calculate the area under the trace, the integral of the absolute value of the difference between the voltage trace and the average baseline was calculated during a short time segment spanning the PFP, and the integral of an equal time segment with no PFP (noise only) subtracted from this value. This definition of duration was chosen (over a direct measurement of total event duration) since it did not require a precise determination of the beginning and ending points of each event.

Descriptive statistics: Sample sizes $(\mathrm{n}=\mathrm{x})$ refer to the number of slices tested; data are reported in the text as mean \pm the standard error of the mean (SEM). When data are illustrated in a figure, SEMs are shown graphically and sample sizes are indicated in the figure legends and not reported in the text.

Statistical tests: Statistical significance (p-values) was computed numerically using exact permutation methods (Good, 1999); calculations were done in MathCad (MathSoft, Cambridge, MA). When the number of all possible permutations was very large, only 10,000 random permutations were computed. All reported p-values are single-tailed probabilities.

\subsection{Results}

3.4.1 GABA $A_{A} R$ antagonists elicited spontaneous paroxysmal events in neonatal CA3 and neocortex.

To test whether $\mathrm{GABA}_{\mathrm{A}} \mathrm{R}$-mediated neurotransmission is excitatory or inhibitory in the neonatal cortex, we bath-applied $\mathrm{GABA}_{\mathrm{A}} \mathrm{R}$ blockers onto brain slices and 
monitored spontaneous population activity by recording extracellular field potentials from layers 5-6 of the parietal neocortex and from stratum radiatum of area CA3 of the hippocampus. A total of 95 hippocampus and 87 neocortex slices from 59 neonatal (P0P7) mice were tested with $\mathrm{GABA}_{\mathrm{A}} \mathrm{R}$ antagonists. In addition, 8 hippocampus and 4 neocortex slices from 5 neonatal rats (P1-P5) were tested; no significant differences were found between mouse and rat data, which will therefore be pooled. All illustrated traces are from the mouse.

With one exception (which was excluded from further analysis), spontaneous extracellular events were not observed either in the hippocampus or in the neocortex when slices were bathed in normal ACSF. When $10 \mu \mathrm{M}$ bicuculline methchloride (BMC), a commonly used competitive $\mathrm{GABA}_{\mathrm{A}} \mathrm{R}$ antagonist, was added to normal ACSF, spontaneous field potential events were observed in $62 \%$ of P2-P3 $(n=13)$ and in $100 \%$ of P4-P7 ( $\mathrm{n}=16)$ CA3 slices, as illustrated in Fig. 1A. Spontaneous events were also observed in $65 \%$ of P4-P7 neocortex slices ( $\mathrm{n}=17$, Fig. 1C). Spontaneous events typically appeared within 5-10 min of drug application, and had stereotypical waveforms, which varied little within any given recording site. In the neocortex, the events were usually simple bi- or triphasic potentials (Fig. 1C, right), while in CA3 they were often of more complex waveforms, and included multiple sharp spikes superimposed on a slow triphasic envelope (Fig. 1A, right). When recorded simultaneously from two separate cortical or hippocampal loci (e.g. CA3 and CA1, or medial and lateral neocortex), they appeared to propagate for long distances without appreciable decrement (not shown). These properties are typical of epileptiform extracellular potentials in the disinhibited slice of the adult hippocampus and neocortex (Schwartzkroin and Prince, 1978; Gutnick 
et al., 1982), and these events were therefore considered spontaneous paroxysmal field potentials (sPFPs).

Bicuculline methyl halogens (bicuculline-M), such as BMC, have recently been reported to have direct excitatory effects which are not related to $\mathrm{GABA}_{\mathrm{A}} \mathrm{R}$ antagonism, including induction of $\mathrm{Ca}^{2+}$ release from internal stores (Wulfert and Margineanu, 1998; Mestdagh and Wulfert, 1999) and block of apamin-sensitive potassium channels (Johnson and Seutin, 1997; Debarbieux et al., 1998; Khawaled et al., 1999). Since the competitive $\mathrm{GABA}_{\mathrm{A}} \mathrm{R}$ antagonist SR-95531 (gabazine, GBZ) was also tested in some of these studies and reported not to induce these confounding effects, we tested its effectiveness in eliciting sPFPs. When exposed to $5 \mu \mathrm{M}$ GBZ, $73 \%$ of P2-P3 and $100 \%$ of P4-P7 CA3 slices tested ( $\mathrm{n}=11$ for both groups) exhibited sPFPs (Fig. 1B), as did 27\% of P4-P7 neocortex slices (n=11, Fig. 1D). Thus, in CA3, GBZ was at least as effective as BMC in inducing sPFPs, while in the neocortex it was somewhat less effective than $\mathrm{BMC}(\mathrm{p}=0.06$ for P4-P7 neocortex, Fisher's exact test). SPFP waveforms in both drugs were similar (compare right sides of Fig. 1A to 1B, and 1C to 1D), and when compared between equivalent age groups, there was no significant difference in mean sPFP amplitudes and frequency elicited by the two drugs. Thus, our data do not support the hypothesis that paroxysmal activity evoked by BMC in CA3 was due to any of the drug's effects other than $\mathrm{GABA}_{\mathrm{A}} \mathrm{R}$ antagonism, although some of these other effects could have contributed to the increased efficacy of BMC over GBZ in the neocortex.

In most cases sPFPs persisted upon removal of the drug (Fig. 1), although their amplitudes and frequency often decreased during drug washout. SPFPs were, in some cases, still present after several hours of superfusion in drug-free ACSF (not shown), 
suggesting that their persistence was not attributable to residual antagonist, but possibly to paroxysmal activity-induced, long-term synaptic modifications (Schneiderman et al., 1994; Valenzuela and Benardo, 1995; Schneiderman, 1997; Bains et al., 1999).

3.4.2 SPFPs elicited by $G A B A_{A} R$ antagonists occurred at earlier ages in $\mathrm{Mg}^{2+}$-free ACSF

With GABAergic neurotransmission blocked (by either drug) in normal ACSF, sPFPs were only rarely observed during the first 2 postnatal days in the hippocampus (1 out of 9 slices) or the first 4 postnatal days in the neocortex ( 4 out of 27 slices). This could have been the result of a more sparse excitatory synaptic network in the younger ages. Alternatively, it could have been the result of the predominance of NMDA- over AMPA-subtype glutamate receptors in the early postnatal hippocampus and neocortex (Agmon and O'Dowd, 1992; Durand et al., 1996; Isaac et al., 1997; Rumpel et al., 1998; Petralia et al., 1999): since NMDA receptor/channels are partially blocked by $\mathrm{Mg}^{2+}$ at resting membrane potentials, and this effect is already fully functional in the neonate (Khazipov et al., 1995), they may not be activated even after removal of inhibition. To distinguish between these possibilities, we removed the $\mathrm{Mg}^{2+}$ block by superfusing slices in nominally $\mathrm{Mg}^{2+}$-free ACSF for at least 20 min before adding $\mathrm{GABA}_{\mathrm{A}} \mathrm{R}$ antagonists. (In these experiments $\mathrm{Mg}^{2+}$ was replaced by an equimolar concentration of $\mathrm{Ca}^{2+}$, to avoid the non-specific increase in excitability associated with a reduced screening of surface charges by divalent cations. The elevated extracellular $\mathrm{Ca}^{2+}$ concentration $(3.3 \mathrm{mM}$, vs 2 $\mathrm{mM}$ in normal ACSF) could have contributed to the observed paroxysmal activity by increasing the probability of glutamate release from synaptic terminals, but this effect was most likely minor compared to the effect of relieving NMDA receptors from the voltage-dependent $\mathrm{Mg}^{2+}$ block (Traub et al, 1994)). When $10 \mu \mathrm{M}$ BMC was added to 
$\mathrm{Mg}^{2+}$-free ACSF (Fig. 2A,C), sPFPs appeared and reached full amplitudes within 2-3 min of drug exposure, in $93 \%$ of $\mathrm{P} 0-\mathrm{P} 1$ hippocampus slices $(\mathrm{n}=14)$, in $59 \%$ of $\mathrm{P} 0-\mathrm{P} 3$ neocortex slices $(n=17)$, and in $100 \%$ of all older slices in both areas $(n=27$ and $n=17$, respectively). Similarly, when $5 \mu \mathrm{M}$ GBZ was added to $\mathrm{Mg}^{2+}$-free ACSF (Fig. 2B,D), sPFPs appeared within $2-3 \mathrm{~min}$ in $100 \%(\mathrm{n}=5)$ of P0-P1 CA3 slices, in $67 \%(\mathrm{n}=9)$ of $\mathrm{P} 0$ P3 neocortex slices, and in $100 \%$ of all older slices in both regions $(n=12$ and $n=7$, respectively). This result suggested that $\mathrm{Mg}^{2+}$-block of NMDARs contributed to the low incidence of paroxysmal activity in the early neonatal period, rather than lack of glutamatergic connections per se. These data also show that GBZ was at least as effective as BMC in eliciting sPFPs in $\mathrm{Mg}^{2+}$-free ACSF, both in CA3 and in the neocortex. As in normal ACSF, sPFP waveforms in $\mathrm{Mg}^{2+}$-free ACSF with BMC resembled those with GBZ (right panels of Fig. 2), and there were no significant differences in mean amplitudes and frequency of sPFPs elicited by the two drugs when equivalent age groups were compared, lending further support to our conclusion that the induction of spontaneous paroxysmal activity by $\mathrm{BMC}$ was attributable to $\mathrm{GABA}_{\mathrm{A}} \mathrm{R}$ antagonism, rather than to non-GABA $\mathrm{R}$ mediated effects unique to bicuculline-M. For all subsequent analysis, data acquired in the presence of either BMC or GBZ were combined.

\subsubsection{GABA $A_{A} R$ blockers elicited paroxysmal activity in an age-dependent manner}

As already noted, the incidence (probability of occurrence) of sPFPs increased with age. This observation is summarized in Fig. 3A. In normal ACSF (solid lines), there was a steep increase in $\mathrm{SPFP}$ incidence in $\mathrm{CA} 3$, from about $10 \%$ probability at $\mathrm{P} 0$ P1 to $100 \%$ in P4 and older slices. In the neocortex, the increase was both delayed and 
slower, with sPFP incidence increasing from about $20 \%$ at $\mathrm{P} 0-\mathrm{P} 3$ to $60 \%$ at $\mathrm{P} 6-\mathrm{P} 7$, reaching $100 \%$ only in the second postnatal week (J.E. Wells and A. Agmon, unpublished observations). Thus, the neocortex lagged by 3-4 days after the hippocampus in its capacity to generate spontaneous paroxysmal activity. Incidence of sPFPs in $\mathrm{Mg}^{2+}-$ free ACSF, which as noted above was considerably higher than in normal ACSF, also increased with age, reaching $100 \%$ in P2 and older hippocampus and in P4 and older neocortex (Fig. 3A, dashed lines). Thus, in $\mathrm{Mg}^{2+}$-free ACSF the incidence vs age curve, in both neocortex and CA3, was shifted to the left by about 3-4 days, while maintaining the developmental lag between the two regions.

\subsubsection{Age-dependent changes in mean SPFP frequency, amplitude and effective duration}

In parallel with the increase in incidence of $\mathrm{GABA}_{\mathrm{A}} \mathrm{R}$ antagonist-elicited sPFPs during the first postnatal week, there were age-dependent changes in their mean frequency (Fig. 3B), amplitude (Fig. 3C) and effective duration (Fig. 3D; see Methods for definitions of these parameters). In normal ACSF (solid lines), both mean frequency and mean amplitude increased over the course of the first postnatal week. In the hippocampus, mean frequency nearly tripled between P2-P3 and P6-P7, from $5.7 \mathrm{mHz}$ (about 1 event $/ 3 \mathrm{~min})$ to $14.3 \mathrm{mHz}(1 / 70 \mathrm{~s} ; \mathrm{p}<0.001$, Pitman correlation test), while amplitude increased by about $50 \%$, from 0.65 to about $1 \mathrm{mV}$, an increase which was only marginally significant statistically $(\mathrm{p}=0.055)$. There was also a small but significant $(\mathrm{p}=0.01)$ decrease in effective duration of sPFPs in CA3, from about 350 to $270 \mathrm{~ms}$. In the neocortex, mean sPFP amplitude and frequency were considerably smaller, and mean effective duration longer, compared to equivalent-aged hippocampus. The first two parameters more than doubled during the developmental period studied, reaching a 
frequency of $8.7 \mathrm{mHz}$ (about 1 event/2 min) and amplitude of $0.23 \mathrm{mV}$ by P6-P7, although only the increase in frequency was statistically significant $(p=0.03)$. There was no significant age-dependent change in effective sPFP duration in the neocortex, which averaged $482 \pm 35 \mathrm{~ms}$ over the full period. In $\mathrm{Mg}^{2+}$-free ACSF (dashed lines), sPFPs were generally higher in frequency but lower in amplitude, compared to sPFPs in normal ACSF in the same region and age group. In the neocortex, mean sPFP frequency in $\mathrm{Mg}^{2+}$-free ACSF increased nearly 5-fold, from $7.6 \mathrm{mHz}$ at P0-P1 to $37.9 \mathrm{mHz}(1 / 26 \mathrm{~s})$ at P6-P7, while mean amplitude tripled over same age range, from 0.068 to about $0.2 \mathrm{mV}$, both changes being highly significant statistically ( $\mathrm{p}=0.002$ and $\mathrm{p}=0.001$, respectively). There was also a small (about $25 \%$ ) but highly significant $(\mathrm{p}=0.004)$ decrease in effective sPFP duration, from $415 \mathrm{~ms}$ at $\mathrm{P} 2-\mathrm{P} 3$ to 306 at P6-P7. In contrast, in CA3, mean sPFP amplitudes in $\mathrm{Mg}^{2+}$-free ACSF remained nearly constant $(0.47 \pm 0.03 \mathrm{mV})$, as did their effective duration ( $326 \pm 10 \mathrm{~ms})$, while mean sPFP frequency actually decreased over the first postnatal week by about 2-fold, from $28 \mathrm{mHz}(1$ event/35 s) to $14 \mathrm{mHz}(1 / 70 \mathrm{~s}$; $\mathrm{p}=0.02)$.

\subsubsection{Spontaneous activity was often observed in $\mathrm{Mg}^{2+}{ }^{-}$free $\mathrm{ACSF}$ alone}

In $35 \%$ of $\mathrm{P} 0-\mathrm{P} 1 \mathrm{CA} 3(\mathrm{n}=17)$ and $11 \%$ of $\mathrm{P} 0-\mathrm{P} 1$ neocortex $(\mathrm{n}=9)$ slices, and in about $75 \%$ of all older slices in both regions ( $n=21$ and $n=22$, respectively), superfusion of $\mathrm{Mg}^{2+}$-free ACSF elicited spontaneous events, typically within 20-30 min, even before addition of $\mathrm{GABA}_{\mathrm{A}} \mathrm{R}$ antagonists (Fig. 2, arrowheads; Fig. 4A). In both regions these events were of a relatively small amplitude $(165 \pm 17 \mu \mathrm{V}, \mathrm{n}=20$, in CA3, and $194 \pm 31 \mu \mathrm{V}$, $\mathrm{n}=18$, in the neocortex) with a small and marginally significant increase in amplitude over the age period studied in CA3 $(\mathrm{p}=0.05)$ and a decrease in the neocortex $(\mathrm{p}=0.06)$. 
Their mean frequency was five times higher in CA3 $(35 \pm 6 \mathrm{mHz}$ or about $2 / \mathrm{min})$ compared to the neocortex $(7.2 \pm 1.4 \mathrm{mHz})$, with a small and marginally significant agerelated decrease in frequency in $\mathrm{CA} 3(\mathrm{p}=0.08)$.

\subsubsection{In $\mathrm{Mg}^{2+}$-free ACSF, GABA ${ }_{A} R$ antagonists increased amplitude (but not frequency) of spontaneous events in CA3 and frequency (but not amplitude) in neocortex}

Adding $\mathrm{GABA}_{\mathrm{A}} \mathrm{R}$ antagonists to slices which exhibited spontaneous events in $\mathrm{Mg}^{2+}$-free ACSF (Fig. 2A,C,D; Fig. 4A) had a pronounced effect, but this effect was very different in CA3 compared to the neocortex: in CA3, there was a rapid and dramatic increase in the amplitudes of spontaneous events, with no consistent change in their frequency, while in the neocortex $\mathrm{GABA}_{\mathrm{A}} \mathrm{R}$ antagonists caused a pronounced increase in the frequency of spontaneous events, with a small decrease in their amplitudes. These effects are summarized in Fig. 4B. In CA3, there was a large increase in the amplitudes of spontaneous events in all 17 slices tested; in over half of the cases the amplitude more than tripled, and the (geometrical) mean increase was 3.8-fold of control $(\mathrm{p}<0.0001)$. The increase in SPFP amplitudes could have been the result of increased level of neuronal firing during each event (i.e. more neurons discharging and/or higher rates of discharge), or alternatively the result of enhanced synchrony of firing between neurons, without an increase in the total number of discharges. If the latter was the case, one would predict that the increase in amplitudes would be accompanied by a significant decrease in the durations of the extracellularly recorded events. Contrary to this prediction, mean event duration did not change (effective sPFP duration with antagonists was 1.03 -fold of the duration before adding antagonists; not shown in Fig. 4B), suggesting that the increase in 
sPFP amplitude was due to an absolute increase in the level of the underlying electrical activity, rather than to an increase in its synchrony.

In 3 of 7 attempts to wash out the drug, amplitudes returned to within $30 \%$ of control levels after drug washout (e.g. Fig. 4A, left panel). In the other cases, amplitudes did not recover to control levels even after a prolonged washout in $\mathrm{Mg}^{2+}$-free ACSF, possibly due to erosion of the $\mathrm{GABA}_{\mathrm{A}}$ system in $\mathrm{Mg}^{2+}$-free solution (Whittington et al., 1995) or to paroxysmal activity-induced synaptic modifications (Schneiderman et al., 1994; Valenzuela and Benardo, 1995; Schneiderman, 1997; Bains et al., 1999). On average, sPFP amplitude after washout was reduced from 3.8- to 2.0-fold of control, and increased back to 3.4-fold of control value after a second application of the drug in the same slice; differences between amplitudes in the presence of drug and after washout, and between washout and the second application of drug, were significant at the $\mathrm{p}<0.05$ level. In contrast to the increase in amplitude, there was no statistically significant change in mean frequency of spontaneous events in $C A 3$ after exposure to $G_{A B A} R$ antagonists ( $89 \%$ of control value; $\mathrm{p}=0.45$ ), nor after washout followed by a second application of the drug.

Unexpectedly, in the neocortex, the effect of $\mathrm{GABA}_{\mathrm{A}} \mathrm{R}$ antagonists on frequency and amplitudes of spontaneous events was reversed compared to that in the hippocampus (Fig. 4B, right panel): in 14 of 15 slices there was a very pronounced increase in sPFP frequency - in over half the cases it more than quintupled, the mean increase being 4.8fold $(\mathrm{p}<0.005)$. After drug washout, mean frequency decreased to 2.7-fold of control, although the difference between drug and washout conditions was not statistically significant. Mean amplitude of spontaneous events actually decreased in P2-P3 
neocortex slices $(n=7)$ after adding $\mathrm{GABA}_{\mathrm{A}} \mathrm{R}$ antagonists, to $64 \%$ of control $(\mathrm{p}=0.06$; see Fig. 2, bottom panels), but there was no significant change in mean amplitude in P4-P7 slices $(113 \%$ of control, $n=8, p=0.33)$.

\subsubsection{GABA $A_{A}$ agonists depressed the amplitude (but not frequency) of sPFPs in CA3}

As spontaneous paroxysmal activity in the neonatal cortex was elicited by blocking $\mathrm{GABA}_{\mathrm{A}} \mathrm{Rs}$, it seemed likely that in the absence of antagonists, such activity was suppressed (in the slice, and presumably in vivo as well) by tonic release of GABA from GABAergic synaptic terminals. Indeed, spontaneous GABAergic synaptic events have been documented in the neonatal hippocampus and neocortex (Hosokawa et al., 1994; Hollrigel and Soltesz, 1997; Owens et al., 1999; Lamsa et al., 2000). To examine directly the ability of $\mathrm{GABA}_{\mathrm{A}} \mathrm{R}$ activation to suppress paroxysmal activity, we tested the effect of muscimol, a potent and specific $\mathrm{GABA}_{\mathrm{A}} \mathrm{R}$ agonist, on spontaneous paroxysmal events. Since co-application of competitive agonists and antagonists of the same receptor could be difficult to interpret, we chose to test the effect of muscimol on sPFPs elicited by bathapplication of $50 \mu \mathrm{M}$ 4-aminopyridine (4-AP), a well studied non-GABAergic convulsant (Rutecki et al., 1987; Chesnut and Swann, 1990; Traub et al., 1995; Psarropoulou and Avoli, 1996). This was done in 28 slices from 9 additional mice (P0-P7). In 85\% of slices exposed to 4-AP, paroxysmal events were elicited in CA3, usually within 10-20 min of drug application; no sPFPs were observed in the neocortex in the range of ages used in our study. Fig. 5A shows a representative experiment from a P3 hippocampus slice, in which $50 \mathrm{nM}$ muscimol was added to ACSF containing 4-AP. As illustrated, muscimol dramatically reduced sPFP amplitudes, but not their frequency; amplitudes recovered after washing out the drug. When another slice from the same 
animal was exposed to $100 \mathrm{nM}$ muscimol (not shown), sPFPs were almost totally blocked within 6 minutes, and recovered within 2 minutes of washout in 4-AP-containing ACSF.

Figure 5B summarizes results from all 7 slices tested in $100 \mathrm{nM}$ muscimol (P0-P7 ages included). In 4 of these slices, sPFPs were fully blocked, consistent with the reported high potency of muscimol in neonatal hippocampal cells (Fiszman et al., 1990). In the remaining 3, mean sPFP amplitude was reduced to $60 \%$ of control amplitude ( $<<0.01$, the blocked cases included in the significance test but not in the mean), while their frequency, on average, remained unchanged ( $95 \%$ of control). In all 7 slices, sPFPs recovered to an average of $96 \%$ of control amplitude and $105 \%$ of control frequency after muscimol washout. Thus, the effect of muscimol, a $\mathrm{GABA}_{\mathrm{A}} \mathrm{R}$ agonist, was the exact mirror image of the effect of $\mathrm{GABA}_{\mathrm{A}} \mathrm{R}$ antagonists in $\mathrm{CA} 3$ (compare Figs. $4 \mathrm{~B}$ and $5 \mathrm{~B}$ ): from the earliest postnatal ages, $\mathrm{GABA}_{\mathrm{A}} \mathrm{R}$ antagonists increased the amplitude of populationsynchronous events in $\mathrm{CA} 3$, while $\mathrm{GABA}_{\mathrm{A}} \mathrm{R}$ agonists reduced them, neither affecting their frequency.

\subsubsection{Glutamatergic antagonists strongly suppressed frequency (but not amplitude) of} sPFPs

The facilitory effect of $\mathrm{Mg}^{2+}$-free $\mathrm{ACSF}$ on induction of $\mathrm{SPFPs}$ by $\mathrm{GABA}_{\mathrm{A}} \mathrm{R}$ antagonists suggested that an NMDAR-dependent mechanism is involved in generating these events (Traub et al., 1994). To test this, we exposed slices bathed in $\mathrm{Mg}^{2+}$-free ACSF and $\mathrm{GABA}_{\mathrm{A}} \mathrm{R}$ antagonists to APV, a highly selective, competitive NMDA receptor antagonist. In the experiment illustrated in Fig. $6 \mathrm{~A}$, addition of $10 \mu \mathrm{M}$ APV to 5 $\mu \mathrm{M} \mathrm{GBZ} \mathrm{in} \mathrm{Mg}^{2+}$-free ACSF caused a reduction in sPFP frequency in CA3 to less than half the initial value, with no change in sPFP amplitude. In the neocortex of the same 
slice, sPFP frequency was reduced to about $10 \%$ of its initial value, with about two-fold reduction in amplitude. Further addition of $10 \mu \mathrm{M}$ CNQX blocked all activity in both structures, and sPFPs reappeared at their near-control frequency after the two glutamatergic antagonists were washed out.

Results of all slices tested with APV (P0-P7 ages represented in both regions) are summarized in Fig. 6B. In both regions, APV caused a profound suppression of mean sPFP frequency, with no (CA3) or only a moderate (neocortex) reduction in mean amplitude. The (geometrical) mean reduction in frequency induced by $10 \mu \mathrm{M}$ APV was to $25 \%$ of control in CA3 $(\mathrm{p}<0.005$, excluding from the mean one slice in which sPFPs were fully blocked), and to $13 \%$ of control in the neocortex ( $\mathrm{p}=0.06$, excluding from the mean, but not from the significance test, one slice in which PFPs were fully blocked), while amplitude in APV was $108 \%$ of control in CA3 ( $\mathrm{p}=0.32)$ and $58 \%$ of control in the neocortex $(\mathrm{p}=0.06)$. In all cases tested $(\mathrm{n}=4$ in the hippocampus and $\mathrm{n}=2$ in the neocortex), addition of $10 \mu \mathrm{M} \mathrm{CNQX}$ to the APV-containing bath fully blocked the sPFPs, and subsequent washout of both glutamatergic antagonists resulted in recovery of sPFP frequency to within $15 \%$ of control value.

Since sPFPs generated in the presence of $\mathrm{GABA}_{\mathrm{A}} \mathrm{R}$ antagonists were blocked by a combination of the glutamatergic antagonists APV and CNQX, and since APV caused little or no change in mean sPFP amplitude, we expected amplitudes to be reduced by CNQX. To our surprise, the effect of CNQX was similar to that of APV. In the two slices illustrated in Fig. 7A, CNQX caused little or no change in SPFP amplitude either in CA3 or in the neocortex, but caused a pronounced, though reversible, depression in frequency. In total (Fig. 7B), addition of $10 \mu \mathrm{M}$ CNQX to $\mathrm{Mg}^{2+}$-free ACSF with 
$\mathrm{GABA}_{\mathrm{A}} \mathrm{R}$ antagonists reduced sPFP frequency, on average, to $46 \%$ of control in CA3 ( $\mathrm{p}=0.002$, excluding from the mean two slices in which PFPs were totally blocked), and to $53 \%$ in the neocortex $(\mathrm{p}=0.06)$, while leaving amplitude virtually unchanged in CA3 ( $93 \%$ of control, $\mathrm{p}=0.24)$ and only moderately reduced in the neocortex ( $67 \%$ of control, $\mathrm{p}=0.08$ ). CNQX had an additional effect on sPFP waveform in CA3: it blocked most or all of the sharp spikes typical of CA3 sPFPs, and left only a slow triphasic envelope (not shown).

In summary, in CA3, glutamatergic and GABAergic agonists/antagonists had complementary effects: GABAergic antagonists (Fig. 4B) and agonists (Fig. 5B) increased and decreased, respectively, mean amplitude of spontaneous events, without affecting their frequency, while glutamatergic antagonists (Figs. 6B and 7B) decreased mean sPFP frequency without affecting sPFP amplitudes. In the neocortex, glutamatergic and GABAergic antagonists had mirror-image effects: GABAergic antagonists increased mean sPFP frequency with no consistent change in their amplitudes, while glutamatergic antagonists decreased mean sPFP frequency with only a moderate change in their amplitudes.

\subsection{Discussion}

\subsubsection{Differential development of excitatory synaptic networks in hippocampus and} neocortex

To our knowledge, this is the first study examining in parallel, under identical conditions, development of network activity in the neonatal hippocampus and neocortex. We found that in mouse and rat slices bathed in normal ACSF, $\mathrm{GABA}_{\mathrm{A}} \mathrm{R}$ antagonists 
induced spontaneous paroxysmal activity with at least $60 \%$ probability in the hippocampus as early as P2 and in the neocortex as early as P6, and with 100\% probability in the hippocampus from $\mathrm{P} 4$ on (this study) and in the neocortex from $\mathrm{P} 9$ on (our unpublished observations). Most previous studies have not observed spontaneous paroxysmal events in the hippocampus before P6 (Swann and Brady, 1984; Ben-Ari et al., 1989; Psarropoulou and Descombes, 1999), or in the neocortex before P8 (Hablitz, 1987), possibly because of their low incidence and frequency at earlier ages. A notable exception is a recent study (Khalilov et al., 1999) which observed, as we did, spontaneous bicuculline-induced paroxysmal events in CA3 as early as P2.

In both the hippocampus and the neocortex, the sPFP incidence vs age relationship was shifted by about 4-days to the left when slices were bathed in $\mathrm{Mg}^{2+}$-free ACSF, suggesting that not lack of glutamatergic connections per se was preventing network activity in the earlier ages, but rather insufficient AMPAR-mediated excitation to overcome the $\mathrm{Mg}^{2+}$ block of NMDARs (Durand et al., 1996; Rumpel et al., 1998; Petralia et al., 1999). Even with the $\mathrm{Mg}^{2+}$ block removed, however, the neocortex still lagged by 3-4 days behind the hippocampus, suggesting a genuine difference in the development of excitatory connections between the two regions.

\subsubsection{GABA prevents runaway excitation in the neonatal cortex}

In the adult cortex, blocking $\mathrm{GABA}_{\mathrm{A}} \mathrm{Rs}$ unfailingly elicits epileptiform events, which consist of volleys of giant synaptic potentials and synchronous discharges in large populations of neurons (Johnston and Brown, 1981; Traub and Miles, 1991). PFPs are the extracellular reflection of this massive synchronous electrical activity (Schwartzkroin and Prince, 1978; Wong and Prince, 1979; Connors, 1984). Thus, PFPs are a reliable 
indicator of an increase in neuronal firing in the cortical network, which by the classical definition of the term is an excitatory - or disinhibitory - effect. Our observation of PFPs following exposure to $\mathrm{GABA}_{\mathrm{A}} \mathrm{R}$ antagonists suggests, therefore, that GABA in the neonatal cortex has the same inhibitory function that it has in the mature brain: preventing runaway excitation leading to synchronous discharges. The dramatic $\mathrm{GABA}_{\mathrm{A}} \mathrm{R}$ antagonists-induced increase in frequency of spontaneous events in the neocortex, and in amplitude, but not duration, of spontaneous events in CA3, suggests that GABA in the neonatal cortex is tonically suppressing the level of electrical activity in the network, not merely reducing its degree of synchrony, and is therefore inhibitory in the classical sense. Similar conclusions have recently been reached in several other studies (Psarropoulou and Descombes, 1999; Lamsa et al., 2000; Palva et al., 2000).

\subsubsection{GABA can be both depolarizing and inhibitory}

Exogenous or synaptically released GABA elicits depolarizations in the neonatal hippocampus and neocortex (Mueller et al., 1984; Ben-Ari et al., 1989; Zhang et al., 1991; Agmon et al., 1996; Owens et al., 1996). $\mathrm{GABA}_{\mathrm{A}} \mathrm{R}$-mediated synaptic inputs with depolarizing reversal potentials are common in the embryonic or neonatal brain (Hales et al., 1994; Serafini et al., 1995; Chen et al., 1996; Warren and Jones, 1997) and are most likely explained by a high intracellular chloride concentration (Owens et al., 1996; Rivera et al., 1999). Depolarizations mediated by $\mathrm{GABA}_{\mathrm{A}} \mathrm{Rs}$ in the neonatal brain can induce $\mathrm{Ca}^{2+}$ entry through voltage-gated $\mathrm{Ca}^{2+}$ channels (Yuste and Katz, 1991; Lin et al., 1994; Leinekugel et al., 1995; Owens et al., 1996; Garaschuk et al., 1998; but see Dailey and Smith, 1994 for a dissenting result), and may thereby trigger a wide variety of developmental events (LoTurco et al., 1995; Fukura et al., 1996; Mitchell and Redburn, 
1996). Our results are not at odds with these previous studies, since a depolarizing synaptic response can still be inhibitory, if it shunts excitatory currents out of the cell. GABAergic synaptic inputs in the hippocampus and neocortex have three properties which make them a highly effective shunt for glutamate-induced currents: they have a relatively large conductance (Connors et al., 1988); their reversal potentials, even when depolarizing, are still considerably more negative than the excitatory reversal potential; and they are preferentially located between the excitatory inputs (on dendritic spines and shafts) and the spike generation zone (in the initial segment of the axon) (Gulyas et al., 1993; Cipolloni et al., 1998). The co-existence of a depolarizing with an inhibitory action of GABA was recently demonstrated in the neonatal CA3 (Psarropoulou and Descombes, 1999; Lamsa et al., 2000), and previously described in other ages and brain areas as well (Staley and Mody, 1992; Chen et al., 1996; Lo et al., 1998; Su and Chai, 1998).

\subsubsection{Spontaneous network activity in the neonatal hippocampus}

The depolarizing action of GABA in the neonatal cortex may contribute to removal of the $\mathrm{Mg}^{2+}$ block from NMDA receptors, and in this manner could facilitate network activity (Khazipov et al., 1995; Ben-Ari et al., 1997; Leinekugel et al., 1997). Indeed, the occurrence of bicuculline-sensitive spontaneous network events in the neonatal hippocampus, called Giant Depolarizing Potentials (GDPs) or Early Network Oscillations (ENOs) (Ben-Ari et al., 1989; Xie et al., 1994; Strata et al., 1997; Garaschuk

et al., 1998; Menendez de la Prida et al., 1998), has been interpreted as evidence for GABA being the major fast excitatory neurotransmitter in the neonate (Leinekugel et al., 1999). However, GDPs and ENOs are also blocked or strongly suppressed by 
glutamatergic antagonists, and are accompanied by synchronous discharges of both glutamatergic and GABAergic neurons, generating synaptic currents with mixed glutamatergic and GABAergic components (Khazipov et al., 1997; Leinekugel et al., 1997; Garaschuk et al., 1998; Bolea et al., 1999). This suggests that GABA may simply be playing a permissive role in generating these events, not unlike the role of $\mathrm{Mg}^{2+}$-free ACSF in our experiments, but that the main excitation is still mediated by glutamate, acting on NMDA or AMPA receptors (Bolea et al., 1999).

In our experiments we did not observe spontaneous events in normal ACSF without $\mathrm{GABA}_{\mathrm{A}} \mathrm{R}$ antagonists, either because they were too small to be detected extracellularly, or because they were truly absent due to differences in experimental conditions (e.g. recording temperature, plane of section, species and strain of animals). However, small-amplitude extracellular events, at nearly the same range of frequencies reported for GDPs, were frequently observed in $\mathrm{CA} 3$ in $\mathrm{Mg}^{2+}$-free ACSF, and could have corresponded to GDPs. Unlike GDPs, these events were augmented, rather than blocked, by $\mathrm{GABA}_{\mathrm{A}} \mathrm{R}$ antagonists. While in apparent contradiction to some previous studies, our results are in substantial agreement with a recent study (Khalilov et al., 1999) which found that in P2-P5 CA3, bicuculline caused a switch from GDPs to paroxysmal network activity, and with another recent study (Lamsa et al., 2000) in which spontaneous extracellular events were observed in P0-P2 CA3 in normal ACSF, and were greatly augmented by bicuculline. Thus it is possible that the various spontaneous network events of the neonatal hippocampus - sPFPs, GDPs and ENOs - are generated, under slightly different conditions, by the same pacemaker circuits. Indeed, the same underlying circuits could persist to adulthood and generate the pathological rhythms of epilepsy. 


\subsubsection{Differential actions of GABAergic and glutamatergic antagonists in hippocampus}

and neocortex

An unexpected finding of our study was that, in CA3, GABAergic and glutamatergic agents had complementary effects on frequency and amplitudes of spontaneous events in $\mathrm{Mg}^{2+}$-free ACSF (Figs. 4-7). This suggests an uncoupling between the cellular mechanisms underlying sPFP amplitude and frequency. We hypothesize that frequency of events in CA3 was controlled by a pacemaker circuit which was NMDARdependent, and generated low-amplitude rhythmic events in $\mathrm{Mg}^{2+}$-free solution. With GABAergic inhibition intact, these events probably involved only a small subset of all neurons. Blocking $\mathrm{GABA}_{\mathrm{A}} \mathrm{Rs}$ released postsynaptic follower cells from tonic inhibition and allowed their recruitment into the population of synchronously firing neurons, thereby transforming these events into a paroxysmal discharge, without affecting their frequency. An intriguing possibility is that recruitment of follower neurons was mediated, at least in part, by gap junctions, which are a documented feature of the neonatal neocortex (Yuste et al., 1992, 1995) and hippocampus (Matsumoto et al., 1991; Strata et al., 1997). This would explain why, in our experiments, glutamatergic antagonists did not reduce the amplitude of sPFPs.

Intriguingly, in the neocortex, blocking $\mathrm{GABA}_{\mathrm{A}} \mathrm{Rs}$ had the exact opposite effects on frequency and amplitudes of $0-\mathrm{Mg}$ spontaneous events, compared to the hippocampus. We hypothesize that sPFPs observed in the neocortex propagated from a distant pacemaker region, and that only events larger than a threshold amplitude were able to propagate. With inhibition intact, this threshold was relatively high. Once inhibition was blocked, the threshold for propagation was reduced, and thereby more - and smaller - 
events propagated, resulting in an increase in frequency and a reduction in mean amplitude of paroxysmal events reaching the recording site. Identifying the location and cellular composition of the postulated hippocampal and neocortical pacemakers should be an important goal of future studies. 


\subsection{Figures}

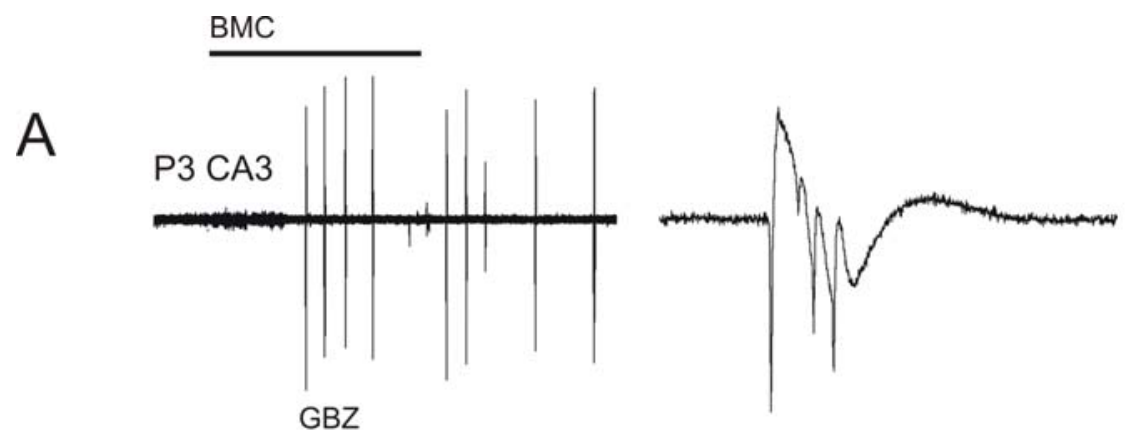

B
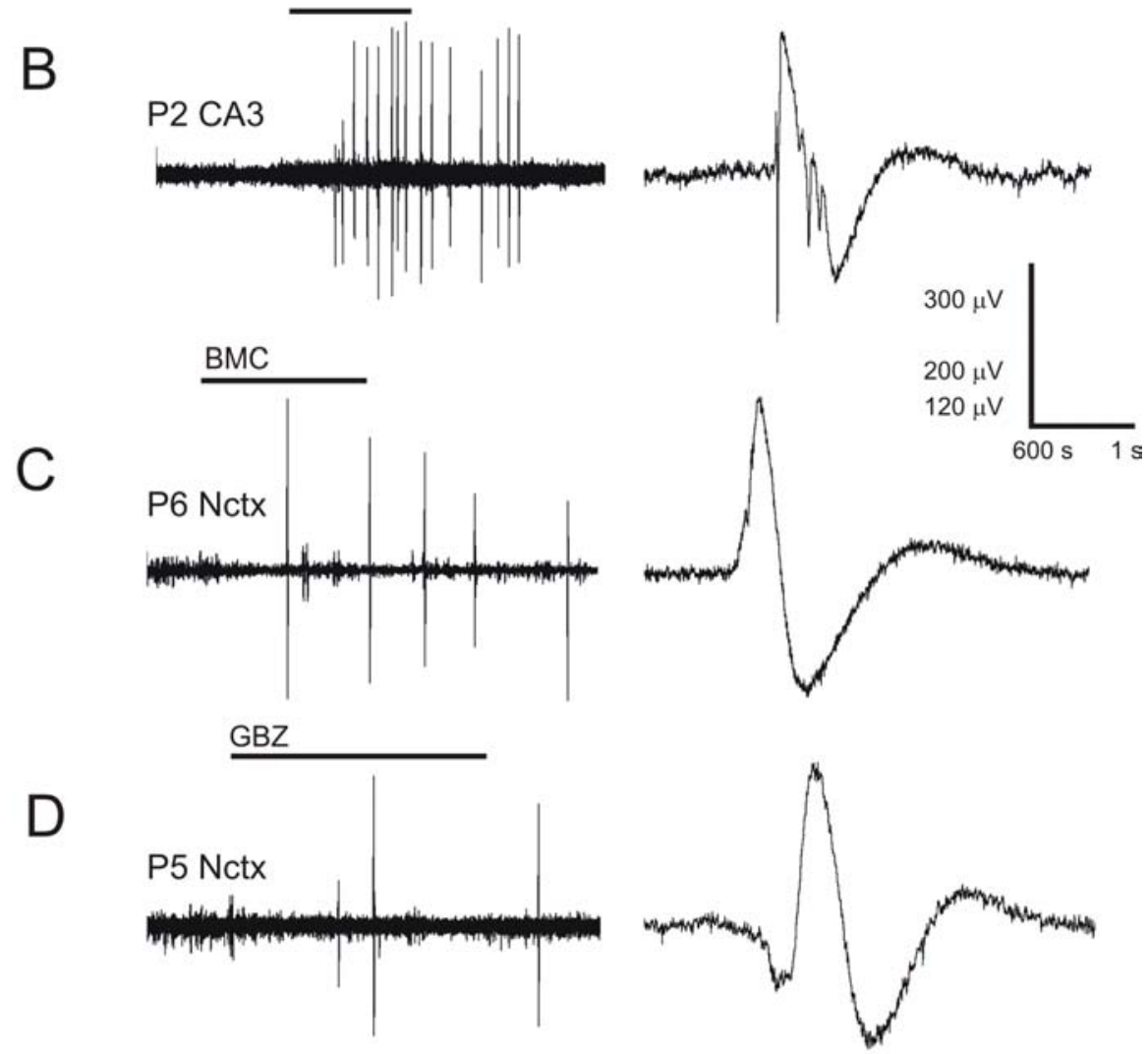

FigURE 3-1. SPONTANEOUS PAROXYSMAL FIELD POTENTIALS (SPFPS) ELICITED IN NEONATAL HIPPOCAMPUS AND NEOCORTEX BY GABAA RECEPTOR (GABAAR) ANTAGONISTS IN NORMAL ARTIFICIAL CSF (ACSF).

Each panel shows a continuous 45 min record on the left illustrating spontaneous activity before, during and after superfusion of drug (drug presence indicated by bar above the trace), and a $4.5 \mathrm{~s}$ record on the right, illustrating a single $\mathrm{sPFP}$ expanded from the trace on the left. $B M C-10 \mu \mathrm{M}$ bicuculline methchloride; $G B Z-5 \mu \mathrm{M}$ gabazine (SR-95531). Postnatal age and region recorded (Nctx - neocortex; CA3 - hippocampus, area CA3) 
noted above each trace. Horizontal calibration bar is $10 \mathrm{~min}$ for left panels, $1 \mathrm{~s}$ for right panels. Vertical calibration bar is $300 \mu \mathrm{V}$ for $\mathrm{A}$ and $\mathrm{B}, 200 \mu \mathrm{V}$ for $\mathrm{C}, 120 \mu \mathrm{V}$ for $\mathrm{D}$. Note the sharp spikes characterizing sPFPs in CA3 (A and B, right panels), and the similarity between sPFPs elicited by BMC and GBZ. 

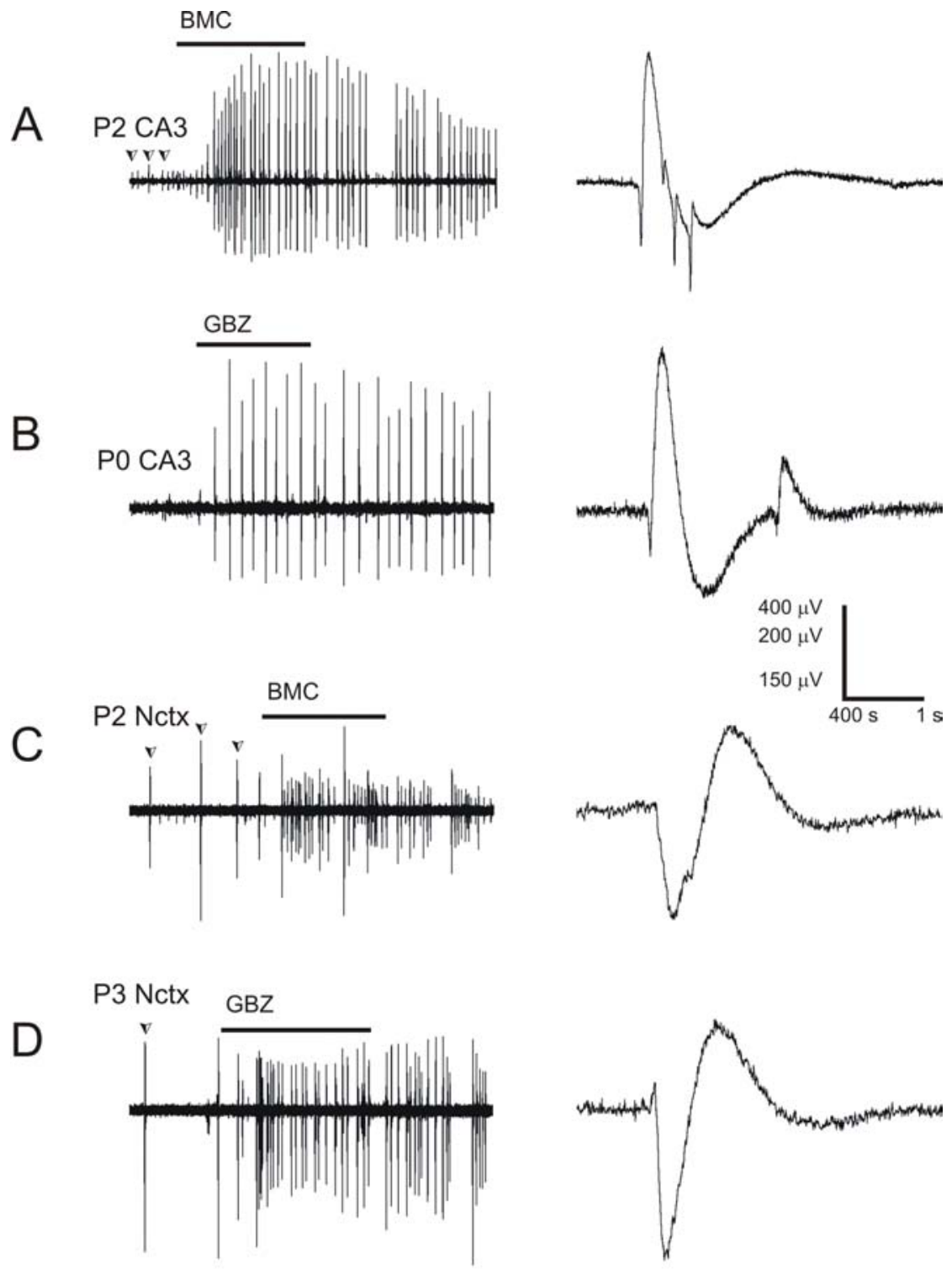

FigURE 3-2. SPFPS ELICITED BY GABA ${ }_{A}$ R ANTAGONISTS IN $\mathrm{MG}^{2+}$-FREE ACSF. Each panel shows a continuous $30 \mathrm{~min}$ record on the left illustrating spontaneous activity before, during and after superfusion of drug (drug presence indicated by bar above the trace; concentrations as in Fig. 1), and a $4.5 \mathrm{~s}$ record on the right, illustrating a single sPFP from the trace on the left. Slices were bathed in $\mathrm{Mg}^{2+}$-free ACSF for at least $20 \mathrm{~min}$ by the beginning of each trace. Arrowheads point to some of the spontaneous events occurring in $\mathrm{Mg}^{2+}$-free ACSF alone, before addition of antagonist. Horizontal calibration bar is $400 \mathrm{~s}$ for left panels, $1 \mathrm{~s}$ for right panels. Vertical calibration bar is $400 \mathrm{~V}$ for A, $200 \mathrm{~V}$ for B, $150 \quad \mathrm{~V}$ for $\mathrm{C}$ and $\mathrm{D}$. 


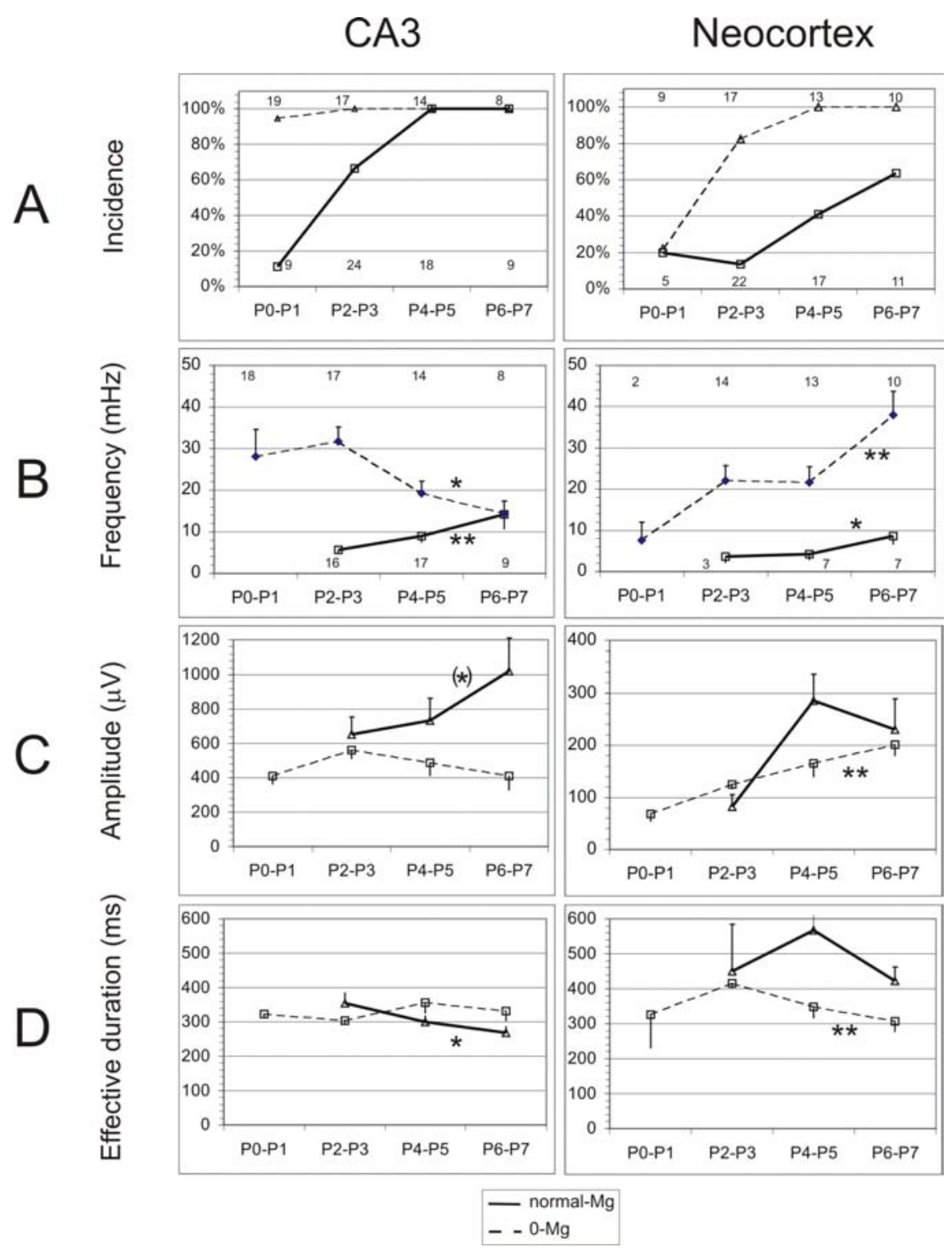

Figure 3-3. AGE-DEPENDENT CHANGES IN INCIDENCE, FREQUENCY, AMPLITUDE AND EFFECTIVE DURATION OF SPFPS ELICITED BY GABA ${ }_{\mathrm{A}}$ R ANTAGONISTS AS A FUNCTION OF AGE.

See Methods for definitions of these four parameters. Data are combined into four 2-day age groups. In normal ACSF, only 1 P0-P1 slice in each of the two regions generated sPFPs, and therefore analysis begins with the P2-P3 age group. In A, number of CA3 slices in the 4 age groups was 9, 24, 18, 9, respectively, in normal ACSF, and 19, 17, 14, 8 in $\mathrm{Mg}^{2+}$-free ACSF. Number of neocortex slices tested was 5, 22, 17, 11 and 9, 17, 13, 10, respectively. In B-D, number of CA3 slices was 16, 17, 9 in normal ACSF, and 18, 
17, 14, 8 in $\mathrm{Mg}^{2+}$-free ACSF. Number of neocortex slices was 3, 7, 7 and 2, 14, 13, 10, respectively. Statistical significance of age-dependency is indicated by one asterisk for $\mathrm{p}<0.05$ (significant), by two asterisks for $\mathrm{p}<0.01$ (highly significant); a marginally significant difference $(\mathrm{p}<0.1)$ is indicated by an asterisk in parenthesis. Significance values were calculated over the whole age range plotted, except in D, neocortex, where the decrease in effective duration was highly significant between P2-P3 and P6-P7 but only significant between P0-P1 and P6-P7. In general, incidence and amplitude of sPFPs were higher in CA3 than in neocortex (note the different scales for CA3 and neocortex in panel C); in both regions, incidence and frequency in $\mathrm{Mg}^{2+}$-free ACSF were higher than in normal ACSF, but amplitudes were smaller. 


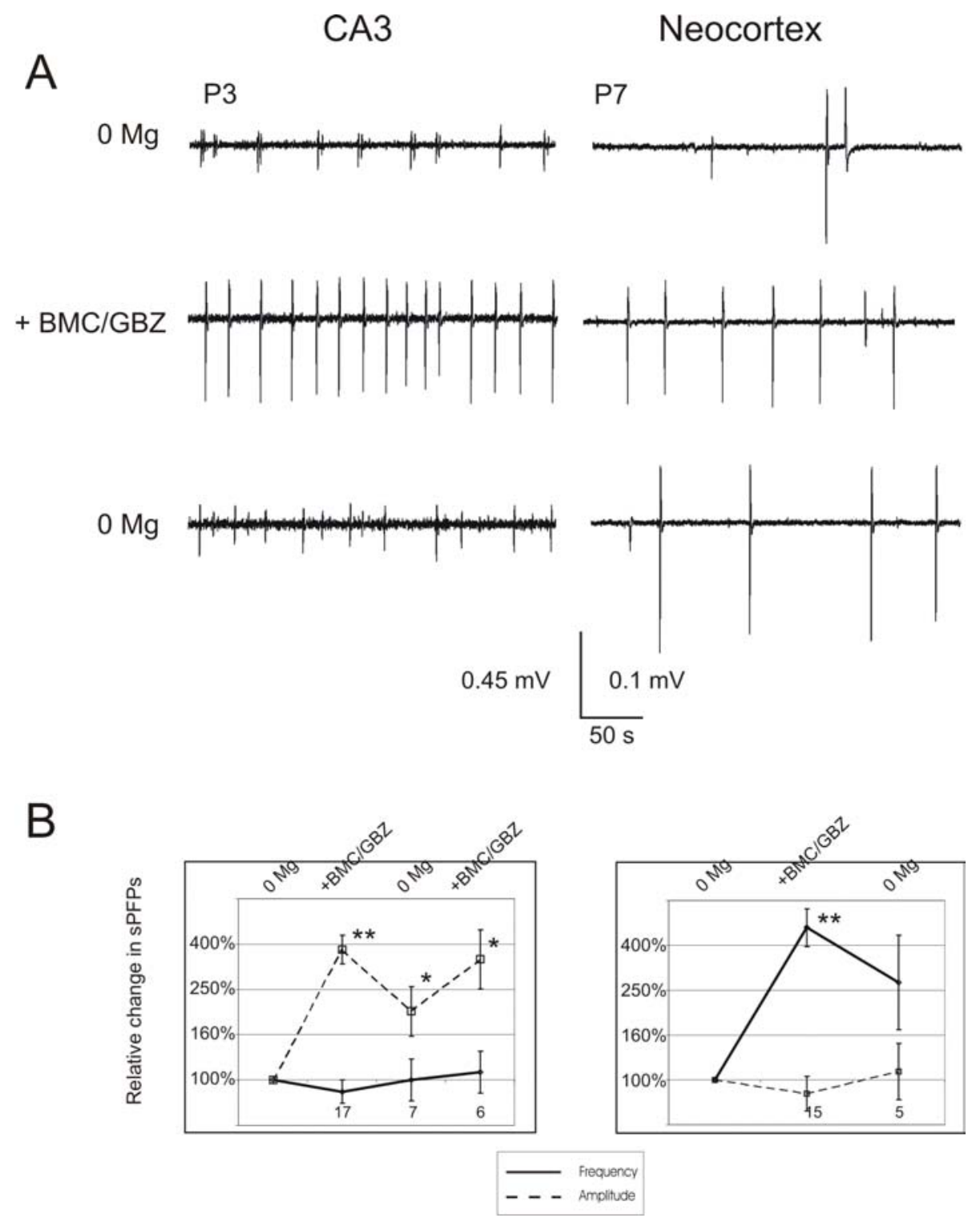

FigURE 3-4. GABA $\mathrm{R}$ ANTAGONISTS ADDED TO $\mathrm{MG}^{2+}$-FREE ACSF INCREASE AMPLITUDES (BUT NOT FREQUENCY) OF SPONTANEOUS EVENTS IN HIPPOCAMPUS, AND FREQUENCY (BUT NOT AMPLITUDES) IN NEOCORTEX.

A, representative cases from $\mathrm{CA} 3$ and neocortex; each trace is a continuous 5 min record. In the CA3 slice illustrated, events before adding antagonists occurred in doublets. $\mathbf{B}$, Summary of results from all slices tested. Y-axis indicates multiplicative change compared to control, on a logarithmic scale ( $0.2 \log _{10}$ units between grid lines). Data points and error bars denote geometric means and SEM, respectively (i.e. the means and SEM of the logarithms of the pairwise experimental/control ratios). For CA3, sample sizes for each of the 3 experimental conditions (drug-washout-drug) were 17, 7,6, respectively. For neocortex, sample sizes were 15 and 5, respectively. Significance 
symbols as in Fig. 3. Drug concentrations were $10 \mu \mathrm{M}$ BMC and $5 \mu \mathrm{M}$ GBZ. Note the different vertical calibration for the left and right panels. 

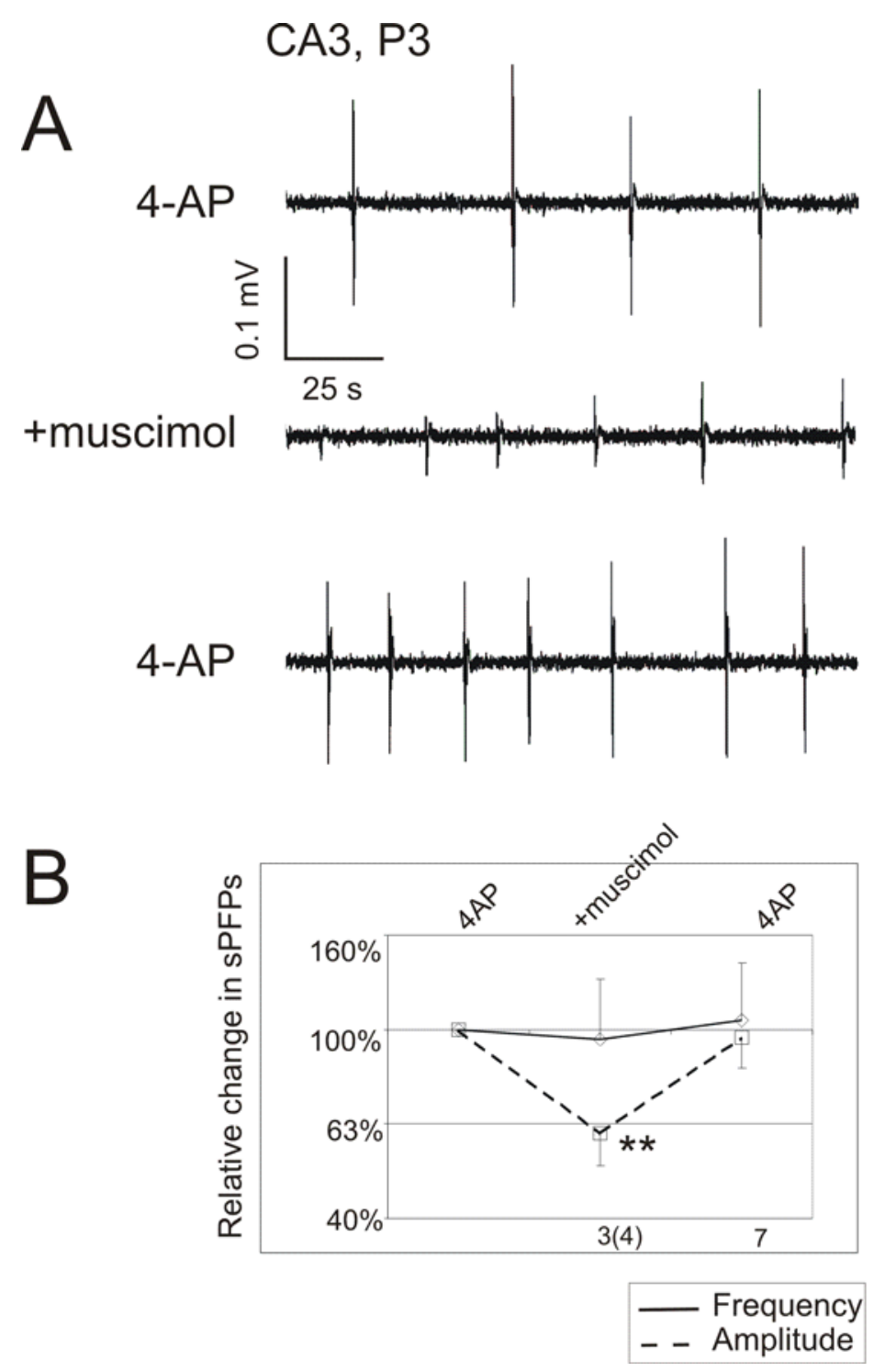

Figure 3-5. ThE GABA ${ }_{A}$ R AGONIST MUSCIMOL DEPRESSED AMPLITUDES (BUT NOT FREQUENCY) OF SPFPS OCCURRING IN $50 \mu \mathrm{M}$ 4-AMINOPYRIDINE (4-AP).

A, a representative experiment using $50 \mathrm{nM}$ muscimol. Each trace is a continuous 2.5 min record. B, summary of all cases tested with $100 \mathrm{nM}$ muscimol; graphic conventions as in Fig. 4. Number of slices tested was 7 in each condition (with muscimol and after washout); with muscimol, in 4 of the 7 slices the sPFPs were fully blocked and are therefore not included in the mean. 
A

$0 \mathrm{Mg}+\mathrm{GBZ}$

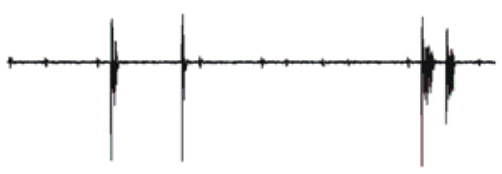

P6

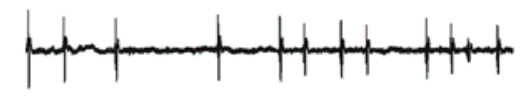

$+\mathrm{APV}+\mathrm{CNQX}$

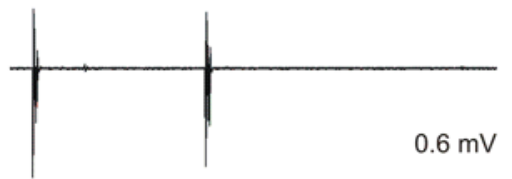

+APV

$0 \mathrm{Mg}+\mathrm{GBZ}$

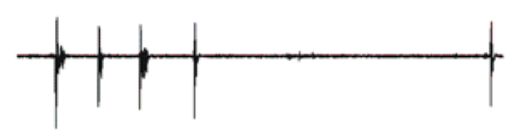

B

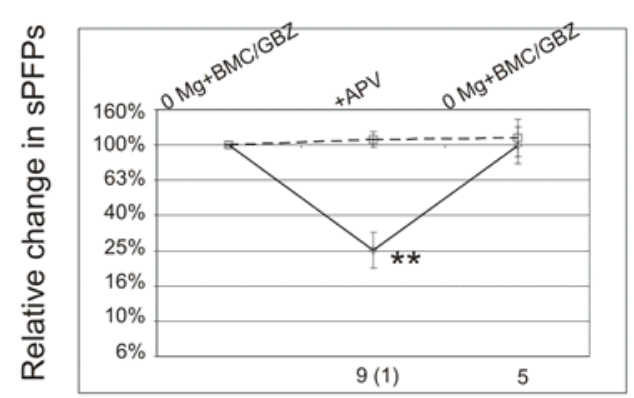

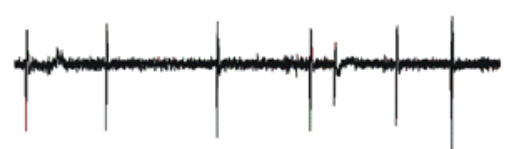

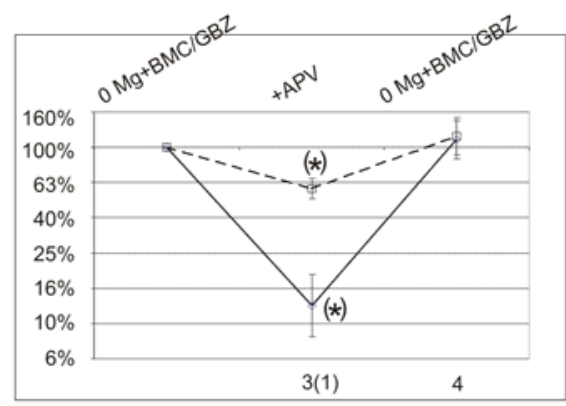

Frequency - - Amplitude

FigurE 3-6. THE N-METHYL-D-ASPARTATE (NMDA)-RECEPTOR ANTAGONIST D(-)-2AMINO-5-PHOSPHONOPENTANOIC ACID (APV) DEPRESSED FREQUENCY, BUT NOT AMPLITUDES, OF SPFPS ELICITED BY GABA $\mathrm{A}$ ANTAGONISTS IN $\mathrm{MG}^{2+}$-FREE ACSF.

A, a representative experiment using $10 \mu \mathrm{M}$ APV; each trace is a continuous 5 min record. Adding $10 \mu \mathrm{M}$ 6-cyano-7-nitroquinoxaline-2,3-dione (CNQX) in addition to APV blocked all events. Note the different vertical calibration for the left and right panels. Records in CA3 and neocortex were taken simultaneously from the same slice; neocortex-originating sPFPs propagated to CA3 and are visible as small-amplitude deflections on the CA3 records, but note that the two sets of events are not temporally correlated. B, summary of all cases tested with APV and after washout. Number of slices tested was 9 and 5 in CA3, 4 and 4 in neocortex; in 1 of the 4 neocortex slices sPFPs 
were fully blocked, and this slice is therefore not included in the mean. GBZ and BMC concentrations and graphic conventions as in Fig. 4. 
CA3

A
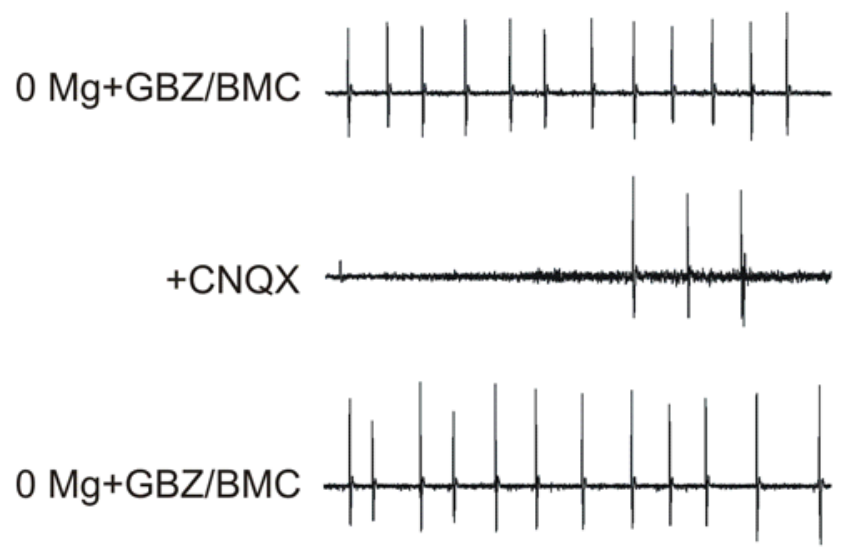

Neocortex

P6
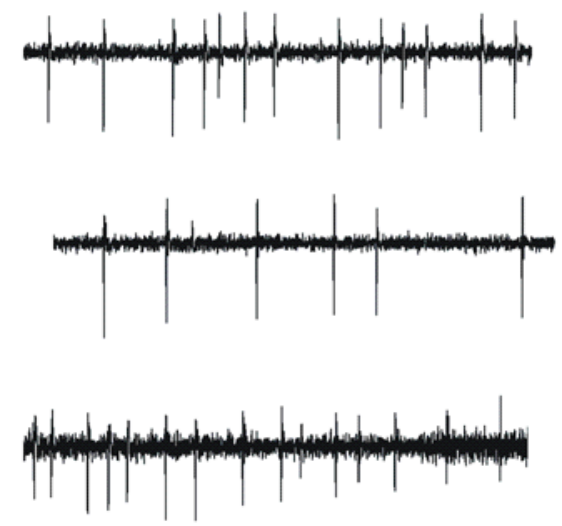

$$
\text { . } 0.4 \mathrm{mV} \frac{0.2 \mathrm{mV}}{50 \mathrm{~s}}
$$

B
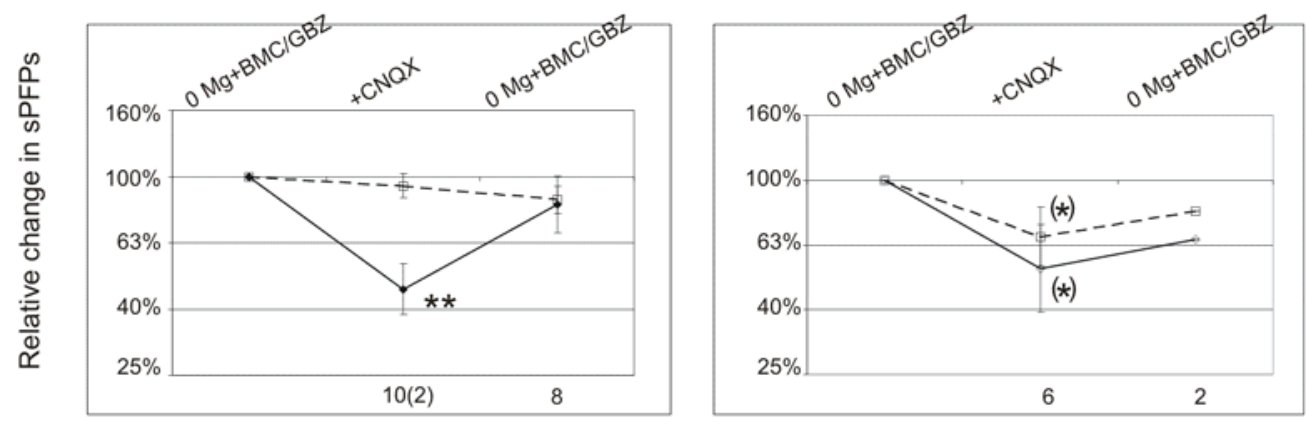

Frequency

- - Amplitude

Figure 3-7. THE NON-NMDA RECEPTOR ANTAGONIST CNQX ALSO DEPRESSED FREQUENCY OF SPFPS ELICITED BY GABA $\mathrm{A}$ R ANTAGONISTS IN $\mathrm{MG}^{2+}$-FREE ACSF.

A, representative cases tested with $10 \mu \mathrm{M}$ CNQX; each trace is a continuous 5 min (CA3) or $4 \mathrm{~min}$ (neocortex) record. Note that both vertical and horizontal calibrations are different for the right and left panels. B, summary plot of all cases. Number of slices tested with CNQX and after washout was 10 and 8 in CA3, 6 and 2 in neocortex. Two of the 10 CA3 slices, in which the sPFPs were fully blocked, are not included in the mean. GBZ and BMC concentrations and graphic conventions as in Fig. 4. 


\subsection{References}

Agmon A, O'Dowd DK (1992) NMDA receptor-mediated currents are prominent in the thalamocortical synaptic response before maturation of inhibition. J Neurophysiol 68:345-349.

Agmon A, Hollrigel G, O'Dowd DK (1996) Functional GABAergic synaptic connection in neonatal mouse barrel cortex. J Neurosci 16:4684-4695.

Bains JS, Longacher JM, Staley KJ (1999) Reciprocal interactions between CA3 network activity and strength of recurrent collateral synapses. Nat Neurosci 2:720-726.

Ben Ari Y, Tseeb V, Raggozzino D, Khazipov R, Gaiarsa JL (1994) gammaAminobutyric acid (GABA): a fast excitatory transmitter which may regulate the development of hippocampal neurones in early postnatal life. Prog Brain Res 102:261-273.

Ben-Ari Y, Cherubini E, Corradetti R, Gaiarsa JL (1989) Giant synaptic potentials in immature rat CA3 hippocampal neurones. J Physiol (Lond) 416:303-325.

Ben-Ari Y, Khazipov R, Leinekugel X, Caillard O, Gaiarsa JL (1997) GABAA, NMDA and AMPA receptors: a developmentally regulated 'menage a trois'. Trends Neurosci 20:523-529.

Bolea S, Avignone E, Berretta N, Sanchez-Andres JV, Cherubini E (1999) Glutamate controls the induction of GABA-mediated giant depolarizing potentials through AMPA receptors in neonatal rat hippocampal slices. J Neurophysiol 81:20952102.

Burgard EC, Hablitz JJ (1993) Developmental changes in NMDA and non-NMDA receptor-mediated synaptic potentials in rat neocortex. J Neurophysiol 69:230240.

Chen G, Trombley PQ, van den Pol AN (1996) Excitatory actions of GABA in developing rat hypothalamic neurones. J Physiol (Lond) 494:451-464.

Chesnut TJ, Swann JW (1990) Suppression of 4-aminopyridine-induced epileptogenesis by the GABAA agonist muscimol. Epilepsy Res 5:8-17.

Cipolloni PB, Kimerer L, Weintraub ND, Smith DV, Keller A (1998) Distribution of inhibitory synapses on the somata of pyramidal neurons in cat motor cortex. Somatosens Mot Res 15:276-286.

Connors BW (1984) Initiation of synchronized neuronal bursting in neocortex. Nature 310:685-687. 
Connors BW, Malenka RC, Silva LR (1988) Two inhibitory postsynaptic potentials, and GABAA and GABAB receptor- mediated responses in neocortex of rat and cat. $J$ Physiol (Lond) 406:443-468.

Dailey ME, Smith SJ (1994) Spontaneous $\mathrm{Ca}^{2+}$ transients in developing hippocampal pyramidal cells. J Neurobiol 25:243-251.

Debarbieux F, Brunton J, Charpak S (1998) Effect of bicuculline on thalamic activity: a direct blockade of IAHP in reticularis neurons. J Neurophysiol 79:2911-2918.

Durand GM, Kovalchuk Y, Konnerth A (1996) Long-term potentiation and functional synapse induction in developing hippocampus. Nature 381:71-75.

Fiszman ML, Novotny EA, Lange GD, Barker JL (1990) Embryonic and early postnatal hippocampal cells respond to nanomolar concentrations of muscimol. Brain Res Dev Brain Res 53:186-193.

Fukura H, Komiya Y, Igarashi M (1996) Signaling pathway downstream of GABAA receptor in the growth cone. J Neurochem 67:1426-1434.

Garaschuk O, Hanse E, Konnerth A (1998) Developmental profile and synaptic origin of early network oscillations in the CA1 region of rat neonatal hippocampus. $\mathrm{J}$ Physiol (Lond) 507:219-236.

Good PI (1999) Resampling Methods. Boston: Birkhauser.

Gulyas AI, Miles R, Hajos N, Freund TF (1993) Precision and variability in postsynaptic target selection of inhibitory cells in the hippocampal CA3 region. Eur J Neurosci 5:1729-1751.

Gutnick MJ, Connors BW, Prince DA (1982) Mechanisms of neocortical epileptogenesis in vitro. J Neurophysiol 48:1321-1335.

Hablitz JJ (1987) Spontaneous ictal-like discharges and sustained potential shifts in the developing rat neocortex. J Neurophysiol 58:1052-1065.

Hales TG, Sanderson MJ, Charles AC (1994) GABA has excitatory actions on GnRHsecreting immortalized hypothalamic (GT1-7) neurons. Neuroendocrinology 59:297-308.

Harris KM, Teyler TJ (1983) Evidence for late development of inhibition in area CA1 of the rat hippocampus. Brain Res 268:339-343.

Hollrigel GS, Soltesz I (1997) Slow kinetics of miniature IPSCs during early postnatal development in granule cells of the dentate gyrus. J Neurosci 17:5119-5128. 
Hosokawa Y, Sciancalepore M, Stratta F, Martina M, Cherubini E (1994) Developmental changes in spontaneous GABAA-mediated synaptic events in rat hippocampal CA3 neurons. Eur J Neurosci 6:805-813.

Isaac JT, Crair MC, Nicoll RA, Malenka RC (1997) Silent synapses during development of thalamocortical inputs. Neuron 18:269-280.

Johnson SW, Seutin V (1997) Bicuculline methiodide potentiates NMDA-dependent burst firing in rat dopamine neurons by blocking apamin-sensitive $\mathrm{Ca}^{2+}$-activated K+ currents. Neurosci Lett 231:13-16.

Johnston D, Brown TH (1981) Giant synaptic potential hypothesis for epileptiform activity. Science 211:294-297.

Khalilov I, Dzhala V, Ben-Ari Y, Khazipov R (1999) Dual role of GABA in the neonatal rat hippocampus. Dev Neurosci 21:310-319.

Khawaled R, Bruening-Wright A, Adelman JP, Maylie J (1999) Bicuculline block of small-conductance calcium-activated potassium channels. Pflugers Arch 438:314321.

Khazipov R, Ragozzino D, Bregestovski P (1995) Kinetics and $\mathrm{Mg}^{2+}$ block of N-methylD-aspartate receptor channels during postnatal development of hippocampal CA3 pyramidal neurons. Neuroscience 69:1057-1065.

Khazipov R, Leinekugel X, Khalilov I, Gaiarsa JL, Ben-Ari Y (1997) Synchronization of GABAergic interneuronal network in CA3 subfield of neonatal rat hippocampal slices. J Physiol (Lond) 498:763-772.

Kriegstein AR, Suppes T, Prince DA (1987) Cellular and synaptic physiology and epileptogenesis of developing rat neocortical neurons in vitro. Brain Res 431:161171.

Lamsa K, Palva JM, Ruusuvuori E, Kaila K, Taira T (2000) Synaptic GABA(A) activation inhibits AMPA-kainate receptor-mediated bursting in the newborn (P0P2) rat hippocampus. J Neurophysiol 83:359-366.

Leinekugel X, Tseeb V, Ben-Ari Y, Bregestovski P (1995) Synaptic GABAA activation induces $\mathrm{Ca}^{2+}$ rise in pyramidal cells and interneurons from rat neonatal hippocampal slices. J Physiol (Lond) 487:319-329.

Leinekugel X, Medina I, Khalilov I, Ben-Ari Y, Khazipov R (1997) $\mathrm{Ca}^{2+}$ oscillations mediated by the synergistic excitatory actions of GABA(A) and NMDA receptors in the neonatal hippocampus. Neuron 18:243-255. 
Leinekugel X, Khalilov I, McLean H, Caillard O, Gaiarsa JL, Ben-Ari Y, Khazipov R (1999) GABA is the principal fast-acting excitatory transmitter in the neonatal brain [In Process Citation]. Adv Neurol 79:189-201.

Lin MH, Takahashi MP, Takahashi Y, Tsumoto T (1994) Intracellular calcium increase induced by GABA in visual cortex of fetal and neonatal rats and its disappearance with development. Neurosci Res 20:85-94.

Lo YJ, Rao SC, Sanes DH (1998) Modulation of calcium by inhibitory systems in the developing auditory midbrain. Neuroscience 83:1075-1084.

LoTurco JJ, Owens DF, Heath MJ, Davis MB, Kriegstein AR (1995) GABA and glutamate depolarize cortical progenitor cells and inhibit DNA synthesis. Neuron 15:1287-1298.

Luhmann HJ, Prince DA (1991) Postnatal maturation of the GABAergic system in rat neocortex. J Neurophysiol 65:247-263.

Matsumoto A, Arai Y, Urano A, Hyodo S (1991) Cellular localization of gap junction mRNA in the neonatal rat brain. Neurosci Lett 124:225-228.

Menendez de la Prida L, Bolea S, Sanchez-Andres JV (1998) Origin of the synchronized network activity in the rabbit developing hippocampus. Eur J Neurosci 10:899906.

Mestdagh N, Wulfert E (1999) Bicuculline increases $\mathrm{Ca}^{2+}$ transients in rat cerebellar granule cells through non-GABA(A) receptor associated mechanisms. Neurosci Lett 265:95-98.

Michelson HB, Lothman EW (1989) An in vivo electrophysiological study of the ontogeny of excitatory and inhibitory processes in the rat hippocampus. Brain Res Dev Brain Res 47:113-122.

Mitchell CK, Redburn DA (1996) GABA and GABA-A receptors are maximally expressed in association with cone synaptogenesis in neonatal rabbit retina. Brain Res Dev Brain Res 95:63-71.

Mueller AL, Taube JS, Schwartzkroin PA (1984) Development of hyperpolarizing inhibitory postsynaptic potentials and hyperpolarizing response to gammaaminobutyric acid in rabbit hippocampus studied in vitro. J Neurosci 4:860-867.

Muller D, Oliver M, Lynch G (1989) Developmental changes in synaptic properties in hippocampus of neonatal rats. Brain Res Dev Brain Res 49:105-114. 
Owens DF, Liu X, Kriegstein AR (1999) Changing properties of GABA(A) receptormediated signaling during early neocortical development. J Neurophysiol 82:570583.

Owens DF, Boyce LH, Davis MB, Kriegstein AR (1996) Excitatory GABA responses in embryonic and neonatal cortical slices demonstrated by gramicidin perforatedpatch recordings and calcium imaging. J Neurosci 16:6414-6423.

Palva JM, Lamsa K, Lauri SE, Rauvala H, Kaila K, Taira T (2000) Fast network oscillations in the newborn rat hippocampus in vitro. J Neurosci 20:1170-1178.

Petralia RS, Esteban JA, Wang YX, Partridge JG, Zhao HM, Wenthold RJ, Malinow R (1999) Selective acquisition of AMPA receptors over postnatal development suggests a molecular basis for silent synapses. Nat Neurosci 2:31-36.

Prince DA, Connors BW (1986) Mechanisms of interictal epileptogenesis. Adv Neurol 44:275-299.

Psarropoulou C, Avoli M (1996) Developmental features of 4-aminopyridine induced epileptogenesis. Brain Res Dev Brain Res 94:52-59.

Psarropoulou C, Descombes S (1999) Differential bicuculline-induced epileptogenesis in rat neonatal, juvenile and adult CA3 pyramidal neurons in vitro. Brain Res Dev Brain Res 117:117-120.

Rivera C, Voipio J, Payne JA, Ruusuvuori E, Lahtinen H, Lamsa K, Pirvola U, Saarma M, Kaila K (1999) The $\mathrm{K}+/ \mathrm{Cl}$ - co-transporter $\mathrm{KCC} 2$ renders GABA hyperpolarizing during neuronal maturation [see comments]. Nature 397:251-255.

Rumpel S, Hatt H, Gottmann K (1998) Silent synapses in the developing rat visual cortex: evidence for postsynaptic expression of synaptic plasticity. J Neurosci 18:8863-8874.

Rutecki PA, Lebeda FJ, Johnston D (1987) 4-Aminopyridine produces epileptiform activity in hippocampus and enhances synaptic excitation and inhibition. $J$ Neurophysiol 57:1911-1924.

Schneiderman JH (1997) The role of long-term potentiation in persistent epileptiform burst- induced hyperexcitability following GABAA receptor blockade. Neuroscience 81:1111-1122.

Schneiderman JH, Sterling CA, Luo R (1994) Hippocampal plasticity following epileptiform bursting produced by GABAA antagonists. Neuroscience 59:259273. 
Schwartzkroin PA (1981) Development of rabbit hippocampus: physiology. Brain Res 254:469-486.

Schwartzkroin PA, Prince DA (1978) Cellular and field potential properties of epileptogenic hippocampal slices. Brain Res 147:117-130.

Serafini R, Valeyev AY, Barker JL, Poulter MO (1995) Depolarizing GABA-activated Cl- channels in embryonic rat spinal and olfactory bulb cells. J Physiol (Lond) 488:371-386.

Staley KJ, Mody I (1992) Shunting of excitatory input to dentate gyrus granule cells by a depolarizing GABAA receptor-mediated postsynaptic conductance. J Neurophysiol 68:197-212.

Strata F, Atzori M, Molnar M, Ugolini G, Tempia F, Cherubini E (1997) A pacemaker current in dye-coupled hilar interneurons contributes to the generation of giant GABAergic potentials in developing hippocampus. J Neurosci 17:1435-1446.

Su CK, Chai CY (1998) GABAergic inhibition of neonatal rat phrenic motoneurons. Neurosci Lett 248:191-194.

Swann JW, Brady RJ (1984) Penicillin-induced epileptogenesis in immature rat CA3 hippocampal pyramidal cells. Brain Res 314:243-254.

Swann JW, Brady RJ, Martin DL (1989) Postnatal development of GABA-mediated synaptic inhibition in rat hippocampus. Neuroscience 28:551-561.

Traub D, Miles R (1991) Neuronal networks of the hippocampus. Cambridge: Cambridge University Press.

Traub RD, Jefferys JG, Whittington MA (1994) Enhanced NMDA conductance can account for epileptiform activity induced by low $\mathrm{Mg}^{2+}$ in the rat hippocampal slice. J Physiol (Lond) 478 Pt 3:379-393.

Traub RD, Colling SB, Jefferys JG (1995) Cellular mechanisms of 4-aminopyridineinduced synchronized after- discharges in the rat hippocampal slice. J Physiol (Lond) 489:127-140.

Valenzuela V, Benardo LS (1995) An in vitro model of persistent epileptiform activity in neocortex. Epilepsy Res 21:195-204.

Warren RA, Jones EG (1997) Maturation of neuronal form and function in a mouse thalamo-cortical circuit. J Neurosci 17:277-295. 
Whittington MA, Traub RD, Jefferys JG (1995) Erosion of inhibition contributes to the progression of low magnesium bursts in rat hippocampal slices. J Physiol (Lond) 486:723-734.

Wong RK, Prince DA (1979) Dendritic mechanisms underlying penicillin-induced epileptiform activity. Science 204:1228-1231.

Wong RK, Traub RD (1983) Synchronized burst discharge in disinhibited hippocampal slice. I. Initiation in CA2-CA3 region. J Neurophysiol 49:442-458.

Wulfert E, Margineanu DG (1998) Thapsigargin inhibits bicuculline-induced epileptiform excitability in rat hippocampal slices. Neurosci Lett 243:141-143.

Xie X, Hider RC, Smart TG (1994) Modulation of GABA-mediated synaptic transmission by endogenous zinc in the immature rat hippocampus in vitro. $\mathrm{J}$ Physiol (Lond) 478:75-86.

Yuste R, Katz LC (1991) Control of postsynaptic $\mathrm{Ca}^{2+}$ influx in developing neocortex by excitatory and inhibitory neurotransmitters. Neuron 6:333-344.

Yuste R, Peinado A, Katz LC (1992) Neuronal domains in developing neocortex. Science 257:665-669.

Yuste R, Nelson DA, Rubin WW, Katz LC (1995) Neuronal domains in developing neocortex: mechanisms of coactivation. Neuron 14:7-17.

Zhang L, Spigelman I, Carlen PL (1990) Whole-cell patch study of GABAergic inhibition in CA1 neurons of immature rat hippocampal slices. Brain Res Dev Brain Res 56:127-130.

Zhang L, Spigelman I, Carlen PL (1991) Development of GABA-mediated, chloridedependent inhibition in CA1 pyramidal neurones of immature rat hippocampal slices. J Physiol (Lond) 444:25-49. 
CHAPTER 4: The Role of the Hyperpolarization-

Activated Cationic Current $I_{h}$ in the Timing of Interictal

Bursts in the Neonatal Hippocampus

This chapter was published in The Journal of Neuroscience, May 1, 2003, 23(9):36583668. 


\subsection{Abstract}

Under both pathological and experimental conditions, area CA3 of the adult or juvenile hippocampus generates periodic population discharges known as interictal bursts. While the ionic and synaptic basis of individual bursts has been comprehensively studied experimentally and computationally, the pacemaker mechanisms underlying interictal rhythmicity remain conjectural. We previously showed that rhythmic population discharges resembling interictal bursts can be induced in hippocampal slices from first postnatal week mice, in $\mathrm{Mg}^{2+}$-free solution with $\mathrm{GABA}_{\mathrm{A}}$ receptor-mediated inhibition blocked. Here we show that these neonatal bursts occurred with high temporal precision and that their frequency and regularity were greatly reduced by the bradycardic agent ZD-7288, when applied at concentrations and durations that selectively block the hyperpolarization-activated, cationic current $\mathrm{I}_{\mathrm{h}}$. Augmenting $\mathrm{I}_{\mathrm{h}}$ by elevating intracellular cAMP dramatically increased burst frequency in a protein kinase A-independent manner. Burst amplitudes were strongly correlated with the preceding, but not the following, interburst intervals. The experimentally observed distribution of interburst intervals was modeled by assuming that a burst was triggered whenever the instantaneous rate of spontaneous EPSPs (sEPSPs) exceeded a threshold, and that the mean sEPSP rate was minimal immediately after a burst and then relaxed exponentially to a steady-state level. The effect of blocking $\mathrm{I}_{\mathrm{h}}$ in any given slice could be modeled by decreasing only the steady-state sEPSP rate, suggesting that the instantaneous rate of sEPSPs is governed by the level of $\mathrm{I}_{\mathrm{h}}$ activation, and raising the novel possibility that interburst intervals reflected the slow activation kinetics of $\mathrm{I}_{\mathrm{h}}$ in the neonatal CA3. 


\subsection{Introduction}

Area CA3 of the adult and juvenile hippocampus is a well studied generator of synchronous neuronal discharges. Under various experimental conditions, both in vivo and in vitro, it generates paroxysmal population bursts that recur at regular intervals of (depending on preparation) 2-20 s (Ayala et al., 1973; Lebovitz, 1974; Schwartzkroin and Prince, 1978; Hablitz, 1984; Korn et al., 1987; Jensen and Yaari, 1988; Arvanov et al., 1995; Merlin et al., 1995; Avoli et al., 1996; de Curtis and Avanzini, 2001). These events resemble pathological "interictal spikes" observed in recordings from epileptic foci in human patients or from excised epileptic tissue from such patients (Cohen et al., 2002), and are therefore called interictal bursts (IBs). IBs can be recorded also in adjacent limbic regions, but in almost all cases are found to propagate to these other regions from their site of origin in CA3 (Bragdon et al., 1992; Stoop and Pralong, 2000). Whether IBs trigger ictal epileptic episodes or, conversely, suppress them, is debated (Bragdon et al., 1992; Barbarosie and Avoli, 1997; de Curtis and Avanzini, 2001); either way, IBs are closely linked with epileptogenesis, and understanding their mechanism of generation is crucial for understanding and treating epilepsy.

The intervals between IBs are highly regular: in vivo, the mean coefficient of variation of interburst intervals can be less than 0.1 (Lebovitz, 1979), a precision comparable with that of the normal human heartbeat (Van Hoogenhuyze et al., 1991). While the ionic and synaptic mechanisms generating individual epileptiform bursts in the hippocampus have been thoroughly studied and modeled (Traub and Miles, 1991), the pacemaker mechanisms underlying the precise timing of IBs remain conjectural. In a 
seminal study in-vivo, Lebovitz (Lebovitz, 1979) suggested that each IB generates a transient post-burst period of suppression during which the system is refractory to the generation of another burst. More recent in vitro studies propose that the refractory period is due to synaptic depression (Staley et al., 1998). An alternative to pacing by recovery from suppression is pacing by a slow build-up of excitation, which in the heart, and in a variety of other regularly bursting neuronal networks, is mediated by the hyperpolarization-activated excitatory current $\mathrm{I}_{\mathrm{h}}$ (Soltesz et al., 1991; Bal and McCormick, 1997; Luthi et al., 1998; Dickson et al., 2000; reviewed by Pape, 1996). However, although $I_{h}$ is expressed in the hippocampus by both pyramidal cells (Maccaferri et al., 1993) and inhibitory interneurons (Maccaferri and McBain, 1996; Strata et al., 1997), it has never been implicated in interictal rhythmogenesis.

We recently demonstrated (Wells et al., 2000) that when $\mathrm{GABA}_{\mathrm{A}}$ receptors $\left(\mathrm{GABA}_{\mathrm{A}} \mathrm{Rs}\right)$ are blocked in slices of neonatal mouse hippocampus bathed in $\mathrm{Mg}^{2+}$-free artificial CSF (ACSF), highly rhythmic population bursts occur as early as the day of birth. Here we show that the frequency of these neonatal interictal bursts (nIBs) is strongly modulated by pharmacological manipulations that are known to affect the level of $I_{h}$ activation, suggesting that $I_{h}$ plays a major role in the timing of nIBs.

\subsection{Methods}

Slice preparation and solutions: Five-hundred $\mu \mathrm{m}$ thick, horizontal brain slices including hippocampus were prepared from neonatal mice, postnatal days 1-6 (P1-P6, P0 being the first 24 hours after birth). Except for the plane of section, procedures were as previously described (Wells et al., 2000). Slices chosen for experiments (1-2 per animal, bisected along the midline to yield two hemislices each) were perpendicular to the long axis of the 
hippocampus or nearly so (Fig. 1). After dissection, slices were submerged in a holding chamber with recirculated, oxygenated ACSF at room temperature. For recording, slices were transferred to a submersion chamber and continuously superfused, using a push-pull configuration of peristaltic pumps, with $2.5-3 \mathrm{ml} / \mathrm{min}$ ACSF at room temperature, saturated with a $95 / 5$ mixture of $\mathrm{O}_{2} / \mathrm{CO}_{2}$. ACSF for dissection and for the holding chamber was composed of (in $\mathrm{mM}$ ) $\mathrm{NaCl} 126, \mathrm{KCl} 3, \mathrm{NaH}_{2} \mathrm{PO}_{4} 1.2, \mathrm{CaCl}_{2} 2.0, \mathrm{MgSO}_{4}$ 1.3, $\mathrm{NaHCO}_{3} 26$, and dextrose 20. In the recording chamber, slices were initially superfused with $\mathrm{Mg}^{2+}$-free ACSF, which was identical in composition except that equimolar $\mathrm{CaCl}_{2}$ was substituted for $\mathrm{MgSO}_{4}$, for a final $\mathrm{Ca}^{2+}$ concentration of $3.3 \mathrm{mM}$, to maintain the total divalent ion concentration. To induce paroxysmal discharges (nIBs, Fig. 2A), $5 \mu \mathrm{M}$ of the $\mathrm{GABA}_{\mathrm{A}} \mathrm{R}$ antagonist gabazine was then added to the bath. $\mathrm{Mg}^{2+}-$ free ACSF with $5 \mu \mathrm{M}$ gabazine will be referred to as "Control ACSF".

Drugs: SR-95531 (gabazine), 3-Isobutyl-1-methylxanthine (IBMX) and staurosporine were purchased from Sigma-RBI (St. Louis, MO). Forskolin, dideoxyforskolin, and ZD7288 were purchased from Tocris (Ballwin, MO). Drugs were prepared as stock solutions in water or DMSO, as required, at (typically) 1000-fold final concentration, divided into aliquots, and stored at $-20^{\circ} \mathrm{C}$. During experiments, thawed aliquots were diluted directly into control ACSF.

Electrophysiological recordings: Extracellular field potentials were recorded using thickwall glass micropipettes broken to a final outside diameter of $\sim 5 \mu \mathrm{m}$ under microscopic control, and filled with $0.9 \% \mathrm{NaCl}$. Differential DC signals (tissue $v s$ bath) were lowpass filtered at $1 \mathrm{kHz}$, amplified 1000X (Intronix Technologies, Bolton, Ontario, 
Canada), digitized at 1000 samples/sec and streamed to disk, using custom software written (by A.A.) in the LabView environment (National Instruments, Austin, TX).

Data analysis: Since the raw data were highly oversampled, data records were smoothed and decimated off-line by replacing successive blocks of datapoints with their average; the size of the averaged block (32 points) was chosen empirically to provide optimal noise reduction with minimum loss of signal amplitude, and was kept the same for all analyzed records. Effects of drugs were quantified as a ratio over control conditions, and are reported as geometric means \pm geometric SEMs, together with the number of slices (n) and the number of animals $(\mathrm{N})$ tested in each condition. To quantify drug effects on nIB frequency (Figs. 3-4), the number of nIBs in a $500 \mathrm{~s}$ window, starting at least $1000 \mathrm{~s}$ after drug arrival and spanning the period of maximal drug effect, was divided by the number of nIBs in a $500 \mathrm{~s}$ window immediately preceding drug arrival. To calculate nIB amplitudes and interburst intervals (IBIs), nIBs were logged, time-stamped and measured by custom software written in LabView (A.A.); each logged event was examined visually and confirmed by the user, who also checked the record to verify that no nIBs were missed by the program. The amplitude of an nIB was defined as its peak-to-peak voltage difference, and the IBI was defined as the interval between the negative peaks of two adjacent events. When bursts occurred in clusters (see Fig. 2A-C and the first paragraph of Results), each cluster was regarded as a single nIB with amplitude equal to that of the first event in the cluster (which was always the largest), and IBIs were measured from the negative peak of the last event in one cluster to the negative peak of the first event in the next cluster (Fig. 2C, arrows). Cumulative IBI histograms (CIHs) were calculated using 
MathCad (MathSoft, Cambridge, MA). All slices with nIBs in control ACSF of at least $200 \mu \mathrm{V}$ in amplitude and $20 \mathrm{mHz}(1 / 50 \mathrm{~s})$ in frequency were included in the analysis.

Statistics: Statistical significance (p-value) was computed numerically using exact permutation methods (Good, 1999); calculations were done in MathCad. Specifically, significance of drug-induced changes was computed using the binomial sign test; significance of differences between population means was computed from 10,000 random permutations of the data; and significance of linear correlations (Fig. 2E-F) was calculated from the Pitman statistic $\Sigma_{\mathrm{i}}\left(\mathrm{i} \cdot \mathrm{X}_{\mathrm{i}}\right)$ computed for 10,000 random permutations of the data. All reported p-values are single-tailed probabilities unless noted otherwise.

Computational modeling of nIBs: All modeling was done using MathCad software; the following description uses MathCad notation. The model assumed that, on average, $\mu$ spontaneous Poissonian events (e.g. sEPSPs) occur in any given time epoch (a single time epoch in the model represented $100 \mathrm{~ms}$ ). The probability that exactly $\mathbf{k}$ events will occur in any given time epoch is given by the Poisson distribution: $P(k, \mu):=\frac{\mu^{k}}{k !} \cdot e^{-\mu}$

The probability $\mathrm{C}(\mathrm{k}, \mu)$ that $\boldsymbol{k}$ or fewer events will occur is given by the cumulative Poisson distribution:

$C(k, \mu):=\sum_{n=0}^{k} P(n, \mu)$

Assume that the occurrence of $\mathbf{M}$ (or more) events within a single time epoch triggers a burst. The unconditional probability $B(\boldsymbol{M}, \boldsymbol{\mu})$ of burst occurrence at any given epoch is, therefore, 1 minus the probability that M-1 or fewer events will occur, or $B(M, \mu):=1-C(M-1, \mu)$ 
A normalized IBI histogram gives the probability of occurrence of an IBI of any given length. Once a burst has occurred, the probability that the next burst will occur after exactly $\mathrm{j}$ time epochs is the product of the $(\mathrm{j}-1)$ probabilities $(1-\mathrm{B}(\mathbf{M}, \mu))$ that a burst will not occur at any of the first $(\mathrm{j}-1)$ epochs, and the probability $\mathrm{B}(\mathrm{M}, \mu)$ that a burst will occur at the $j^{\text {th }}$ epoch:

$I B I \_$histogram $_{j}:=(1-B(M, \mu))^{j-1} \cdot B(M, \mu)$

(In the limit of infinitesimally short epochs, this simply gives the interevent interval histogram of Poissonian events, which is a decaying exponential.)

Now assume that $\mu$ itself is not stationary, but drops to 0 immediately after a burst and then relaxes exponentially to an asymptotic steady-state level $\mu_{\mathrm{ss}}$ :

$\mu_{j}:=\mu_{s s} \cdot(1-\exp (-j / \tau))$

where $\mathrm{j}$ is the index of the current time epoch (counting from the occurrence of the last burst), and $\tau$ is the time constant of relaxation expressed in time epochs. The expression for the normalized IBI histogram will now be:

$I B I \_$histogram $_{j}:=\left(\prod_{i=0}^{j-1}\left(1-B\left(M, \mu_{i}\right)\right)\right) \cdot B\left(M, \mu_{j}\right)$

From this vector, the mean IBI and the $\mathrm{CV}_{\mathrm{IBI}}$ are easily calculated:

$$
\begin{aligned}
& \text { Mean_IBI }:=\sum_{j} j \cdot I B I_{-} \text {histogram }_{j} \\
& S D_{-} I B I:=\sqrt{\sum_{j}\left(j-\text { Mean_IBI }^{2} \cdot I B I_{-} \text {histogram }_{j}\right.} \\
& C V_{-} I B I:=\frac{S D_{-} I B I}{\text { Mean_IBI }}
\end{aligned}
$$


Finally, the CIH is simply the time integral of the normalized IBI histogram:

$$
\mathrm{CIH}_{j}:=\sum_{i=0}^{j} I B I_{-} \text {histogram }_{i}
$$

To fit experimental CIHs with simulated curves (Fig. 7), this vector was calculated for $1<j<1000$ (equivalent to $100 \mathrm{~s}$ ) for different values of the 3 free parameters $\left(\mathbf{M}, \mu_{\mathrm{ss}}\right.$ and

$\tau$ ). In addition to computing CIHs (Fig. 7A), IBIs and $\mathrm{CV}_{\mathrm{IBI}} \mathrm{S}$ (Fig. 6E-F), the assumptions of the model were also used to simulate directly trains of nIBs (Fig. 6A-D), using the MathCad function rpois $(m, \lambda)$ which returns a vector of $m$ random numbers having a Poisson distribution with a mean $\lambda$.

\subsection{Results}

We monitored epileptiform population activity in area CA3 of neonatal mice, by recording extracellular field potentials from stratum radiatum in horizontal hippocampal brain slices (Fig. 1; asterisk denotes a typical recording location). As previously reported (Wells et al., 2000), superfusing the slice with $\mathrm{Mg}^{2+}$-free ACSF with $5 \mu \mathrm{M}$ of the $\mathrm{GABA}_{\mathrm{A}} \mathrm{R}$ antagonist gabazine ("Control ACSF") resulted in the appearance of largeamplitude, rhythmic population discharges (Fig. 2A) which will be referred to here as neonatal interictal bursts (nIBs). An initial exposure to $\mathrm{Mg}^{2+}$-free ACSF alone for 20-30 min, before addition of gabazine, seemed to be required to "prime" the burst mechanism, since slices superfused directly with control ACSF often failed to burst regularly. Individual nIBs consisted of a triphasic extracellular potential (Fig. 2B), with an early, large-amplitude negative "spike", about $0.5 \mathrm{~s}$ in duration, followed by a slower and smaller positive "wave", and ending with an even smaller negative undershoot. In many slices some of the nIBs occurred in doublets or triplets, or (rarely) in clusters of 4-5 
events (Fig. 2B illustrates a sequence of 2 doublets followed by 2 single bursts). Intracluster intervals (typically $<5 \mathrm{~s}$ ) were always much shorter than inter-cluster intervals, and formed a clearly separable peak in the IBI histogram (Fig. 2C). Unlike inter-cluster intervals, intra-cluster intervals were not affected by our experimental manipulations (data not shown) and were likely to be under the control of a separate mechanism. Intracluster intervals were therefore excluded from analysis, and each cluster was treated as a single, prolonged event for the sake of determining IBIs (in Fig. 2B, arrows demonstrate the definition of IBIs in this study; see also Methods).

\subsubsection{Neonatal IBs exhibit pacemaker-like regularity}

The bursting characteristics of each slice were quantified by calculating the mean IBI, the coefficient of variation of the IBIs ( $\mathrm{CV}_{\mathrm{IBI}}$, i.e. the $\mathrm{SD} /$ mean of the IBIs) and the cumulative IBI histogram ( $\mathrm{CIH}$; the normalized integral of the IBI histogram). The $\mathrm{CIH}$ of the slice illustrated in Fig. 2A is superimposed on the IBI histogram of the same slice in Fig. 2C. CIHs of all the slices in our sample recorded in control ACSF are shown superimposed in Fig. 2D. In control ACSF, nIBs occurred at highly regular intervals of 11-32 s, with the $\mathrm{CV}_{\mathrm{IBI}}$ averaging $0.20 \pm 0.02(\mathrm{n}=22, \mathrm{~N}=17)$. Moreover, as illustrated in Fig. 2D, the majority of our slices (73\%) had CIHs tightly clustered at the left end of the range, with IBIs for this group averaging $14.2 \pm 0.4 \mathrm{~s}(\mathrm{n}=16)$ and with a mean $\mathrm{CV}_{\text {IBI }}$ of $0.18 \pm 0.02$. The mean IBI did not change significantly with age over the developmental period of our study (Fig. 2E; $\mathrm{p}=0.30$, 2-tailed), but the $\mathrm{CV}_{\mathrm{IBI}}$ showed a small but significant increase (Fig. $2 \mathrm{~F}, \mathrm{p}<0.05,2$-tailed), indicating some loss of precision with maturation. Indeed, interictal activity in slices from juvenile animals was considerably less regular than in neonatal slices (Wells and Agmon, in preparation). 


\subsubsection{Blocking $I_{h}$ strongly reduced $n I B$ frequency and regularity}

The high regularity of nIBs prompted us to look for an underlying pacemaker mechanism. A hypothesis proposed over two decades ago (Lebovitz, 1979) suggests that each IB is followed by a post-burst refractory period during which generation of additional bursts is suppressed. This suppression was postulated to be caused by a slowly decaying inhibitory conductance activated by the burst itself, hence this mechanism was named "autorhythmicity". If indeed an inhibitory conductance activated by the burst was responsible for pacing nIBs, then blocking it should cause a pronounced acceleration of the rhythm. However, blocking any of the known inhibitory conductances had little or no effect on nIB frequency (Wells and Agmon, in preparation; see also Staley et al., 1998).

An alternative to a slowly decaying inhibition is a slow build-up of excitation, for example by a slow inward "pacemaker" current. If such a current is involved in the timing of nIBs, then blocking it should decrease nIB frequency. A current implicated in pacing the heart, as well as various neuronal oscillators in the CNS, is the hyperpolarization-activated cationic current $I_{h}$ (Pape, 1996). We therefore tested the effect of ZD-7288, which, until very recently (Chevaleyre and Castillo, 2002), was considered a highly selective blocker of $\mathrm{I}_{\mathrm{h}}$ (Harris and Constanti, 1995; Gasparini and DiFrancesco, 1997; Satoh and Yamada, 2000), on nIB frequency. In the experiment illustrated in Fig. 3A, $20 \mu \mathrm{M}$ ZD-7288 caused a 3-fold decrease in nIB frequency, with the mean IBI increasing from 12.0 to $35.9 \mathrm{~s}$. The time course of this effect of ZD-7288 is plotted in Fig. 3B, in which the instantaneous burst rate (1/previous IBI) and its running average are plotted against time after drug arrival in the recording chamber. As illustrated by the graph, the reduction in bursting rate developed over several minutes, 
and the maximal effect was reached within about $1000 \mathrm{~s}$ from the moment of drug arrival. In a total of 6 slices in which the time course of drug action was examined in detail, on average $\sim 1200$ s superfusion with $20 \mu \mathrm{M}$ ZD-7288 was required for maximal reduction in nIB frequency (range: 700-1650 s). The time to maximal effect of ZD-7288 on nIB frequency was consistent with the time to maximal block of $\mathrm{I}_{\mathrm{h}}$ by ZD-7288, reported to be 10-20 min in studies using 20-100 $\mu \mathrm{M}$ of the drug (Harris and Constanti, 1995; Maccaferri and McBain, 1996; Gasparini and DiFrancesco, 1997; Chevaleyre and Castillo, 2002).

The CIHs of the experiment in Fig. 3A, before and after exposure to ZD-7288, are shown in Fig. 3C. In addition to the pronounced reduction in the frequency of nIBs, evident from the rightward shift of the CIH, ZD-7288 also markedly reduced their temporal precision, as evident from the pronounced decrease in the slope of the CIH (Fig. 3C). In this slice, the $\mathrm{CV}_{\mathrm{IBI}}$ increased from 0.11 to 0.28 . In Fig. 3D, the $\mathrm{CV}_{\mathrm{IBI}}$ is plotted against mean IBI for all slices tested in 10-20 $\mu \mathrm{M}$ ZD-7288, with datapoints corresponding to the same slice before and after addition of drug connected by lines. The concomitant increase in both mean IBI and $\mathrm{CV}_{\mathrm{IBI}}$ is clearly evident from the general upward-and-rightward direction of the connecting lines. On average, application of ZD$7288(10-20 \mu \mathrm{M})$ decreased the rate of nIBs to about one half of the control frequency $\left(0.54 \pm 0.03, \mathrm{n}=22, \mathrm{~N}=17 ; \mathrm{p}<10^{-6}\right)$ and increased the $\mathrm{CV}_{\mathrm{IBI}}$ by $1.52 \pm 0.14$ fold over control $\operatorname{ACSF}(p<0.001)$.

$\mathrm{CsCl}(2 \mathrm{mM})$, another (though less specific) blocker of $\mathrm{I}_{\mathrm{h}}$ (Magee, 1998), reduced nIB frequency in neonatal slices to $0.45 \pm 0.10$ of control ( $n=N=3$; Fig. 3E). Unlike ZD7288, the effect of $\mathrm{Cs}^{+}$was readily reversed upon washout. Fig. 3F summarized the 
effects of 10-20 $\mu \mathrm{M}$ ZD-7288 (circles and triangles, respectively) and $\mathrm{Cs}^{+}$on $\mathrm{nIB}$ frequency in all slices tested.

While generally considered a highly selective blocker of $I_{h}$ in various systems (BoSmith et al., 1993; Briggs et al., 1994; Harris et al., 1994; Satoh and Yamada, 2000), ZD-7288 was very recently reported to depress synaptic transmission in the hippocampus through an unknown mechanism, apparently independent of its effect on $\mathrm{I}_{\mathrm{h}}$ (Chevaleyre and Castillo, 2002). The time course of synaptic depression was very slow, compared to the effect on $I_{h}$ examined in the same study, with no obvious depression occurring until at least $30 \mathrm{~min}$ of exposure to drug, and with maximal effect requiring at least $60 \mathrm{~min}$ of exposure to $50 \mu \mathrm{M}$ ZD-7288; lower concentrations of drug $(10 \mu \mathrm{M})$ caused only a slight depression after a similar exposure time. Thus, it seemed highly unlikely that these nonspecific effects of ZD-7288 could have contributed to the pronounced reduction in nIB frequency after $20 \mathrm{~min}$ of exposure to $20 \mu \mathrm{M}$ ZD-7288 in our experiments. Also, the pronounced increase in nIB amplitudes induced by ZD-7288 in our experiments seemed inconsistent with synaptic depression. Nevertheless, we tested for any synaptic depression under the conditions of our experiments by quantifying the effect of ZD-7288 on field EPSPs (fEPSPs) evoked in CA1 by stimulation of the CA3 to CA1 pathway, the same pathway tested by Chevaleyre and Castillo (2002). These control experiments were done on slices from P5-P29 mice, since in slices from younger animals the evoked fEPSP was too small and labile for reliable analysis. Seven slices in which the evoked fEPSP was stable (to $\pm 20 \%$ of control amplitude) for at least 30 min prior to drug application were selected for analysis. In these slices, the evoked response remained virtually unchanged after 60 min of superfusion with $20-25 \mu \mathrm{M}$ ZD-7288 (1.01 \pm 0.14 of control 
amplitude, $n=7, N=6$; data not shown). We conclude that the typical concentration of ZD-7288 used in our study did not cause any appreciable synaptic depression within the time course of the experiments. However, very high concentrations $(500 \mu \mathrm{M})$ of $\mathrm{ZD}$ 7288 caused drastic reduction in the frequency of nIBs (to $0.21 \pm 0.05$ of control, $n=5$, $\mathrm{N}=3$; $\mathrm{p}<0.05$; Fig. $3 \mathrm{~F}$, squares) and, in contrast to the lower concentrations, also strongly depressed nIB amplitudes (not shown), suggesting that high concentrations of ZD-7288 may indeed cause synaptic depression.

\subsubsection{Increasing intracellular cAMP strongly increased nIB frequency}

$\mathrm{I}_{\mathrm{h}}$ is strongly modulated by cyclic nucleotides, which bind directly to the cytoplasmic domain of the channel (Pape, 1996; Santoro and Tibbs, 1999; Wainger et al., 2001); we therefore tested whether modulating intracellular cAMP affected nIB frequency. In the experiment illustrated in Fig. 4A, the adenylyl cyclase activator forskolin $(25 \mu \mathrm{M})$ accelerated nIBs more than 3-fold while markedly reducing their amplitude; both effects were reversed by $20 \mu \mathrm{M}$ ZD-7288. Overall, forskolin (10-25 $\mu \mathrm{M})$ caused a $2.0 \pm 0.5$ fold increase in nIB frequency $(n=N=3)$. Forskolin $(5-25 \mu M)$ still increased nIB frequency in the presence of ZD-7288 $(15 \mu \mathrm{M})$, causing a 2.1-3 fold increase over the frequency in ZD-7288 alone ( $\mathrm{n}=\mathrm{N}=2$, not shown); this could have represented the effect of elevated intracellular cAMP concentration on residual $I_{h}$ channels, since $15 \mu \mathrm{M}$ ZD-7288 is expected to block only about $50 \%$ of the channels in hippocampal pyramidal neurons (Gasparini and DiFrancesco, 1997).

Since forskolin also adds to excitability by blocking $\mathrm{K}^{+}$channels, we tested the effects of the analog dideoxyforskolin (DDF), which also blocks $\mathrm{K}^{+}$channels but does 
not activate adenylyl cyclase (Hoshi et al., 1988). DDF $(5-25 \mu \mathrm{M})$ caused a modest $(1.23 \pm 0.11$-fold $)$ increase in nIB frequency compared to control ACSF; however replacing DDF by equimolar amounts of forskolin caused a further increase (compared to the frequency in DDF) of $1.47 \pm 0.09$-fold $(n=11, N=9 ; p<0.001)$, as summarized in Fig. 4E. We also tested the effect on nIB frequency of IBMX, a non-selective inhibitor of the enzymatic degradation of cAMP by phosphodiesterase (Fredholm et al., 1976). Application of $200 \mu \mathrm{M}$ IBMX caused, on average, a $1.87 \pm 0.25$ fold increase in nIB frequency $(n=6, N=3 ; p<0.02$; Fig. 4B). Since both forskolin and IBMX are expected to increase the intracellular concentration of cAMP, we conclude that intracellular cAMP has a strong positive modulatory effect on nIB frequency.

\subsubsection{Cyclic AMP effects on nIB frequency were PKA-independent}

Cyclic AMP could potentially modulate nIB frequency by mechanisms independent of $\mathrm{I}_{\mathrm{h}}$, for example by reducing the slow $\mathrm{I}_{\mathrm{AHP}}$ (Dunwiddie et al., 1992; Pedarzani and Storm, 1995a), by increasing synaptic efficacy (Chavez-Noriega and Stevens, 1992; Boulanger and Poo, 1999; Castro-Alamancos and Calcagnotto, 1999) or by opening gap junctions (Burghardt et al., 1995; Banoub et al., 1996; Paulson et al., 2000; van Rijen et al., 2000; Carystinos et al., 2001). All these effects, however, are thought to be mediated by protein kinase A (PKA), while the effect of cAMP on $\mathrm{I}_{\mathrm{h}}$ in CA1 and elsewhere is attributed to direct gating of the channel by cAMP (DiFrancesco and Tortora, 1991; Pedarzani and Storm, 1995b; Wainger et al., 2001). To test whether PKA-mediated effects could have contributed to the observed effect of forskolin, we superfused the slices with the broad spectrum protein kinase blocker staurosporine (100 $\mathrm{nM}$ ) for 30-60 min before addition of forskolin. Preincubation in staurosporine caused a 
variable reduction in $\mathrm{nIB}$ amplitude but no change in frequency (not shown; $\mathrm{n}=7, \mathrm{~N}=4$, $\mathrm{p}=0.47,2$-tailed). Preincubation in staurosporine did not affect the large increase in nIB frequency seen with 10-25 $\mu \mathrm{M}$ forskolin (Fig. 4C; nIB frequency increased by $2.1 \pm 0.2$ fold, $n=5, N=4 ; p<0.05$ ). In the presence of staurosporine, $25 \mu \mathrm{M}$ DDF caused a small, $1.13 \pm 0.10$-fold increase in nIB frequency, but replacing DDF by equimolar amounts of forskolin (Fig. 4D) caused a further increase in frequency (compared to DDF) of $1.50 \pm 0.03$-fold $(\mathrm{n}=5, \mathrm{~N}=4 ; \mathrm{p}<0.05)$, which was not significantly different from the effect of forskolin without staurosporine in the bath ( $\mathrm{p}=0.80,2$-tailed). The effects of DDF and forskolin in the presence of staurosporine are summarized in Fig. 4F. We conclude that the strong acceleration of nIBs by forskolin and IBMX was not dependent on PKA but was consistent with a direct action of cAMP on the $I_{h}$ channel. This does not exclude the possibility of PKA-mediated effects on $\mathrm{I}_{\mathrm{h}}$ (Mellor et al., 2002; Vargas and Lucero, 2002), since these indirect effects could have been occluded by the direct effects of cAMP.

(To verify that our batch of staurosporine was effective, we tested it on the cAMP-mediated presynaptic enhancement of the mossy fibers to CA3 pathway, which is PKA-dependent (Weisskopf et al., 1994; Lonart et al., 1998). In 2 slices from 2 P13 mice, a 20 min application of $25 \mu \mathrm{M}$ forskolin caused a 1.6-2.4 fold increase in the amplitude of the postsynaptic (but not the presynaptic) component of the field potential evoked in CA3 by a $50-80 \mu \mathrm{A}$ stimulus in the hilus of the dentate gyrus. In a second slice from each animal, preincubation with $100 \mathrm{nM}$ staurosporine for 30-45 min totally blocked this forskolin-induced potentiation (data not shown), providing evidence that our batch of staurosporine effectively blocked PKA.) 


\subsubsection{Burst amplitudes were strongly correlated with the preceding but not the following}

$I B I$

As is evident from Figs. 3-4, drugs that reduced the frequency of nIBs also increased their amplitude, while drugs that accelerated the bursts reduced their amplitude. The change in amplitude could have been a result of the change in frequency; conversely, the change in frequency could have been secondary to the change in amplitude. To determine whether the primary effect of ZD-7288 was on the frequency of nIBs or on their amplitudes, we examined the correlation between event amplitudes and both the preceding and the following IBIs. If the primary effect of the drug was to increase nIB amplitude, and the increased amplitude in turn slowed down the rhythm, one would expect that nIB amplitudes would be correlated with the following, but not with the preceding, IBIs. As evident from Fig. 5, the opposite was the case: nIB amplitudes were strongly dependent on the IBIs preceding the events (Fig. 5A,C) and not at all on the IBIs following them (Fig. 5B,D). In slices with IBIs not exceeding $30 \mathrm{~s}$, the relationship between the amplitudes of nIBs and the preceding IBIs was well described by linear regression (Fig. 5A); the mean coefficient of determination $\left(\mathrm{r}^{2}\right)$ of the linear regression line was $0.64 \pm 0.04$ in control, $0.78 \pm 0.03$ in $\mathrm{ZD}-7288(\mathrm{n}=25, \mathrm{~N}=20)$. When $\mathrm{nIB}$ amplitudes from the same slices were plotted against the following IBIs (Fig. 5B), no such correlation was observed $\left(\mathrm{r}^{2}=0.04 \pm 0.01\right.$ for both control and ZD-7288 conditions). In slices with IBIs longer than $30 \mathrm{~s}$, nIB amplitudes seemed to reach a ceiling at IBIs of 30-40 s, and the relationship between nIBs and preceding IBIs was better fit by a decaying exponential (Fig. 5C); again, no such relationship was observed with the following IBIs (Fig. 5D). This analysis strongly suggested that ZD-7288 directly affected 
the frequency of the nIBs, and that the change in amplitude was a secondary effect caused by the slowing of the rhythm, and not vice versa. In most slices (e.g. the two illustrated in Fig. 5A,C), data points from nIBs in control solution were distributed along or close to the same line fitted to data points collected in the presence of ZD-7288, suggesting that the drug affected only the timing of the events and did not disturb the relationship between timing and amplitude.

\subsubsection{A simple computational model simulated the effect of ZD-7288 on nIB frequency and regularity}

To gain insight into the mechanism by which $\mathrm{I}_{\mathrm{h}}$ modulates nIB rhythm, we constructed a network-level mathematical model of the pacemaker driving nIBs, which generated computed IBI distributions closely resembling experimental CIHs (see Methods for mathematical details of the model). Our model formally resembled a model recently described by Staley et al. (2001) but differed in some of its underlying assumptions, and in using Poissonian rather than binomial statistics. The model assumed that excitatory synapses in CA3 are spontaneously active at a rate that fluctuates with a Poissonian distribution around a mean instantaneous rate $\mu$ (Fatt and Katz, 1952; Rotshenker and Rahamimoff, 1970; Isaacson and Walmsley, 1995). It further assumed that $\mu$ falls to 0 immediately after an nIB and then recovers exponentially, with a time constant $\tau$, to a steady-state level $\mu_{\text {ss }}$ (Staley et al., 1998; Staley et al., 2001). Finally, it assumed that a burst is triggered whenever the actual instantaneous rate of sEPSPs in the network exceeds a threshold M (Prida and Sanchez-Andres, 1999). A Monte-Carlo implementation of the model (based on a random number generator) was used to generate simulated trains of nIBs (Fig. 6A-D), and a computational implementation was used to 
calculate mean IBIs, $\mathrm{CV}_{\mathrm{IBI}}$ and $\mathrm{CIHs}$ of modeled nIBs (Fig. 6E-F) and to fit them to experimental CIHs (Fig. 7A). It should be noted that the model made no assumptions about the underlying cellular constituents. For example, the parameter $\mu$ could be interpreted as the aggregate rate of sEPSPs in the network, or it could refer to the rate of sEPSPs in a subset of cells functioning as a pacemaker "kernel".

Although the model depended on 3 free parameters $\left(\mathrm{M}, \mu_{\mathrm{ss}}\right.$ and $\left.\tau\right)$, within a relatively wide range of values the simulated $\mathrm{CIHs}$ were sensitive mostly to the difference between $\mathbf{M}$ and $\mu_{\mathrm{ss}}$, not to their absolute values (see Fig. 6F); we therefore effectively reduced the number of free parameters to 2 by fixing $\mathbf{M}$ at the arbitrary value $\mathbf{M}=200$, and varied the other two parameters ( $\tau$ and $\mu_{\mathrm{ss}}$ ) independently. Varying these two parameters had very different effects on the behavior of the model. When $\tau$ was increased, the frequency of simulated nIBs was reduced, but little change in their regularity was evident (Fig. 6A,C), as corroborated by calculating the mean IBI and the $\mathrm{CV}_{\mathrm{IBI}}$ for a range of values of $\tau$; the computed $\mathrm{CV}_{\mathrm{IBI}}$ values slightly decreased as the computed mean IBIs increased (Fig. 6E). In contrast, decreasing $\mu_{\text {ss }}$ also reduced the frequency of simulated nIBs, but at the same time markedly reduced their regularity (Fig. 6B,D). When $\mathrm{CV}_{\mathrm{IBI}}$ values were plotted against corresponding IBIs computed for a range of values of $\mu_{\mathrm{ss}}$, it was evident that the $\mathrm{CV}_{\mathrm{IBI}}$ values increased in parallel with the mean IBI (Fig. 6F, squares). When, instead of decreasing $\mu_{\text {ss }}$ while keeping the threshold $\mathbf{M}$ constant, $\mathbf{M}$ was increased while keeping $\mu_{\mathrm{ss}}$ constant, the computed data points (Fig. $6 \mathrm{~F}$, circles) fell along the same line as the datapoints computed by varying $\mu_{\mathrm{ss}}$ while holding M constant. 
4.4.8 The effect of blocking $I_{h}$ was well modeled by a reduction in the steady-state rate of sEPSPs but not by an increase in its time constant of recovery

As evident from a comparison of Fig. 3D with Figs. 6E-F, a reduction in $\mu_{\mathrm{ss}}$ or an increase in $\mathbf{M}$, but not a change in $\tau$, could reproduce the experimental effect of blocking $\mathrm{I}_{\mathrm{h}}$, which was an increase in both the mean IBI and in the $\mathrm{CV}_{\mathrm{IBI}}$. The model would therefore be consistent with our data if blocking $\mathrm{I}_{\mathrm{h}}$ increased the difference $\mathbf{M}-\mu_{\mathrm{ss}}$, but not if it changed $\tau$. To test this directly, we fitted computed CIHs to experimentally determined ones, by keeping $\mathbf{M}=200$ and varying independently both $\mu_{\text {ss }}$ and $\tau$. Fig. 7A illustrates experimental CIHs from a P6 slice, recorded before and after addition of ZD7288. The superimposed solid lines were the best fit computed from our model. In control ACSF the best fit was achieved with the parameter values $\mu_{\mathrm{ss}}=184$ and $\tau=4.0 \mathrm{~s}$. In ZD-7288, the best fit was achieved with parameter values $\mu_{\mathrm{ss}}=167.5$ and $\tau=4.6 \mathrm{~s}$, which represents a doubling of the difference $\mathbf{M}-\mu_{\text {ss }}$ but only a $15 \%$ increase in the time constant $\tau$. Increasing $\tau$ alone (by 2.5 -fold), without changing in $\mu_{\mathrm{ss}}$, shifted the computed control $\mathrm{CIH}$ to the right but did not change its slope (dotted line), corresponding to an increase in the median IBI with little or no change in $\mathrm{CV}_{\mathrm{IBI}}$, as demonstrated in Fig. 6E. On average, ZD-7288 application had no effect on the best-fit value of $\tau$ (in control, $\tau=6.7 \pm 0.6 \mathrm{~s}, \mathrm{n}=19, \mathrm{~N}=15$; in ZD-7288, $\tau$ increased by $1.04 \pm 0.05$ fold and was not significantly greater than control, $\mathrm{p}=0.23$ ). In contrast, the best fit for the mean difference M- $\mu_{\mathrm{ss}}$ nearly tripled, from 10.7 \pm 3.0 in control to $28.8 \pm 2$ in ZD-7288 $\left(\mathrm{p}<10^{-6}\right)$.

In the example of Fig. $7 \mathrm{~A}$, a reduction in $\mu_{\mathrm{ss}}$ from 184 to $167.5 \mathrm{sEPSPs} / 100 \mathrm{~ms}$, which represents a fractional reduction by less than $9 \%$, caused more than 2.5 -fold increase in the mean IBI and more than 1.5 -fold increase in the $\mathrm{CV}_{\mathrm{IBI}}$. To understand why 
a relatively small change in the steady-state rate of synaptic activity could cause a dramatic decrease in both the frequency and the regularity of nIBs, it is instructive to examine how the probability for the occurrence of a burst $(B(M, \mu)$ in the model, see Methods) was influenced by the difference $\mathbf{M}-\mu_{\text {ss. }}$. The drug-induced decrease in $\mu_{\text {ss }}$ is illustrated in Fig. 7B, which plots $\mu$ (heavy solid line for control, heavy dashed-dotted line for ZD-7288) as a function of time elapsed from the previous burst, for the same values of the model parameters used to fit the experimental data in Fig. 7A. Although the reduction in $\mu_{\text {ss }}$ induced by ZD-7288 was modest, the maximal probability for a burst to occur decreased from $0.127 / 100 \mathrm{~ms}$ in control ACSF (Fig. 7B, light solid line) to only 0.0088/100 $\mathrm{ms}$ in the presence of ZD-7288 (light dash-dotted line) - a 14-fold decrease. The result of this large reduction in burst probability was that, by the time $20 \mathrm{~s}$ have elapsed from the previous burst, a burst had occurred with near-certainty $(99.9 \%$ probability) in control ACSF, but with only $20 \%$ probability in the presence of ZD-7288, as seen from the CIHs in Fig. 7A.

\subsection{Discussion}

Our results indicate that the frequency and the temporal precision of spontaneous interictal bursts in the neonatal CA3 are positively modulated by the hyperpolarizationactivated, cyclic-nucleotide sensitive cationic current $I_{h}$. This conclusion is based on the pronounced decrease in nIB frequency and regularity when $\mathrm{I}_{\mathrm{h}}$ was blocked either by $\mathrm{Cs}^{+}$ or by ZD-7288 (Fig. 3), a specific bradycardic agent whose only known effect, at the concentrations and exposure times we used, is to block $\mathrm{I}_{\mathrm{h}}$ (Harris and Constanti, 1995; Gasparini and DiFrancesco, 1997; Satoh and Yamada, 2000). This conclusion was further supported by the pronounced increase in nIB frequency induced by manipulations 
that are expected to elevate intracellular cAMP levels (Fig. 4). The cAMP-mediated effect was not affected by blocking PKA with staurosporine, consistent with a direct action of cAMP on the $I_{h}$ channel (Pedarzani and Storm, 1995b; Wainger et al., 2001). To our knowledge, this is the first report implicating $\mathrm{I}_{\mathrm{h}}$ in the timing of interictal epileptiform bursts. The strong acceleration of interictal epileptiform bursts by cAMP is also demonstrated here, to our knowledge, for the first time (but see Boulton et al., 1993, for modest effects in adult rats), and may need to be considered when prescribing to epilepsy-prone patients drugs which may potentially affect cAMP levels.

\subsubsection{Blocking $I_{h}$ can be modeled either by an increase in the burst threshold or by a} decrease in the rate of spontaneous synaptic release

How does $I_{h}$ modulate burst frequency? To gain insight into this question, we developed a simple computational model based on the assumption that a burst is triggered whenever the instantaneous rate of spontaneous EPSPs exceeds a threshold M; a similar mechanism appears to determine the timing of "giant depolarizing potentials", another form of oscillatory activity in the neonatal hippocampus (Prida and Sanchez-Andres, 1999). The rate of sEPSPs, in turn, was assumed to be a Poissonian variable, with a mean $\mu$ that dropped to zero immediately after a burst and then recovered to an asymptotic steady-state value $\mu_{\mathrm{ss}}$ with a time constant $\tau$. (A formally similar model described by Staley et al. (2001) uses binomial, rather than Poissonian statistics, and is based on somewhat different assumptions.) Once an appropriate set of parameters ( $\mathbf{M}, \mu_{\mathrm{ss}}$ and $\tau$ ) was found to generate a cumulative IBI histogram that fit the experimental record from a given slice, the effect of blocking $I_{h}$ in the same slice could be satisfactorily reproduced by increasing the difference $\mathbf{M}-\mu_{\mathrm{ss}}$, either by increasing the threshold $\mathbf{M}$ or by 
decreasing the steady-state sEPSP rate $\mu_{\text {ss }}$, but not by increasing the time constant $\tau$. This allows two different interpretations for the role of $\mathrm{I}_{\mathrm{h}}$ in the timing of nIBs:

First, $I_{h}$ could be increasing neuronal excitability in general, for example by contributing to a more depolarized resting potential, as has been demonstrated in the hippocampus and elsewhere (Akasu et al., 1993; Li et al., 1993; Maccaferri et al., 1993; Travagli and Gillis, 1994; Maccaferri and McBain, 1996; Seutin et al., 2001). According to this interpretation, $\mathrm{I}_{\mathrm{h}}$ would be contributing to a reduced threshold $\mathbf{M}$ but would have no effect on $\mu$. The post-burst depression and recovery of $\mu$ would then need to be explained by other mechanisms, e.g. by depletion of synaptic vesicles (caused by high frequency firing during the burst) followed by their gradual replenishment (Zucker and Regehr, 2002). The major determinant of the time constant $\tau$, according to this hypothesis, would be the time course of synaptic vesicle replenishment, and $\mathrm{I}_{\mathrm{h}}$ would only be modulating the rhythm, not pacing it. While recovery from synaptic depression has been successfully used to model rhythmic bursting in a variety of systems (Staley et al., 1998; Tabak et al., 2000; Tsodyks et al., 2000; Staley et al., 2001), the role of synaptic vesicle replenishment in pacing interictal bursts is yet to be tested directly by pharmacological or genetic manipulations that accelerate it or slow it down.

An alternative interpretation for the role of $\mathrm{I}_{\mathrm{h}}$ in timing nIBs, also consistent with the model, is that instead of decreasing the threshold $\mathrm{M}, \mathrm{I}_{\mathrm{h}}$ increases $\mu_{\mathrm{ss}}$, the steady-state rate of sEPSPs, e.g. by directly depolarizing presynaptic terminals (Beaumont and Zucker, 2000; Southan et al., 2000; Mellor et al., 2002). Depolarization of presynaptic terminals will increase calcium influx through voltage-gated calcium channels, enhancing the probability of spontaneous neurotransmitter release (Alger et al., 1996; Frerking et al., 
2001; Turecek and Trussell, 2001). This interpretation is consistent with the forskolininduced increase in miniature GABAergic currents described in immature CA3 neurons (Sciancalepore and Cherubini, 1995), and is attractive because it also explains the postburst modulation in $\mu$ : if $\mu$ is governed by $\mathrm{I}_{\mathrm{h}}$, its time course between bursts should reflect the time course of $\mathrm{I}_{\mathrm{h}}$, which is expected to be inactivated immediately after the burst (due to the strong depolarization during the burst) and then to re-activate slowly (by the postburst hyperpolarization) to a steady-state level. The time constant of recovery $\tau$ would therefore be determined by the activation kinetics of $\mathrm{I}_{\mathrm{h}}$, and $\mathrm{I}_{\mathrm{h}}$ would actually function as the pacemaker for nIBs. This interpretation is consistent with our finding that the effect of ZD-7288 could be simulated by reducing $\mu_{\mathrm{ss}}$ and not by increasing $\tau$, since ZD-7288 strongly reduces the steady-state amplitude of the $I_{h}$ current with little or no change in its activation kinetics (Harris and Constanti, 1995; Satoh and Yamada, 2000).

\subsection{2 $I_{h}$ channels with the appropriate properties are expressed in the neonatal CA3}

A major constraint on the alternative interpretation above is that $I_{h}$ needs to be activated with a time constant comparable to $\tau$, which in our data averaged about $7 \mathrm{sec}$. A very recent study of $I_{h}$ in the developing mouse hippocampus (Vasilyev and Barish, 2002) indicates that activation kinetics of $\mathrm{I}_{\mathrm{h}}$ in neonatal (P1-P5) CA3 pyramidal neurons are indeed dominated by a slow component with a time constant of 5-10 s at physiological hyperpolarized potentials. Of the four known subunits from which $I_{h}$ channels may be assembled, pyramidal cells in the neonatal CA3 express HCN1 and HCN2 mRNA (Bender et al., 2001) and protein (Vasilyev and Barish, 2002). In heterologous expression systems, $I_{h}$ channels consisting solely of the HCN2 subunit exhibit much slower kinetics and considerably higher cAMP sensitivity compared to 
HCN1-only or to mixed HCN1/HCN2 channels (Santoro et al., 2000; Chen et al., 2001; Wainger et al., 2001); it is therefore tempting to speculate that the HCN2 subunit is the major contributor to $I_{h}$ channels in the neonatal CA3. Regardless of molecular composition, however, $\mathrm{I}_{\mathrm{h}}$ channels in the neonatal CA3 exhibit activation kinetics consistent with our model and with a possible role in pacing interictal bursts.

\subsubsection{Burst amplitudes reflect recovery from synaptic depression}

As shown in Fig. 5, the amplitude of nIBs was correlated with the preceding, but not with the following, IBI; a similar relationship was previously demonstrated in the mature CA3 (Staley et al., 1998), in the embryonic spinal cord (Streit, 1993; Tabak et al., 2001), in the retina (Grzywacz and Sernagor, 2000) and in networks of dissociated cortical neurons (Opitz et al., 2002), suggesting that this relationship is a common feature of rhythmically bursting synaptic networks (O'Donovan, 1999). Burst intensity (which can be reflected in burst amplitude and/or in burst duration) is thought to be determined by the total number of readily releasable synaptic vesicles at the moment of burst initiation (Staley et al., 1998); this number presumably declines to near zero immediately after the burst, since virtually all synapses are activated during a paroxysmal event, and then gradually increases as vesicles are replenished from the reserve pool (Zucker and Regehr, 2002). In our experiments, burst amplitudes did not recover fully until 30-40 s following the previous burst (Fig. 5C), suggesting that the time constant of vesicle replenishment was considerably longer than the time constant $\tau$, calculated to be $\sim 7 \mathrm{~s}$ from our experimental data. This lends further support to the alternative interpretation above, that the activation of $\mathrm{I}_{\mathrm{h}}$, and not recovery from synaptic depression, was the process pacing $\mathrm{nIBs}$ in the neonatal CA3. 


\subsubsection{The mechanisms of pacing by $I_{h}$ are system-specific}

Whether $\mathrm{I}_{\mathrm{h}}$ acts as a bona-fide "pacemaker" of interictal activity in the neonatal hippocampus, or merely modulates the rhythm by affecting overall excitability, remains to be determined. Indeed, the common characterization of $\mathrm{I}_{\mathrm{h}}$ as a "pacemaker current" (Pape, 1996) may obscure its very different modes of action in different systems, which may oscillate at frequencies orders of magnitude apart. For example, $I_{h}$ accelerates both the heartbeat (DiFrancesco and Ojeda, 1980) and the much faster oscillations in thalamocortical relay neurons (McCormick and Pape, 1990; Soltesz et al., 1991); it also accelerates nIBs in CA3, which are an order of magnitude (at least) slower than the heartbeat. In contrast, $\mathrm{I}_{\mathrm{h}}$ actually slows down spindles in the thalamus, which oscillate at roughly the same frequency as nIBs (Luthi et al., 1998). The recent cloning of HCN channels (Ludwig et al., 1998; Monteggia et al., 2000) will no doubt be followed by the generation of knockout mice in which the precise role of $I_{h}$ in pacing oscillations in different systems could be tested directly. 


\subsection{Figures}

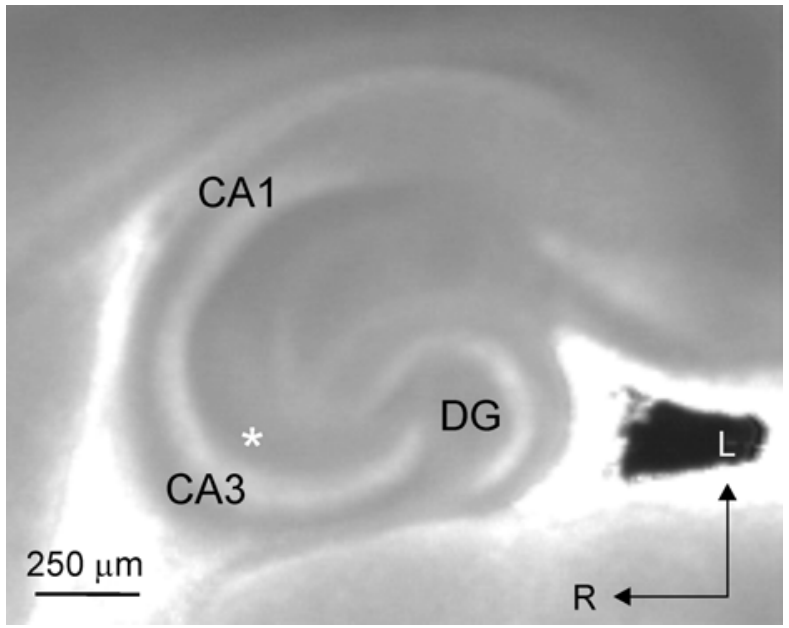

FIGURE 4-1. A HORIZONTAL HIPPOCAMPAL SLICE FROM A P4 MOUSE AS VISUALIZED DURING THE EXPERIMENT.

CA1, CA3 and dentate gyrus $(D G)$ are indicated; typical recording position in CA3 stratum radiatum is indicated by the asterisk. Arrows denote lateral $(L)$ and rostral $(R)$ directions. 
A

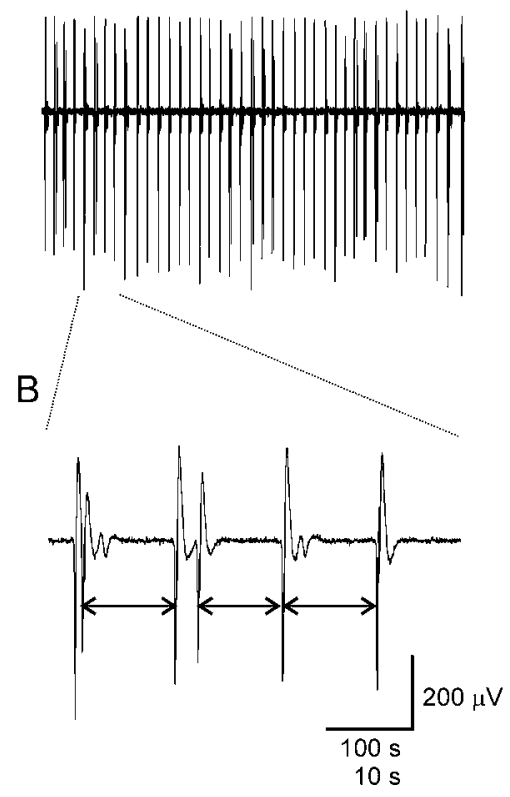

C

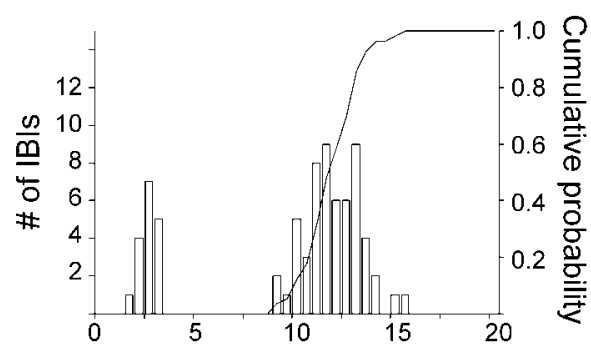

D

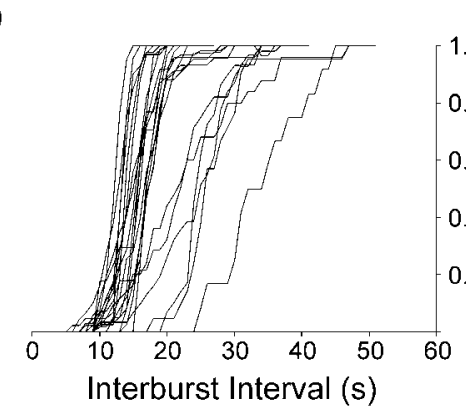

E

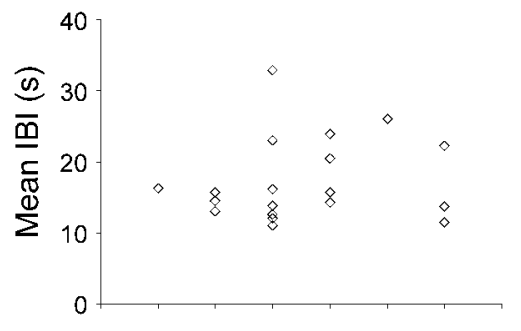

$\mathrm{F}$

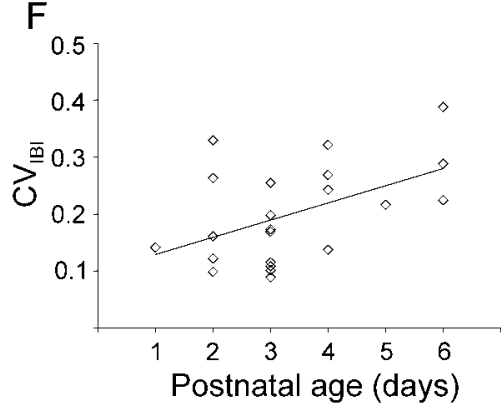

Figure 4-2. NeONATAl interictal BURSts (NIBs) In AREA CA3 ARE Highly REgular. A, a 500 s long extracellular record from a P3 slice bathed in control ACSF $\left(\mathrm{Mg}^{2+}\right.$-free, with $5 \mu \mathrm{M}$ gabazine), illustrating the high regularity of nIBs. B, a segment expanded from the record in A, illustrating that inter-cluster intervals (two-sided arrows) but not intra-cluster intervals were included in the analysis in this study. $\mathbf{C}$, the interburst interval (IBI) histogram for the experiment of panel A shows two well-separated peaks; the peak below $5 \mathrm{~s}$ consists of intra-cluster intervals, which were excluded in the calculation of the cumulative IBI histogram $(\mathrm{CIH}$; solid line $)$. The coefficient of variation of IBIs $\left(\mathrm{CV}_{\mathrm{IBI}}\right)$ for this experiment was 0.12. D, superimposed CIHs from all 22 slices recorded in control ACSF. Note the tight clustering and steep slope of 16 CIHs on the left side of the plot, illustrating the pacemaker-like character of nIBs. $\mathbf{E}$, the mean IBI of all slices showed no change with postnatal age. F, in contrast, the $\mathrm{CV}_{\mathrm{IBI}}$ increased significantly between P1 and P6 (note regression line). 

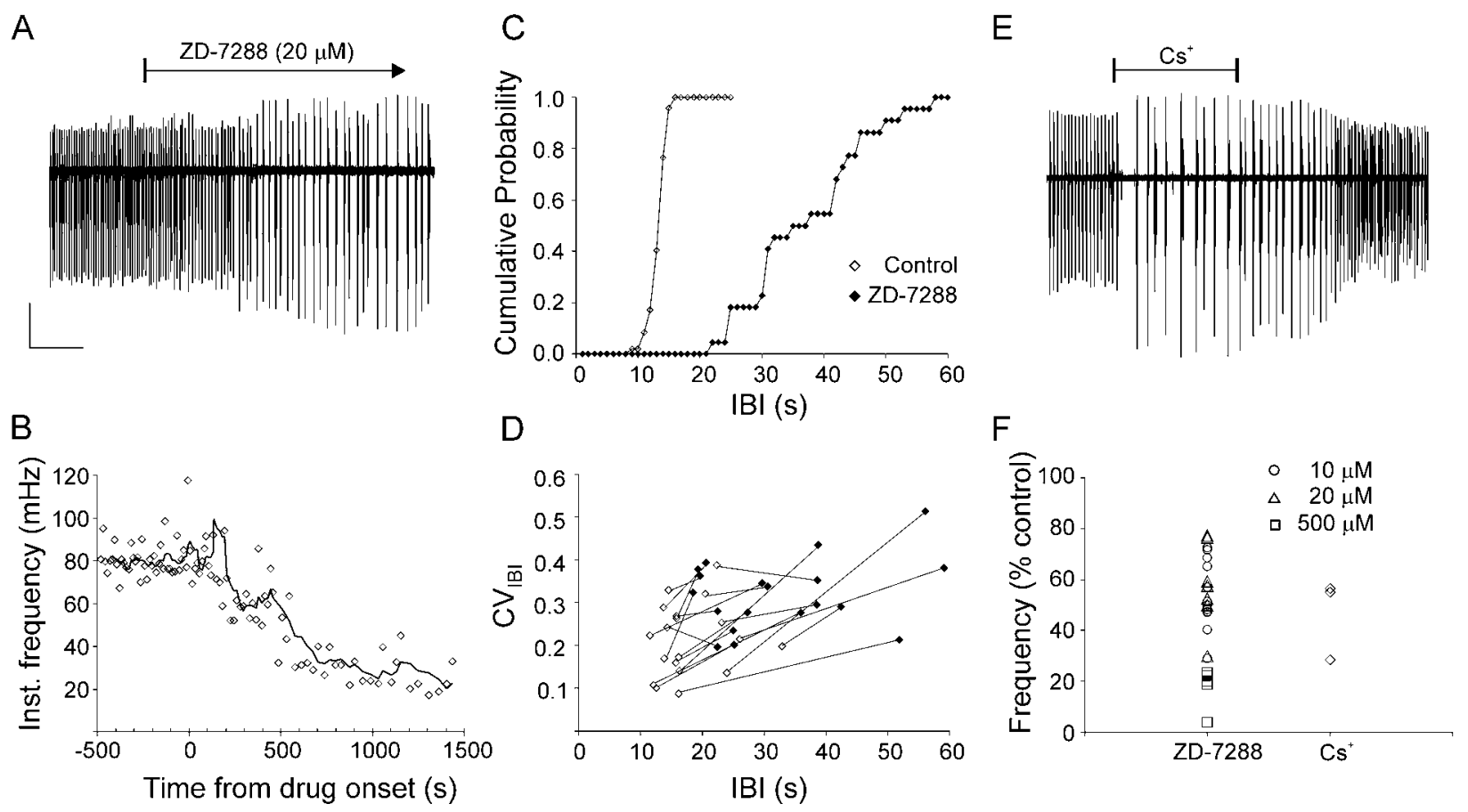

FIGURE 4-3. BLOCKING I I STRONGLY REDUCED IIB FREQUENCY AND REGULARITY.

A, blocking $\mathrm{I}_{\mathrm{h}}$ with the specific blocker ZD-7288 caused over 3-fold reduction in nIB frequency, coupled to a pronounced increase in nIB amplitudes. B, the time course of decrease in nIB frequency for the experiment shown in panel A, plotted at the same time scale. Data points represent instantaneous frequency (1/previous IBI); solid line is a running average, calculated using a sliding window of 5 datapoints. Time 0 designates drug arrival in the recording chamber. $\mathbf{C}$, the rightward shift and decreased slope of the $\mathrm{CIH}$ for the experiment of panel A illustrates the drug-induced increase in the IBI and the $\mathrm{CV}_{\text {IBI }}$, respectively. CIHs were calculated using $1 \mathrm{~s}$ bins. $\mathrm{D}, \mathrm{CV}_{\mathrm{IBI}}$ plotted against mean IBI, with datapoints from the same slice before (empty symbols) and after (filled symbols) adding ZD-7288 connected by lines. Note that in the great majority of cases, the ZD7288-induced increase in the mean IBI was coupled to a pronounced increase in the 
$\mathrm{CV}_{\mathrm{IBI}}$. E, a reduction in nIB frequency of a similar magnitude to that induced by ZD7288 was caused by the less specific (but reversible) $\mathrm{I}_{\mathrm{h}}$ blocker $\mathrm{Cs}^{+}(2 \mathrm{mM})$. F, summary of the percent reduction in nIB frequency due to ZD-7288 (see legend for concentrations) and $\mathrm{Cs}^{+}(2 \mathrm{mM})$ in all experiments. A and $\mathrm{E}$ are from different $\mathrm{P} 3$ animals. Scale bar is $100 \mu \mathrm{V}, 300 \mathrm{~s}(\mathrm{~A})$ and $150 \mu \mathrm{V}, 250 \mathrm{~s}(\mathrm{E})$. 

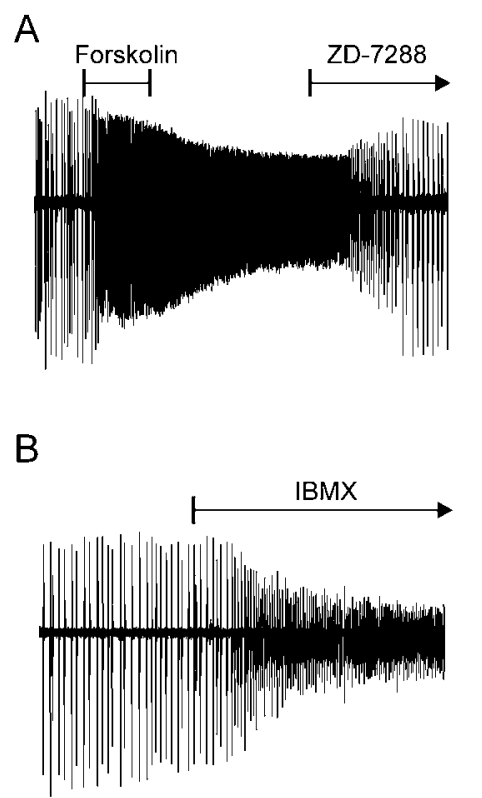

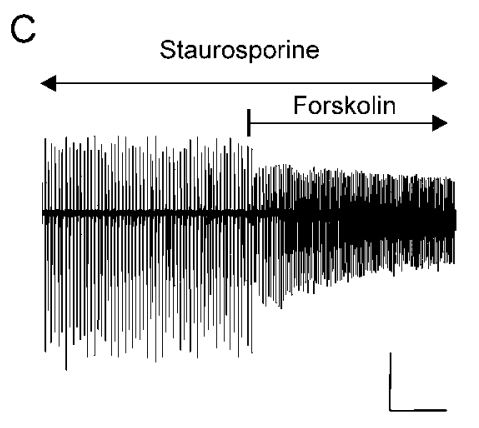

D

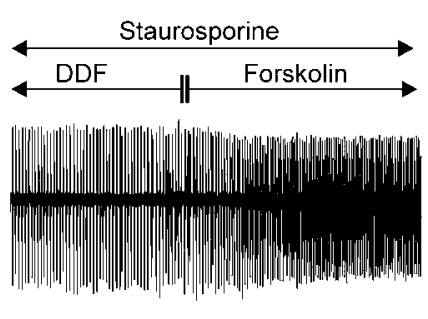

E

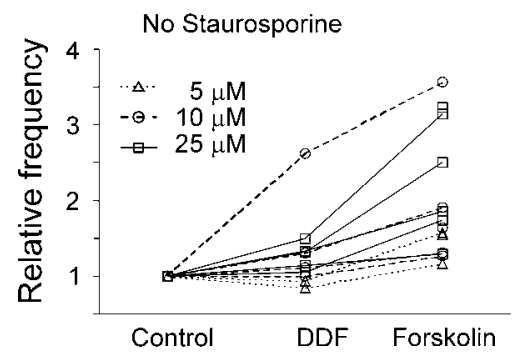

$\mathrm{F}$

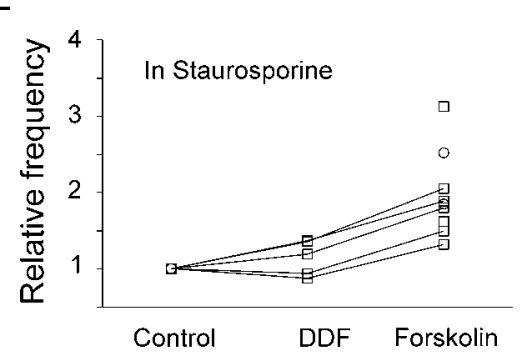

FIGURE 4-4. INCREASING INTRACELLULAR CAMP STRONGLY ACCELERATED NIB FREQUENCY IN A PKA-INDEPENDENT MANNER.

A, the adenylyl-cyclase activator forskolin $(25 \mu \mathrm{M})$ caused a 3-fold increase in nIB frequency, and a concomitant decrease in amplitudes, within minutes after application; the $\mathrm{I}_{\mathrm{h}}$ blocker ZD-7288 $(20 \mu \mathrm{M})$ reversed this increase, and further reduced the nIB frequency to $60 \%$ of its control value before forskolin application (P1 slice). B, application of the phosphodiesterase inhibitor IBMX $(200 \mu \mathrm{M})$ caused a 2.5-fold increase in $\mathrm{nIB}$ frequency and a concomitant reduction in amplitudes (P3 slice). C, preincubation for over $1 \mathrm{hr}$ with the broad spectrum protein kinase inhibitor staurosporine $(100 \mathrm{nM})$ did not prevent forskolin $(20 \mu \mathrm{M})$ from accelerating nIBs by 1.7 fold (P3 slice). D, in the presence of staurosporine, forskolin $(25 \mu \mathrm{M})$ still caused a 1.5-fold increase in nIB frequency over the frequency in equimolar concentration of the analog dideoxyforskolin (DDF), which does not activate adenylyl cyclase (P5 slice). E, summary plot of all slices tested in DDF and forskolin without staurosporine; datapoints not connected by lines are 
from slices tested only in forskolin. Symbols and lines are coded by drug concentration (legend). F, summary plot as in E but for slices tested in the presence of $100 \mathrm{nM}$ staurosporine. Scale bar is $100 \mu \mathrm{V}, 500 \mathrm{~s}$ (A); $200 \mu \mathrm{V}, 400 \mathrm{~s}$ (B); $200 \mu \mathrm{V}, 250 \mathrm{~s}$ (C); $100 \mu \mathrm{V}, 250 \mathrm{~s}(\mathrm{D})$. 


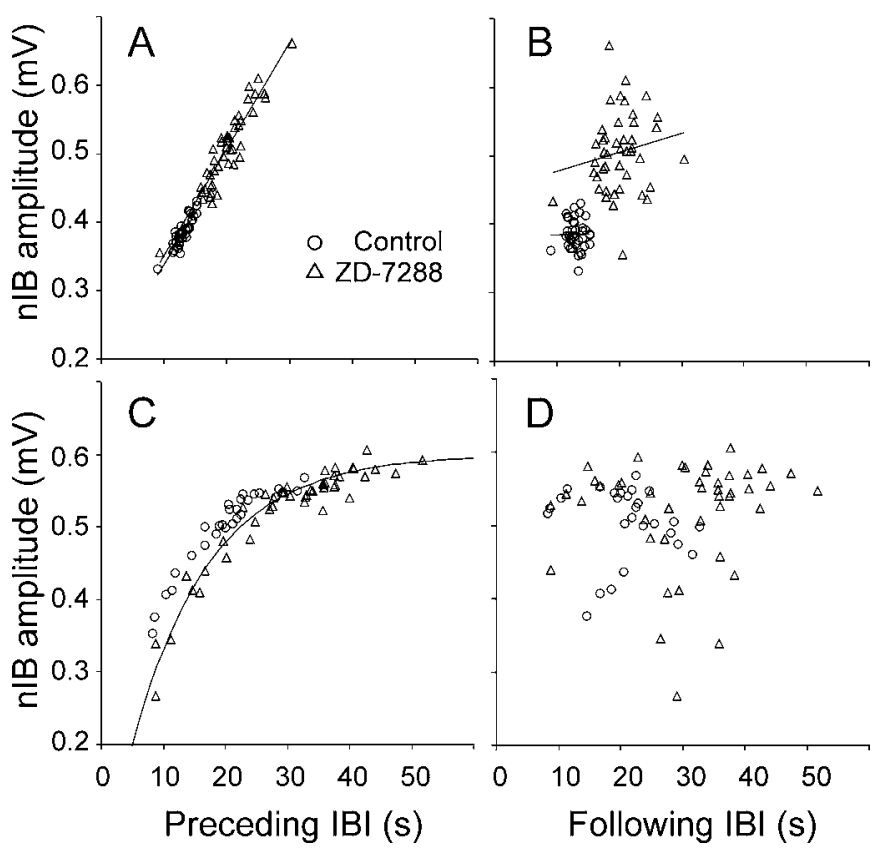

FIGURE 4-5. AMPLITUDES OF NIBS WERE STRONGLY CORRELATED WITH THE PRECEDING BUT NOT THE FOLLOWING INTERBURST INTERVALS.

Illustrated data were recorded before (circles) and after (triangles) adding ZD7288 to a P2 slice $(\mathrm{A}, \mathrm{B})$ and a $\mathrm{P} 4$ slice $(\mathrm{C}, \mathrm{D})$. In A and $\mathrm{B}$, datapoints in control and in ZD-7288 were fitted separately with linear regression lines, illustrating a strong correlation in $\mathrm{A}\left(\mathrm{r}^{2}=0.80\right.$ and $\mathrm{r}^{2}=0.87$, respectively $)$ but lack of correlation in $\mathrm{B}\left(\mathrm{r}^{2}=5 \cdot 10^{-5}\right.$ and $\mathrm{r}^{2}=0.03$, respectively). Note that the two regression lines in A nearly coincide. In C, datapoints in ZD-7288 were fitted by a decaying exponential with an asymptote of 0.6 $\mathrm{mV}$ and a time constant of $12.5 \mathrm{~s}$; note that datapoints in control ACSF fall along nearly the same curve 
A

B
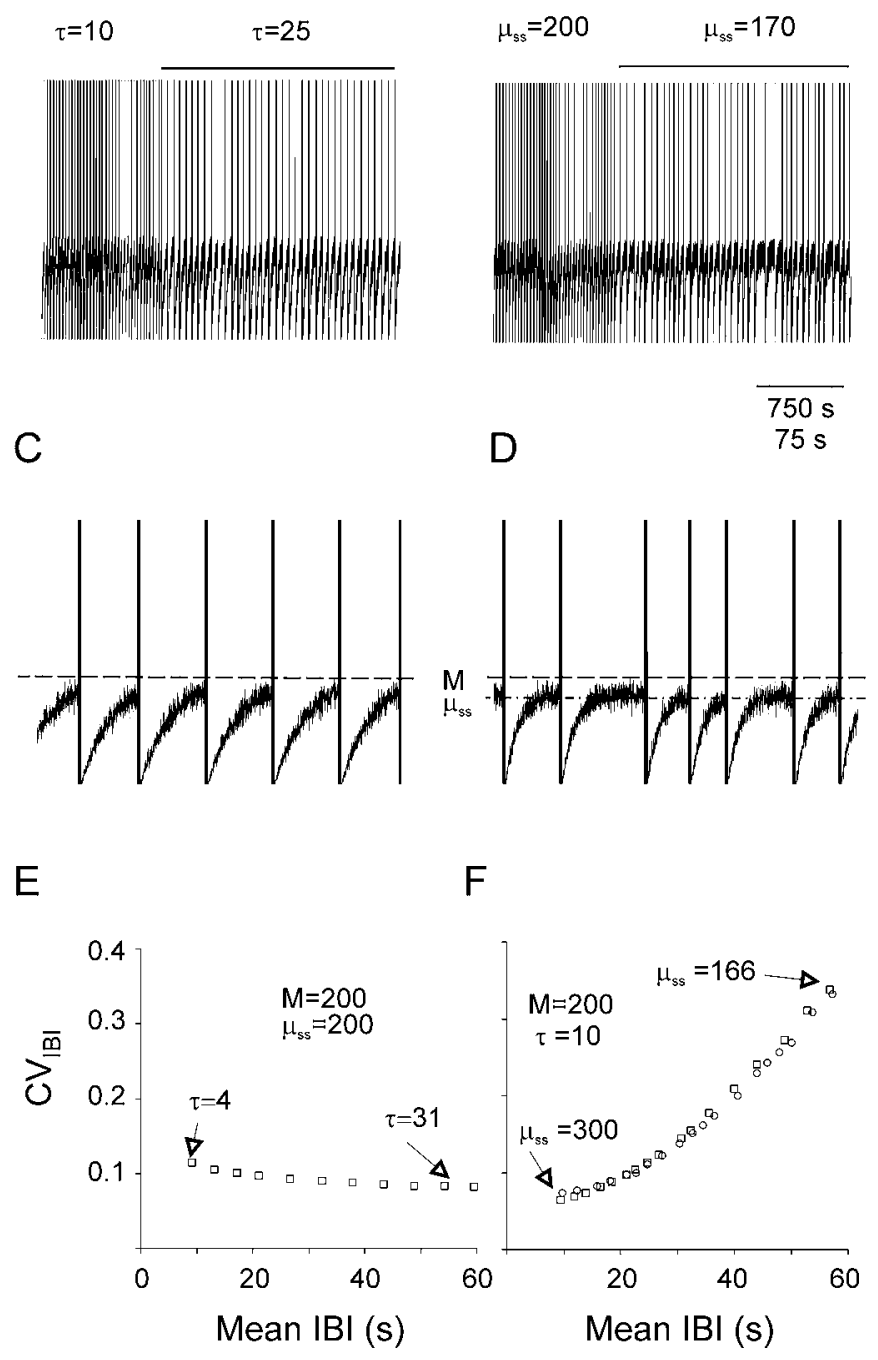

FiguRE 4-6. A 3-PARAMETER COMPUTATIONAL MODEL SIMULATED THE EFFECT OF ZD7288 ON NIB FREQUENCY AND REGULARITY.

A-D, simulated sequences of nIBs are plotted at a slow (A,B) and a 10-fold faster $(\mathrm{C}, \mathrm{D})$ time base. Simulated nIBs were generated by assuming that the mean instantaneous sEPSP rate $(\mu)$ is reset to 0 after each burst and then relaxes exponentially to an asymptote $\left(\mu_{\mathrm{ss}}\right)$ with a time constant $\tau$. Fluctuations around $\mu$ were generated by a Poissonian random-number generator; each time a fluctuation crossed the threshold $\mathbf{M}$ (dashed line in $\mathrm{C}, \mathrm{D}$ ), a burst was assumed to be triggered. In $\mathrm{A}, \mathrm{B}$, the initial part of the 
trace was computed using the values $\mathbf{M}=\mu_{\mathbf{s s}}=200$ and $\tau=10 \mathrm{~s}$; during the time indicated by the horizontal lines above the trace, either $\tau(\mathrm{A}, \mathrm{C})$ or $\mu_{\mathrm{ss}}(\mathrm{B}, \mathrm{D})$ were changed to the values indicated ( $\mu_{\mathrm{ss}}$ is also indicated by the dashed-dotted line in D). The traces represent the value of $\mu$, except that the occurrence of a burst is indicated by a vertical line of arbitrary height. Note that increasing $\tau(\mathrm{A}, \mathrm{C})$ reduced the frequency of bursts without affecting their regularity, while reducing $\mu_{\mathrm{ss}}(\mathrm{B}, \mathrm{D})$ affected both the frequency and the regularity of the bursts. $\mathbf{E}$, the simulated $\mathrm{CV}_{\mathrm{IBI}} v s$ the simulated mean IBI, computed using the indicated values of $\mathbf{M}$ and $\mu_{\text {ss }}$ while varying the value of $\tau$ as indicated. Note that changing $\tau$ had very little effect on the $\mathrm{CV}_{\mathrm{IBI}} . \mathbf{F}$, the simulated $\mathrm{CV}_{\mathrm{IBI}}$ $v s$ the simulated mean IBI, computed using the indicated values of $\mathbf{M}$ and $\tau$ while varying $\mu_{\mathrm{ss}}$ as indicated (squares). Note that changing $\mu_{\mathrm{ss}}$ affected in parallel both the mean IBI and the $\mathrm{CV}_{\mathrm{IBI}}$. Changing $\mathbf{M}$ from 140 to 238 while keeping $\mu_{\mathrm{ss}}=200$ generated datapoints (circles) that fell along the same curve generated by changing $\mu_{\mathrm{ss}}$ while keeping $\mathbf{M}$ constant. 

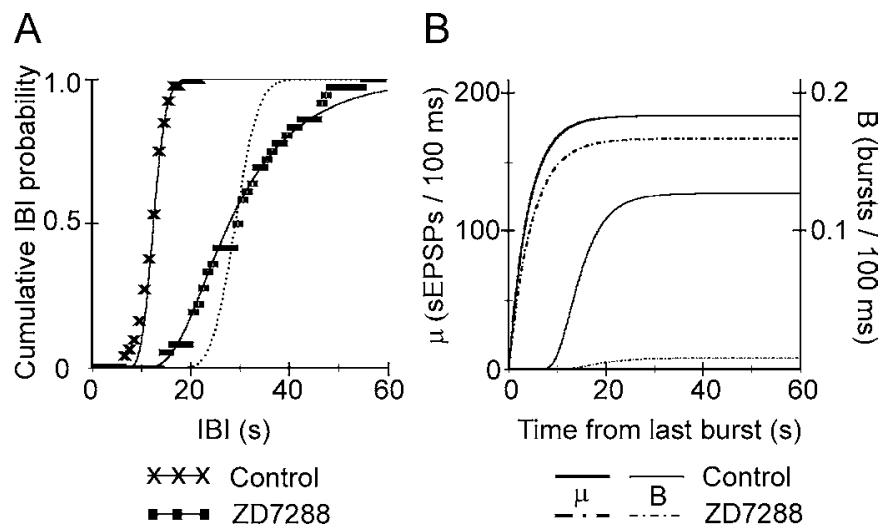

FigurE 4-7. A CHANGE IN $\mu_{\mathrm{SS}}$, BUT NOT IN $\tau$, CAN ACCOUNT FOR THE EFFECT OF ZD-7288 ON NIB FREQUENCY AND REGULARITY.

A, CIHs of experimental nIBs from a P6 slice in control ACSF $(X s)$ was fitted by a curve (solid line) computed with the parameter values $\mu_{\mathrm{ss}}=184, \tau=4 \mathrm{~s}$. The effect of 20 $\mu \mathrm{M}$ ZD-7288 (squares) was well fitted (solid line) by reducing $\mu_{\mathrm{ss}}$ to 167.5 , with only a minor increase in $\tau$ (to $4.6 \mathrm{~s}$ ). With $\mu_{\mathrm{ss}}$ unchanged, a 2.5 -fold increase in $\tau$ (to $10.5 \mathrm{~s}$ ) was required to achieve the same rightward shift in the median IBI, but the resulting curve (dotted line) did not reproduce the pronounced decrease in the slope of the experimental CIH. Experimental CIHs were calculated in $1 \mathrm{~s}$ bins. B, the value of the model parameter $\mu$ (left $y$-axis) in control ACSF (heavy solid line) and in ZD-7288 (heavy dashed-dotted line), as a function of the time elapsed since the previous burst, for the same parameter values used in panel $\mathrm{A}$. The relatively small reduction in $\mu_{\mathrm{ss}}$ required to simulate the effect of the drug caused a dramatic drop in the probability of burst occurrence per $100 \mathrm{~ms}$ (right y-axis) in ZD-7288 (light dashed-dotted line) compared to control ACSF (light solid line), since now fluctuations around $\mu$ only rarely crossed threshold (compare with Fig. 6C-D). 


\subsection{References}

Akasu T, Shoji S, Hasuo H (1993) Inward rectifier and low-threshold calcium currents contribute to the spontaneous firing mechanism in neurons of the rat suprachiasmatic nucleus. Pflugers Arch 425:109-116.

Alger BE, Pitler TA, Wagner JJ, Martin LA, Morishita W, Kirov SA, Lenz RA (1996) Retrograde signalling in depolarization-induced suppression of inhibition in rat hippocampal CA1 cells. J Physiol 496 ( Pt 1):197-209.

Arvanov VL, Holmes KH, Keele NB, Shinnick-Gallagher P (1995) The functional role of metabotropic glutamate receptors in epileptiform activity induced by 4aminopyridine in the rat amygdala slice. Brain Res 669:140-144.

Avoli M, Barbarosie M, Lucke A, Nagao T, Lopantsev V, Kohling R (1996) Synchronous GABA-mediated potentials and epileptiform discharges in the rat limbic system in vitro. J Neurosci 16:3912-3924.

Ayala GF, Dichter M, Gumnit RJ, Matsumoto H, Spencer WA (1973) Genesis of epileptic interictal spikes. New knowledge of cortical feedback systems suggests a neurophysiological explanation of brief paroxysms. Brain Res 52:1-17.

Bal T, McCormick DA (1997) Synchronized oscillations in the inferior olive are controlled by the hyperpolarization-activated cation current I(h). J Neurophysiol 77:3145-3156.

Banoub RW, Fernstrom M, Malkinson AM, Ruch RJ (1996) Enhancement of gap junctional intercellular communication by dibutyryl cyclic AMP in lung epithelial cells. Anticancer Res 16:3715-3719. 
Barbarosie M, Avoli M (1997) CA3-driven hippocampal-entorhinal loop controls rather than sustains in vitro limbic seizures. J Neurosci 17:9308-9314.

Beaumont V, Zucker RS (2000) Enhancement of synaptic transmission by cyclic AMP modulation of presynaptic Ih channels. Nat Neurosci 3:133-141.

Bender RA, Brewster A, Santoro B, Ludwig A, Hofmann F, Biel M, Baram TZ (2001) Differential and age-dependent expression of hyperpolarization- activated, cyclic nucleotide-gated cation channel isoforms 1-4 suggests evolving roles in the developing rat hippocampus. Neuroscience 106:689-698.

BoSmith RE, Briggs I, Sturgess NC (1993) Inhibitory actions of ZENECA ZD7288 on whole-cell hyperpolarization activated inward current (If) in guinea-pig dissociated sinoatrial node cells. Br J Pharmacol 110:343-349.

Boulanger L, Poo M (1999) Gating of BDNF-induced synaptic potentiation by cAMP. Science 284:1982-1984.

Boulton CL, McCrohan CR, O'Shaughnessy CT (1993) Cyclic AMP analogues increase excitability and enhance epileptiform activity in rat neocortex in vitro. Eur $\mathbf{J}$ Pharmacol 236:131-136.

Bragdon AC, Kojima H, Wilson WA (1992) Suppression of interictal bursting in hippocampus unleashes seizures in entorhinal cortex: a proepileptic effect of lowering $[\mathrm{K}+]$ o and raising $[\mathrm{Ca} 2+]$ o. Brain Res 590:128-135.

Briggs I, BoSmith RE, Heapy CG (1994) Effects of Zeneca ZD7288 in comparison with alinidine and UL-FS 49 on guinea pig sinoatrial node and ventricular action potentials. J Cardiovasc Pharmacol 24:380-387. 
Burghardt RC, Barhoumi R, Sewall TC, Bowen JA (1995) Cyclic AMP induces rapid increases in gap junction permeability and changes in the cellular distribution of connexin43. J Membr Biol 148:243-253.

Carystinos GD, Alaoui-Jamali MA, Phipps J, Yen L, Batist G (2001) Upregulation of gap junctional intercellular communication and connexin 43 expression by cyclicAMP and all-trans-retinoic acid is associated with glutathione depletion and chemosensitivity in neuroblastoma cells. Cancer Chemother Pharmacol 47:126132.

Castro-Alamancos MA, Calcagnotto ME (1999) Presynaptic long-term potentiation in corticothalamic synapses. J Neurosci 19:9090-9097.

Chavez-Noriega LE, Stevens CF (1992) Modulation of synaptic efficacy in field CA1 of the rat hippocampus by forskolin. Brain Res 574:85-92.

Chen S, Wang J, Siegelbaum SA (2001) Properties of hyperpolarization-activated pacemaker current defined by coassembly of $\mathrm{HCN} 1$ and $\mathrm{HCN} 2$ subunits and basal modulation by cyclic nucleotide. J Gen Physiol 117:491-504.

Chevaleyre V, Castillo PE (2002) Assessing the role of Ih channels in synaptic transmission and mossy fiber LTP. Proc Natl Acad Sci U S A 99:9538-9543.

Cohen I, Navarro V, Clemenceau S, Baulac M, Miles R (2002) On the origin of interictal activity in human temporal lobe epilepsy in vitro. Science 298:1418-1421.

de Curtis M, Avanzini G (2001) Interictal spikes in focal epileptogenesis. Prog Neurobiol 63:541-567. 
Dickson CT, Magistretti J, Shalinsky MH, Fransen E, Hasselmo ME, Alonso A (2000) Properties and role of $\mathrm{I}(\mathrm{h})$ in the pacing of subthreshold oscillations in entorhinal cortex layer II neurons. J Neurophysiol 83:2562-2579.

DiFrancesco D, Ojeda C (1980) Properties of the current if in the sino-atrial node of the rabbit compared with those of the current iK, in Purkinje fibres. J Physiol 308:353-367.

DiFrancesco D, Tortora P (1991) Direct activation of cardiac pacemaker channels by intracellular cyclic AMP. Nature 351:145-147.

Dunwiddie TV, Taylor M, Heginbotham LR, Proctor WR (1992) Long-term increases in excitability in the CA1 region of rat hippocampus induced by beta-adrenergic stimulation: possible mediation by cAMP. J Neurosci 12:506-517.

Fatt P, Katz B (1952) Spontaneous subthreshold activity at motor nerve endings. J Physiol 117:109-128.

Fredholm BB, Fuxe K, Agnati L (1976) Effect of some phosphodiesterase inhibitors on central dopamine mechanisms. Eur J Pharmacol 38:31-38.

Frerking M, Schmitz D, Zhou Q, Johansen J, Nicoll RA (2001) Kainate receptors depress excitatory synaptic transmission at CA3-->CA1 synapses in the hippocampus via a direct presynaptic action. J Neurosci 21:2958-2966.

Gasparini S, DiFrancesco D (1997) Action of the hyperpolarization-activated current (Ih) blocker ZD 7288 in hippocampal CA1 neurons. Pflugers Arch 435:99-106.

Good PI (1999) Resampling Methods. Boston: Birkhauser.

Grzywacz NM, Sernagor E (2000) Spontaneous activity in developing turtle retinal ganglion cells: statistical analysis. Vis Neurosci 17:229-241. 
Hablitz JJ (1984) Picrotoxin-induced epileptiform activity in hippocampus: role of endogenous versus synaptic factors. J Neurophysiol 51:1011-1027.

Harris NC, Constanti A (1995) Mechanism of block by ZD 7288 of the hyperpolarization-activated inward rectifying current in guinea pig substantia nigra neurons in vitro. J Neurophysiol 74:2366-2378.

Harris NC, Libri V, Constanti A (1994) Selective blockade of the hyperpolarizationactivated cationic current (Ih) in guinea pig substantia nigra pars compacta neurones by a novel bradycardic agent, Zeneca ZM 227189. Neurosci Lett 176:221-225.

Hoshi T, Garber SS, Aldrich RW (1988) Effect of forskolin on voltage-gated K+ channels is independent of adenylate cyclase activation. Science 240:1652-1655.

Isaacson JS, Walmsley B (1995) Counting quanta: direct measurements of transmitter release at a central synapse. Neuron 15:875-884.

Jensen MS, Yaari Y (1988) The relationship between interictal and ictal paroxysms in an in vitro model of focal hippocampal epilepsy. Ann Neurol 24:591-598.

Korn SJ, Giacchino JL, Chamberlin NL, Dingledine R (1987) Epileptiform burst activity induced by potassium in the hippocampus and its regulation by GABA-mediated inhibition. J Neurophysiol 57:325-340.

Lebovitz RM (1974) Inhibitory phasing of penicillin interictal discharge. Brain Res 79:301-305.

Lebovitz RM (1979) Autorhythmicity of spontaneous interictal spike discharge at hippocampal penicillin foci. Brain Res 172:35-55. 
Li SJ, Wang Y, Strahlendorf HK, Strahlendorf JC (1993) Serotonin alters an inwardly rectifying current (Ih) in rat cerebellar Purkinje cells under voltage clamp. Brain Res 617:87-95.

Lonart G, Janz R, Johnson KM, Sudhof TC (1998) Mechanism of action of rab3A in mossy fiber LTP. Neuron 21:1141-1150.

Ludwig A, Zong X, Jeglitsch M, Hofmann F, Biel M (1998) A family of hyperpolarization-activated mammalian cation channels. Nature 393:587-591.

Luthi A, Bal T, McCormick DA (1998) Periodicity of thalamic spindle waves is abolished by ZD7288,a blocker of Ih. J Neurophysiol 79:3284-3289.

Maccaferri G, McBain CJ (1996) The hyperpolarization-activated current (Ih) and its contribution to pacemaker activity in rat CA1 hippocampal stratum oriens-alveus interneurones. J Physiol 497:119-130.

Maccaferri G, Mangoni M, Lazzari A, DiFrancesco D (1993) Properties of the hyperpolarization-activated current in rat hippocampal CA1 pyramidal cells. J Neurophysiol 69:2129-2136.

Magee JC (1998) Dendritic hyperpolarization-activated currents modify the integrative properties of hippocampal CA1 pyramidal neurons. J Neurosci 18:7613-7624.

McCormick DA, Pape HC (1990) Properties of a hyperpolarization-activated cation current and its role in rhythmic oscillation in thalamic relay neurones. J Physiol 431:291-318.

Mellor J, Nicoll RA, Schmitz D (2002) Mediation of hippocampal mossy fiber long-term potentiation by presynaptic Ih channels. Science 295:143-147. 
Merlin LR, Taylor GW, Wong RK (1995) Role of metabotropic glutamate receptor subtypes in the patterning of epileptiform activities in vitro. J Neurophysiol 74:896-900.

Monteggia LM, Eisch AJ, Tang MD, Kaczmarek LK, Nestler EJ (2000) Cloning and localization of the hyperpolarization-activated cyclic nucleotide-gated channel family in rat brain. Brain Res Mol Brain Res 81:129-139.

O'Donovan MJ (1999) The origin of spontaneous activity in developing networks of the vertebrate nervous system. Curr Opin Neurobiol 9:94-104.

Opitz T, De Lima AD, Voigt T (2002) Spontaneous development of synchronous oscillatory activity during maturation of cortical networks in vitro. J Neurophysiol $88: 2196-2206$

Pape HC (1996) Queer current and pacemaker: the hyperpolarization-activated cation current in neurons. Annu Rev Physiol 58:299-327.

Paulson AF, Lampe PD, Meyer RA, TenBroek E, Atkinson MM, Walseth TF, Johnson RG (2000) Cyclic AMP and LDL trigger a rapid enhancement in gap junction assembly through a stimulation of connexin trafficking. J Cell Sci 113:3037-3049.

Pedarzani P, Storm JF (1995a) Dopamine modulates the slow $\mathrm{Ca}(2+)$-activated $\mathrm{K}+$ current IAHP via cyclic AMP-dependent protein kinase in hippocampal neurons. J Neurophysiol 74:2749-2753.

Pedarzani P, Storm JF (1995b) Protein kinase A-independent modulation of ion channels in the brain by cyclic AMP. Proc Natl Acad Sci U S A 92:11716-11720.

Prida LM, Sanchez-Andres JV (1999) Nonlinear frequency-dependent synchronization in the developing hippocampus. J Neurophysiol 82:202-208. 
Rotshenker S, Rahamimoff R (1970) Neuromuscular synapse: stochastic properties of spontaneous release of transmitter. Science 170:648-649.

Santoro B, Tibbs GR (1999) The HCN gene family: molecular basis of the hyperpolarization-activated pacemaker channels. Ann N Y Acad Sci 868:741-764.

Santoro B, Chen S, Luthi A, Pavlidis P, Shumyatsky GP, Tibbs GR, Siegelbaum SA (2000) Molecular and functional heterogeneity of hyperpolarization-activated pacemaker channels in the mouse CNS. J Neurosci 20:5264-5275.

Satoh TO, Yamada M (2000) A bradycardiac agent ZD7288 blocks the hyperpolarization-activated current $(\mathrm{I}(\mathrm{h})$ ) in retinal rod photoreceptors. Neuropharmacology 39:1284-1291.

Schwartzkroin PA, Prince DA (1978) Cellular and field potential properties of epileptogenic hippocampal slices. Brain Res 147:117-130.

Sciancalepore M, Cherubini E (1995) Protein kinase A-dependent increase in frequency of miniature GABAergic currents in rat CA3 hippocampal neurons. Neurosci Lett 187:91-94.

Seutin V, Massotte L, Renette MF, Dresse A (2001) Evidence for a modulatory role of Ih on the firing of a subgroup of midbrain dopamine neurons. Neuroreport 12:255258.

Soltesz I, Lightowler S, Leresche N, Jassik-Gerschenfeld D, Pollard CE, Crunelli V (1991) Two inward currents and the transformation of low-frequency oscillations of rat and cat thalamocortical cells. J Physiol 441:175-197. 
Southan AP, Morris NP, Stephens GJ, Robertson B (2000) Hyperpolarization-activated currents in presynaptic terminals of mouse cerebellar basket cells. J Physiol 526 Pt 1:91-97.

Staley KJ, Longacher M, Bains JS, Yee A (1998) Presynaptic modulation of CA3 network activity. Nat Neurosci 1:201-209.

Staley KJ, Bains JS, Yee A, Hellier J, Longacher JM (2001) Statistical model relating CA3 burst probability to recovery from burst- induced depression at recurrent collateral synapses. J Neurophysiol 86:2736-2747.

Stoop R, Pralong E (2000) Functional connections and epileptic spread between hippocampus, entorhinal cortex and amygdala in a modified horizontal slice preparation of the rat brain. Eur J Neurosci 12:3651-3663.

Strata F, Atzori M, Molnar M, Ugolini G, Tempia F, Cherubini E (1997) A pacemaker current in dye-coupled hilar interneurons contributes to the generation of giant GABAergic potentials in developing hippocampus. J Neurosci 17:1435-1446.

Streit J (1993) Regular oscillations of synaptic activity in spinal networks in vitro. J Neurophysiol 70:871-878.

Tabak J, Rinzel J, O'Donovan MJ (2001) The role of activity-dependent network depression in the expression and self-regulation of spontaneous activity in the developing spinal cord. J Neurosci 21:8966-8978.

Tabak J, Senn W, O'Donovan MJ, Rinzel J (2000) Modeling of spontaneous activity in developing spinal cord using activity-dependent depression in an excitatory network. J Neurosci 20:3041-3056. 
Traub D, Miles R (1991) Neuronal networks of the hippocampus. Cambridge: Cambridge University Press.

Travagli RA, Gillis RA (1994) Hyperpolarization-activated currents, IH and IKIR, in rat dorsal motor nucleus of the vagus neurons in vitro. J Neurophysiol 71:1308-1317.

Tsodyks M, Uziel A, Markram H (2000) Synchrony generation in recurrent networks with frequency-dependent synapses. J Neurosci 20:RC50.

Turecek R, Trussell LO (2001) Presynaptic glycine receptors enhance transmitter release at a mammalian central synapse. Nature 411:587-590.

Van Hoogenhuyze D, Weinstein N, Martin GJ, Weiss JS, Schaad JW, Sahyouni XN, Fintel D, Remme WJ, Singer DH (1991) Reproducibility and relation to mean heart rate of heart rate variability in normal subjects and in patients with congestive heart failure secondary to coronary artery disease. Am J Cardiol 68:1668-1676.

van Rijen HV, van Veen TA, Hermans MM, Jongsma HJ (2000) Human connexin40 gap junction channels are modulated by cAMP. Cardiovasc Res 45:941-951.

Vargas G, Lucero MT (2002) Modulation by PKA of the hyperpolarization-activated current (Ih) in cultured rat olfactory receptor neurons. J Membr Biol 188:115-125.

Vasilyev DV, Barish ME (2002) Postnatal development of the hyperpolarizationactivated excitatory current ih in mouse hippocampal pyramidal neurons. $\mathrm{J}$ Neurosci 22:8992-9004.

Wainger BJ, DeGennaro M, Santoro B, Siegelbaum SA, Tibbs GR (2001) Molecular mechanism of cAMP modulation of HCN pacemaker channels. Nature 411:805810. 
Weisskopf MG, Castillo PE, Zalutsky RA, Nicoll RA (1994) Mediation of hippocampal mossy fiber long-term potentiation by cyclic AMP. Science 265:1878-1882.

Wells JE, Porter JT, Agmon A (2000) GABAergic inhibition suppresses paroxysmal network activity in the neonatal rodent hippocampus and neocortex. J Neurosci 20:8822-8830.

Zucker RS, Regehr WG (2002) Short-term synaptic plasticity. Annu Rev Physiol 64:355405. 
CHAPTER 5: Properties of Rhythmic Interictal Bursts in Area CA3 of the Neonatal Hippocampus 


\subsection{Abstract}

We have previously demonstrated that rhythmic IIBs occur in neonatal hippocampal slices when they are bathed in $\mathrm{Mg}^{2+}$-free medium in the presence of $\mathrm{GABA}_{\mathrm{A}}$ receptor antagonists (Chapter 3). Additionally, we have recently demonstrated that the hyperpolarization-activated cationic current, $\mathrm{I}_{\mathrm{h}}$, plays a major role in this rhythmogenesis (Chapter 4). However, many other ionic conductances exist with the potential to modulate the frequency of this rhythm. The purpose of this project was to ascertain the effect these other conductances have on this rhythm, to identify the anatomical source of the IIBs, and to determine if the frequency and precision of this rhythm changed beyond the first postnatal week. We show here that these rhythmic IIBs are synchronous network events that originate in the $\mathrm{CA} 3$ region of the hippocampal slice, and that the precision of the rhythm declines after the early postnatal period. Furthermore, we demonstrate that rhythmicity of the IIBs is not modulated by $\mathrm{GABA}_{\mathrm{B}}$ receptors, calcium-activated potassium currents, or internally released calcium, but can be modulated by metabotropic glutamate receptors. Moreover, increasing the extracellular potassium concentration, which enhances $I_{h}(F u$ et al, 1997), increases the frequency of the rhythm, a further testament that $\mathrm{I}_{\mathrm{h}}$ times neonatal IIBs.

\subsection{Introduction}

Rhythmic phenomena or "oscillations" are a ubiquitous feature of living systems, and are characterized by a periodic change over time in certain parameter(s) of the system. Oscillations are especially prominent in neural systems. The periods of such oscillations vary considerably between and even within different neural systems. For example, neuronal oscillations in the cerebral cortex (neocortex and hippocampus) have 
been described at frequencies ranging over 3 orders of magnitude, from a $200 \mathrm{~Hz}$ "ripple" (Buzsaki et al., 1992) to "slow" oscillations of $0.3 \mathrm{~Hz}$ (Steriade et al., 1993).

In previous studies (Chapters 3 and 4), we described spontaneous IIBs occurring in the neonatal (first postnatal week) hippocampal slice bathed in $\mathrm{Mg}^{2+}$-free ACSF in the presence of $\mathrm{GABA}_{\mathrm{A}}$ receptor $\left(\mathrm{GABA}_{\mathrm{A}} \mathrm{R}\right)$ antagonists. This paroxysmal activity has a frequency that is not only much slower than most previously described neuronal rhythms, but it also exhibited striking regularity. An ionic current underlying many oscillations in excitable tissues, such as the heart (DiFrancesco, 1985, 1993), thalamus (McCormick and Pape, 1990) and hippocampus (Strata et al, 1997), is the hyperpolarization-activated cation current, $I_{h}$. Its nonconventional mechanism of activation upon membrane hyperpolarization makes $I_{h}$ particularly useful in functioning as a pacemaking current by providing a slow depolarization ramp during rhythmic-oscillatory activity (Pape, 1996). Most recently, we have shown that IIB frequency in the neonatal hippocampus is strongly modulated by $I_{h}$ (Chapter 4). While $I_{h}$ is certainly a key player, there are many other candidate conductances with the potential to modulate the frequency of the IIB rhythm in the neonatal hippocampus.

The source of IIBs in the neonate is unknown. Different types of nonepileptiform rhythmic activity in the hippocampus are generated consistently from a single pacemaker region. For example, early network oscillations are generated within the CA1 region (Garaschuk et al, 1998), and giant depolarizing potentials are generated from the septal pole of the CA3 region (Leinekugel 1998). Epileptiform activity in the adult often arises in the CA3 region (Nagao et al, 1996; Barbarosie et al, 1997). 
Here we set out to (1) identify the anatomical source of IIBs to determine if there is a pacemaker focus in the hippocampus, (2) to test the dependence of IIBs on action potentials, chemical, and electrical transmission to determine if these means of neurotransmission are necessary for achieving the network synchrony needed to generate an IIB, and (3) to test the role of ionic conductances other than $\mathrm{I}_{\mathrm{h}}$ on IIB frequency. We show here that IIBs are synchronous network events that originate in the CA3 region. Furthermore, we demonstrate that the frequency of IIBs is not affected by $\mathrm{GABA}_{B} \mathrm{Rs}$, calcium-activated potassium currents, or by internally released calcium, but is affected by mGluRs and by increasing the extracellular potassium concentration.

\subsection{Methods}

Slice preparation and solutions

Timed-pregnant ICR white mouse dams (Hilltop Lab Animals, Scottdale, PA) were monitored at $12 \mathrm{hr}$ intervals to determine the time of birth. The first $24 \mathrm{hr}$ following birth were designated as postnatal day $0(\mathrm{P} 0)$. Pups were anesthetized by the inhalation of methoxyflurane (Metofane; Mallinckrodt Veterinary, Mandelein, IL) in a glass jar and decapitated, and the brain removed into ice-cold artificial cerebrospinal fluid (ACSF; composition in $\mathrm{mM}, \mathrm{NaCl} 126, \mathrm{KCl} 3, \mathrm{NaH}_{2} \mathrm{PO}_{4} 1.2, \mathrm{CaCl}_{2} 2.0, \mathrm{MgSO}_{4} 1.3, \mathrm{NaHCO}_{3}$ 26 , and dextrose 20) saturated with a $95 / 5$ mixture of $\mathrm{O}_{2} / \mathrm{CO}_{2}$. Horizontal slices (500 $\mu \mathrm{m}$ thick) were cut using a Vibraslicer (WPI, Sarasota, FL), and those slices containing hippocampus sectioned perpendicular to its long axis were selected (see Figure 4-1 for picture), bisected along the midline, and maintained for at least $1 \mathrm{hr}$ submerged in a holding chamber filled with recirculated, oxygenated ACSF at room temperature before being transferred to a submersion recording chamber. As done previously for experiment 
using $\mathrm{Mg}^{2+}$-free ACSF (Chapters 3 and 4), $\mathrm{MgSO}_{4}$ was replaced by an equimolar amount of $\mathrm{CaCl}_{2}$ (for a total of $3.3 \mathrm{mM} \mathrm{CaCl}_{2}$ ) to maintain the total divalent cation concentration and avoid surface charge effects. To block chemical transmission, in some experiments $1.3 \mathrm{mM} \mathrm{Mn}^{2+}\left(\mathrm{MnCl}_{2}\right)$ was added to $\mathrm{Mg}^{2+}$-free ACSF, the $\mathrm{CaCl}_{2}$ concentration was kept at $2.0 \mathrm{mM}$ and $\mathrm{NaH}_{2} \mathrm{PO}_{4}$ was omitted to prevent the formation of a $\mathrm{Mn}^{2+}$ precipitate.

\section{Drugs}

SR-95531 (gabazine), tetrodotoxin $\quad(T T X), \quad(\alpha \mathrm{S})-\alpha-a m i n o-\alpha-[(1 \mathrm{~S}, 2 \mathrm{~S})-2-$ carboxycyclopropyl]-9H-xanthine-9-propanoic acid (LY 341495), (2S)-3-[[(1S)-1-(3,4Dichlorophenyl)ethyl]amino-2-hydroxypropyl](phenylmethyl)phosphinic acid (CPG 55845), baclofen, nifedipine, and thapsigargin were purchased from Research Biochemicals (Natwick, MA), Sigma (St. Louis, MO), and/or Tocris (Ballwin, MO), prepared as stock solutions at (typically) 1000-fold final concentration, divided into aliquots, and stored at $-20^{\circ} \mathrm{C}$. During experiments, thawed aliquots were maintained at $4^{\circ} \mathrm{C}$ until use. 1-Octanol (Sigma, St. Louis, MO) was maintained at room temperature and diluted in ACSF to its final concentration immediately prior to use.

\section{Electrophysiological recordings}

For electrophysiological recordings, individual slices were transferred to a submersion chamber, transilluminated, and continuously superfused with oxygenated, room temperature $\mathrm{Mg}^{2+}$-free ACSF containing $5 \mu \mathrm{M}$ gabazine at a rate of $2-3 \mathrm{ml} / \mathrm{min}$. Extracellular field potentials were recorded using glass micropipettes $(1 \mathrm{~mm}$ outer diameter; $0.58 \mathrm{~mm}$ inner diameter; A-M systems, Carlsborg, WA) pulled on a Flaming- 
Brown pipette puller (Sutter Instruments, Novato, CA), their tips broken to a final outside diameter of $\sim 5 \mu \mathrm{m}$ under microscopic control, and filled with $0.9 \% \mathrm{NaCl}$. Field potentials were recorded by positioning the pipettes in the stratum radiatum. Differential DC signals (tissue vs. bath) were recorded using a unity gain headstage connected to a 1000x gain amplifier (Intronix Technologies, Bolton, Ontario, Canada), low-pass filtered at $1 \mathrm{kHz}$, digitized with an analog-to-digital board (National Instruments, Austin, TX) at 1,000 samples/sec, and streamed to disk using custom software in the LabView environment (National Instruments, Austin, TX). Superfusion of the slices was not interrupted during data acquisition.

\section{Data analysis}

Data analysis was performed in the same manner as previously described (Wells et al, 2002; Agmon and Wells, 2003) using custom software routines written in the LabView environment. Records were smoothed off-line by pooling and averaging data points in groups of 32 points, resulting in $10-20 \mu \mathrm{V}$ peak-to-peak noise level in the final record and an effective sampling rate of $32-80 \mathrm{~Hz}$, more than adequate for sampling IIBs (which ranged from $\sim 1-3 \mathrm{~s}$ in total duration and $\sim 200-1200 \mu \mathrm{V}$ in amplitude). IIBs were identified by custom computer software written in the LabView environment, and verified by visual examination. Frequency of IIBs was defined as their mean rate of occurrence (i.e. number of events/duration of record). Instantaneous frequency was defined as the inverse of the time interval between two IIBs. Amplitude was defined as the difference between the highest and lowest voltages during an IIB. For each slice, average IIB amplitude was calculated from all the bursts in the same record used for 
determining frequency. Typically, for experiments involving receptor antagonists or neurotransmission blockers, we defined the effect of the drug as the average change in IIB parameters (frequency or amplitude in drug divided by the frequency or amplitude in control conditions) for all the events in a $300-500 \mathrm{~s}$ window that began $500 \mathrm{~s}$ after the drug was added to the bath, and the control parameters were derived from the average of IIB parameters in a $500 \mathrm{~s}$ window immediately prior to the drug entering the bath solution. For experiments involving receptor agonists, all of the events within a 200-300 $\mathrm{s}$ long window (depending on the amount of time the drug was present in the bath solution) immediately prior to the onset of drug washout were used to determine the change in IIB parameters. We defined the absence of events as no events occurring within a $300 \mathrm{~s}$ minute time window. All probability curves were generated from records containing a minimum of 25 events. Data are presented as mean \pm 1 standard error; error bars indicate standard error; $\mathrm{n}=$ number of slices; $\mathrm{N}=$ number of animals. Illustrated traces are representative of their particular condition. Statistics were performed with two-tailed students $t$ test. The level of significance was set at $p<0.05$; insignificant $p$ values are not reported.

\subsection{Results}

\subsubsection{Periodic IIBs in hippocampal slices were limited to the early postnatal period}

To study network activity in the hippocampus, we recorded extracellular field potentials in horizontal brain slices from area CA3 of neonatal (P0-P7) and juvenile (P18P27) hippocampus. As reported in coronal neonatal slices (Chapter 3) and horizontal neonatal slices (Chapter 4), upon bathing the slices in $\mathrm{Mg}^{2+}$-free ACSF and adding $5 \mu \mathrm{M}$ 
gabazine, large amplitude $(>200 \mu \mathrm{V})$ spontaneous periodic paroxysmal events (referred to as IIBs) were observed. A total of 210 neonatal and 15 juvenile slices from 86 neonatal and 10 juvenile animals were used in this study. As seen in Fig. 5-1A, this network activity occurred with pacemaker-like regularity in the neonatal hippocampus. To determine whether the regularity is unique to the neonatal hippocampus, we tested 15 slices from juvenile mice (P18 to P27). In all of these older slices the rhythm was both slower and less precise (Fig. 5-1A), as shown by the rightward shift and slower slope of the cumulative probability curve (Fig. 5-1B) and the increased coefficient of variation (CV; defined as standard deviation/mean) of the IIB (Fig. 5-1C). In the 42 P0-P3 slices sampled the CV was $21.9 \pm 3.5 \%$ and the mean interburst interval was $18.4 \pm 2.2 \mathrm{sec}$; in the 58 P4-P7 slices sampled the CV was $25.1 \pm 1.7 \%$ and the mean interburst interval was 19.2 $\pm 3.5 \mathrm{sec}$; the average $\mathrm{CV}$ for the P18-P27 slices was significantly increased to $42.4 \pm 1.4 \%(p<0.005)$ and the mean interburst interval was significantly increased to $34.1 \pm 5.5 \mathrm{sec}(p<0.05)$. This suggests that the while the pacemaker mechanism might still be present in the P18-P27 slices, it generates a rhythm that is less precise and slower than the rhythm generated in the neonatal hippocampal slice. The rest of the experiments presented here were performed in neonatal (P0-P7) slices.

\subsubsection{The IIBs originated in the CA3 region}

While epileptiform activity in the adult often arises in the CA3 region (Nagao et al, 1996; Barbarosie et al, 1997), the source of IIB in the neonate is unknown. Since IIBs could be recorded in other areas of the hippocampus, e.g. area CA1 and the dentate gyrus (DG) (Fig. 5-2A), we performed simultaneous multiple recordings to determine if 
neonatal IIBs also originated in CA3. When spontaneous activity in the hippocampus was recorded simultaneously in 2 or 3 locations, onset of the events in CA3 appeared to lead the onset in the other hippocampal locations (Fig. 5-2B), indicating that the CA3 region was the origin of this activity.

To further investigate this matter, CA1, CA3 and DG were separated from each other by two or three knife cuts as illustrated in Fig. 5-2A (dotted line). As shown in Fig. 5-2C, spontaneous network activity persisted in CA3 after the cut, albeit slowed down, possibly because influence of mossy fibers on the rhythm was removed or because the slice was slightly damaged from the isolation procedure. In contrast, network activity was absent from the isolated area CA1 and the DG. Similar results were obtained in 12 out of 14 slices $(\mathrm{N}=11)$, supporting the conclusion that IIBs originated in CA3. We found it interesting that IIBs propagated from the CA3 to DG in the intact slice, opposite the normal direction of activity propagation, and hypothesize that this occurs due to antidromic activation of mossy fibers by a massive increase in $\left[\mathrm{K}^{+}\right]_{\mathrm{o}}$ as a result of the IIB in CA3.

\subsubsection{IIBs are synchronous network events requiring chemical and electrical} neurotransmission

Other network oscillations that have been previously described, in the neonatal hippocampal slice (Garaschuk, 1998) and cultured hippocampal neurons (Bacci et al, 1999), depended upon chemical synaptic transmission for their generation. Additionally, IIBs in the adult are dependent upon gap junctions for their generation (Ross et al, 2000; Kohling et al, 2001; Uusisaari et al, 2002). To test whether IIBs in the neonatal hippocampus were dependent on action potentials or on chemical or electrical synapses 
we tested the effects of TTX, $\mathrm{Mn}^{2+}$ and octanol, respectively. Representative results are illustrated in Fig. 5-3. Adding $1 \mu \mathrm{M}$ TTX to the bath (Fig. 5-3A) resulted in total elimination of IIBs in 5 of 6 slices tested $(\mathrm{N}=2)$. In a sixth slice, small-amplitude events of much lower frequency $(0.001 \mathrm{~Hz})$ persisted in TTX (not shown). To block chemical neurotransmission, $1.3 \mathrm{mM} \mathrm{Mn}^{2+}$ (Fig. 5-3B) was used ( $\mathrm{n}=13$; $\mathrm{N}=5$;). A 3 to 20 minute application of $\mathrm{Mn}^{2+}$ blocked IIBs in 10 of 13 slices. In the remaining 3 slices, the frequency was reduced to less than $27 \%$ of control. To test the dependence of IIBs on electrical synapses (i.e. gap junctions), slices were exposed to $1 \mathrm{mM}$ octanol for 11-16 minutes (Fig. 5-3C); in 6 of 11 slices ( $\mathrm{N}=5$ ) the IIBs were completely eliminated, and in the remaining slices IIB frequency was reduced to $23.9 \pm 10.2 \%(p<0.005)$ of control. We conclude that IIBs are dependent upon inter-neuronal communication through action potentials and chemical and electrical synapses.

\subsubsection{IIB frequency was sensitive to extracellular $K^{+}$concentration}

Since (1) we have previously shown that the IIBs in the neonatal hippocampus were timed by $I_{h}$ (Chapter 4); (2) the $I_{h}$ channel is selective to $\mathrm{K}^{+}$over $\mathrm{Na}^{+}$and is sensitive to extracellular $\mathrm{K}^{+}$concentration $\left(\left[\mathrm{K}^{+}\right]_{\mathrm{o}}\right)$ (Pape, 1996), and (3) increasing the $\left[\mathrm{K}^{+}\right]_{\mathrm{o}}$ has been used previously to induce epileptiform bursting and to modulate IIB frequency in adult and juvenile animals (Korn et al, 1987; Traynelis and Dingledine, 1988; McBain, 1994), we investigated the effects of varying $\left[\mathrm{K}^{+}\right]_{\mathrm{o}}$ on the frequency of rhythmic IIBs. In the experiment illustrated in Fig. 5-4A, the slice was initially bathed in $3 \mathrm{mM} \mathrm{K}^{+}$(control aCSF), and the median interburst interval was $23 \mathrm{sec}$. When $\left[\mathrm{K}^{+}\right]_{\mathrm{o}}$ was increased first to $5 \mathrm{mM}$, and then to 7.5 and $10 \mathrm{mM}$, the median interburst interval decreased to $19 \mathrm{sec}, 8 \mathrm{sec}$ and $4 \mathrm{sec}$, respectively (Fig. 5-4B). Concomitant with the 
increase in frequency, there was a pronounced decrease in the amplitude of the events (see Fig. 4-5 in Chapter 4). Varying $\left[\mathrm{K}^{+}\right]_{\mathrm{o}}$ between $3 \mathrm{mM}$ and $10 \mathrm{mM}\left[\mathrm{K}^{+}\right]$increased the frequency to $469.7 \pm 68.9 \%(p<0.005)$ with a concomitant decrease in event amplitude to $38.7 \pm 4.7 \%(p<0.005)$ of control $(\mathrm{n}=49 ; \mathrm{N}=22)$. The effect of $\mathrm{K}^{+}$for all slices studied is summarized in Fig. 5-4C.

\subsubsection{Effects of metabotropic receptors on IIBs}

$\mathrm{GABA}_{\mathrm{B}} \mathrm{Rs}$ are metabotropic receptors that elicit a long IPSP (Alger, 1984) that could affect IIB frequency by inducing a period of post-IIB suppression during which another IIB could not occur. We blocked $\mathrm{GABA}_{\mathrm{B}} \mathrm{Rs}$ with $1 \mu \mathrm{M}$ CGP 55845, a potent $\mathrm{GABA}_{\mathrm{B}}$ antagonist (Davies et al, 1993), to determine if $\mathrm{GABA}_{\mathrm{B}} \mathrm{Rs}$ play a role in pacing IIBs (Figs. 5-5A,E). CGP 55845 did not have a significant effect on the rhythm's frequency, increasing it to only $106.7 \pm 3.4 \%$ of control values $(n=14 ; N=5)$. This is further illustrated by plotting the change in IIB instantaneous frequency from control (Fig. 5-5B). CGP 55845 did, however, reverse the reduction in IIB rate elicited by the GABA $_{B}$ agonist baclofen $(5-10 \mu \mathrm{M} ; \mathrm{N}=3 ; \mathrm{n}=3$; data not shown), verifying that CGP 55845 was indeed blocking $\mathrm{GABA}_{\mathrm{B}} \mathrm{Rs}$. These results indicate that post-IIB suppression elicited by $\mathrm{GABA}_{\mathrm{B}} \mathrm{Rs}$ does not play a significant role in IIB frequency.

Activation of metabotropic glutamate receptors (mGluRs) can affect IIB frequency in the adult hippocampus (Rutecki and Yang, 1997) and amygdala (Arvanov et al, 1995), so we studied the role of mGluRs in the neonate with the mGluR antagonist LY341495, at a concentration $(20 \mu \mathrm{M})$ known to block all known groups of mGluRs (Kingston et al, 1998), and found that it increased the frequency of IIBs to $126.8 \pm 7.1 \%$ of control ( $p<0.05$; Fig. $5-5 \mathrm{C}, \mathrm{E} ; \mathrm{N}=6 ; \mathrm{n}=7$ ). This is further illustrated by plotting the 
change in IIB instantaneous frequency from control (Fig. 5-5D). These results indicate that in the neonate, as in the adult, mGluRs are able to modulate IIB frequency to a modest degree (see Discussion for details).

\subsubsection{Post-paroxysmal suppression mediated by calcium-activated potassium currents} does not modulate IIB frequency

Post-paroxysmal suppression could also be mediated by IIB-activated intrinsic conductances. Important intrinsic conductances that could be involved in such suppression are calcium-activated potassium currents underlying the slow $\mathrm{I}_{\mathrm{AHP}}$ (Hotson and Prince, 1980; Stocker et al, 1999; Pederzani et al, 2001). These currents are activated by $\mathrm{Ca}^{2+}$ entry through voltage-gated calcium channels due to a membrane depolarization. This conductance has a decay time constant of up to $2 \mathrm{sec}$ (Domann et al, 1991). Calcium-activated potassium currents can be suppressed by blocking calcium entry through L-type calcium channels, which are the main source for somatic calcium entry during an epileptiform burst (Empson and Jefferys, 2001). To test whether calciumactivated potassium currents are involved in modulating IIB frequency, we used the Ltype calcium channel antagonist nifedipine at $10 \mu \mathrm{M}$, a concentration known to be maximally effective at blocking the calcium-activated potassium currents (Shah and Haylett, 2000). Nifedipine increased IIB frequency on average to $147.6 \pm 13.8 \%$ of control $(p<0.005$; Fig. 5-6A; $\mathrm{N}=5 ; \mathrm{n}=13)$. This is further illustrated by examining a plot of the instantaneous IIB frequency (Fig. 5-6B). However, due to the wide variety of $\mathrm{Ca}^{2+}$ triggered intracellular processes, nifedipine could have been acting via other mechanisms in addition to suppressing the calcium-activated potassium currents. For example, many

$\mathrm{Ca}^{2+}$-dependent processes (but not activation of $\mathrm{Ca}^{2+}$-dependent $\mathrm{K}^{+}$channels underlying 
the calcium-activated potassium currents) are mediated by the $\mathrm{Ca}^{2+}$-binding protein calmodulin (Bredt, 1999; Chetkovich et al, 2002;). Therefore, we retested the effect of nifedipine in the presence of calmodulin antagonists. As shown in Fig. 5-6C, the accelerating effect of nifedipine on IIB frequency was mostly abolished by preincubating the slices with W-7 or TFP (both at $100 \mu \mathrm{M}$ ), drugs known to block calmodulin (Tanaka and Hidaka, 1980). After preincubation with these drugs, nifedipine changed the frequency to only $104 \pm 2.4 \%$ of control $(n=15 ; N=5)$, indicating that the nifedipine effect was mediated by calmodulin-dependant effects, such as a $\mathrm{Ca}^{2+} /$ calmodulin dependent change of post-synaptic proteins at excitatory synapses (Chetkovich et al, 2002). This is further illustrated by examining a plot of the instantaneous IIB frequency (Fig. 5-6D). Therefore, calcium-activated potassium currents do not appear to play a role in modulating IIB frequency.

\subsubsection{Intracellular $\mathrm{Ca}^{2+}$ release does not modulate IIB frequency}

Activation of excitatory synapses in many central neurons produces signals that increase intracellular $\mathrm{Ca}^{2+}$ concentration, such as $\mathrm{Ca}^{2+}$-activated $\mathrm{Ca}^{2+}$ release from intracellular stores (Rose and Konnerth, 2001). Since the level of intracellular $\mathrm{Ca}^{2+}$ has been demonstrated to be greatly altered in some models of epilepsy (Pal et al, 2000), we investigated whether $\mathrm{Ca}^{2+}$ released from internal stores is involved in pacing IIBs, by blocking the release of such $\mathrm{Ca}^{2+}$ by bath application of thapsigargin, which depletes internal $\mathrm{Ca}^{2+}$ stores (Treiman et al, 1998). Perfusion of thapsigargin ( $2 \mu \mathrm{M}$; Figs. 5-6E; $\mathrm{n}=7 ; \mathrm{N}=4$ ) for up to 60 minutes did not have a significant effect on the IIBs, increasing the frequency on average to only $109.7 \pm 4.4 \%$ of control. This is further illustrated by 
examining a plot of the instantaneous IIB frequency (Fig. 5-6G). Our experiments indicate that intracellular $\mathrm{Ca}^{2+}$ release does not play an important role in IIB generation.

\subsection{Discussion}

The most important conclusions to be drawn from our results are that neonatal IIBs originate in the CA3 region of the hippocampus, and are not paced by $\mathrm{GABA}_{B} \mathrm{Rs}$, $\mathrm{I}_{\mathrm{AHP}}$, or internally released calcium, and they require action potentials, chemical and electrical neurotransmission. These conclusions are founded on the demonstration that IIBs remained only in CA3 when the hippocampal fields were surgically isolated, that blocking neuronal communication through either action potentials, chemical synapses or gap junctions prevented IIB occurrence, and that blocking the effects of GABA ${ }_{B} R s, I_{A H P}$, or internally released calcium (all potential candidates for modulating IIB frequency) had no effect on IIB frequency. Also, increasing the extracellular potassium concentration or decreasing mGluR activation, increases the frequency of the rhythm. As explained below, this further supports the hypothesis posed in Chapter 4 that $I_{h}$ times IIBs in the neonatal hippocampus.

\subsubsection{The role of gap junctions in IIBs generation}

Epileptiform bursts are synchronous neuronal events, and given that (1) gap junctions strongly facilitate neuronal synchrony (Dudek et al., 1986; Dudek et al., 1999; Schmitz et al., 2001), (2) they are highly expressed throughout the hippocampus (Yamamoto et al., 1989; Matsumoto et al, 1991; Condorellie et al, 1998; Aberg et al, 1999; Belluardo et al, 2000), and (3) hippocampal pyramidal neurons are coupled by axoaxonic gap junctions permitting very fast electrical communication (Schmitz et al., 2001), 
it is likely that gap junctions are involved in the generation of epileptiform bursts. Indeed, epileptiform bursting in the adult can be reduced by uncoupling gap junctions (Ross et al., 2000; Kohling et al., 2001; Szente et al., 2002; Uusisaari et al., 2002); moreover, epileptiform bursting can be facilitated by opening gap junctions (de Curtis et al., 1998; Schuchmann et al., 2002). We report here the novel finding that the generation of IIBs in the neonate, as in the adult, requires gap junctions. It has been suggested that gap junction blockade only reduces neuronal synchrony, and does not affect neuronal excitability (Margineanu and Klitgaard, 2001). Given that $\mathrm{I}_{\mathrm{h}}$ plays a role in IIB generation (Chapter 4), testable predictions from this hypothesis posed by Margineanu and Klitgaard (2001) would be that in neonatal hippocampal slices in the presence of gap junction blockers under conditions known to elicit IIBs, $\mathrm{I}_{\mathrm{h}}$ should be unaffected and there should also be pyramidal neurons firing bursts of action potentials at a rate similar to the rate of neonatal IIBs.

\subsubsection{Effects of $\left[K^{+}\right]_{o}$ on IIBS}

We previously demonstrated that $\mathrm{I}_{\mathrm{h}}$ is involved with the generation of paroxysmal discharges in the neonatal hippocampus (Chapter 4). It has also been shown that by increasing $\left[\mathrm{K}^{+}\right]_{\mathrm{o}}$ from $3 \mathrm{mM}$ to $10 \mathrm{mM}, \mathrm{I}_{\mathrm{h}}$ is facilitated: the activation curve for $\mathrm{I}_{\mathrm{h}}$ current is shifted more positive by about $30 \mathrm{mV}$ (Fu et al, 1997), thereby increasing its ability to depolarize neurons. In the present study we demonstrated that increasing the $\left[\mathrm{K}^{+}\right]_{\mathrm{o}}$ to 10 $\mathrm{mM}$ increases the frequency of IIBs by nearly 5-fold. This was expected since previous studies have indicated that elevated levels of $\left[\mathrm{K}^{+}\right]_{\mathrm{o}}$ will induce IIBs in the hippocampus (Zuckermann and Glaser, 1968; Jensen and Yaari, 1997). The effects of $\left[\mathrm{K}^{+}\right]_{\mathrm{o}}$ on IIBs have been previously attributed to (1) $\left[\mathrm{K}^{+}\right]_{\mathrm{o}}$ depolarization of the neuronal membrane, 
bringing resting membrane potential closer to firing threshold, and (2) $\left[\mathrm{K}^{+}\right]_{\mathrm{o}}$ reduction of the efficiency of $\mathrm{K}^{+}-\mathrm{Cl}^{-}$cotransport (Staley and Proctor, 1999) which causes the $\mathrm{Cl}^{-}$ reversal potential to move in the positive direction, thus reducing the hyperpolarizing effect of $\mathrm{GABA}_{\mathrm{A}}$ receptor activation. Additionally, since elevating $\left[\mathrm{K}^{+}\right]_{\mathrm{o}}$ will shift the activation curve of $I_{h}$ to more positive values ( $F u$ et al, 1997), we propose that the facilitation of $I_{h}$ could also play a role in the elevated- $\left[\mathrm{K}^{+}\right]_{\mathrm{o}}$ model of epilepsy.

\subsubsection{Effects of mGluRs on IIBs}

We applied LY341495 at a concentration that blocks all three groups of mGluRs (Kingston et al, 1998), and found that although the effect of LY341495 was somewhat variable (see Fig. 5-5E), on average mGluR blockade caused a significant increase in IIB frequency. This result is consistent with reports that indicate the activation of mGluR groups II and III will reduce epileptiform bursting (Sacaan and Schoepp, 1992; Attwell et al, 1995; Burke and Hablitz, 1995). While activation of mGluR groups II and III is antiepileptic, meaning they reduce epileptiform bursting, mGluR group I activation is proepileptic, meaning they increase epileptiform bursting (Taylor et al, 1995; Dalby and Thomsen, 1996). Therefore, the large variability we observed in IIB frequency from mGluR blockade could have resulted from the blockade of both pro- and anti-epileptic mGluRs; since LY341495 is a more potent antagonist of mGluR groups II and III than to group I (Kingston et al, 1998), the effect of LY341495 increased IIB frequency. To differentiate between the effects of these receptor groups, highly selective agonists and antagonists for each of the mGluR groups should be tested.

The anti-epileptic effects of mGluR groups II and III have been attributed to their suppression of excitatory neurotransmitter release (Forsythe and Clements, 1990; Baskys 
and Malenka, 1991; Vignes et al, 1995). Here we propose an additional mechanism. mGluR groups II and III are negatively-coupled to the adenylyl cyclase-cAMP cascade (Tanabe et al, 1992; Cartmell et al, 1994); therefore, their activation decreases intracellular cAMP levels. Since (1) $\mathrm{I}_{\mathrm{h}}$ is facilitated by cAMP (Ishii et al, 1999; Ludwig et al, 1999; Chen et al, 2001; Wainger et al, 2001) and (2) $\mathrm{I}_{\mathrm{h}}$ plays a strong role in IIB generation (Chapter 4), we suggest that the activation of mGluR groups II and III is antiepileptic because they suppress $I_{h}$ by reducing intracellular cAMP concentration.

\subsubsection{Role of $G A B A_{B}$ and calcium-activated potassium conductances in IIBS}

A potential mechanism that can account for rhythmic IIBs has three components: (1) a slow escalation of a cellular parameter (i.e. restoring functional synaptic vesicles (Staley et al, 2001) or excitation mediated through $\mathrm{I}_{h}($ Chapter 4)), 2) generation of an IIB once the parameter crossed a critical threshold, and 3) resetting of the parameter as a result of the IIB. For example, epileptiform bursting can be explained by a slow depolarization of the membrane potential to threshold, and a hyperpolarization following the burst. The slow depolarization may be due to a continuous, slow current (i.e. $\mathrm{I}_{\mathrm{h}}$, Pape, 1996; Chapter 4). However, other models have proposed that a slow recovery from a suppressive refractory period paces IIBs instead of a slow build-up of excitation. Mechanisms that have been proposed to be responsible for generating the post-burst suppression include 1) calcium-activated potassium conductances (Chamberlin and Dingledine, 1989) and 2) IPSPs mediated by $\mathrm{GABA}_{B} R$ s (Bal, 1993; Wang, 1993; Warren, 1994; Huguenard, 1994; Sanchez-Vives, 1997; Avoli, 2001). Experiments performed on neonatal slices in this study and older slices in another study (Staley et al, 2000) effectively rule out these mechanisms, since if either of them were involved with 
suppressing IIBs, then their blockade should have increased IIB frequency, and this was not found in our experiments. To further elucidate the role of calcium-activated potassium currents in IIB generation in the neonatal hippocampus, specific blockers of these currents should be studied, for example, apamin could be used which blocks the SK-channel (Stocker et al, 1999).

\subsubsection{Conclusion}

The frequency of IIBs in the neonatal hippocampus does not appear to be from the recovery of a post-IIB refractory period, since blocking the ionic conductances that could induce such a refractory period (i.e. $\mathrm{GABA}_{\mathrm{B}}$ or calcium-activated potassium conductances) had no effect on IIB frequency. However, manipulations that could enhance $I_{h}$ (i.e. increasing $\left[\mathrm{K}^{+}\right]_{\mathrm{o}}$ and blocking mGluRs) increase the frequency of the rhythm. The results of this study suggest that rather than a recovery from a refractory period, a slow build-up of excitation mediated by $\mathrm{I}_{\mathrm{h}}$ is responsible for pacing IIBs.

The precision of IIBs significantly decreases after the first postnatal week. Since the properties of $I_{h}$ in the hippocampus change during early postnatal development (Vasilyev and Barish, 2002), it is likely that the developmental loss of IIB precision is due to a change in $I_{h}$. Investigation of $I_{h}$ channel subunits with immunocytochemistry could determine if subunit expression in the neonate has a distribution different than the

adult that permits the early rhythmic generation of IIBs, and this will be addressed in Chapter 6. 


\subsection{Figures}

Figure 5-1
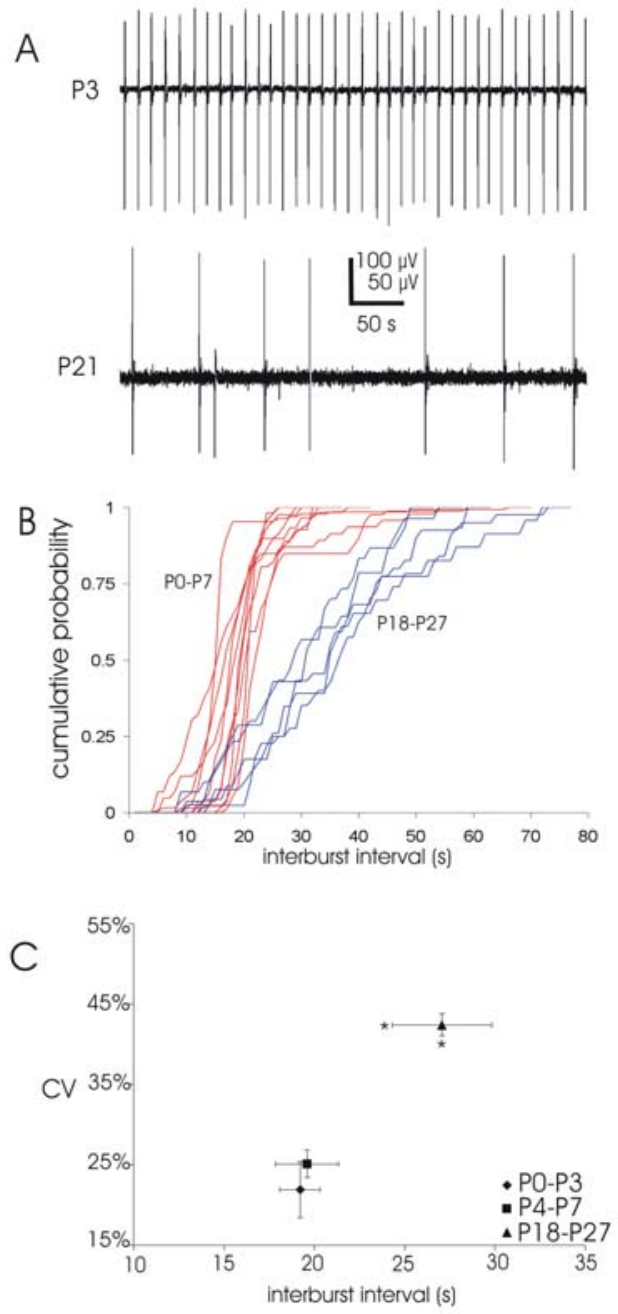

FIGURE 5-1. IIBS ELICITED IN HORIZONTAL SLICES OF NEONATAL HIPPOCAMPUS BY GABAZINE IN $\mathrm{MG}^{2+}$-FREE ACSF FOLLOW A RHYTHMIC PATTERN.

$A$, A continuous record illustrating spontaneous activity in CA3 after washout of $\mathrm{Mg}^{2+}$ and after superfusion of the $\mathrm{GABA}_{\mathrm{A}}$ receptor antagonist gabazine (GBZ) in $\mathrm{P} 3$ and $\mathrm{P} 21$ slices. Notice the IIBs in the neonatal slice follow a faster and more precise rhythm than that of the juvenile hippocampus. $B$, Probability of an interictal event occurring at the 
indicated age groups when the slices are bathed in $\mathrm{Mg}^{2+}$-free aCSF with $5 \mu \mathrm{M}$ gabazine. Notice that the curves from older slices are shifted to the right and have a lower slope. Curves generated using representative records from 10 neonatal and 5 juvenile slices. $C$, The average coefficient of variation and the average interburst intervals of IIBs within the noted age groups. 


\section{Figure 5-2}
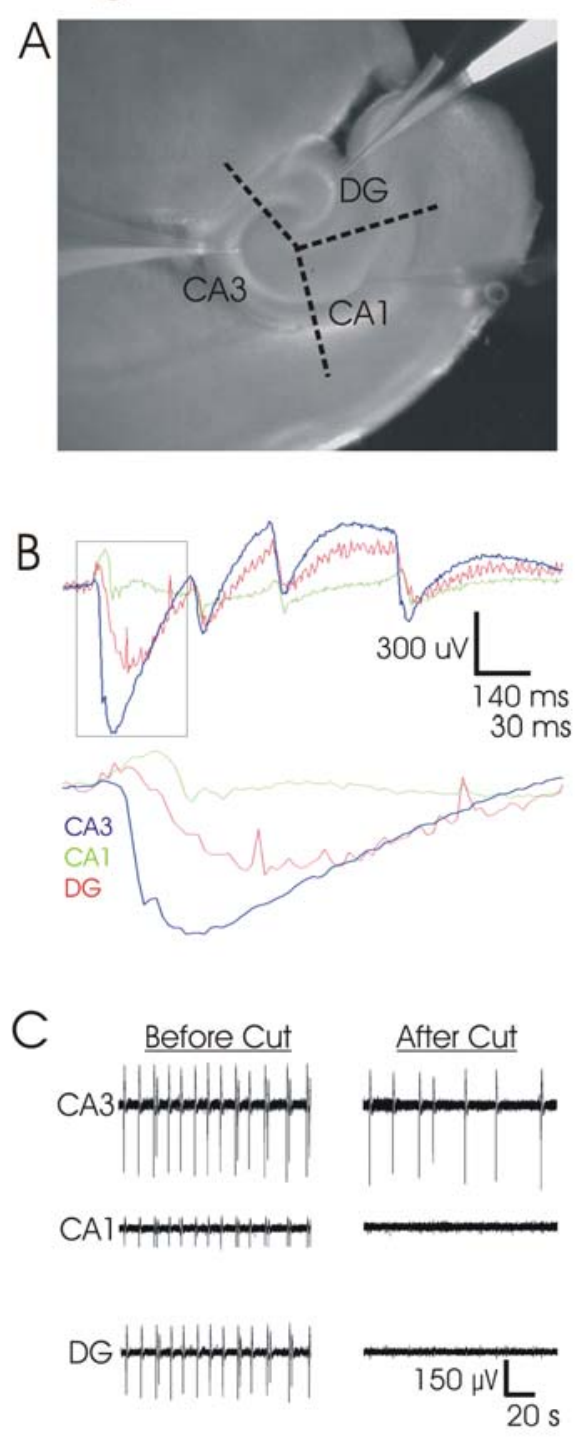

FIGURE 5-2. THE IIBS ORIGINATE IN CA3.

$A$, P5 horizontal hippocampal slice demonstrating experimental set-up. $B$, upper, Simultaneous field recordings from the three regions of a P5 hippocampus. Lower, an expanded view of the area within the square in the upper trace. Notice the activity occurs first in CA3. $C$, Simultaneous field recordings from a P5 slice. Two-minute traces from the same slice before and after surgical separation of the hippocampal fields. Dashed 
lines in $A$ indicate typical position of knife cuts. Notice the IIBs remain only in the isolated $\mathrm{CA} 3$ region. 


\section{Figure 5-3}
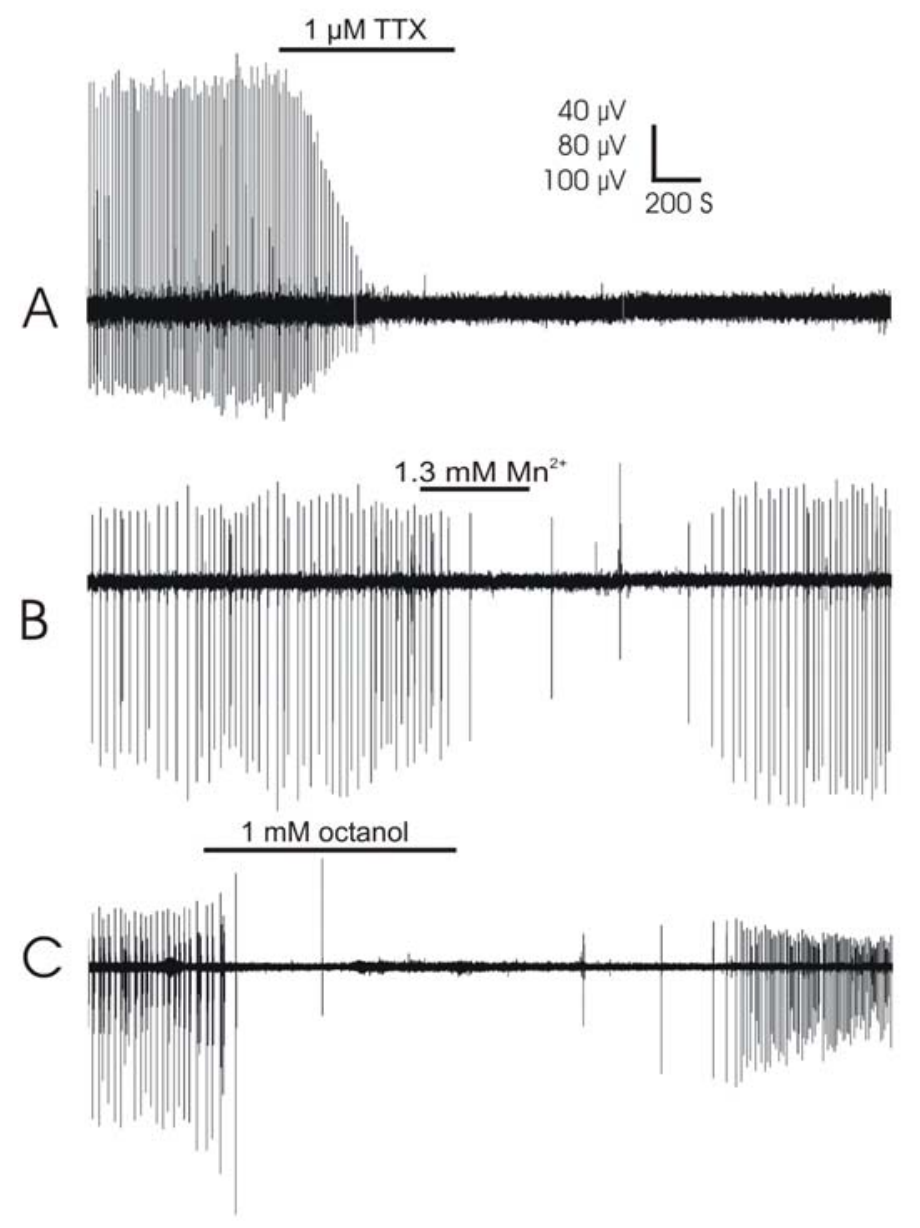

FIGURE 5-3. THE IIBS ARE SYNCHRONOUS, NETWORK EVENTS REQUIRING ACTION POTENTIALS AND CHEMICAL AND ELECTRICAL NEUROTRANSMISSION.

$A-C$, Continuous traces $(A, \mathrm{P} 5 ; B, \mathrm{P} 7 ; C, \mathrm{P} 4)$ illustrating spontaneous activity before, during, and after the superfusion of the drug indicated. Drug presence indicated by the horizontal bar above each trace. Notice all transmission blockers prevented or reduced IIBs. Vertical scale bar: $A, 40 \mathrm{uV} ; B, 80 \mu \mathrm{V} ; C, 100 \mu \mathrm{V}$. 


\section{Figure 5-4}

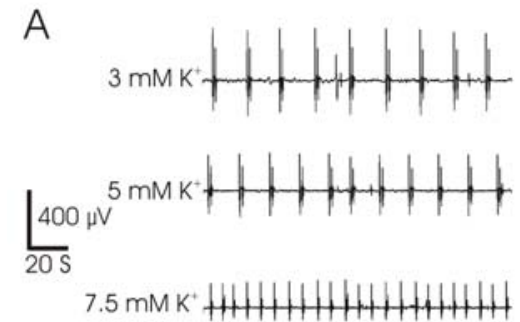

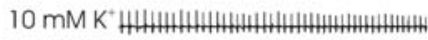
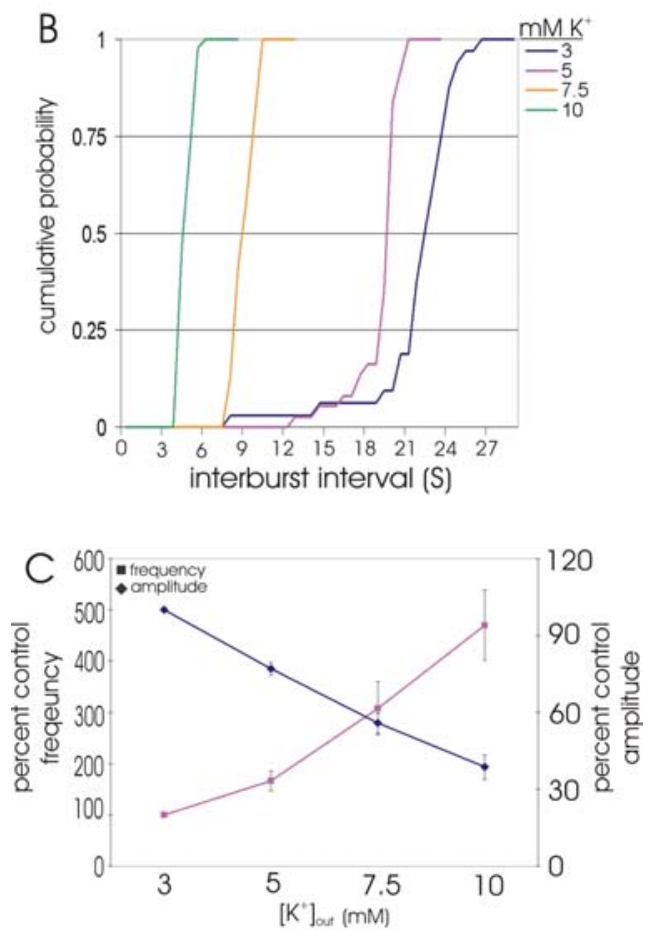

FIGURE 5-4. INCREASING $\left[\mathrm{K}^{+}\right]_{\mathrm{O}}$ INCREASES THE FREQUENCY OF IIBS.

$A$, Portions of consecutive records from the same P3 slice while bathed in the indicated concentration of $\mathrm{K}^{+} . \quad B$, Cumulative probability of an IIB occurring at the given potassium concentration in the same slice. $C$, Summary graph illustrating the average changes in frequency and amplitude of the events due to increasing extracellular $\mathrm{K}^{+}$ concentration for all slices tested $(\mathrm{N}=22 ; \mathrm{n}=49)$. 


\section{Figure 5-5}

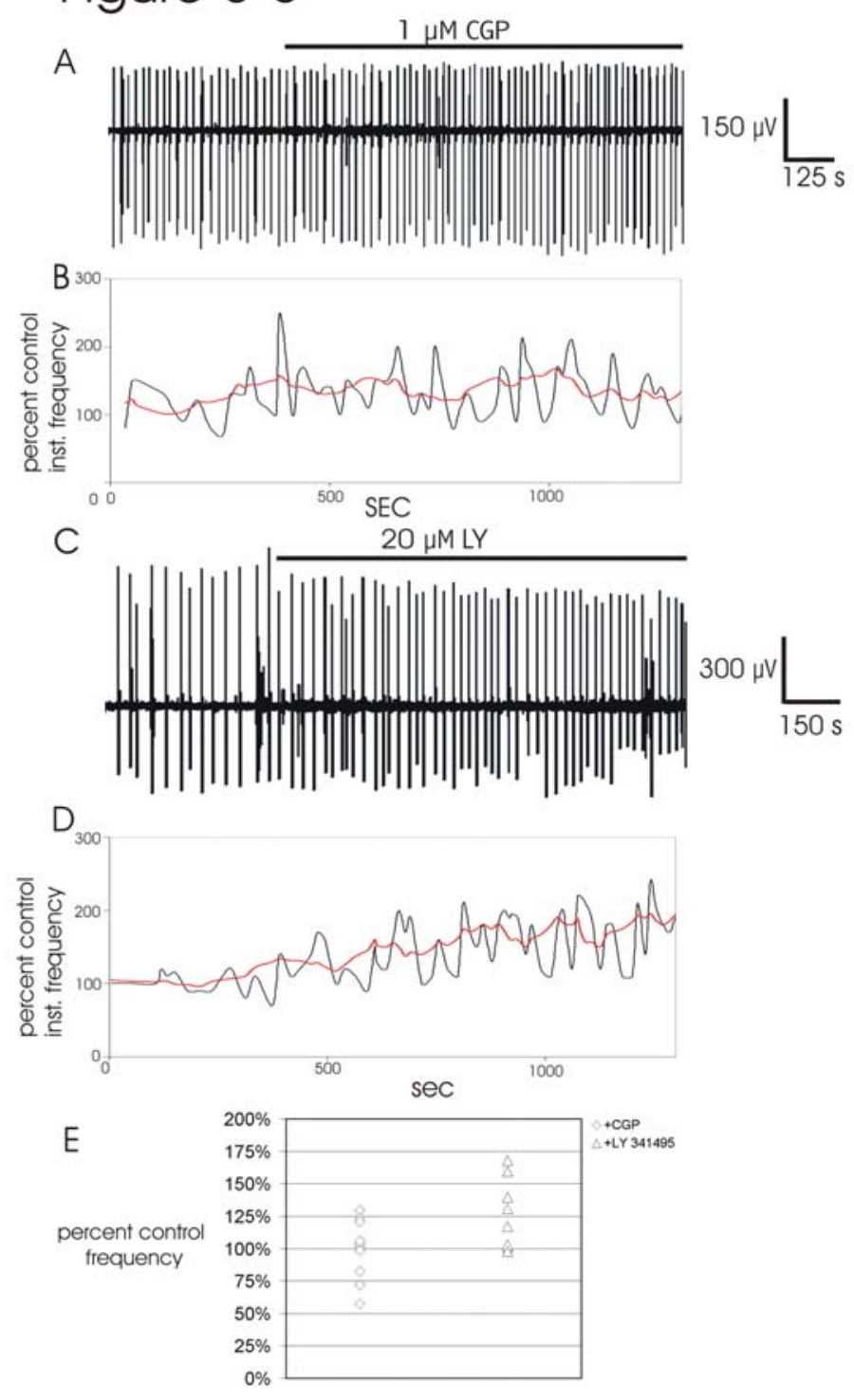

FIGURE 5-5. THE EFFECTS OF GABA B AND MGLURS ON IIB FREQUENCY.

$A$, Continuous P5 trace with the $\mathrm{GABA}_{\mathrm{B}}$ antagonist CGP $55845(1 \mu \mathrm{M})$ present. $B$, Black line, Percent of control instantaneous frequency of the IIBs illustrated in A. Red line, Running average, calculated using a sliding window of five data points. $C$, Record from a P0 hippocampal slice in which $20 \mu \mathrm{M} \mathrm{LY}$ was added to the bath. D, Black line, Percent 
of control instantaneous frequency of the IIBs illustrated in A. Red line, Running average, calculated using a sliding window of five data points. E, Chart illustrating the normalized change in frequency from control conditions with drug present for all of the slices tested. 


\section{Figure 5-6}
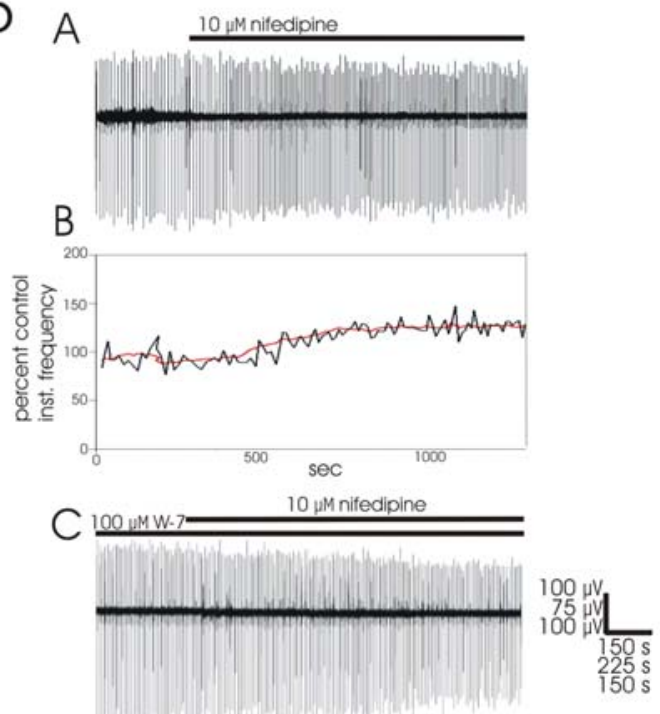

$\mathrm{D}$
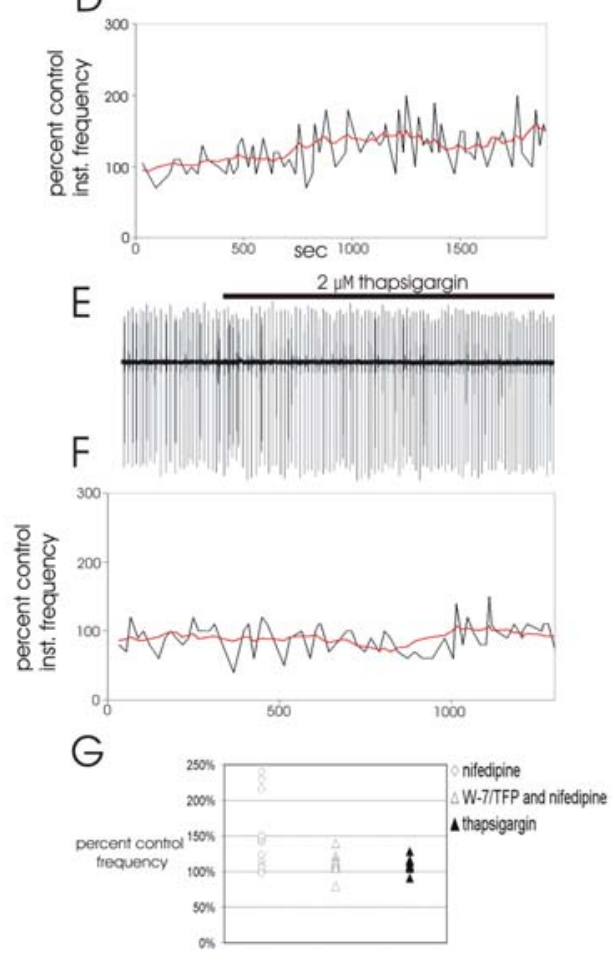

FiguRE 5-6. CALCIUM ACTIVATED POTASSIUM CONDUCTANCES AND CALCIUM RELEASE FROM INTERNAL STORES HAVE NO EFFECT ON IIB FREQUENCY.

$A$, Field recording from a P5 slice demonstrating the L-type calcium channel

blocker nifedipine $(10 \mu \mathrm{M})$ caused an increase in interictal event frequency. $B$, Black 
line, Percent of control instantaneous frequency of the IIBs illustrated in A. Red line, Running average, calculated using a sliding window of five data points. C, P4 slice showing the effect of nifedipine was abolished by pre-incubation with the calmodulin antagonist $\mathrm{W}-7(100 \mu \mathrm{M})$, indicating the effect of $\mathrm{Ca}^{2+}$ was mediated by calmodulin and not by $\mathrm{Ca}^{2+}$-activated potassium conductances. D, Black line, Percent of control instantaneous frequency of the IIBs illustrated in A. Red line, Running average, calculated using a sliding window of five data points. E, P6 slice showing that thapsigargin $(2 \mu \mathrm{M})$, an intracellular calcium releaser, had no effect on IIB frequency. $F$, Black line, Percent of control instantaneous frequency of the IIBs illustrated in A. Red line, Running average, calculated using a sliding window of five data points. $G$, Chart illustrating the normalized change in frequency from control conditions with drug present for individual slices. 


\subsection{References}

Aberg ND, Ronnback L, Eriksson PS (1999) Connexin43 mRNA and protein expression during postnatal development of defined brain regions. Brain Res Dev Brain Res 115:97-101.

Agmon A, Wells JE (2003) The role of the hyperpolarization-activated cationic current $I_{h}$ in the timing of interictal bursts in the neonatal hippocampus. J. Neurosci 23(9):3658-3668.

Alger, BE (1984) Characteristics of a slow hyperpolarizing synaptic potential in rat hippocampal pyramidal cells in vitro. J Neurophysiol 52:892-910.

Arellano RO, Rivera A, Ramon F (1990) Protein phosphorylation and hydrogen ions modulate calcium-induced closure of gap junction channels. Biophys J 57:363367.

Arvanov VL, Holmes KH, Keele NB, Shinnick-Gallagher P (1995) The functional role of metabotropic glutamate receptors in epileptiform activity induced by 4aminopyridine in the rat amygdala slice. Brain Res 669:140-144.

Attwell PJ, Kaura S, Sigala G, Bradford HF, Croucher MJ, Jane DE, Watkins JC (1995) Blockade of both epileptogenesis and glutamate release by (1S,3S)-ACPD, a presynaptic glutamate receptor agonist. Brain Res 698:155-162.

Bacci A, Verderio C, Pravettoni E, Matteoli M (1999) Synaptic and intrinsic mechanisms shape synchronous oscillations in hippocampal neurons in culture. Eur J Neurosci: Feb;11(2):389-97.

Bal T, McCormick D.A. (1997) Synchronized oscillations in the inferior olive are controlled by the hyperpolarization-activated cation current I(h). J Neurophysiol 77(6):3145-56.

Barbarosie M, Avoli M (1997) CA3-driven hippocampal-entorhinal loop controls rather than sustains in vitro limbic seizures. J Neurosci 17:9308-9314.

Baskys A, Malenka RC (1991) Agonists at metabotropic glutamate receptors presynaptically inhibit EPSCs in neonatal rat hippocampus. J Physiol 444:687701.

Belluardo NG, Trovato-Salinaro A, Le Gurun S, Charollais A, Serre-Beinier V, Amato G, Haefliger JA, Meda P, Condorelli DF (2000) Expression of connexin36 in the adult and developing rat brain. Brain Res 865:121-138. 
Bond CT, Maylie J, Adelman JP (1999) Small-conductance calcium-activated potassium channels. Ann N Y Acad Sci 868:370-378.

Bredt DS (1999) Endogenous nitric oxide synthesis: biological functions and pathophysiology. Free Radic Res 31:577-596.

Brown H, Difrancesco D Voltage-clamp investigations of membrane currents underlying pace-maker activity in rabbit sino-atrial node. J Physiol Nov:308:331-51

Burke JP, Hablitz JJ (1995) Modulation of epileptiform activity by metabotropic glutamate receptors in immature rat neocortex. J Neurophysiol 73:205-217.

Cartmell J, Kemp JA, Alexander SP, Shinozaki H, Kendall DA (1994) Modulation of cyclic AMP formation by putative metabotropic receptor agonists. Br J Pharmacol 111:364-369.

Chamberlin NL, Dingledine R (1989) Control of epileptiform burst rate by CA3 hippocampal cell afterhyperpolarizations in vitro. Brain Res 492:337-346.

Chen S, Wang J, Siegelbaum SA (2001) Properties of hyperpolarization-activated pacemaker current defined by coassembly of $\mathrm{HCN} 1$ and $\mathrm{HCN} 2$ subunits and basal modulation by cyclic nucleotide. J Gen Physiol 117:491-504.

Chetkovich DM, Bunn RC, Kuo SH, Kawasaki Y, Kohwi M, Bredt DS (2002) Postsynaptic targeting of alternative postsynaptic density-95 isoforms by distinct mechanisms. J Neurosci 22:6415-6425.

Condorelli DF, Parenti R, Spinella F, Trovato Salinaro A, Belluardo N, Cardile V, Cicirata F (1998) Cloning of a new gap junction gene (Cx36) highly expressed in mammalian brain neurons. Eur J Neurosci 10:1202-1208.

Dalby NO, Thomsen C (1996) Modulation of seizure activity in mice by metabotropic glutamate receptor ligands. J Pharmacol Exp Ther 276:516-522.

Davies CH, Pozza MF, Collingridge GL (1993) CGP 55845A: a potent antagonist of GABAB receptors in the CA1 region of rat hippocampus. Neuropharmacology 32:1071-1073.

de Curtis M, Manfridi A, Biella G (1998) Activity-dependent $\mathrm{pH}$ shifts and periodic recurrence of spontaneous interictal spikes in a model of focal epileptogenesis. $\mathbf{J}$ Neurosci 18:7543-7551.

Dudek FE, Snow RW, Taylor CP (1986) Role of electrical interactions in synchronization of epileptiform bursts. Adv Neurol 44:593-617. 
Dudek FE, Patrylo PR, Wuarin JP (1999) Mechanisms of neuronal synchronization during epileptiform activity. Adv Neurol 79:699-708.

Dickson CT, Magistretti J, Shalinsky MH, Fransen E, Hasselmo ME, Alonso A. (2000) Properties and role of $\mathrm{I}(\mathrm{h})$ in the pacing of subthreshold oscillations in entorhinal cortex layer II neurons. J Neurophysiol 83(5):2562-79

Difrancesco D (1984) Characterization of the pace-maker current kinetics in calf Purkinje fibres. J Physiol 348:341-67.

Difrancesco D (1985) The cardiac hyperpolarizing-activated current, If. Origins and developments. Prog Biophys Mol Biol 46(3):163-83.

DiFrancesco, D. (1993). Pacemaker mechanisms in cardiac tissue. Annu Rev Physiol, 55: 455-72.

Draguhn A, Traub RD, Bibbig A, Schmitz D (2000) Ripple (approximately 200-Hz) oscillations in temporal structures [In Process Citation]. J Clin Neurophysiol 17:361-376.

Domann, R., Dorn, T., Witte, O.W. (1991). Afterpotentials fowlloing penicillin-induced proxysmal depolarizations in rat hippocampal CA1 pyramdial cells in vitro. Pflugers Arch., 417(5):469-478

Empson, R.M., Jefferys, J.G. (2001). $\mathrm{Ca}^{2+}$ entry through L-type $\mathrm{Ca}^{2+}$ channels terminates epileptiform activity by activation of a $\mathrm{Ca}^{2+}$ dependent afterhyperpolarization in hippocampal CA3. Neuroscience, 102(2): 297-306.

Flint AC, Dammerman RS, Kriegstein AR (1999) Endogenous activation of metabotropic glutamate receptors in neocortical development causes neuronal calcium oscillations. Proc Natl Acad Sci U S A 96:12144-12149.

Forsythe ID, Clements JD (1990) Presynaptic glutamate receptors depress excitatory monosynaptic transmission between mouse hippocampal neurones. J Physiol 429:1-16.

Fu XC, Brezden BL, Wu, SH (1997) Hyperpolarization-activated inward current in neurons of the rat's dorsal nucleus of the lateral lemniscus in vitro. J Neurophys

Garaschuk O, Hanse E, Konnerth A (1998) Developmental profile and synaptic origin of early network oscillations in the CA1 region of rat neonatal hippocampus. $J$ Physiol (Lond) 507:219-236.

Garaschuk O, Linn J, Eilers J, Konnerth A. (2000) Large-scale oscillatory calcium waves in the immature cortex. Nat Neurosci 2000 May;3(5):452-9 
Gasparini, S. and DiFrancesco, D. (1997). Action of the hyperpolarization-activated current $\left(\mathrm{I}_{\mathrm{h}}\right)$ blocker ZD7288 in hippocampal CA1 neurons. European Journal of Neuroscience, 435:99-106.

Goldbeter A (1996) Biochemical Oscillations and Cellular Rhythms. Cambridge, U.K.: Cambridge University Press.

Good PI (1999) Resampling Methods. Boston: Birkhauser.

Haglund MM, Schwartzkroin PA (1990) Role of Na-K pump potassium regulation and IPSPs in seizures and spreading depression in immature rabbit hippocampal slices. J Neurophysiol 63:225-239.

Hotson JR, Prince DA (1980) A calcium-activated hyperpolarization follows repetitive firing in hippocampal neurons. J Neurophysiol 43:409-419.

Ishii TM, Takano M, Xie LH, Noma A, Ohmori H (1999) Molecular characterization of the hyperpolarization-activated cation channel in rabbit heart sinoatrial node. J Biol Chem 274:12835-12839.

Jensen MS, Yaari Y. (1997) Role of intrinsic burst firing, potassium accumulation, and electrical coupling in the elevated potassium model of hippocampal epilepsy. J Neurophysiol 77(3):1224-33.

Khalilov I, Dzhala V, Ben-Ari Y, Khazipov R (1999) Dual role of GABA in the neonatal rat hippocampus. Dev Neurosci 21:310-319.

Kohling R, Gladwell SJ, Bracci E, Vreugdenhil M, Jefferys JG (2001) Prolonged epileptiform bursting induced by $0-\operatorname{Mg}(2+)$ in rat hippocampal slices depends on gap junctional coupling. Neuroscience 105:579-587.

Korn, S.J., Giacchino, J.L., Chamberlain, N.L., Dingledine, R. (1987). Epileptiform burst activity induced by potassium in the hippocampus and its regulation by GABA-mediated inhibition. Journal of Neurophysiology, 57(1):325-340.

Lamsa K, Palva JM, Ruusuvuori E, Kaila K, Taira T (2000) Synaptic GABA(A) activation inhibits AMPA-kainate receptor-mediated bursting in the newborn (P0P2) rat hippocampus. J Neurophysiol 83:359-366.

Lastoczi, B., Kovacs, R., Nyikos, L., Kardos, J. (2002). A glutamate receptor subtype antagonist inhibits seizures in rat hippocampal slices. Neuroreport, 13(3):351356.

Leinekugel X, Medina I, Khalilov I, Ben-Ari Y, Khazipov R (1997) Ca2+ oscillations mediated by the synergistic excitatory actions of GABA(A) and NMDA receptors in the neonatal hippocampus. Neuron 18:243-255. 
Leinekugel X, Khalilov I, Ben-Ari Y, Khazipov R (1998) Giant depolarizing potentials: the septal pole of the hippocampus paces the activity of the developing intact septohippocampal complex in vitro. J Neurosci 18:6349-6357.

Leresche N, Lightowler S, Soltesz I, Jassik-Gerschenfeld D, Crunelli V. (1991) Lowfrequency oscillatory activities intrinsic to rat and cat thalamocortical cells. J Physiol 441:155-74.

Ludwig A, Zong X, Stieber J, Hullin R, Hofmann F, Biel M (1999) Two pacemaker channels from human heart with profoundly different activation kinetics. Embo $\mathrm{J}$ 18:2323-2329.

Maccaferri, G., Mangoni, M., Lazzari, A., DiFrancesco, D. (1993). Properties of the hyperpolarization-activated current in rat hippocampal CA1 pyramidal cells. Journal of Neurophysiology, 69(6):2129-2136.

Margineanu DG, Klitgaard H (2001) Can gap-junction blockade preferentially inhibit neuronal hypersynchrony vs. excitability? Neuropharmacology 41:377-383.

Matsumoto A, Arai Y, Urano A, Hyodo S (1991) Cellular localization of gap junction mRNA in the neonatal rat brain. Neurosci Lett 124:225-228.

McCormick DA, Pape HC (1990) Properties of a hyperpolarization-activated cation current and its role in rhythmic oscillation in thalamic relay neurones. J Physiol 431:291-318.

Miles R, Wong RK (1987) Inhibitory control of local excitatory circuits in the guinea-pig hippocampus. J Physiol (Lond) 388:611-629.

Murphy TH, Blatter LA, Wier WG, Baraban JM. (1992) Spontaneous synchronous synaptic calcium transients in cultured cortical neurons. J Neurosci 12(12):483445

Nagao T, Alonso A, Avoli M (1996) Epileptiform activity induced by pilocarpine in the rat hippocampal- entorhinal slice preparation. Neuroscience 72:399-408.

Numann RE, Wadman WJ, Wong RK (1987) Outward currents of single hippocampal cells obtained from the adult guinea-pig. J Physiol (Lond) 393:331-353.

Nunez A, Garcia-Austt E, Buno W, Jr. (1987) Intracellular theta-rhythm generation in identified hippocampal pyramids. Brain Res 416:289-300.

Pal, S., Limbrick, D.D., Jr., Rafiq, A., DeLorenzo, R.J. (2000). Induction of spontaneous recurrent epileptiform discharges causes long-term changes in intracellular calcium homeostatic mechanisms. Cell Calcium, 28(3):181-193. 
Pape HC (1996) Queer current and pacemaker: the hyperpolarization-activated cation current in neurons. Annu Rev Physiol 58:299-327.

Pedarzani P, Mosbacher J, Rivard A, Cingolani LA, Oliver D, Stocker M, Adelman JP, Fakler B (2001) Control of electrical activity in central neurons by modulating the gating of small conductance Ca2+-activated K+ channels. J Biol Chem 276:97629769.

Rose, C.R., Konnerth, A. (2001). Stores not just for storage. Intracellular calcium release and synaptic plasticity. Neuron, 31(4):519-522.

Ross FM, Gwyn P, Spanswick D, Davies SN (2000) Carbenoxolone depresses spontaneous epileptiform activity in the CA1 region of rat hippocampal slices. Neuroscience 100:789-796.

Sacaan AI, Schoepp DD (1992) Activation of hippocampal metabotropic excitatory amino acid receptors leads to seizures and neuronal damage. Neurosci Lett 139:77-82.

Sanotoro, B., Chen, S., Luthi, A., Pavlidis, P., Shumyatski, G.P., Tibbs, G.T., Siegelbaum, S.A. (2000). Molecular and functional heterogeneity of hyperpolarization-activated pacemaker channels in the mouse CNS. The Journal of Neuroscience, 20(14):5364-5275.

Santoro, B. and Tibbs, G.R. (1999). The HCN gene family: Molecular basis of the hyperpolarization-activated pacemaker channels. Annals of the New York Academy of Sciences, 868:741-764.

Selverston AI, Mazzoni P (1989) Flexibility of Computational Units in Invertebrate CPGs. In: The Computing Neuron (Durbin R, Miall C, Mitchison G, eds). Wokingham, England: Addison-Wesley.

Shah, M., Haylett, D.G. (2000). $\mathrm{Ca}^{2+}$ channels involved in the generation of the slow afterhyperpolarization in cultured rat hippocampal pyramidal neurons. Journal of Neurophysiology, 83(5): 2554-2561.

Schmitz D, Schuchmann S, Fisahn A, Draguhn A, Buhl EH, Petrasch-Parwez E, Dermietzel R, Heinemann U, Traub RD (2001) Axo-axonal coupling. a novel mechanism for ultrafast neuronal communication. Neuron 31:831-840.

Schuchmann S, Meierkord H, Stenkamp K, Breustedt J, Windmuller O, Heinemann U, Buchheim K (2002) Synaptic and nonsynaptic ictogenesis occurs at different temperatures in submerged and interface rat brain slices. J Neurophysiol 87:29292935. 
Southan, A.P., Morris, N.P., Stephens, G.J., Robertson, B. (2000). Hyperpolarizationactivated currents in presynaptic terminals of mouse cerebellar basket cells. Journal of Physiology, 526(1):91-97.

Staley KJ, Bains JS, Yee A, Hellier J, Longacher JM (2001) Statistical model relating CA3 burst probability to recovery from burst- induced depression at recurrent collateral synapses. J Neurophysiol 86:2736-2747.

Stocker M, Krause M, Pedarzani P (1999) An apamin-sensitive Ca2+-activated K+ current in hippocampal pyramidal neurons. Proc Natl Acad Sci U S A 96:46624667.

Strata F, Atzori M, Molnar M, Ugolini G, Tempia F, Cherubini E (1997) A pacemaker current in dye-coupled hilar interneurons contributes to the generation of giant GABAergic potentials in developing hippocampus. J Neurosci 17:1435-1446.

Szente M, Gajda Z, Said Ali K, Hermesz E (2002) Involvement of electrical coupling in the in vivo ictal epileptiform activity induced by 4-aminopyridine in the neocortex. Neuroscience 115:1067-1078.

Tanabe Y, Masu M, Ishii T, Shigemoto R, Nakanishi S (1992) A family of metabotropic glutamate receptors. Neuron 8:169-179.

Tanaka T, Hidaka H (1980) Hydrophobic regions function in calmodulin-enzyme(s) interactions. J Biol Chem 255:11078-11080.

Taylor GW, Merlin LR, Wong RK (1995) Synchronized oscillations in hippocampal CA3 neurons induced by metabotropic glutamate receptor activation. J Neurosci 15:8039-8052.

Thompson SM, Prince DA (1986) Activation of electrogenic sodium pump in hippocampal CA1 neurons following glutamate-induced depolarization. J Neurophysiol 56:507-522.

Thompson SM, Deisz RA, Prince DA (1988) Relative contributions of passive equilibrium and active transport to the distribution of chloride in mammalian cortical neurons. J Neurophysiol 60:105-124.

Traub D, Miles R (1991) Neuronal networks of the hippocampus. Cambridge: Cambridge University Press.

Treiman M, Caspersen C, Christensen SB (1998) A tool coming of age: thapsigargin as an inhibitor of sarco-endoplasmic reticulum $\mathrm{Ca}(2+)$-ATPases. Trends Pharmacol Sci 19:131-135. 
Uchida, I., Cestari, I.N., Yang, J. (1996). The differential antagonism by bicuculline and SR95531 of pentobarbitone-induced currents in cultured hippocampal neurons. Eur J Pharmacol, 307(1):89-96.

Uusisaari M, Smirnov S, Voipio J, Kaila K (2002) Spontaneous epileptiform activity mediated by GABA(A) receptors and gap junctions in the rat hippocampal slice following long-term exposure to GABA(B) antagonists. Neuropharmacology 43:563-572.

Vignes M, Clarke VR, Davies CH, Chambers A, Jane DE, Watkins JC, Collingridge GL (1995) Pharmacological evidence for an involvement of group II and group III mGluRs in the presynaptic regulation of excitatory synaptic responses in the CA1 region of rat hippocampal slices. Neuropharmacology 34:973-982.

Wainger BJ, DeGennaro M, Santoro B, Siegelbaum SA, Tibbs GR (2001) Molecular mechanism of cAMP modulation of HCN pacemaker channels. Nature 411:805810.

Wells JE, Porter JT, Agmon A (2000) GABAergic Inhibition Suppresses Paroxysmal Network Activity in the Neonatal Rodent Hippocampus and Neocortex. J Neurosci 20:8822-8830.

Wong RK, Traub RD (1983) Synchronized burst discharge in disinhibited hippocampal slice. I. Initiation in CA2-CA3 region. J Neurophysiol 49:442-458.

Wu, R.L., Barish, M.E. (1996) Modulation of a slowly inactivating potassium current, I(D), by metabotropic glutamate receptor activation in cultured hippocampal pyramidal neurons. J. Neurosci 19(16):6825-37.

Yamamoto T, Shiosaka S, Whittaker ME, Hertzberg EL, Nagy JI (1989) Gap junction protein in rat hippocampus: light microscope immunohistochemical localization. $\mathrm{J}$ Comp Neurol 281:269-281. 
Chapter 6: Developmental Alterations of HCN1 and

HCN2 Expression in the Mouse Neocortex and

Hippocampus 


\subsection{Abstract}

We recently demonstrated that interictal bursts in the neonatal hippocampus are timed by the hyperpolarization activated cation current, $I_{h}$. $I_{h}$ could also time other rhythms located within the cerebral cortex that also demonstrate a developmental change in their periodicity. The mRNAs for the $\mathrm{I}_{\mathrm{h}}$ channel subunits, $\mathrm{HCN} 1$ through $\mathrm{HCN} 4$, are distributed throughout the adult brain, including the cerebral cortex, and their expression pattern changes during development. Antibodies for these subunits have permitted the direct investigation of subunit protein distribution as opposed to mRNA distribution. Previous immunocytochemical studies of these subunits in the cerebral cortex have either focused on the adult brain, or examined changes in $\mathrm{I}_{\mathrm{h}}$ immunoreactivity at the level of the tissue, but not at the cellular level. Therefore, the purpose of this study was to investigate developmental alterations in the expression of $\mathrm{HCN} 1$ and $\mathrm{HCN} 2$ at the cellular level in the cerebral cortex. We demonstrate that in the neocortex, HCN1 progresses from pyramidal somata to apical dendrites during development and is also located in GABAergic synaptic terminals, while $\mathrm{HCN} 2$ expression decreases in pyramidal neurons during development. In the hippocampus, $\mathrm{HCN} 1$ expression moves from pyramidal somata to apical dendrites during development and is also located in GABAergic synaptic terminals, while HCN2 expression remains constant in pyramidal somata. These maturational alterations could underlie the developmental changes occurring in the periodicity of some cerebral cortical rhythms. 


\subsection{Introduction}

Nervous system maturation involves progressive changes in ionic currents that underlie neuronal activation (Spitzer, 1979; O'Dowd et al., 1988; Desarmenien et al., 1993; Liu et al., 1996; Gao and Ziskind-Conhaim, 1998; Moody, 1998), and among these is the hyperpolarization-activated current, $\mathrm{I}_{\mathrm{h}}$ (Pape, 1996; Richter et al., 1997; Robinson and Siegelbaum, 2003). This current has the capacity to function as a pacemaker, thus aiding the coordination of synchronous neuronal activity and facilitating the production of spontaneous, synchronous, oscillatory activity in a neuronal network (Pape, 1996). This synchronous oscillatory activity timed by $I_{h}$ (Strata et al., 1997) has been linked to the maturation of neural circuitry in the cerebral cortex, and has also been implicated in human (Foehring and Waters, 1991), feline (Timofeev et al., 2002), and rodent (Chen et al., 2001a; Agmon and Wells, 2003) epileptic paradigms.

The channels underlying $\mathrm{I}_{\mathrm{h}}$ are composed of 4 known protein subunits encoded by the hyperpolarization-activated, cyclic-nucleotide gated cation channel $(\mathrm{HCN})$ gene family. Four subunits are currently recognized (HCN1-4), and $I_{h}$ channels have electrophysiological properties determined by their subunit composition, since each subunit has unique activation kinetics (Santoro et al., 1998; Santoro and Tibbs, 1999; Santoro et al., 2000; Chen et al., 2001b). The level of mRNA expression of each subunit is activity and developmentally regulated. In addition to being modulated by epileptiform activity (Brewster et al., 2002), HCN mRNA expression demonstrates large variations of expression across the first four postnatal weeks (Bender et al., 2001). The recent development of antibodies against the subunit proteins allowed the investigation of their expression in adult rodents. Until now, it has only been demonstrated that HCN1 
subunits have a compartmentalized expression limited to the dendrites of mature pyramidal cells (Lorincz et al., 2002), and that the overall level of HCN1, HCN2, and HCN4 expression in hippocampal tissue changes with development (Vasilyev and Barish, 2002). Specific developmental changes of HCN subunit expression at the cellular and subcellular level have yet to be determined.

We recently demonstrated that the neonatal hippocampus generates a temporally precise rhythm of interictal-like bursts that is timed by $\mathrm{I}_{\mathrm{h}}$ (Chapter 4$)$, and that this temporal regularity diminishes shortly after the first postnatal week (Chapter 5). Furthermore, $I_{h}$ has been proposed to pace giant depolarizing potentials in the hippocampus (Strata et al., 1997), network bursts that are limited to the first postnatal week (Ben-Ari et al., 1989). The developmental variations in these neuronal rhythms could reflect distinct changes in the expression of $\mathrm{HCN}$ subunits in specific cell types or in subcellular locations. Here we investigated alterations in immunoreactivity for HCN1 and $\mathrm{HCN} 2$, the predominant $\mathrm{HCN}$ subtypes found in the cerebral cortex (Santoro et al., 2000), at the cellular and sub-cellular levels during neocortical and hippocampal development in the mouse. We demonstrate developmental changes in $\mathrm{HCN}$ subunit immunoreactivity in both regions.

\subsection{Methods}

Preparation of tissue sections: Timed-pregnant ICR white mouse dams (Hilltop Lab Animals, Scottdale, PA) were monitored at 12-hour intervals to determine time of delivery. The first 24 hours after birth were designated P0. Brain tissue was fixed by either aortic perfusion of fixative or by immersing the fresh brain in fixative. For perfusions, mice were anesthetized by interperitoneal injection of $4 \%$ chloral hydrate $(0.2$ 
cc per $100 \mathrm{~g}$ bodyweight). Once deep anesthesia was achieved, the mice were perfused transcardially via a gravity flow system with either $0.9 \%$ saline or $0.15 \mathrm{M}$ phosphate buffered saline (PBS) until the solution returning to the right atrium was clear $(\sim 30 \mathrm{~s})$, followed by pump perfusion of $30-45 \mathrm{ml}$ of $4 \%$ paraformaldahyde or $4 \%$ paraformaldahyde with 0.1 or $0.025 \%$ glutaraldehyde in PBS at $1-3 \mathrm{ml} / \mathrm{min}$. The brain was typically allowed to rest in the skull for 30 minutes before being removed and placed into 30\% sucrose in PBS overnight for cryoprotection. For immersion fixation, mice were anesthetized with isoflurane in a gas anesthetic chamber, and then their brains were removed quickly into ice-cold artificial cerebrospinal fluid (aCSF). The dorsal portion of the cerebral cortex was removed to expose the dorsal portion of the hippocampus, and the brain was then transferred to fixative (4\% paraformaldahyde or $4 \%$ paraformaldahyde with 0.1 or $0.025 \%$ glutaraldehyde in PBS). To improve anti-GABA staining, sections were occasionally post-fixed for 30 minutes in $4 \%$ paraformaldahyde with $0.1 \%$ glutaraldehyde in PBS before application of primary antibody. ACSF was composed of (in $\mathrm{mM}$ ) $\mathrm{NaCl} 126, \mathrm{KCl} 3, \mathrm{NaH}_{2} \mathrm{PO}_{4} 1.2, \mathrm{CaCl}_{2} 2.0, \mathrm{MgSO}_{4} 1.3, \mathrm{NaHCO}_{3} 26$, and dextrose 20, and was saturated with a $95 / 5$ mixture of $\mathrm{O}_{2} / \mathrm{CO}_{2}$.

The cryoprotected brain was mounted to a freezing stage microtome (Microm; Germany) with M-1 embedding matrix (Lipshaw; Pittsburgh, PA), frozen, and 40-60 $\mu \mathrm{M}$ horizontal sections were cut and collected into PBS. Developing mice, P5 through P25, and adult mice $(>\mathrm{P} 180)$ were studied. A total of 55 mice were used for these experiments. 
Immunocytochemistry: Sections were rinsed 3 times ( $>15$ min each) in PBS. Sections were blocked by bathing with $4 \%$ normal horse serum (NHS) in PBS with $0.5 \%$ Triton X-100 (Fisher Biotech, New Jersey) for 1 hour at room temperature with gentle agitation and then transferred directly into primary antibody. Primary antibodies include: affinity purified rabbit anti-HCN1 IgG, rabbit anti-HCN2 IgG, (Alomone labs, Jerusalem, Israel), monoclonal mouse anti-GAD65, mouse anti-parvalbumin, mouse anti-calmodulin kinase type II, and monoclonal mouse anti-GABA, all from SimgaRBI (St. Louis, MO). AntiHCN antibodies were typically diluted at 1:250 in a vehicle of PBS with $4 \%$ NHS and $0.1 \%$ Triton X-100. Other antibodies were used at concentrations ranging from 1:5001:2000. For experiments utilizing double-labeling of antigens, both primary antibodies were included simultaneously in the vehicle. Incubation in primary antisera began with 1 hour at room temperature with gentle agitation followed by either 24 hours at room temperature with agitation then 24 hours at $4{ }^{\circ} \mathrm{C}$ without agitation or 48 hours at $4{ }^{\circ} \mathrm{C}$ without agitation. Sections were then rinsed 3 times $(10 \mathrm{~min}$ each) in preparation for application of the appropriate secondary antibodies. Secondary antibodies were diluted at 1:500 in vehicle and include: Alexa 546 mouse anti-rabbit $\operatorname{IgG}\left(\mathrm{ab}^{\prime}\right)_{2}$ fragments, Alexa 546 goat anti-rabbit $\operatorname{IgG}\left(\mathrm{ab}^{\prime}\right)_{2}$ fragments, Alexa 633 mouse anti-rabbit $\operatorname{IgG}(\mathrm{ab})_{2}$ fragments, Alexa 633 goat anti-rabbit IgG (ab') $)_{2}$ fragments, Alexa 633 goat anti-mouse $\operatorname{IgG}\left(a b^{\prime}\right)_{2}$ fragments and FITC horse anti-mouse $\operatorname{IgG}(\mathrm{H}+\mathrm{L})$ (Vector Laboratories, CA). In experiments needing two different secondary antibodies, sections were incubated with both antibodies simultaneously. Sections were incubated in the dark with secondary antibodies for 1 hour at room temperature with gentle agitation, and then washed three 
times (10 min each) with PBS. They were then mounted with Vectashield (Vector Laboratories, CA), cover slipped, and kept at $4^{\circ} \mathrm{C}$ until imaged.

Controls were performed to verify immunocytochemical specificity, and they included omitting the primary antibody and pre-adsorbing the primary antibody with its antigen. For the latter, HCN antibody solution was prepared as described. However, a portion of the antibody solution was removed from the lot, and antigen was added to the solution at a concentration ration of 1:1 (antigen:antibody) by weight. The lots with and without antigen both rest at room temperature with gentle agitation for 1-2 hours, then they were used to process sections from the same animals in the manner described above. Representative examples of control experiments are presented with the appropriate Results figures.

All experiments were performed on at least 2 separate animals simultaneously with the same solutions. This increased the reliability of data compared between age groups, since both animals were exposed to identical solutions, temperature alterations, agitation, etc.

Imaging: Imaging was done with an inverted Zeiss LSM 510 laser-scanning microscope and an inverted Zeiss LSM 510-Meta laser-scanning microscope. The slices were imaged with a $5 \mathrm{x} 0.15 \mathrm{NA}$ objective, a $10 \mathrm{x} 0.5 \mathrm{NA}$ objective, a $20 \mathrm{x} 0.75 \mathrm{NA}$ objective, a $63 \mathrm{x}$ 1.20NA water-immersion objective, and a 100x 1.40NA oil-immersion objective. Most pictures illustrated in the Figures are $2 \mu \mathrm{M}$ optical sections. For imaging FITC conjugated antibody, the $488 \mathrm{~nm}$ HeNe laser line was used for excitation with a 505-530 nm bandpass emission filter; for imaging Alexa 546 conjugated antibody, the $543 \mathrm{HeNe}$ 
laser line was used for excitation with a 560-615 bandpass emission filter; for imaging Alexa 633 conjugated antibody, the HeNe $633 \mathrm{~nm}$ laser line was used for excitation with a 650 long pass emission filter.

Cell counting: For the experiment that utilized cell counting, a $2 \mu \mathrm{m}$ thick optical slice located 18-20 $\mu \mathrm{m}$ below the surface of neocortical tissue sections was analyzed. A square with sides of $250 \mu \mathrm{m}$ was digitally overlaid upon layer III from these optical slices, and all neurons with a gray value two-standard deviations above the mean background gray value were counted within this square. An area clearly devoid of cellular immunostaining was sampled for background intensity (see Figure 6-2 and legend for example). A total of nine sections from nine animals were studied in this manner; three from each of three ages (P5, P15, and P25).

\subsection{Results}

\subsubsection{HCN1 expression in the developing and mature neocortex}

In the first postnatal week, cytoplasmic immunostaining was found inside the somata and proximal dendrites of nearly all pyramidal neurons located in cortical layers II, III, V and VI (Figs. 6-1,A-B; see arrows in Fig. 1B). Cells were identified as pyramidal neurons based on their numerical density, pyramidal morphology, and positive immunolabelling with antibodies for type $\mathrm{II} \mathrm{Ca}^{2+} /$ calmodulin-dependent protein kinase (CamK) (Figs. 6-2,A-C), a protein exclusively expressed in the cortex by pyramidal neurons (Erondu and Kennedy, 1985; Liu and Jones, 1997). Additionally, in all cortical layers, HCN1 immunostaining was found inside the somata of non-pyramidal 
interneurons; these were identified as such based on their non-pyramidal morphology and their immunostaining by anti-GABA antibodies (Figs. 6-2,D-F). This HCN1 immunoreactivity in GABAergic neurons did not change throughout development.

After the first postnatal week, HCN1 immunostaining within pyramidal cell somata was absent (Figs. 6-1,C-D). However, the middle and distal portions of apical dendrites were now immunostained for $\mathrm{HCN} 1$ (Fig. 6-1C), and punctate $\mathrm{HCN} 1$ immunoreactivity surrounded pyramidal neuron somata (arrows in Figs. 6-1,C-D).

By the fourth postnatal week, the density of immunoreactive distal apical dendrites had increased and the supragranular layers contained very dense HCN1immunostained apical dendritic tufts (Fig. 6-1E), consistent with previous reports (Lorincz et al., 2002; Vasilyev and Barish, 2002). The expression of HCN1 immunoreactivity remained unchanged after P25 (data not shown).

Punctate HCN1 immunoreactivity surrounding pyramidal cell somata was present at least as early as P12 and maintained throughout later development (Figs. 6-1,C-F). The punctate $\mathrm{HCN} 1$ immunostaining surrounded the CamK immunopositive cytoplasm (arrows in Figs. 6-2,J-L) and also colocalized with immunostaining for GAD65 (Figs. 62,G-I and 6-2,P-R), a marker for synaptic terminals containing GABA (Kaufman et al., 1991). Furthermore, non-pyramidal interneurons that stained immunopositive for parvalbumin (PV) were also immunopositive for HCN1 in their somata (arrows in Figs. 6-2,M-O). Double-labeling of HCN1-expressing non-pyramidal interneurons with PV could not be tested prior to P11, as PV is not expressed until this time period (de Lecea et al., 1995; Vogt Weisenhorn et al., 1998). 
HCN1 immunostaining was not seen with the omission of the primary antibody (data not shown) or when the primary antibody was pre-incubated with its antigen (Figs. 6-1,G-H). A summary diagram of the development of HCN1 immunoreactivity in the neocortex is provided in Figure 6-9A.

\subsubsection{HCN2 expression in the developing and mature neocortex}

HCN2 immunoreactivity was found in the entire rostral to caudal extent of the neocortex with an abrupt decrease in staining upon transition to the entorhinal cortex (Fig. 6-3A). HCN2 immunostaining was not seen with omission of the primary antibody (data not shown) or when the primary antibody was pre-incubated with its antigen (Fig. 6-3B). At the end of the first postnatal week (P5-P7), HCN2 immunostaining was intense inside the somata of neurons in layers II and III and weaker in deeper layers (Figs. 6-3C). The majority of immunopositive neurons were identified as pyramidal neurons based on their numerical density, their morphology, and their positive immunoreactivity for CamK (Figs. 6-4,A-B).

By the beginning of the third postnatal week there was a decrease in the intensity and numerical density of neurons staining immunopositive for HCN2 (Fig. 6-3D). This trend continued with development, reaching the mature pattern at P25 (Fig. 6-3E) that remained unchanged in the adult (data not shown). As a quantitative measure of the decrease in the number of HCN2 immunopositive neurons, cell counting was performed (see Methods for details). P16 and P25 animals had on average $62 \%$ and $21 \%$, respectively, of the HCN2 immunostained neurons compared with P5 (compare Figs. 6- 
3,C-E). It is likely that this was partially due to a decrease in HCN2 immunoreactive pyramidal neurons, since there was a developmental decrease in the number of neurons that were immunopositive for both HCN2 and CamK (Figs. 6-4, G-I).

In the first postnatal week, $\mathrm{HCN} 2$ immunoreactivity was found inside the somata of some but not all neurons in layers II to VI that also stained immunopositive for GABA (Figs. 6-4,D-F) and were found throughout development (data not shown). At no age were PV neurons immunoreactive for HCN2 (Figs. 6-4,J-L). A summary diagram of the development of $\mathrm{HCN} 2$ immunoreactivity in the neocortex is provided in Figure 6-9B.

\subsubsection{HCN1 expression in the developing and mature hippocampus}

In the first postnatal week (P5-P7), HCN1 immunostaining was observed inside the somata of pyramidal neurons in the strata radiatum, oriens, and pyramidale (Figs. 65A-C); CA3 stained more intensely than did CA1 (Fig. 6-5A). As in the neocortex, from the middle of the second postnatal week, somatic HCN1 immunoreactivity in most pyramidal neurons was no longer detectable (Figs. 6-5D-F), but HCN1 immunostaining was present in the stratum lacunosum-moleculare of CA1 and subiculum. This pattern

remained unchanged in P25 (Fig. 6-5G) to adult (not shown). Given the high concentration of distal apical dendrites from CA1 pyramidal neurons that occupy the stratum lacunosum-moleculare, we hypothesized that $\mathrm{HCN} 1$ immunoreactivity was localized on these dendrites; indeed, under high-power objectives, immunopositive tubular dendrite-like structures were visible in the stratum lacunosum-moleculare (Fig. 65I). This staining appeared to be within the membrane. The stratum lacunosum- 
moleculare of CA3 and dentate gyrus were only very weakly immunopositive for HCN1 (Figs. 6-5D,G).

From the end of the second postnatal week and later, the stratum pyramidale of CA3 still stained strongly immunopositive for HCN1 (Figs. 6-5D-H) in spite of the loss of HCN1 immunostaining in pyramidal neuron somata. This HCN1 staining was punctate (Figs. 6-5E,F,H) and was found to be outside of pyramidal somata (notice that HCN1 immunoreactivity surrounds the CamK staining in Figs. 6-6,G-I) and contained within GAD65 immunoreactive puncta (Figs. 6-6J-L).

Although absent from pyramidal somata, HCN1 immunoreactivity was present within the somata of non-pyramidal neurons (arrows in Figs. 6-5E,F). HCN1 immunoreactivity was found inside the somata of GABA (Figs. 6-6,A-C) and PV (Figs. 6-6,D-F) immunopositive interneurons. HCN1 immunostaining was not seen when the primary antibody was pre-incubated with its antigen (Figs. 6-5J,K) or with omission of the primary antibody (Fig. 6-5L). A summary diagram of the development of HCN1 immunoreactivity in the hippocampus is provided in Figure 6-9C.

\subsubsection{HCN2 expression in the developing and mature hippocampus}

As for HCN1 in the neonatal hippocampus (P5-P7), expression of HCN2 was found in the strata radiatum, oriens, and pyramidale, with the highest immunoreactivity in CA3 (Fig. 6-7A). HCN2 immunostaining was found inside the somata of neurons in the stratum pyramidale in the neonate (Fig. 6-7,A-B), and this pattern remained throughout development (Figs. 6-7D,G). However, scattered cells were observed in CA3 
demonstrating a uniquely intense HCN2 staining within their somata (see arrows in Figs. 6-7,B-C for examples); these were found only in the first postnatal week (contrast Figs. 6-7,B,C with 6-7,E-F). The cells that were intensely immunopositive for HCN2 inside their somata were immunonegative for CamK (Figs. 6-8,A-C), but immunopositive for GABA (Fig. 6-8,D-F); therefore, they were non-pyramidal GABAergic interneurons. However, not all GABA immunopositive neurons were HCN2 immunopositive (Fig. 68,D-F). By the fourth postnatal week, the stratum lacunosum-moleculare of CA3 and the stratum lacunosum-moleculare of dentate gyrus demonstrated intense HCN2 immunostaining, which is illustrated in a P26 section in Figure 6-7G. In contrast to HCN1 immunoreactivity, the stratum lacunosum-moleculare of CA1 and subiculum was only very weakly immunopositive for $\mathrm{HCN} 2$ (Fig. 6-7,G). Also in contrast to $\mathrm{HCN} 1$, HCN2 immunoreactivity was present inside the somata of cells immunoreactive for PV (Figs. 6-8,G-I)

HCN2 immunostaining was not observed when the primary antibody was preincubated with its antigen (Figs. 6-7,I). A summary diagram of the development of HCN2 immunoreactivity in the hippocampus is provided in Figure 6-9D.

\subsection{Discussion}

This study provides a detailed immunocytochemical examination of the developmental changes in the expression of $\mathrm{HCN} 1$ and $\mathrm{HCN} 2$ subunits in the neocortex and hippocampus. The main findings of this study are: 1) these two HCN subunits have a different pattern of expression in pyramidal neurons and inhibitory interneurons, and this immunoreactivity pattern changes with development, 2) different neuronal cellular compartments (i.e. somata, dendrites, and axon terminals) display immunoreactivity for 
HCN1 and HCN2 at different points in development, and 3) the developmental pattern of HCN1 and HCN2 described here correlates with known developmental changes observed in hippocampal physiology (Vasilyev and Barish, 2002) and synchronous activity of the hippocampal neuronal network in vitro (Ben-Ari et al., 1989; Garaschuk et al., 1998; Agmon and Wells 2003) and in vivo (Leinekugel et al., 2002), raising the possibility that the developmental variations of $\mathrm{HCN}$ subunits may play a specific role in the course of neocortical and hippocampal maturation and function.

\subsubsection{Summary of HCN and $I_{h}$ expression in the neocortex}

Given that immunoreactivity for $\mathrm{HCN} 1$ and $\mathrm{HCN} 2$ should indicate the presence of the respective protein, our immunocytochemical results indicate that different neuronal types and cellular compartments vary during development their expression of $\mathrm{HCN}$ subunits and thereby altering the properties of $\mathrm{I}_{\mathrm{h}}$. In pyramidal neurons, HCN1 expression was observed solely inside the somata in the neonate, and predominantly in the dendritic membrane at later stages of development; dendritic expression of HCN1 in adult neocortex was also shown by Lorincz et al., (2002). Our data are consistent with the finding that in mature pyramidal cells, $\mathrm{I}_{\mathrm{h}}$ is found at much higher levels in the apical dendrite than in the soma (Magee, 1998; Poolos et al., 2002); however, based on our data, it is expected that in the neonate the somatic membrane would contain the majority of $\mathrm{I}_{\mathrm{h}}$ channels given the lack of $\mathrm{HCN} 1$ and $\mathrm{HCN} 2$ in the dendrites at this age. With development there was a marked decrease in the number of neocortical pyramidal neurons expressing $\mathrm{HCN} 2$; additionally, the intensity of $\mathrm{HCN} 2$ expression decreased. At 
all ages HCN2 expression was completely limited to inside the somata and proximal dendrites.

HCN1 and HCN2 were both expressed in a sub-population of GABAergic neurons. However, PV neurons expressed solely HCN1. Additionally, we provide the first direct indication that HCN1 subunits are found within GABAergic terminals of the neocortex. While $\mathrm{I}_{\mathrm{h}}$ is present in GABAergic terminals in other areas of the central nervous system (Southan et al., 2000), our results predict that $I_{h}$ will be found in GABAergic terminals in the neocortex. If our immunostaining revealed functional subunits in the somata, then it is expected that the fast component of somatic $\mathrm{I}_{\mathrm{h}}$ would decrease during development since there is a developmental decrease of somatic immunostaining for $\mathrm{HCN} 1$, the subunit with the fastest activation rate (Santoro et al, 2000).

\subsubsection{Summary of HCN and $I_{h}$ expression in the hippocampus}

In the hippocampus, HCN mRNA expression differs between neuron types and changes with development (Bender et al., 2001). However, the level of mRNA transcript present is not necessarily correlated with protein levels. Our study demonstrates that, in parallel with the developmental alteration of HCN mRNA transcript expression, there is a developmental change in the neuronal types and compartments that express HCN protein subunits. In the neonate, both pyramidal neurons and non-pyramidal GABAergic neurons expressed immunoreactivity inside their somata for HCN1 in the strata radiatum, pyramidale, and oriens throughout Ammon's horn. In the course of development, the 
expression in the non-pyramidal neurons remained, while the expression in the pyramidal neuronal somata virtually disappeared. The vast majority of HCN1 expression in the stratum pyramidale in the mature hippocampus was due to HCN1 expression inside GABAergic terminals. This is consistent with the developmental decrease in hippocampal HCN1 mRNA levels in pyramidal cells (Bender et al., 2001). However, while the somatic HCN1 expression decreased with development, the apical dendrites showed increased expression. Interestingly, the fast component of $I_{h}$ in pyramidal neurons, which is presumably mediated by channels containing HCN1 subunits (Ludwig et al., 1999; Moosmang et al., 2001), increases in relative contribution to total $\mathrm{I}_{\mathrm{h}}$ level with development (Vasilyev and Barish, 2002); this suggests that the dendritic HCN1 expression must be increasing at a rate higher than the decrease in somatic HCN1 expression.

HCN2 was expressed inside the somata of adult pyramidal neurons in the neonate. This is apparently inconsistent with results demonstrating decreased HCN2 mRNA expression in developing hippocampal pyramidal cells (Bender et al, 2001). However, this inconsistency could be resolved if only low levels of HCN2 subunit mRNA are needed to maintain $\mathrm{HCN} 2$ protein expression in older neurons. HCN2 expression was also found in GABAergic (including PV immunopositive) interneurons in the strata radiatum, pyramidale, and oriens throughout Ammon's horn. Additionally, GABAergic neurons with intense $\mathrm{HCN} 2$ expression were found scattered within the neonatal CA3; the intensity of staining in these neurons, taken together with their absence after the first postnatal week, suggest these neurons may have a special role in the development of the hippocampal neuronal network. 


\subsubsection{Co-expression of multiple HCN subunits}

While double-labeling experiments to investigate the co-expression of more than one HCN subunit within single neurons were not performed in this study due to the lack of suitable antibodies, our results allow us to make some inferences. Nearly every neocortical pyramidal neuron was immunopositive for $\mathrm{HCN} 2$ and most were immunopositive for HCN1 in the neonate. Therefore, co-expression of HCN1 and HCN2 in most neocortical pyramidal neurons is highly likely in the neonate. Interestingly, it seems that in the neonate, the soma contains both HCN1 and HCN2 expression; however, in the adult HCN1 is expressed in the apical dendrite, while HCN2 is expressed exclusively in the soma. Consequently, it is possible that mature pyramidal cells express somatic and dendritic $\mathrm{I}_{\mathrm{h}}$ currents with different properties.

Due to the large number of pyramidal neurons staining for both HCN1 and HCN2 in the neonatal hippocampus, it seems very likely that the vast majority of pyramidal neurons express both subunits, possibly within the same channel. However, HCN1 displays a developmental migration to the apical dendrites in the stratum lacunosummoleculare of CA1. Therefore, while both subunits might appear in the same neuron, heteromeric channels are likely to be found only during the first postnatal week. In both the neocortex and hippocampus, only a portion of GABAergic neurons expressed either HCN1 or HCN2, leaving open the possibility for both hetero- and homomeric channels.

Others have shown that the mRNA for HCN1 is found in cells expressing HCN2 subunit protein, and that mRNA for $\mathrm{HCN} 2$ is found in cells expressing $\mathrm{HCN} 1$ subunit protein (Brewster et al, 2002). However, it is still unknown if the protein for both HCN1 and HCN2 subunits is expressed in the same cell. The production of primary antibodies 
against $\mathrm{HCN}$ subunits raised in different host species will permit double-staining neurons to study HCN co-expression. It should also be noted that much of the immunostaining observed in this study was inside neuronal somata. Immunostaining inside the somata does not necessarily indicate that there is subunit protein present in the cell membrane, and if such subunit protein represents functional channels.

\subsubsection{Potential functional roles of $I_{h}$ channels}

HCN subunit composition determines the activation kinetics of $I_{h}$ (Franz et al., 2000; Chen et al., 2001b; Ishii et al., 2001; Moosmang et al., 2001); consequently, selective subunit expression could have profound effects on neuronal properties. For example, PV expressing interneurons are typically regarded as fast-spiking neurons (Kawaguchi et al., 1987; Kawaguchi, 1993; Kawaguchi and Kubota, 1993; Pawelzik et al., 2002), and we demonstrate that these interneurons in the neocortex express solely HCN1, the subunit with the fastest activation rate (Santoro and Tibbs, 1999; Franz et al., 2000; Moosmang et al., 2001). This would permit $I_{h}$ to participate in the production of very fast firing rates associated with this neuronal subtype.

The hippocampus exhibits rhythmic oscillations of neuronal activity both in vitro (Ben-Ari et al., 1989; Garaschuk et al., 1998) and in vivo (Leinekugel et al., 2002). Some of these are present only during the neonatal period. The developmental restriction of these oscillations could be due to specific neuronal types altering their expression of HCN subunits. For example, unique GABAergic neurons strongly immunopositive for HCN2 (see Fig. 4B) are found scattered in the neonatal CA3, but not in the juvenile or mature hippocampus. These neurons could participate in pacing so-called giant depolarizing potentials (GDPs), which are found in the hippocampus and are confined to 
the neonatal period (Ben-Ari et al., 1989; Ben-Ari, 2001). Additionally, we demonstrate that hippocampal pyramidal neuron somata contain both $\mathrm{HCN} 1$ and $\mathrm{HCN} 2$ expression in the first postnatal week, and only days later in development they lack HCN1. This temporal pattern parallels the developmental loss of the rhythmicity (Chapter 5) in $\mathrm{I}_{\mathrm{h}}$ regulated interictal bursting of the neonatal hippocampus (Chapter 4), suggesting that the higher total $\mathrm{HCN} 1$ and $\mathrm{HCN} 2$ levels in the neonatal pyramidal neuron somas is facilitating this rhythmic network activity.

In summary, our results show that HCN levels in the neocortex and hippocampus are selectively expressed in different neuron classes and neuronal cellular compartments, and the level of HCN expression varies in the course of cortical development. Selective HCN knockout mice, such the HCN2 knockout recently reported (Ludwig et al., 2003), will provide insight into the role of individual HCN subunits in neuronal function and network activity in the cerebral cortex. 


\subsection{Figures}

\section{Figure 6-1}
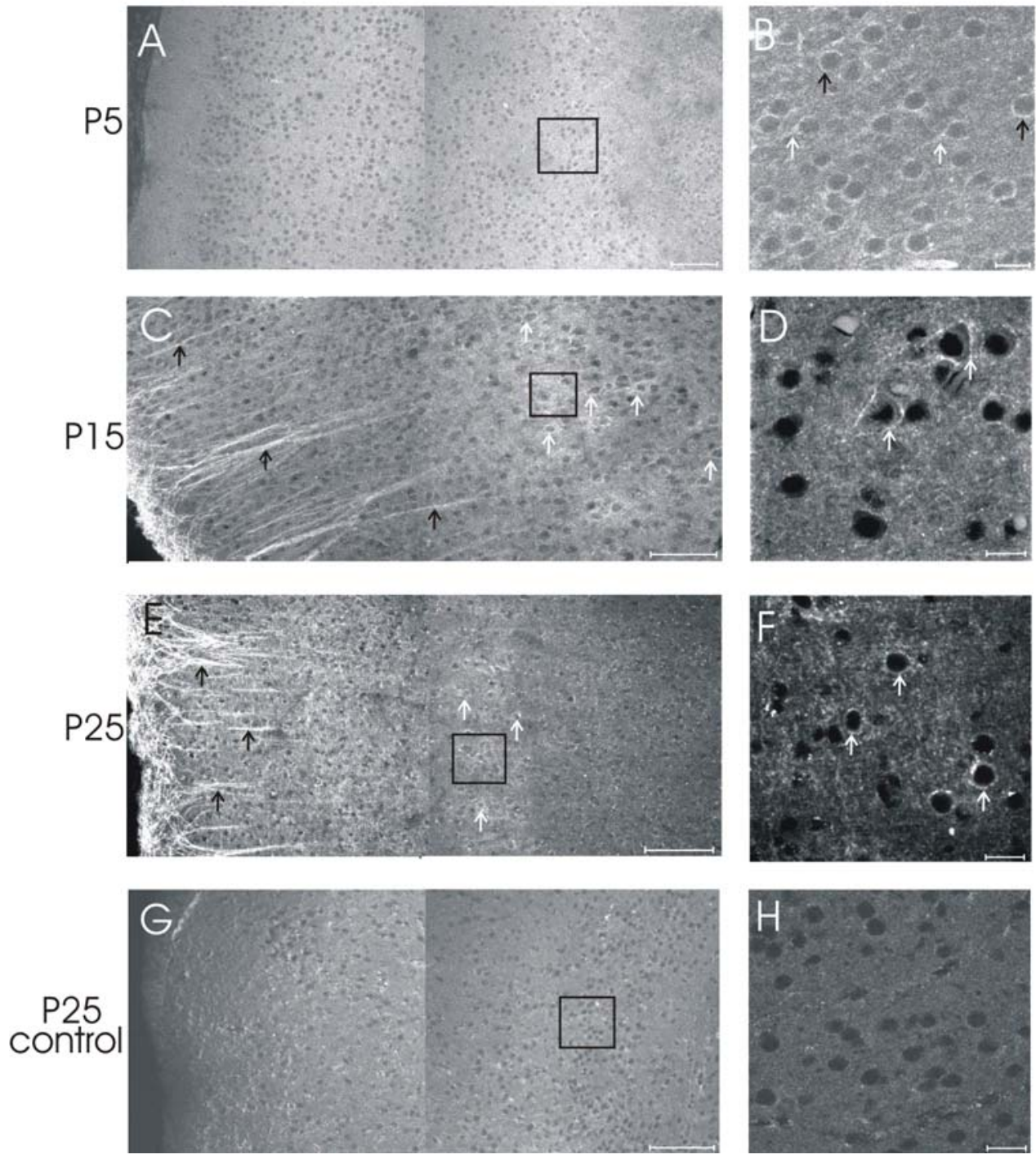

FIGURE 6-1. HCN1 IMMUNOREACTIVITY EXHIBITS A DEVELOPMENTAL PROGRESSION TOWARDS DISTAL APICAL DENDRITES IN THE NEOCORTEX.

$A$, P5 slice illustrating somatic immunostaining of cells in layers II-VI and absence of dendritic immunostaining in the supragranular layers. Pia is towards the left for all panels. $B$, higher magnification from an area equivalent to that outlined by black box in A. Black and white arrows indicate examples of somata and proximal dendrites, 
respectively, that are immunoreactive. $C, \mathrm{P} 15$ slice illustrating $\mathrm{HCN} 1$ immunoreactivity in middle and distal apical dendrites and immunoreactivity surrounding somata (white arrows). Black arrows point to immunopositive dendrites. $D$, higher magnification from area of a different slice similar to area outlined by black box in $C$. Arrows indicate HCN1 immunoreactivity surrounding somata. Note that the cytoplasm is distinctintly immunonegative. $E, \mathrm{P} 25$ slice illustrating a near absence of $\mathrm{HCN} 1$ immunoreactivity in middle portions of apical dendrites and an increased density of HCN1 immunoreactive distal apical dendrites. $F$, higher magnification from area of a different slice similar to area outlined by black box in $E$. Arrows illustrate $\mathrm{HCN} 1$ immunoreactivity surrounding the somatic membrane of pyramidal cells. $G$, P25 slice from same animal as in $E$. Primary antibody was pre-adsorbed with antigen and slice was processed with slice shown in $E$ (see Methods for details). Notice the lack of HCN1 immunoreactive dendrites. $H$, higher magnification from area of a different slice similar to area outlined by black box in $G$ with primary antibody pre-adsorbed with antigen. Notice the lack of HCN1 immunoreactivity surrounding pyramidal cell somata. Scale bars: Left panels, 100 $\mu \mathrm{m}$; Right panels, $20 \mu \mathrm{m}$. For all fields white indicates positive immunoreactivity. 

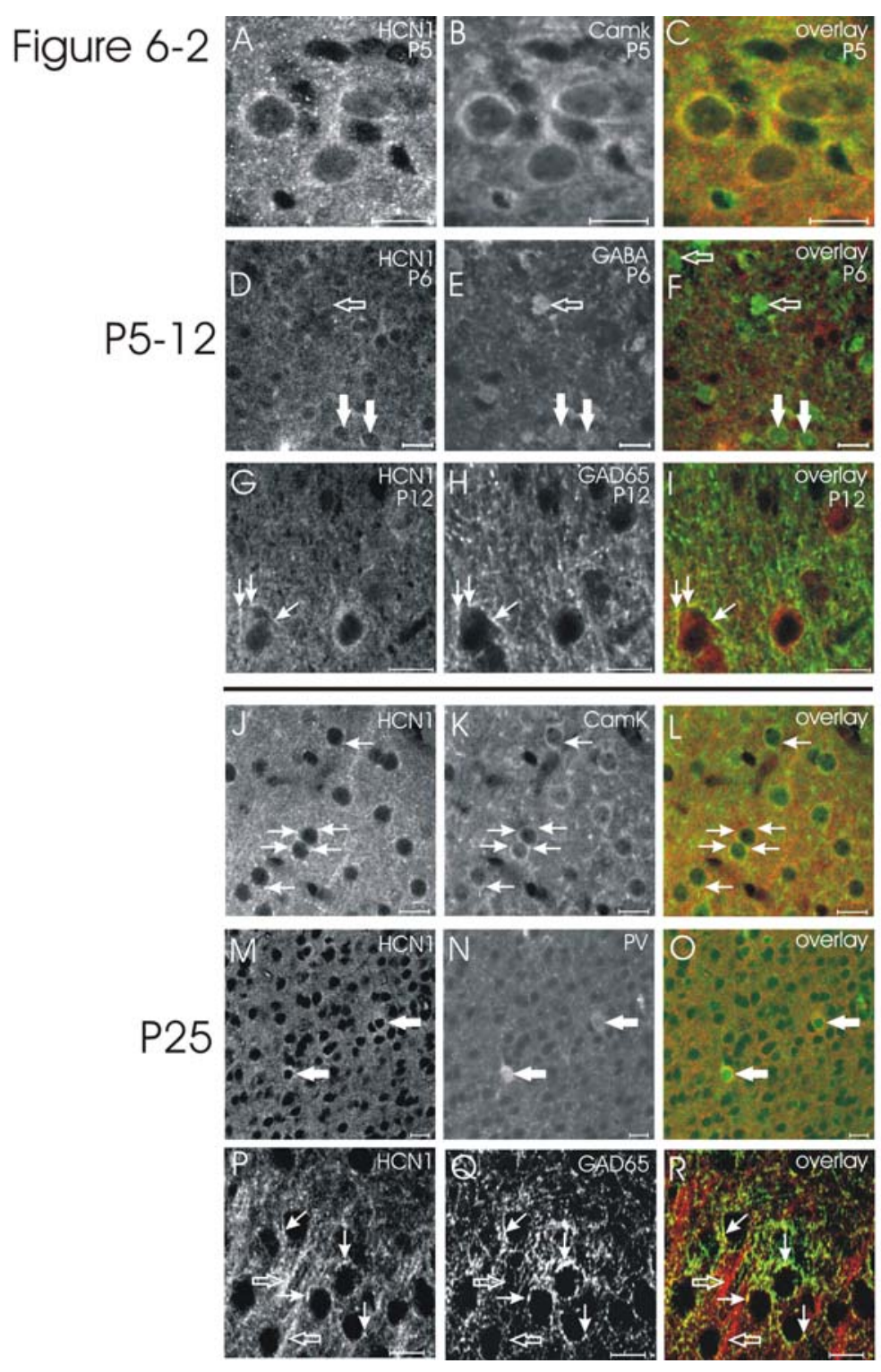

Figure 6-2. DEVELOPMENTAL VARIATIONS OF HCN1 IMMUNOREACTIVITY IN THE NEOCORTEX OCCURS WITHIN SOMATA AND PUNCTA.

Left column, HCN1 immunoreactivity. Middle column, immunoreactivity for antigen indicated in panels. Right column, overlay. Red, HCN1 immunostaining; Green, indicated antigen immunostaining. Hollow and filled arrows indicate single- and doublelabeled structures, respectively. Left and middle columns, white indicates positive immunoreactivity. $A-C$, Field from layer II of a P5 slice. Notice that HCN1 
immunoreactive cells are also CamK immunoreactive. $D-F$, Field from layer II of a P6 slice. Notice that not all GABA immunopositive cells are HCN1 immunoreactive. G-I, Field from layer II of a P12 slice. Notice that the punctate HCN1 immunostaining is also immunopositive for GAD65. $J-L$, Field from layer II of a P25 slice. Notice the HCN1 staining surrounds CamK immunoreactive cells. $M-O$, Field from a P25 slice. Notice that cells with HCN1 immunoreactive somata are also PV immunopositive. Hollow arrows indicate punctate $\mathrm{HCN} 1$ immunoreactivity for comparison. P-R, Field from a P25 slice. Notice that the punctate $\mathrm{HCN} 1$ immunostaining is also immunopositive for GAD65. Hollow arrows indicate HCN1 immunoreactive dendrites. Scale bars: $20 \mu \mathrm{m}$. Pia is towards the top for all panels. 

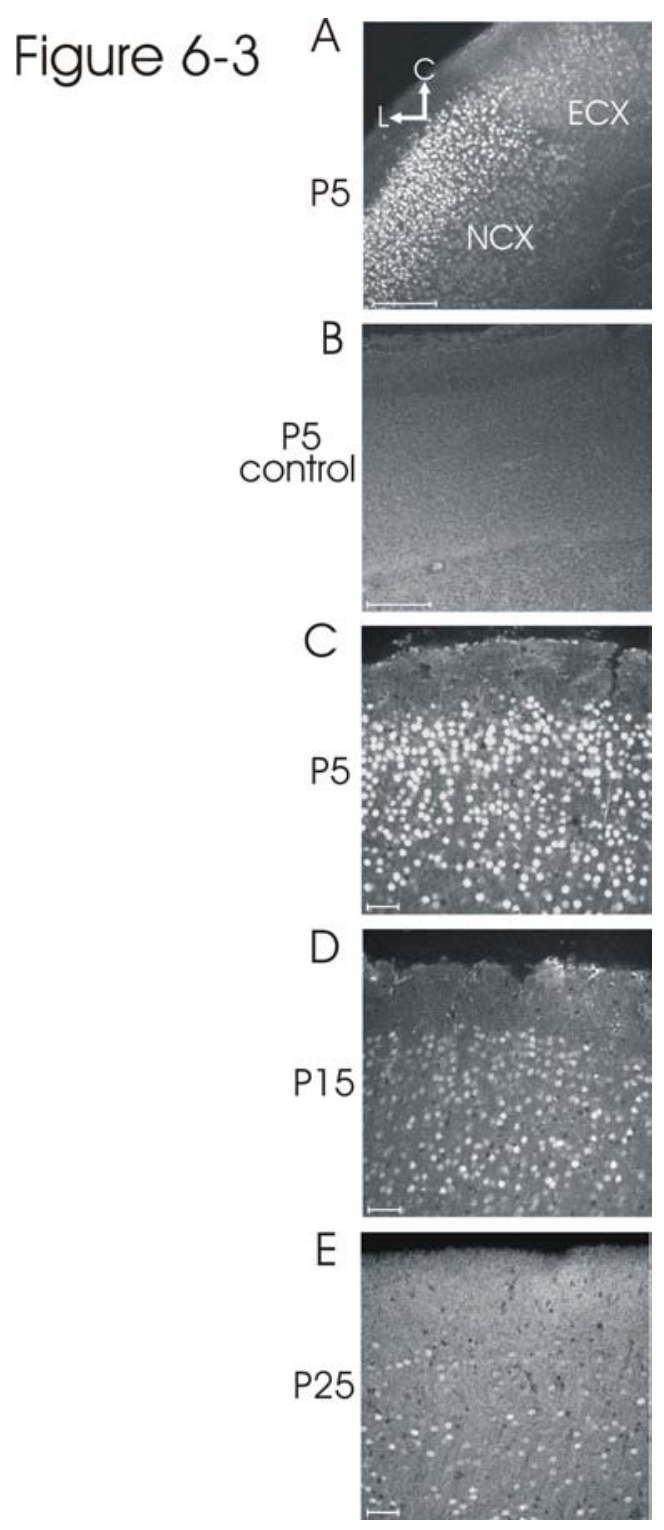

FIGURE 6-3. HCN2 IMMUNOREACTIVITY IN THE NEOCORTEX DECREASES WITH DEVELOPMENT.

$A$, P5 slice from same animal as in $B$ and $C$. Antibody was pre-adsorbed with antigen and slice was processed with slices shown in $B$ and $C$. Notice the absence of HCN2 immunoreactivity. Dotted line indicates border of layer VI and white matter. $B$, P5 slice illustrating HCN2 immunoreactivity. Notice the sharp decrease in staining at the border of the entorhinal cortex (ECX) and neocortex (NCX). Arrows denote lateral (L) and 
caudal (C). $C-D, \mathrm{HCN} 2$ immunostaining in upper layers of neocortex from P5, P15, and P25 animals, respectively. Notice that the number and intensity of cells immunostaining for HCN2 decreases with age. Scale bars: $A, B, 100 \mu \mathrm{m} ; C-D, 50 \mu \mathrm{m}$. Pia is towards the top for all panels. For all fields white indicates positive immunoreactivity. 


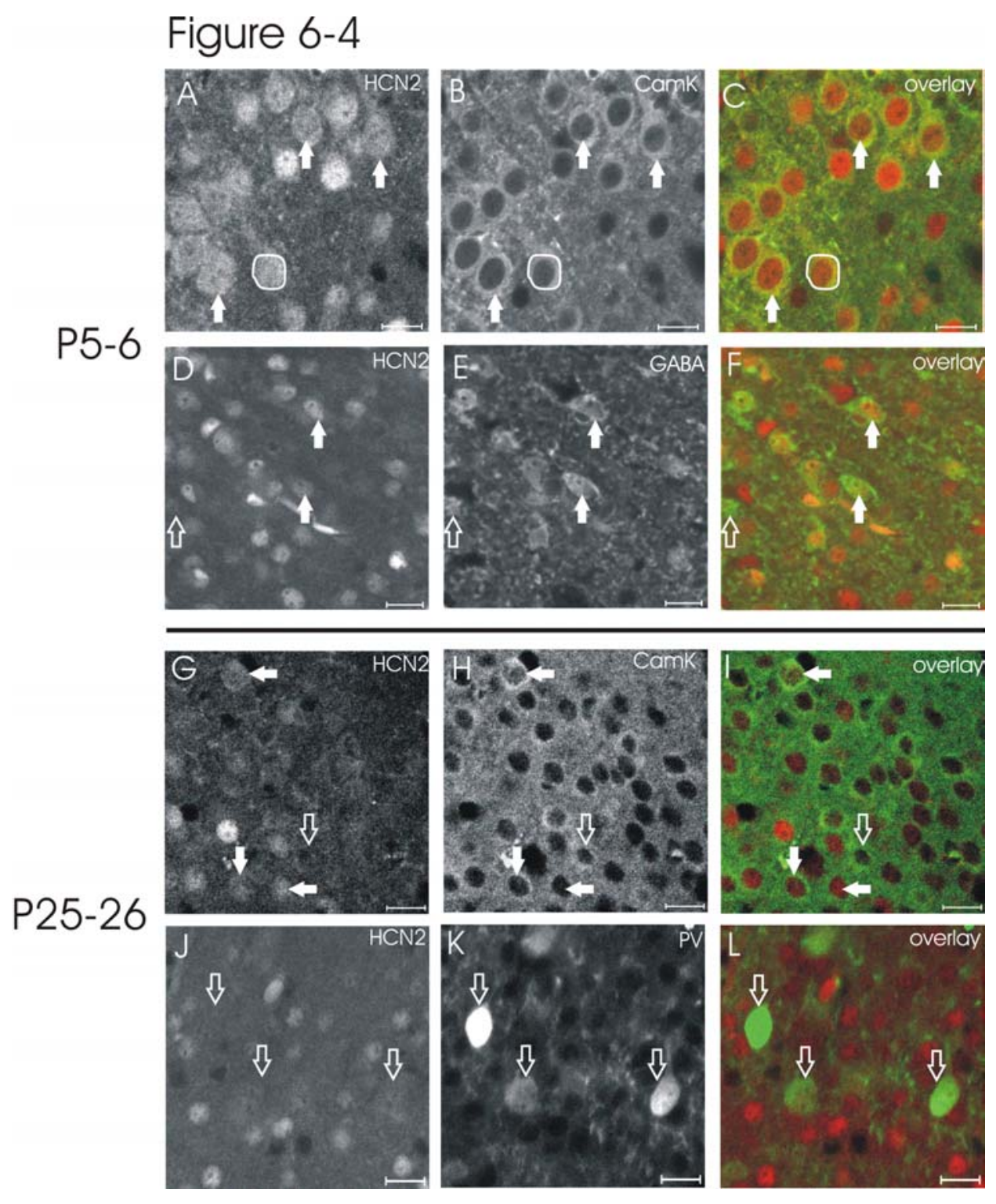

FIGURE 6-4. DEVELOPMENTAL VARIATIONS OF HCN2 IMMUNOREACTIVITY IN THE NEOCORTEX OCCURS WITHIN PYRAMIDAL AND GABAERGIC SOMATA.

Left column, HCN2 immunoreactivity. Middle column, immunoreactivity for antigen indicated in panels. Right column, overlay. Red, HCN2 immunostaining; Green, indicated antigen immunostaining. Hollow and filled arrows indicate single- and doublelabeled structures, respectively. Left and middle columns, white indicates positive immunoreactivity. $A-C$, Field from a P6 slice illustrating that nearly every CamK 
immunoreactive cells is also $\mathrm{HCN} 2$ immunoreactive. White circle sourrounds HCN2 immunostaining; note the circle also outlines the CamK staining. $D-F$, Field from a P5 slice indicating that not all GABA immunoreactive cells are HCN2 immunoreactive. G-I, Field from a P26 slice illustrating that not all CamK immunoreactive cells are immunopositive for HCN2. J-L, Field from a P25 slice illustrating that PV immunoreactive cells are not HCN2 immunoreactive. Scale bars: $A-B, 20 \mu \mathrm{m} ; D-H, 50$ $\mu \mathrm{m}$. Pia is towards the top-left for all panels. 


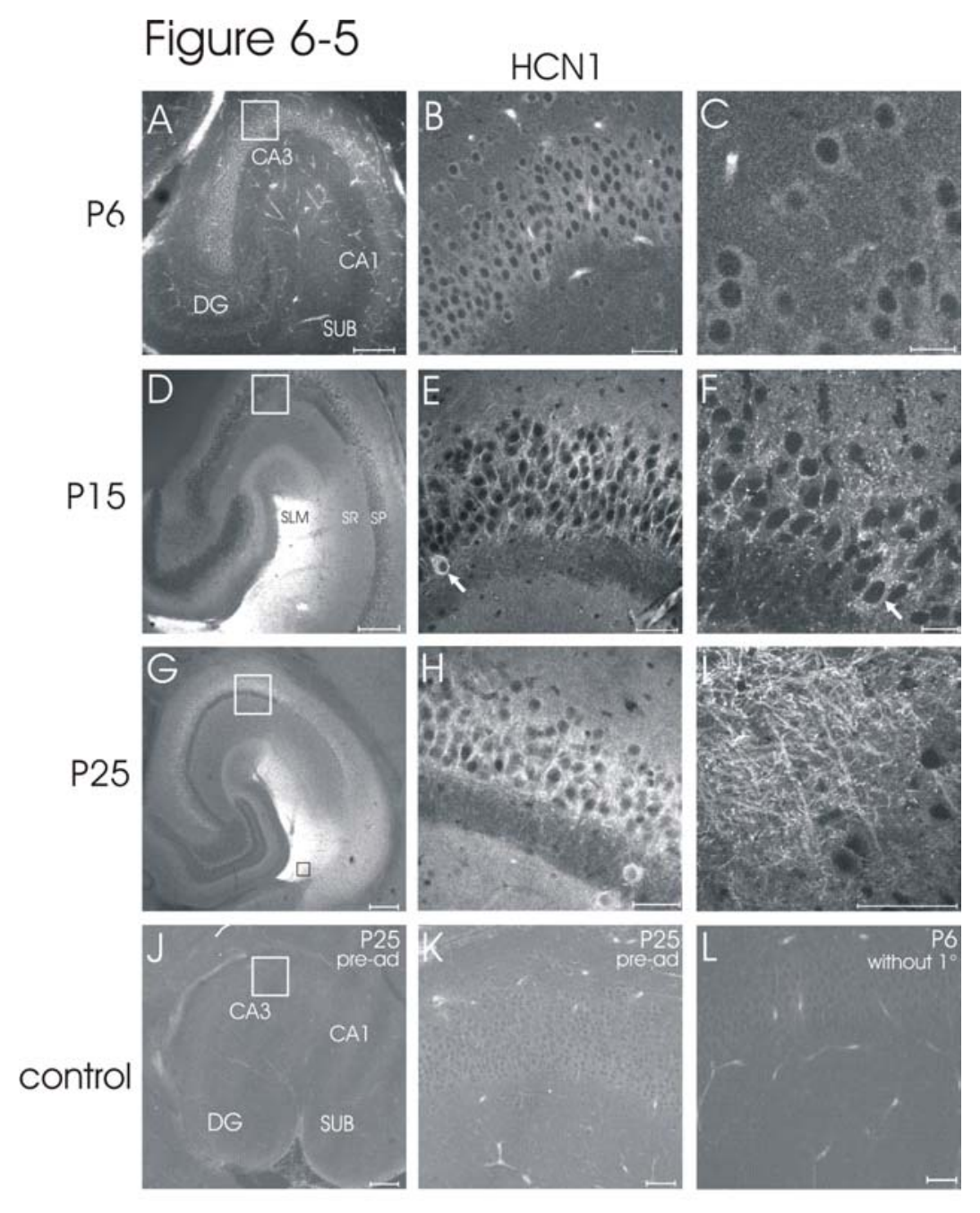

FiguRE 6-5. DeVELOPMENTAL VARIATIONS OF HCN1 IMMUNOREACTIVITY IN THE HIPPOCAMPUS OCCUR WITHIN PYRAMIDAL CELL SOMATA AND DENDRITES AND WITHIN GABAERGIC PUNCTA.

$A, D, G, \mathrm{HCN} 1$ immunoreactivity in $\mathrm{P} 6, \mathrm{P} 15$, and $\mathrm{P} 25$ slices, respectively. $\mathrm{HCN} 1$ immunoreactivity increased with development in the stratum lacunosum-moleculare of the CA1. Also note the difference in HCN1 immunoreactivity of the pyramidal cell layer, shown in $B$ and $C$ for P6, $E$ and $F$ for P15, and $H$ for $P 25$. B,E,H, higher magnification from regions in the white squares shown in $A, D$, and $G$. Notice that at P6 
nearly every somata was HCN1 immunopositive, but by P15 most pyramidal somata were immunonegative but surrounded by immunopositive puncta. $C$, higher magnification of $B . F$, higher magnification of CA3 from a different slice. Arrows in $E$ and $F$ point to labeled somata; the orientation of these cells (basal surface towards the stratum $F$ ) preclude these cells from being pyramidal neurons. Also notice that the P15P25 slices but not P6 exhibit immunostaining surrounding the pyramidal cells. I, HCN1 immunoreactive dendrites from different slice from area similar to area within black square in $G . J$, P25 slice from same animal as in $G$. Primary antibody was pre-adsorbed with antigen and slice was processed with slice shown in $G . K$, field from square in $J . L$, P6 slice from same animal as in $A$. Primary antibody was omitted from staining procedure and slice was processed with slice shown in $A$. Notice the absence of HCN1 immunoreactivity in J-L. Scale bars: left column, $200 \mu \mathrm{m}$; middle column, $50 \mu \mathrm{m}$; right column, $20 \mu \mathrm{m}$. For all fields white indicates positive immunoreactivity. 


\section{Figure 6-6}
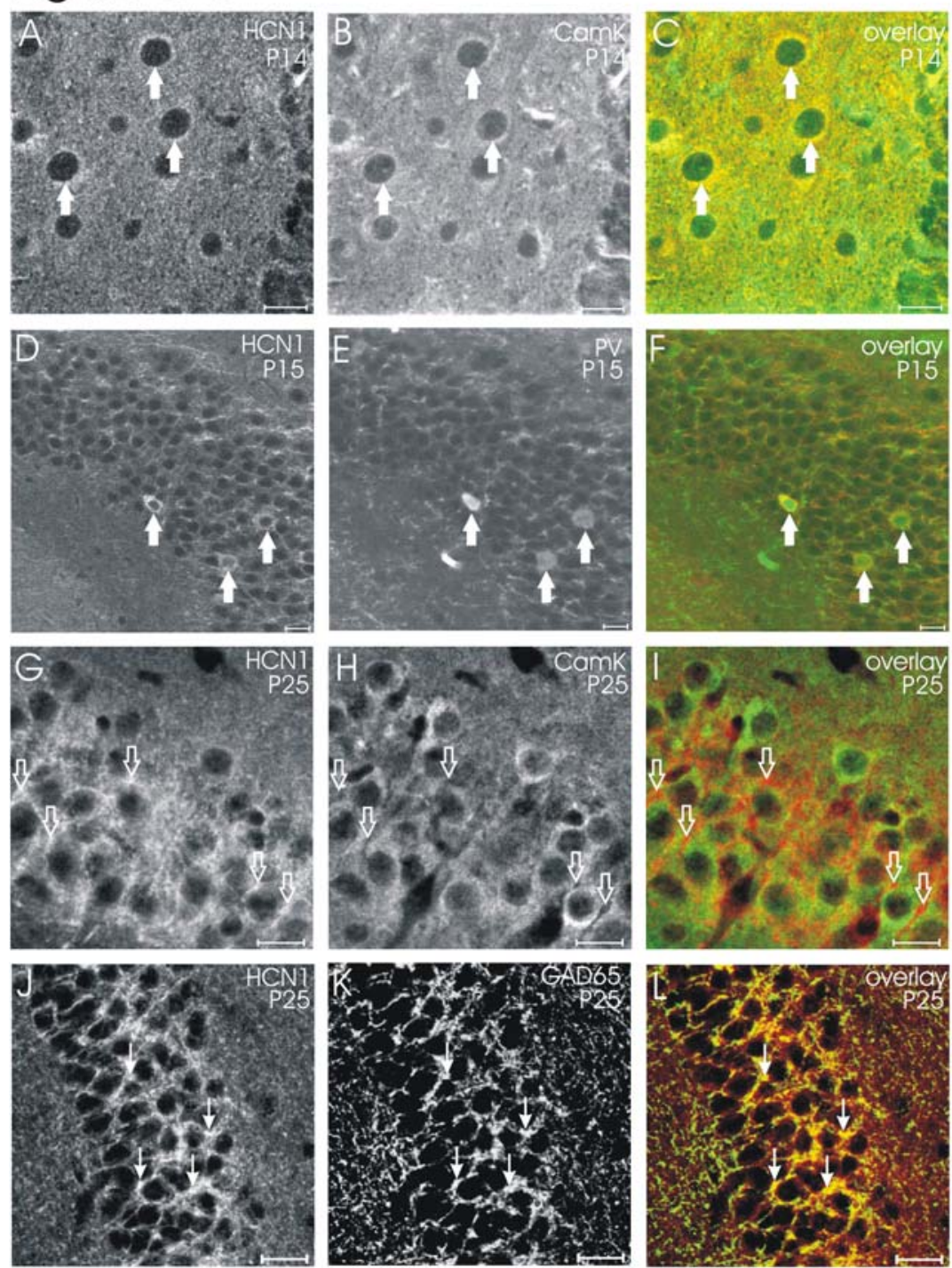
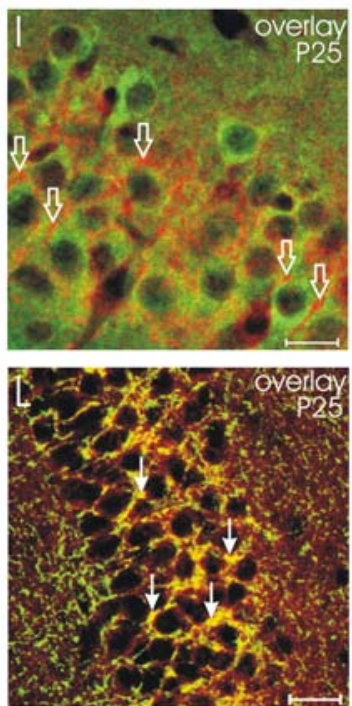

Figure 6-6. GABAERGIC CELLS, PV CELLS, AND GABAERGIC PUNCTA EXPRESS HCN1 IN THE HIPPOCAMPUS.

Left column, HCN1 immunoreactivity. Middle column, immunoreactivity for antigen indicated in panels. Right column, overlay. Red, HCN1 immunostaining; Green, indicated antigen immunostaining. Hollow and filled arrows indicate single- and doublelabeled structures, respectively. Left and middle columns, white indicates positive immunoreactivity. $A-C$, Field from a P14 slice illustrating that GABA immunoreactive 
cells are HCN1 immunoreactive. D-E, Field from a P15 slice illustrating that PV immunoreactive cells are also HCN1 immunoreactive. G-I, Field from a P25 slice illustrating punctate $\mathrm{HCN} 1$ immunostaining (arrows) surrounding CamK immunoreactive cells. J-L, Field from a P25 slice illustrating that the punctate HCN1 immunostaining surrounding pyramidal cells is immunopositive for GAD65 (arrows). Scale bars: $20 \mu \mathrm{m}$. 


\section{Figure 6-7}

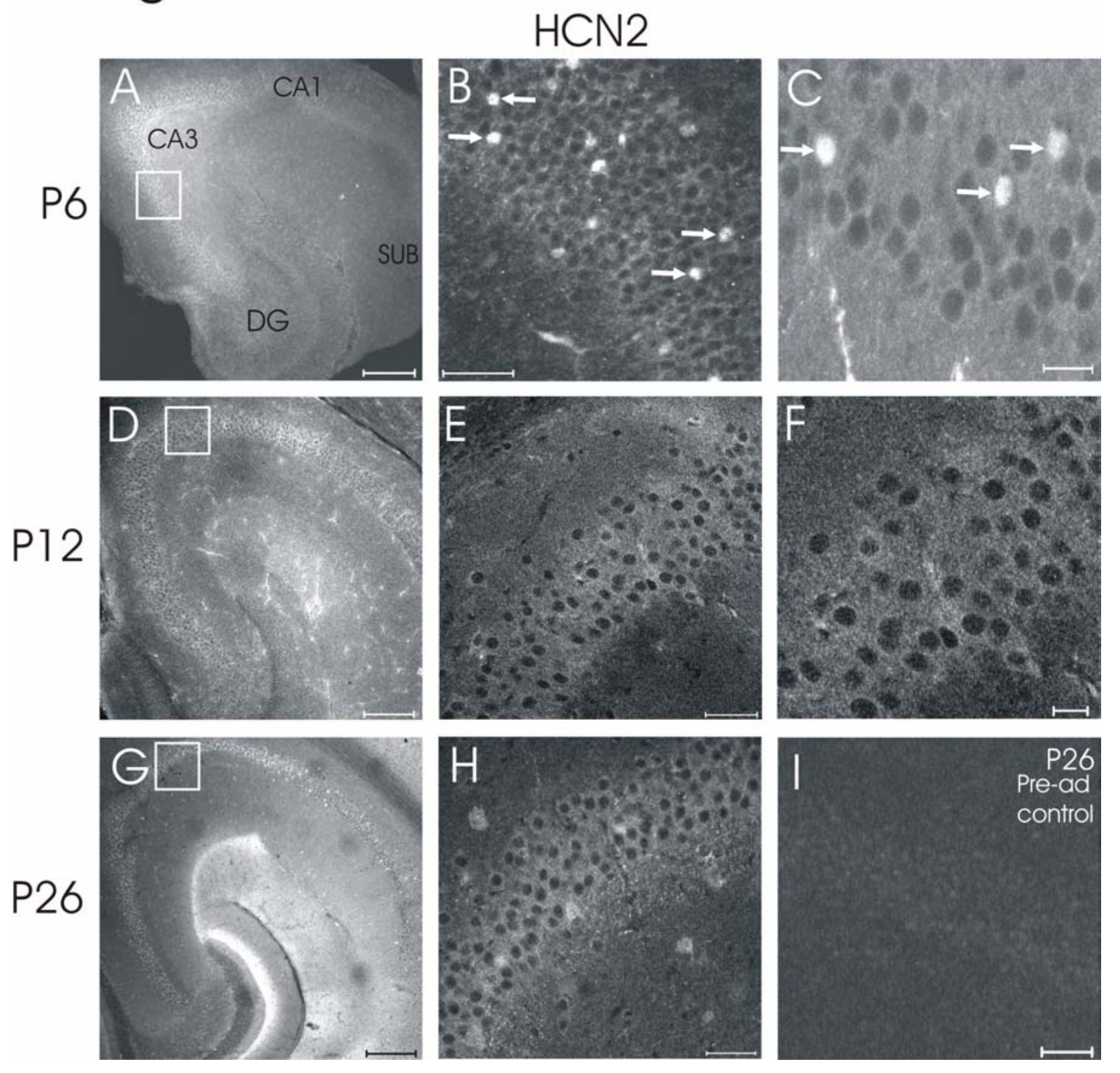

Figure 6-7. DEVELOPMENTAL VARIATIONS OF HCN2 IMMUNOREACTIVITY IN THE HIPPOCAMPUS OCCUR WITHIN SOMATA AND DENDRITES.

$A, D, G, \mathrm{HCN} 2$ immunoreactivity in $\mathrm{P} 6, \mathrm{P} 12$, and $\mathrm{P} 26$ slices, respectively. $\mathrm{HCN} 2$ immunoreactivity increased with development in the stratum lacunosum-moleculare of the CA3 and DG with development. $B, E, H$, higher magnification of area in the white squares from the slices shown in $A, C$, and $E$, respectively. C,F, higher magnifications of 
fields shown in B and E, respectively. Notice the scattered cells demonstrating intense HCN2 immunoreactivity that are present only in the P5 slice (examples are marked with arrows in $B$ and $C$ ). $I$, P26 slice from same animal as in $G$. Primary antibody was preadsorbed with antigen and slice was processed with slice shown in $G$. Field from within CA3. Notice the absence of HCN2 immunoreactivity in $I$. For all fields white indicates positive immunoreactivity. Scale bars: $A, D, G, 200 \mu \mathrm{m} ; B, E, H, I, 50 \mu \mathrm{m} ; C, F, 20 \mu \mathrm{m}$. 


\section{Figure 6-8}
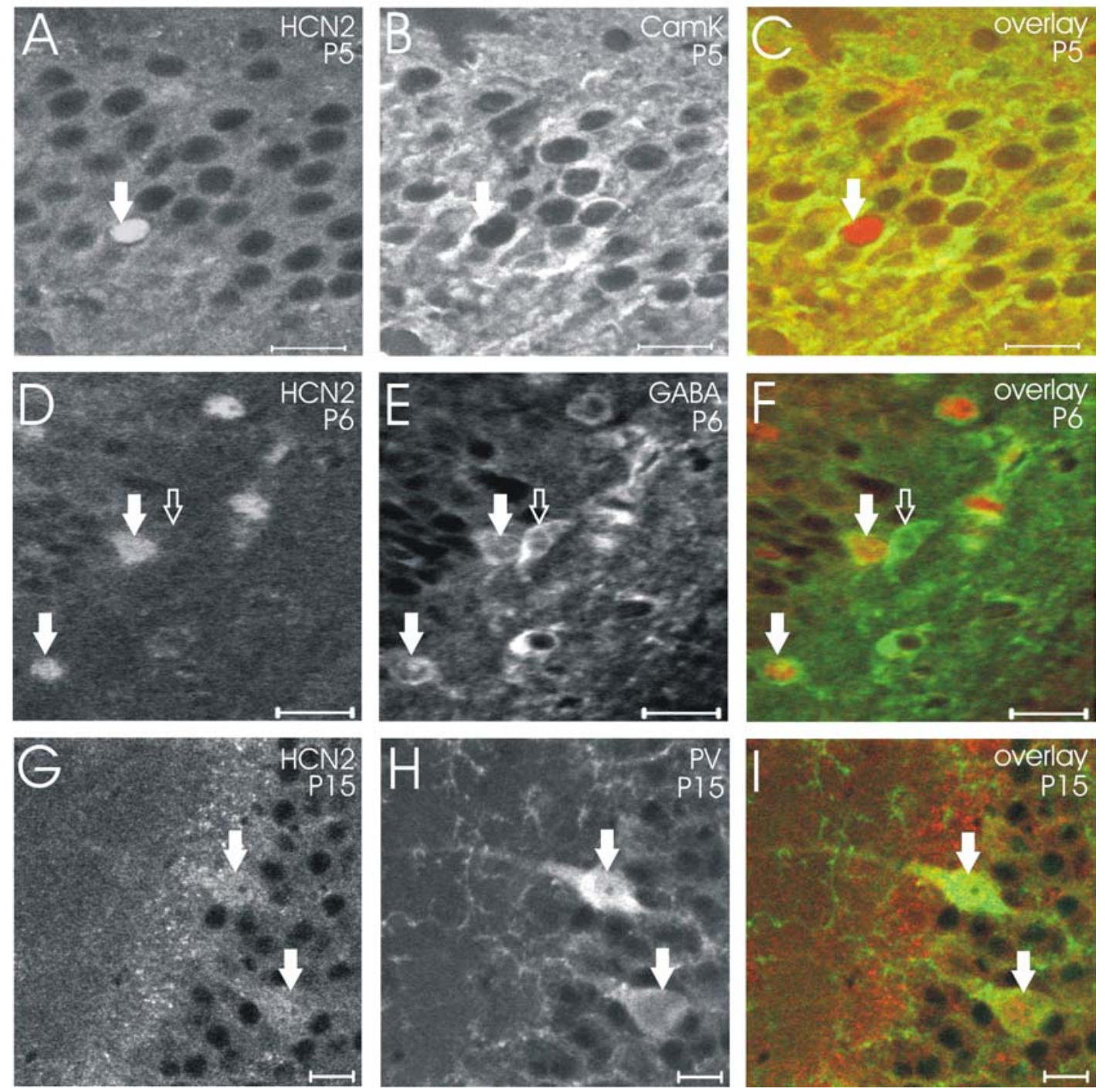

FIGURE 6-8. HCN2 IMMUNOREACTIVITY IS FOUND WITHIN GABAERGIC AND PARVALBUMIN NEURONS.

Left column, HCN2 immunoreactivity. Middle column, immunoreactivity for antigen indicated in panels. Right column, overlay. Red, HCN2 immunostaining; Green, indicated antigen immunostaining. Hollow and filled arrows indicate single- and doublelabeled structures, respectively. Left and middle columns, white indicates positive immunoreactivity. $A-C$, Field from a P5 slice illustrating that the intense HCN2 
immunoreactive cells (arrows) are not CamK immunoreactive. D-E, Field from a P6 slice illustrating that the intense HCN2 immunoreactive cells (arrows) are GABA immunoreactive. F-G, Field from a P15 slice illustrating that PV immunoreactive neurons are also HCN2 immunoreactive. Scale bars: $20 \mu \mathrm{m}$. 


\section{Figure 6-9}

A $\mathrm{HCNI}^{\text {in neocortex }}$

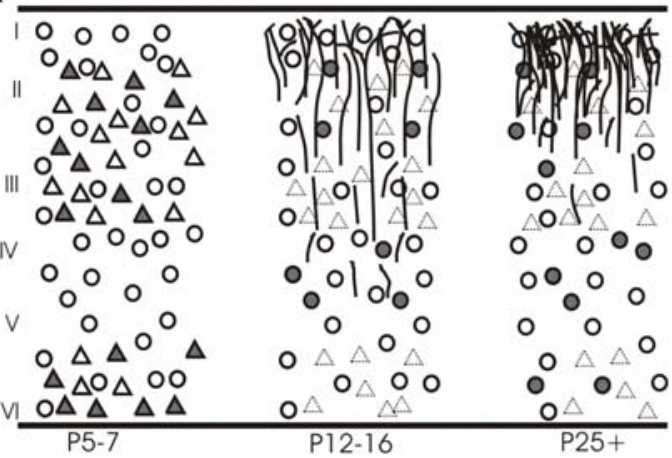

$\triangle$ Pyramidal cell with $\mathrm{HCN}$ i immunoreactive soma

$\mathrm{O}$ Cell immunostaining for $\mathrm{HCN} 1$ and GABA

OCell immunoreactive for $\mathrm{HCN} 1$ and parvalbumin

$\triangle$ GAD65 and HCN1 immunoreactive puncta

C $\mathrm{HCN1}$ in hippocampus (CA1 illustrated)

SL/M
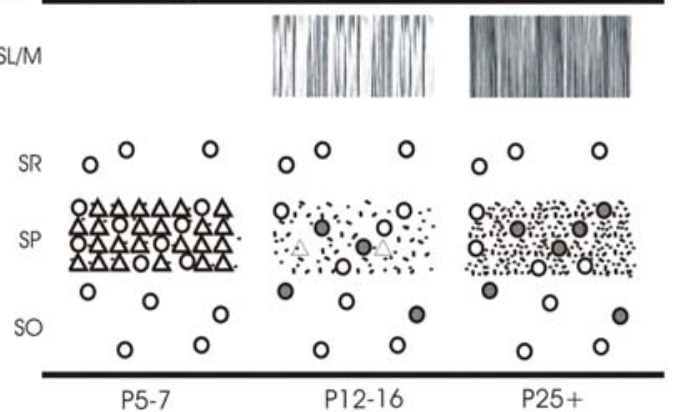

$\triangle$ Pyramidal cell with $\mathrm{HCN}$ i immunoreactivity

$\mathrm{O}$ Cell immunoreactive for $\mathrm{HCN}$ l and GABA

Cell immunoreactive for parvalbumin and $\mathrm{HCN}$ I

$\therefore$ GAD65 and HCN1 immunoreactive puncta

IIITI HCN1 immunoreactive dendrites
B HCN2 in neocortex

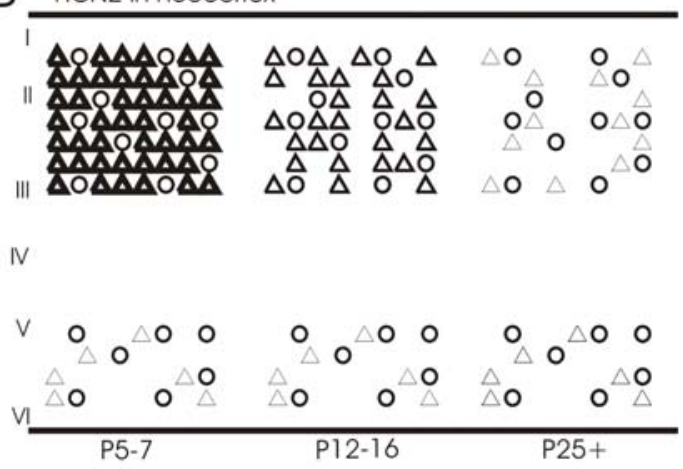

$\Delta \triangle \triangle$ Pyramidal cells liustrating relative degree of HCN2 immunostaining $\mathrm{O}$ cell immunostaining for $\mathrm{HCN} 2$ and GABA

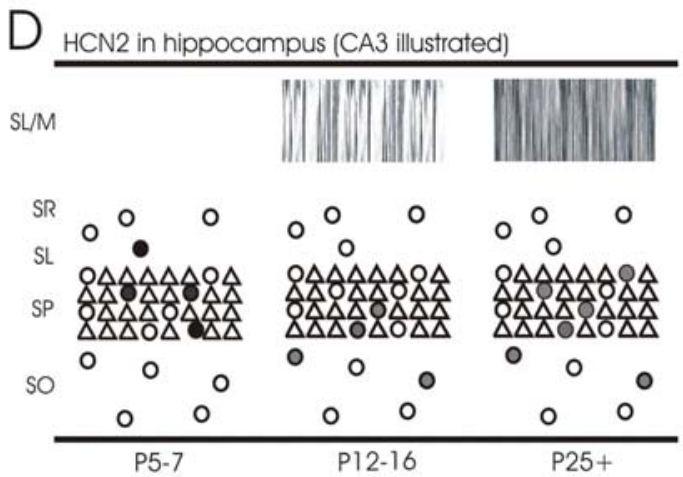

$\triangle$ Pyramidal cell with HCN2 immunoreactivity

O Cell immunoreactive for HCN2 and GABA

Cell immunoreactive for GABA displaying intense HCN2 immunoreactivity O Cell immunoreactive for parvalbumin and HCN2 iinil HCN2 immunoreactive dendrites

FIGURE 6-9. SUMMARY DIAGRAMS ILLUSTRATING THE DEVELOPMENTAL ALTERATION OF HCN1 AND HCN2 IN THE NEOCORTEX AND HIPPOCAMPUS.

$A$ and $B$, diagrams of neocortex illustrating structures that express the indicated $\mathrm{HCN}$ subunit. Numbers to left indicate cortical layers. $C$ and $D$, diagrams of hippocampus illustrating structures that express the indicated $\mathrm{HCN}$ subunit. Letters to left indicate hippocampal layers. $S O$, stratum oriens; $S P$, stratum pyramidale; $S L$, stratum lucidum; $S R$, stratum radiatum; $S L-M$, stratum lacunosum-moleculare. 


\subsection{References}

Ben-Ari Y (2001) Developing networks play a similar melody. Trends Neurosci 24:353360.

Ben-Ari Y, Cherubini E, Corradetti R, Gaiarsa JL (1989) Giant synaptic potentials in immature rat CA3 hippocampal neurones. J Physiol 416:303-325.

Bender RA, Brewster A, Santoro B, Ludwig A, Hofmann F, Biel M, Baram TZ (2001) Differential and age-dependent expression of hyperpolarization- activated, cyclic nucleotide-gated cation channel isoforms 1-4 suggests evolving roles in the developing rat hippocampus. Neuroscience 106:689-698.

Brewster A, Bender RA, Chen Y, Dube C, Eghbal-Ahmadi M, Baram TZ (2002) Developmental febrile seizures modulate hippocampal gene expression of hyperpolarization-activated channels in an isoform- and cell-specific manner. $\mathrm{J}$ Neurosci 22:4591-4599.

Chen K, Aradi I, Thon N, Eghbal-Ahmadi M, Baram TZ, Soltesz I (2001a) Persistently modified h-channels after complex febrile seizures convert the seizure-induced enhancement of inhibition to hyperexcitability. Nat Med 7:331-337.

Chen S, Wang J, Siegelbaum SA (2001b) Properties of hyperpolarization-activated pacemaker current defined by coassembly of HCN1 and HCN2 subunits and basal modulation by cyclic nucleotide. J Gen Physiol 117:491-504.

Chevaleyre V, Castillo PE (2002) Assessing the role of Ih channels in synaptic transmission and mossy fiber LTP. Proc Natl Acad Sci U S A 99:9538-9543.

de Lecea L, del Rio JA, Soriano E (1995) Developmental expression of parvalbumin mRNA in the cerebral cortex and hippocampus of the rat. Brain Res Mol Brain Res 32:1-13.

Desarmenien MG, Clendening B, Spitzer NC (1993) In vivo development of voltagedependent ionic currents in embryonic Xenopus spinal neurons. J Neurosci $13: 2575-2581$.

Erondu NE, Kennedy MB (1985) Regional distribution of type II Ca2+/calmodulindependent protein kinase in rat brain. J Neurosci 5:3270-3277.

Foehring RC, Waters RS (1991) Contributions of low-threshold calcium current and anomalous rectifier (Ih) to slow depolarizations underlying burst firing in human neocortical neurons in vitro. Neurosci Lett 124:17-21. 
Franz O, Liss B, Neu A, Roeper J (2000) Single-cell mRNA expression of HCN1 correlates with a fast gating phenotype of hyperpolarization-activated cyclic nucleotide-gated ion channels (Ih) in central neurons. Eur J Neurosci 12:26852693.

Gao BX, Ziskind-Conhaim L (1998) Development of ionic currents underlying changes in action potential waveforms in rat spinal motoneurons. J Neurophysiol 80:30473061 .

Garaschuk O, Hanse E, Konnerth A (1998) Developmental profile and synaptic origin of early network oscillations in the CA1 region of rat neonatal hippocampus. J Physiol 507:219-236.

Ishii TM, Takano M, Ohmori H (2001) Determinants of activation kinetics in mammalian hyperpolarization- activated cation channels. J Physiol 537:93-100.

Kaufman DL, Houser CR, Tobin AJ (1991) Two forms of the gamma-aminobutyric acid synthetic enzyme glutamate decarboxylase have distinct intraneuronal distributions and cofactor interactions. J Neurochem 56:720-723.

Kawaguchi Y (1993) Physiological, morphological, and histochemical characterization of three classes of interneurons in rat neostriatum. J Neurosci 13:4908-4923.

Kawaguchi Y, Kubota Y (1993) Correlation of physiological subgroupings of nonpyramidal cells with parvalbumin- and calbindinD28k-immunoreactive neurons in layer V of rat frontal cortex. J Neurophysiol 70:387-396.

Kawaguchi Y, Katsumaru H, Kosaka T, Heizmann CW, Hama K (1987) Fast spiking cells in rat hippocampus (CA1 region) contain the calcium- binding protein parvalbumin. Brain Res 416:369-374.

Khazipov R, Leinekugel X, Khalilov I, Gaiarsa JL, Ben-Ari Y (1997) Synchronization of GABAergic interneuronal network in CA3 subfield of neonatal rat hippocampal slices. J Physiol 498:763-772.

Leinekugel X, Khazipov R, Cannon R, Hirase H, Ben-Ari Y, Buzsaki G (2002) Correlated bursts of activity in the neonatal hippocampus in vivo. Science 296:2049-2052.

Liu X, Jones EG (1997) Alpha isoform of calcium-calmodulin dependent protein kinase II (CAM II kinase-alpha) restricted to excitatory synapses in the CA1 region of rat hippocampus. Neuroreport 8:1475-1479.

Liu YB, Lio PA, Pasternak JF, Trommer BL (1996) Developmental changes in membrane properties and postsynaptic currents of granule cells in rat dentate gyrus. J Neurophysiol 76:1074-1088. 
Lorincz A, Notomi T, Tamas G, Shigemoto R, Nusser Z (2002) Polarized and compartment-dependent distribution of HCN1 in pyramidal cell dendrites. Nat Neurosci 5:1185-1193.

Ludwig A, Zong X, Stieber J, Hullin R, Hofmann F, Biel M (1999) Two pacemaker channels from human heart with profoundly different activation kinetics. Embo J 18:2323-2329.

Ludwig A, Budde T, Stieber J, Moosmang S, Wahl C, Holthoff K, Langebartels A, Wotjak C, Munsch T, Zong X, Feil S, Feil R, Lancel M, Chien KR, Konnerth A, Pape HC, Biel M, Hofmann F (2003) Absence epilepsy and sinus dysrhythmia in mice lacking the pacemaker channel HCN2. Embo J 22:216-224.

Magee JC (1998) Dendritic hyperpolarization-activated currents modify the integrative properties of hippocampal CA1 pyramidal neurons. J Neurosci 18:7613-7624.

Mellor J, Nicoll RA, Schmitz D (2002) Mediation of hippocampal mossy fiber long-term potentiation by presynaptic Ih channels. Science 295:143-147.

Menendez de la Prida L, Sanchez-Andres JV (2000) Heterogeneous populations of cells mediate spontaneous synchronous bursting in the developing hippocampus through a frequency-dependent mechanism. Neuroscience 97:227-241.

Moody WJ (1998) The development of voltage-gated ion channels and its relation to activity-dependent development events. Curr Top Dev Biol 39:159-185.

Moosmang S, Biel M, Hofmann F, Ludwig A (1999) Differential distribution of four hyperpolarization-activated cation channels in mouse brain. Biol Chem 380:975980.

Moosmang S, Stieber J, Zong X, Biel M, Hofmann F, Ludwig A (2001) Cellular expression and functional characterization of four hyperpolarization-activated pacemaker channels in cardiac and neuronal tissues. Eur J Biochem 268:16461652.

O'Dowd DK, Ribera AB, Spitzer NC (1988) Development of voltage-dependent calcium, sodium, and potassium currents in Xenopus spinal neurons. J Neurosci 8:792-805.

Pape HC (1996) Queer current and pacemaker: the hyperpolarization-activated cation current in neurons. Annu Rev Physiol 58:299-327.

Pawelzik H, Hughes DI, Thomson AM (2002) Physiological and morphological diversity of immunocytochemically defined parvalbumin- and cholecystokinin-positive interneurones in CA1 of the adult rat hippocampus. J Comp Neurol 443:346-367. 
Poolos NP, Migliore M, Johnston D (2002) Pharmacological upregulation of h-channels reduces the excitability of pyramidal neuron dendrites. Nat Neurosci 5:767-774.

Richter H, Klee R, Heinemann U, Eder C (1997) Developmental changes of inward rectifier currents in neurons of the rat entorhinal cortex. Neurosci Lett 228:139141.

Robinson RB, Siegelbaum SA (2003) HYPERPOLARIZATION-ACTIVATED CATION CURRENTS: From Molecules to Physiological Function. Annu Rev Physiol 65:453-480.

Santoro B, Tibbs GR (1999) The HCN gene family: molecular basis of the hyperpolarization-activated pacemaker channels. Ann N Y Acad Sci 868:741-764.

Santoro B, Liu DT, Yao H, Bartsch D, Kandel ER, Siegelbaum SA, Tibbs GR (1998) Identification of a gene encoding a hyperpolarization-activated pacemaker channel of brain. Cell 93:717-729.

Santoro B, Chen S, Luthi A, Pavlidis P, Shumyatsky GP, Tibbs GR, Siegelbaum SA (2000) Molecular and functional heterogeneity of hyperpolarization-activated pacemaker channels in the mouse CNS. J Neurosci 20:5264-5275.

Southan AP, Morris NP, Stephens GJ, Robertson B (2000) Hyperpolarization-activated currents in presynaptic terminals of mouse cerebellar basket cells. J Physiol 526 Pt 1:91-97.

Spitzer NC (1979) Ion channels in development. Annu Rev Neurosci 2:363-397.

Strata F, Atzori M, Molnar M, Ugolini G, Tempia F, Cherubini E (1997) A pacemaker current in dye-coupled hilar interneurons contributes to the generation of giant GABAergic potentials in developing hippocampus. J Neurosci 17:1435-1446.

Timofeev I, Bazhenov M, Sejnowski T, Steriade M (2002) Cortical hyperpolarizationactivated depolarizing current takes part in the generation of focal paroxysmal activities. Proc Natl Acad Sci U S A 99:9533-9537.

Vasilyev DV, Barish ME (2002) Postnatal development of the hyperpolarizationactivated excitatory current ih in mouse hippocampal pyramidal neurons. J Neurosci 22:8992-9004.

Vogt Weisenhorn DM, Celio MR, Rickmann M (1998) The onset of parvalbuminexpression in interneurons of the rat parietal cortex depends upon extrinsic factor(s). Eur J Neurosci 10:1027-1036. 


\section{CHAPTER 7:General Discussion}




\subsection{Summary and significance of the current study}

In the adult cerebral cortex, GABA performs the role of a fast inhibitory neurotransmitter by activating the $\mathrm{GABA}_{\mathrm{A}}$ receptor. $\mathrm{GABA}_{\mathrm{A}}$ receptor activation opens a chloride conductance that reverses near resting potential, thereby reducing the likelihood of action potential generation (Staley et al, 1995). When $\mathrm{GABA}_{\mathrm{A}}$ neurotransmission is blocked in the adult, IIBs spontaneously occur (Traub and Miles, 1991). In the neonatal cerebral cortex, the chloride concentration gradient across the neuronal membrane is different than the adult hippocampus rendering a high intracellular $\mathrm{Cl}^{-}$concentration compared to the adult since $\mathrm{KCC}$, a $\mathrm{Cl}^{-}$transporter, is not fully expressed in the neonate (Rivera et al, 1999); therefore the chloride conductance opened by $\mathrm{GABA}_{\mathrm{A}}$ receptor activation depolarizes neurons (Gao and Ziskind-Conhaim 1995; Sun and Murali 1999). This GABA-induced depolarization has been interpreted as GABA being an excitatory neurotransmitter in the neonatal cerebral cortex (Owens et al. 1996), and it has even been suggested that GABA is the main excitatory neurotransmitter at this stage of cortical development (Leinekugel et al. 1999) since it is claimed that glutamatergic synapses are not yet fully functional (Tyzio et al, 1999; Hennou et al, 2002). However, if GABA is an excitatory neurotransmitter, it is unclear what would prevent excitation from becoming synchronized and spreading through the network. Therefore, this study investigated the neonatal cerebral cortex to determine if GABA prevents the synchronization of network activity in the neonate as it does in the adult. Using field potential recordings, we found that GABA prevents the synchronization of neuronal firing in the neonate. This conclusion is based on two experimental findings which are described fully in Chapter 3

(Wells et al, 2000): (1) when $\mathrm{GABA}_{\mathrm{A}}$ receptors were antagonized, which prevented 
spontaneously released GABA from activating receptors, the synchrony of neuronal activity greatly increased as manifested by the generation of large glutamate-mediated excitatory paroxysmal bursts (i.e. IIBs), and (2) activating $\mathrm{GABA}_{\mathrm{A}}$ receptors by an exogenously applied agonist dampened the synchrony of neuronal activity as manifested by a decrease in the amplitude of IIBs. Therefore, in the neonatal hippocampus, excitatory glutamatergic synapses are functional and GABA acts to prevent network synchronization. This has significant implications for understanding and clinically treating epileptic disorders of the immature cerebral cortex.

\subsection{Comparisons with previous studies}

The following is a reiteration and an explanation of these differences between this study versus the previously addressed studies. There are three previous assertions to be addressed. The first is the assertion that GABA is an excitatory neurotransmitter in the neonatal cerebral cortex (Owens et al. 1996; Leinekugel et al. 1999; Dzhala and Staley, 2003). The basis for this claim is that the reversal potential for GABA is more positive than is resting membrane potential, and agonizing $\mathrm{GABA}_{\mathrm{A}} \mathrm{Rs}$ will depolarize neurons, sometimes sufficiently to elicit action potentials in the presence of glutamate receptor antagonists. This on its own, however, does not indicate that GABA is excitatory in the intact neonatal network, since even a depolarizing GABA response will still shunt out excitatory glutamatergic currents, as explained in the discussion to Chapter 3. The second previous assertion is that blocking $\mathrm{GABA}_{\mathrm{A}} \mathrm{Rs}$ does not elicit IIBs in the neonatal cerebral cortex (Ben-Ari et al. 1989). We disagree with this claim given our demonstration that blocking $\mathrm{GABA}_{\mathrm{A}} \mathrm{Rs}$ permits the spontaneous generation of IIBs in the neonatal cerebral cortex. Indeed, a later study from the same group (Khalilov et al. 1999) 
showed that IIBs occur in the neonate after $\mathrm{GABA}_{\mathrm{A}}$ blockade. Finally, it was claimed that glutamatergic synapses in the neonate are immature (Ben-Ari et al., 1997). Our experiments indicate that while glutamatergic synapses may by immature, they are still capable of sustaining IIBs after the blockade of $\mathrm{GABA}_{\mathrm{A}} \mathrm{Rs}$.

As already noted, blocking the effects of spontaneously released GABA permitted the generation of spontaneous paroxysmal events resembling IIB, which are a clinical hallmark of epileptic tissue. Moreover, the IIBs did not occur at random time intervals in the neonate, but instead occurred in a temporally precise rhythm that lost precision in the course of development. This suggested an underlying pacemaker mechanism that is most prominent in the neonatal hippocampus. Therefore, several potential pacing mechanisms were investigated and are described in Chapters 4 and 5. Mechanisms determined not to be involved in pacing IIBs were: (1) inhibition mediated through $\mathrm{GABA}_{\mathrm{B}}$ receptors, (2) $\mathrm{I}_{\mathrm{AHP}}$, and (3) $\mathrm{Ca}^{2+}$ release from intracellular stores. However, it was demonstrated that mGluRs modestly affected IIB frequency and that frequency of IIBs was strongly modulated by the hyperpolarization-activated cationic current, $\mathrm{I}_{\mathrm{h}}$. Given the adverse complications often resulting from current therapies used to treat epilepsy in the immature brain (Prichard 1974; Fishman 1979; Krishnamoorthy et al. 1983; Pellock 1998; Gilbert and Glauser 1999; de Bode and Curtiss 2000; Besag 2001; Meador 2002), drugs that could selectively block $I_{h}$ in the hippocampus might serve as an additional treatment option.

Changes in subunit protein levels during development could lead to a difference in the level and properties of $I_{h}$ which could potentially explain the decrease in the frequency and precision of IIBs that occurs during early postnatal development. The 
mRNA levels for $I_{h}$ channel subunits, members of the HCN gene family, change in the course of the first four postnatal weeks (Bender et al, 2001). However, the level of mRNA transcription does not necessarily equate to the level of protein translation; additionally, mRNA studies do not identify the subcellular location of the translated protein (Santoro et al, 2000; Bender et al, 2001). Therefore, to study $I_{h}$ channel subunits directly we used immunocytochemistry to stain for the two most prominent $I_{h}$ channel subunits found in the cerebral cortex, HCN1 and HCN2 (Santoro et al, 2000). We studied the cerebral cortex through development from the first neonatal week to adulthood, and found developmental changes in the expression of these subunits (Chapter 6). $\mathrm{HCN} 1$ subunits in neonatal pyramidal neurons were distributed predominately inside the somata, while in the juvenile and mature hippocampus the subunits were found in the membrane of apical dendrites with diminished expression in somata. This change in HCN distribution may contribute to the higher frequency and precision of IIB in the neonate. For example, the developmental loss of somatic HCN1 expression in pyramidal cells, might account for the slower frequency of IIBs in the older animals if these are functional changes.

\subsection{Directions for future study}

The current investigation utilized field potential recordings to study network neuronal activity in the neonatal hippocampus. The frequency and precision of IIBs greatly increased or decreased with pharmacological manipulations that facilitated or repressed $\mathrm{I}_{\mathrm{h}}$, respectively, thus indicating that $\mathrm{I}_{\mathrm{h}}$ is involved in timing the IIBs (Chapter 4). One of the possible mechanisms $I_{h}$ could be utilizing to generate the IIBs, would be a slow ramp depolarization of the neuronal membrane, similar to the pacemaker potential 
in the heart (DiFrancesco, 1985). However, studies that recorded intracellularly from CA3 pyramidal neurons during interictal activity (Staley et al., 2001) did not report the presence of such a pacemaker potential. This could be because only a small subset of pyramidal neurons display a pacemaker potential. Therefore, future studies should sample a large number of $\mathrm{CA} 3$ pyramidal neurons during interictal bursting, to determine if any of these neurons exhibit a pacemaker potential between IIBs. If such a potential is found, an $\mathrm{I}_{\mathrm{h}}$ antagonist (i.e. $\mathrm{Cs}^{+}$or ZD7288) should be applied to determine if it reduced the slope of the pacemaker potential (measured as $\Delta \mathrm{V} / \Delta \mathrm{t}$ ), indicating that $\mathrm{I}_{\mathrm{h}}$ is involved in generating the ramp.

Alternatively, as suggested by a computational model in Chapter $4, \mathrm{I}_{\mathrm{h}}$ could increase the rate of spontaneous release of neurotransmitter vesicles from synaptic terminals made on CA3 pyramidal neurons. An increase in vesicular release rate from excitatory terminals could cause the postsynaptic neuron's membrane potential to cross over firing threshold. This hypothesis should be tested experimentally in the neonate. CA3 pyramidal neurons should be voltage-clamped and the rate of miniature excitatory post-synaptic potentials (mEPSPs) (a measure of pre-synaptic vesicular release rate) should be examined to determine if it accelerates during the interval between IIBs. An $\mathrm{I}_{\mathrm{h}}$ antagonist (i.e. $\mathrm{Cs}^{+}$or ZD7288) should then be bath applied to the slice to determine if the $I_{h}$ blocker reduced the rate of mEPSPs between IIBs. This would indicate that $I_{h}$ was responsible for controlling vesicular release rate and this could be a mechanism to time IIBs.

Genetically modified mice will certainly permit further investigation into the role of $I_{h}$ in neuronal rhythm generation. The reported production of an HCN2 knockout 
mouse (Ludwig et al., 2003), and the expected creation of other HCN knockout mice, will permit further investigation into the roles of $I_{h}$ in the generation of IIBs by studying the periodicity of IIBs in these mice. Also, mice expressing an HCN2-GFP fusion protein will allow physiological investigation of the scattered GABAergic interneurons in the stratum pyramidale that express $\mathrm{HCN} 2$ in the neonate (Chapter 6). The ability to identify these neurons in the living slice will permit investigations designed to determine if they play a role in GDP generation (see Chapter 6).

The mRNA levels of $\mathrm{HCN} 1$ and $\mathrm{HCN} 2$ subunits changes after epileptiform activity (Brewster et al, 2002). However, it is not known whether the change in mRNA levels results in a change in $\mathrm{HCN}$ subunit expression, and if it is increased, it is also not known where the additional subunit expression is located in the neurons (i.e. dendrites, axons, somata, etc.). To determine if there is a change in $\mathrm{HCN}$ subunit expression after the generation of IIBs and where this change in expression might be occurring, organotypic culture slices should be bathed in $\mathrm{Mg}^{2+}$-free medium with $\mathrm{GABA}_{\mathrm{A}}$ receptors blocked to induce IIBs. After allowing several days for protein synthesis to occur, the organotypic culture slices should be immersed into fixative then stained by immunocytochemistry to determine if the $\mathrm{HCN}$ immunostaining is different from organotypic culture hippocampal slices that were never epileptic. This experiment would indicate whether epileptiform activity changes $\mathrm{HCN}$ subunit expression. If $\mathrm{HCN}$ subunit expression does change, epilepsy could change $\mathrm{I}_{\mathrm{h}}$ in the cerebral cortex.

The CA3 region was identified as the origin of the IIBs (Chapter 5), because when the hippocampus was surgically isolated from the rest of the hippocampus, IIBs remained solely in the CA3. However, these experiments did not determine if a specific 
region within the CA3 was responsible or if there were multiple regions of IIB generation within the CA3. To answer this question, the slice preparations could be studied using voltage- or $\mathrm{Ca}^{2+}$-sensitive dyes. These dyes alter their fluorescent properties according to voltage or $\mathrm{Ca}^{2+}$ changes, respectively, in the cell; therefore this technique would permit the precise investigation of IIB generation and propagation at high spatial resolution.

\subsection{Conclusions}

In conclusion, despite much literature suggesting otherwise, our data indicate that GABAergic neurotransmission in the neonatal hippocampus is inhibitory, and serves to suppress synchronized neuronal activity. Upon GABAergic blockade, IIBs spontaneously occur demonstrating that excitatory glutamatergic synapses are established and functional as early as P0. Gap junctions are necessary for IIB generation in the neonate. Additionally, in the neonatal hippocampus, IIBs occurred in a temporally precise rhythm that is timed by $\mathrm{I}_{h}$. The expression of $\mathrm{I}_{h}$ channel subunits in the neonatal hippocampus was different from the older hippocampus; this difference could contribute to faster and more precisely timed IIBs in the neonate. $\mathrm{GABA}_{\mathrm{A}}$ agonists, gap junction blockers, and selective blockers of $I_{h}$ could potentially treat epileptic seizures in the immature brain. Future research will determine the exact role $\mathrm{I}_{\mathrm{h}}$ plays in timing IIBs. 


\subsection{References}

Agmon A, Wells JE (2003) The role of the hyperpolarization-activated cationic current $\mathrm{I}(\mathrm{h})$ in the timing of interictal bursts in the neonatal hippocampus. J Neurosci 23:3658-3668.

Ben-Ari Y, Cherubini E, Corradetti R, Gaiarsa JL (1989) Giant synaptic potentials in immature rat CA3 hippocampal neurones. J Physiol 416:303-325.

Ben-Ari Y, Khazipov R, Leinekugel X, Caillard O, Gaiarsa JL (1997) GABAA, NMDA and AMPA receptors: a developmentally regulated 'menage a trois'. Trends Neurosci 20:523-529.

Besag, F. M. (2001) Behavioural effects of the new anticonvulsants. Drug Saf 24(7): 51336.

Brewster A, Bender RA, Chen Y, Dube C, Eghbal-Ahmadi M, Baram TZ (2002) Developmental febrile seizures modulate hippocampal gene expression of hyperpolarization-activated channels in an isoform- and cell-specific manner. J Neurosci 22:4591-4599.

de Bode, S. and S. Curtiss (2000). "Language after hemispherectomy.” Brain Cogn 43(13): $135-8$.

Dzhala, VI, Staley KJ (2003) Excitatory actions of endogenously released GABA contribute to initiation of ictal epileptiform activity in the developing hippocampus. J Neurosci 23:1840-1846.

Fishman, M. A. (1979). "Febrile seizures: the treatment controversy." J Pediatr 94(2): $177-84$.

Gao, B. X. and L. Ziskind-Conhaim (1995). "Development of glycine- and GABA-gated currents in rat spinal motoneurons." J Neurophysiol 74(1): 113-21.

Gilbert, D. L. and T. A. Glauser (1999). "Complications and costs of treatment of refractory generalized convulsive status epilepticus in children." J Child Neurol 14(9): 597-601.

Hennou S, Khalilov I, Diabira D, Ben-Ari Y, Gozlan H (2002) Early sequential formation of functional GABA(A) and glutamatergic synapses on CA1 interneurons of the rat foetal hippocampus. Eur J Neurosci 16:197-208.

Khalilov I, Dzhala V, Ben-Ari Y, Khazipov R (1999) Dual role of GABA in the neonatal rat hippocampus. Dev Neurosci 21:310-319. 
Krishnamoorthy, K. S., E. L. Zalneraitis, et al. (1983). "Phenytoin-induced choreoathetosis in infancy: case reports and a review." Pediatrics 72(6): 831-4.

Leinekugel, X., I. Khalilov, et al. (1999). "GABA is the principal fast-acting excitatory transmitter in the neonatal brain." Adv Neurol 79: 189-201.

Ludwig, A., T. Budde, et al. (2003). "Absence epilepsy and sinus dysrhythmia in mice lacking the pacemaker channel HCN2." Embo J 22(2): 216-224.

McLean, M. J. (1995). “Gabapentin.” Epilepsia 36(Suppl 2): S73-86.

Meador, K. J. (2002). "Neurodevelopmental effects of antiepileptic drugs.” Curr Neurol Neurosci Rep 2(4): 373-8.

Owens, D. F., L. H. Boyce, et al. (1996). "Excitatory GABA responses in embryonic and neonatal cortical slices demonstrated by gramicidin perforated-patch recordings and calcium imaging." J Neurosci 16(20): 6414-23.

Pellock, J. M. (1998). "Use of midazolam for refractory status epilepticus in pediatric patients." J Child Neurol 13(12): 581-7.

Prichard, J. S. (1974). "Convulsive disorders in children: some notes on the diagnosis and treatment." Pediatr Clin North Am 21(4): 981-9.

Rivera C, Voipio J, Payne JA, Ruusuvuori E, Lahtinen H, Lamsa K, Pirvola U, Saarma $\mathrm{M}$, Kaila $\mathrm{K}$ (1999) The $\mathrm{K}+/ \mathrm{Cl}$ - co-transporter $\mathrm{KCC} 2$ renders GABA hyperpolarizing during neuronal maturation. Nature 397:251-255.

Santoro, B., S. Chen, et al. (2000). "Molecular and functional heterogeneity of hyperpolarization-activated pacemaker channels in the mouse CNS." J Neurosci 20(14): 5264-75.

Staley KJ, Bains JS, Yee A, Hellier J, Longacher JM (2001) Statistical model relating CA3 burst probability to recovery from burst- induced depression at recurrent collateral synapses. J Neurophysiol 86:2736-2747.

Staley KJ, Soldo BL, Proctor WR (1995) Ionic mechanisms of neuronal excitation by inhibitory GABAA receptors. Science 269:977-981.

Sun, D. and S. G. Murali (1999). "Na+-K+-2Cl- cotransporter in immature cortical neurons: A role in intracellular Cl- regulation." J Neurophysiol 81(4): 1939-48.

Traub D, Miles R (1991) Neuronal networks of the hippocampus. Cambridge: Cambridge University Press 
Treiman, D. M. (1988). “Clinical benefits of vigabatrin.” Br J Clin Pract Suppl 61: 24-9.

Tyzio R, Represa A, Jorquera I, Ben-Ari Y, Gozlan H, Aniksztejn L (1999) The establishment of GABAergic and glutamatergic synapses on CA1 pyramidal neurons is sequential and correlates with the development of the apical dendrite. $\mathrm{J}$ Neurosci 19:10372-10382

Vasilyev, D. V. and M. E. Barish (2002). "Postnatal development of the hyperpolarization-activated excitatory current $\mathrm{Ih}$ in mouse hippocampal pyramidal neurons." J Neurosci 22(20): 8992-9004

Wells JE, Porter JT, Agmon A (2000) GABAergic inhibition suppresses paroxysmal network activity in the neonatal rodent hippocampus and neocortex. J Neurosci 20:8822-8830.

Whittington, M. A., R. D. Traub, et al. (1995). Erosion of inhibition contributes to the progression of low magnesium bursts in rat hippocampal slices. J Physiol 486(Pt 3): 723-34. 
Curriculum Vitae 


\author{
Jason Eric Wells \\ Southern Illinois University \\ School of Dental Medicine \\ Department of Growth, Structure and Development \\ Section of Anatomy \\ 2800 College Avenue \\ Alton, IL 62002
}

\title{
Educational Background
}

1998-2003, West Virginia University School of Medicine, Department of Neurobiology and Anatomy, Morgantown, WV; Ph.D. in Anatomy

1994-1998, Allegheny College, Meadville, PA; B.S. in Neuroscience

\section{Employment History}

2003, Assistant Professor, Southern Illinois University, School of Dental Medicine, Department of Growth, Structure and Development, Section of Anatomy

\section{Publications}

Agmon A, Wells JE (2003) The role of the hyperpolarization-activated cationic current $\mathrm{I}(\mathrm{h})$ in the timing of interictal bursts in the neonatal hippocampus. J Neurosci 23:3658-3668.

J.E. Wells, J.T. Porter, and A. Agmon (2000) GABAergic Inhibition Suppresses Paroxysmal Network Activity in the Neonatal Rodent Hippocampus and Neocortex. Journal of Neuroscience, 20(23): 8822-8830. 